\title{
Avaliação comparativa de diferentes aditivos na prevenção da acidose láctica ruminal em bovinos de corte
}
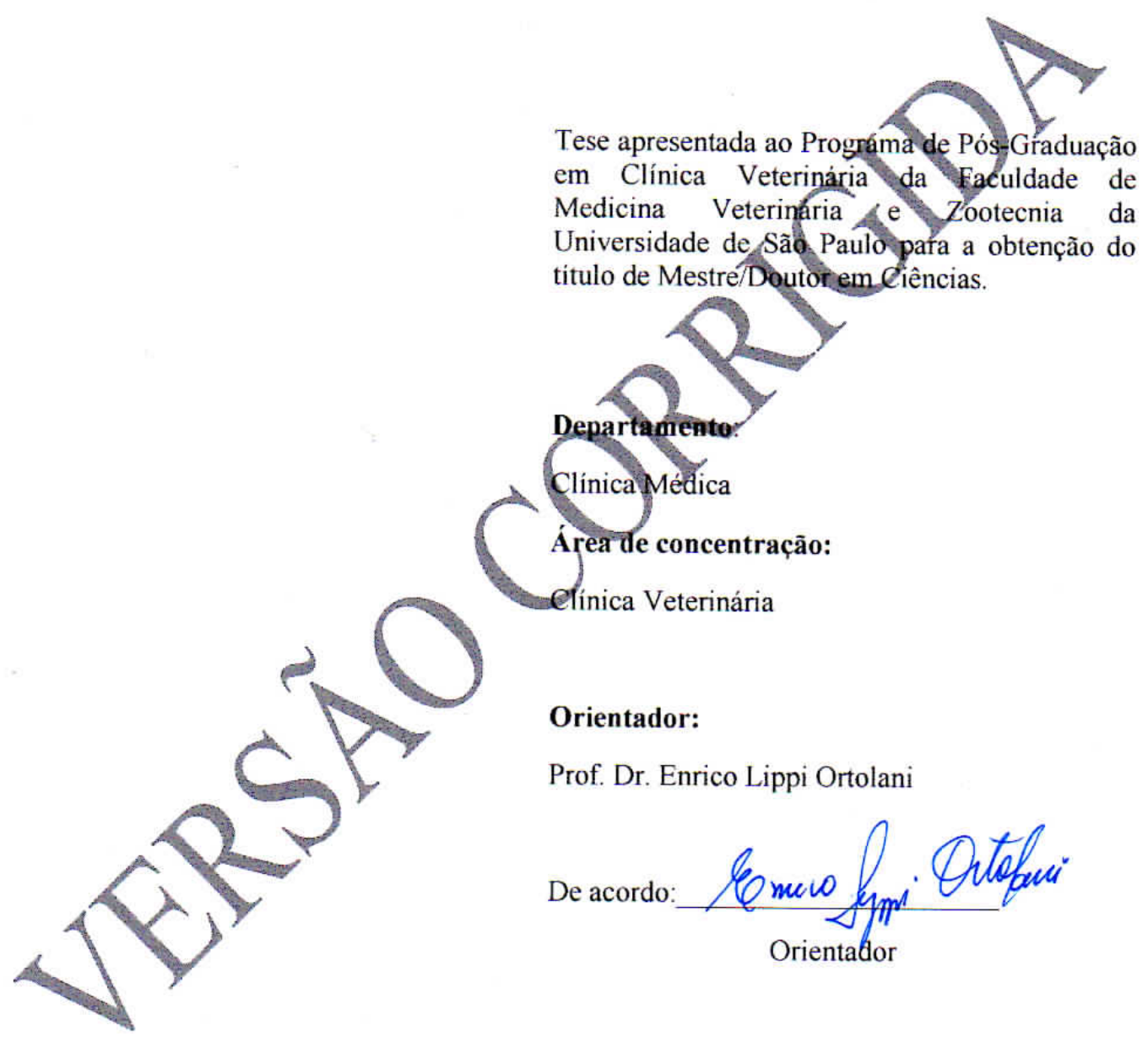

Orientador:

Prof. Dr. Enrico Lippi Ortolani

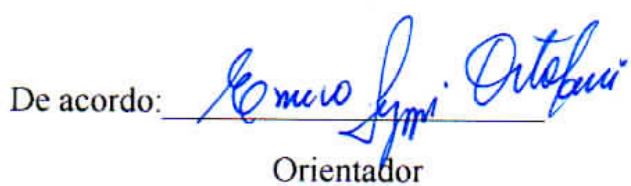

São Paulo

2018

Obs: A versão original encontra-se disponível na Biblioteca da FMVZ/USP 


\section{FRANCISCO LEONARDO COSTA DE OLIVEIRA}

\section{Avaliação comparativa de diferentes aditivos na prevenção da acidose}

láctica ruminal em bovinos de corte

Tese apresentada ao Programa de Pós-Graduação em

Clínica Veterinária da Faculdade de Medicina Veterinária e Zootecnia da Universidade de São Paulo para a obtenção do título de Doutor em Ciências

Departamento:

Clínica Médica

Área de concentração:

Clínica Veterinária

Orientador:

Prof. Dr. Enrico Lippi Ortolani

São Paulo

2018 
Autorizo a reprodução parcial ou total desta obra, para fins acadêmicos, desde que citada a fonte.

\section{DADOS INTERNACIONAIS DE CATALOGAÇÃO NA PUBLICAÇÃO}

(Biblioteca Virginie Buff D’Ápice da Faculdade de Medicina Veterinária e Zootecnia da Universidade de São Paulo)

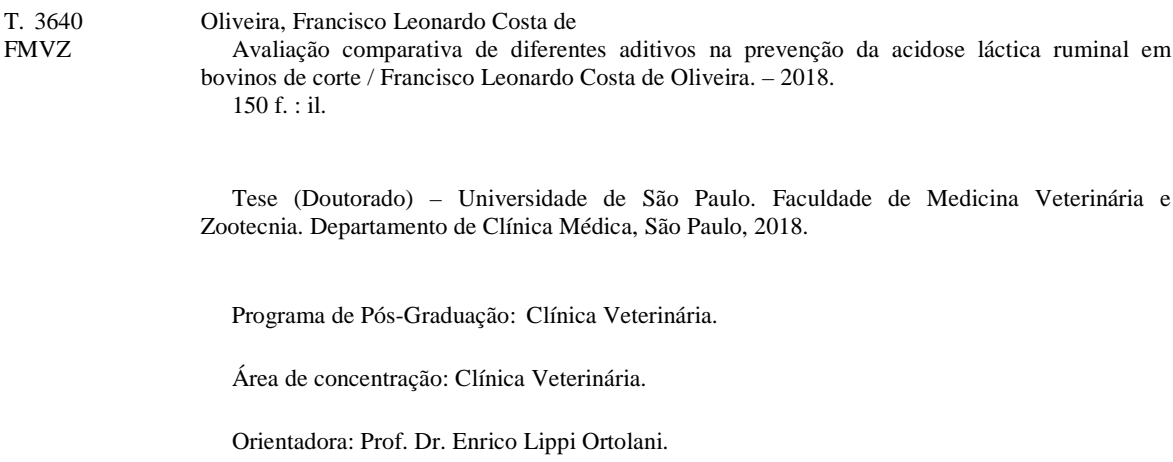

Tese (Doutorado) - Universidade de São Paulo. Faculdade de Medicina Veterinária e Zootecnia. Departamento de Clínica Médica, São Paulo, 2018.

Programa de Pós-Graduação: Clínica Veterinária.

Área de concentração: Clínica Veterinária.

Orientadora: Prof. Dr. Enrico Lippi Ortolani.

1. Ácido láctico. 2. Nelore. 3. Sacarose. 4. Virginiamicina. 5. Monensina. I. Título.

Ficha catalográfica elaborada por Sandra Regina Toledo, CRB-8/8146, da FMVZ. 
IImo(a). Sr(a).

Responsável: Enrico Lippi Ortolani

Área: Clínica Médica Veterinária

Prof. Dr. Enrico Lippi Ortolani (orientador)

Título da proposta: "Avaliação da viginiamicina como auxiliar na prevenção e controle da acidose láctica ruminal em bovinos ".

\section{Parecer Consubstanciado da Comissão de Ética no Uso de Animais FMVZ/USP}

A Comissão de Ética no Uso de Animais da Faculdade de Medicina Veterinária e Zootecnia da Universidade de São Paulo, no cumprimento das suas atribuições, analisou e APROVOU o Relatório Final (versão de 01/setembro/2016) da proposta acima referenciada.

Resumo apresentado pelo pesquisador: "1. Os objetivos propostos foram todos cumpridos? Resp: Sim. Os resultados obtidos propiciaram a criação de novos projetos? Resp: Sim. 2. O N amostral proposto inicialmente foi suficiente? Qual o N amostral total alocado? Resp: Sim. 30 animais, como descrito no projeto. 3. Houve perdas? se sim, quantas? Resp: Não. 4. Ocorreu algum evento adverso durante a condução do estudo? Resp: Não. 5. Resultados já apresentados em congresso? Resp: Sim. 6 . Resultados já publicados? Resp: Não.".

Comentário da CEUA: "Pelo apresentado o projeto foi executado sem alteração do pedido inicial e já foi concluído.".

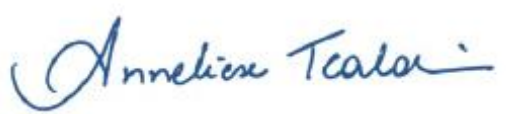

Profa. Dra. Anneliese de Souza Traldi Presidente da Comissão de Ética no Uso de Animais Faculdade de Medicina Veterinária e Zootecnia da Universidade de São Paulo

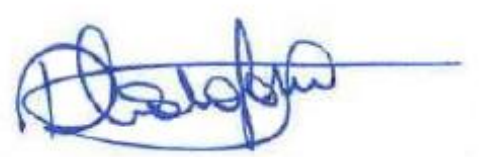

Profa. Dra. Claudia Madalena Cabrera Mori Vice-Presidente da Comissão de Ética no Uso de Animais Faculdade de Medicina Veterinária e Zootecnia da Universidade de São Paulo 
FOLHA DE AVALIAÇÃo

Autor: OLIVEIRA, Francisco Leonardo Costa

Título: Avaliação comparativa de diferentes aditivos na prevenção da acidose láctica ruminal induzida por sacarose em bovinos de corte

Tese apresentada ao Programa de Pós-Graduação em

Clínica Veterinária da Faculdade de Medicina Veterinária e Zootecnia da Universidade de São Paulo para obtenção do título de Doutor em Ciências

Data:

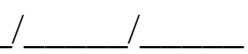

\section{Banca Examinadora}

Prof. Dr.

Instituição: Julgamento:

Prof. Dr.

Instituição: Julgamento:

Prof. Dr.

Instituição: Julgamento:

Prof. Dr.

Instituição: Julgamento:

Prof. Dr.

Instituição: Julgamento: 
A Deus que sempre esteve ao meu lado

À minha mãe Maria Iône e meu pai Francisco Édesio Minhas irmãs Mariane e Marielle, as (minhas sobrinhas) Meus avós paternos (Maria Severo e Francisco Martins) e maternos (Ieda Barreira e José Costa) À Yana Freitas e toda sua família. À Elias David e toda sua família À toda a minha família 


\section{AGRADECIMENTOS}

Ao meu orientador Prof. Dr. Enrico Lippi Ortolani, agradeço a compreensão, paciência e o auxílio durante este importante período de minha vida (muito obrigado por esses 8 anos que trabalhei com o senhor, tive um grande crescimento profissional e pessoal). Agradeço pela disposição de transmitir generosamente aquilo que dedicou sua vida a adquirir: o conhecimento. Um exemplo de dedicação, apoio e estímulo ao crescimento pessoal. Um exemplo de profissional dedicado à ciência, causa de todos os seus orientados sentirem-se confiantes e orgulhosos de tê-lo como orientador. Espero contar com a sua eterna amizade, assim como sempre terá a minha gratidão.

A minha família Ortolani: Antônio Humberto Hamad Minervino, Carolina Akiko Cabral Araújo, Frederico Augusto Mazzocca Lopes Rodrigues, Rejane dos Santos Sousa, Leonardo Frasson dos Reis, Natalia Sato Minami e Mailson Rennan Borges Dias que foram à família que eu tive durante a minha passagem por esta instituição, sinceramente espero um dia ser capaz de retribuir tudo que fizeram pela minha pessoa, tanto profissional como pessoalmente. Com vocês mesmo os momentos de trabalho mais cansativos sempre foram momentos felizes, os quais eu jamais esquecerei. Cada momento vivido tornou-se uma experiência de aprendizado com vocês, conservarei as qualidades que vi em cada um de vocês como espelhos que utilizarei em meu aperfeiçoamento pessoal. Saibam que cada um de vocês me ensinou muito mais do que meu silêncio ao longo desses anos demonstrou. Saibam que ter vocês como família foi um dos melhores presentes que a vida poderia me proporcionar, não havendo espaço para o significado que a família Ortolani têm para mim em um simples agradecimento.

A empresa Phibro nas pessoas de Christopher White e Bruno Honda pelo financiamento da pesquisa e por todo o apoio para a realização da mesma.

Ao Prof. Dr. Luís Felipe Prada por sempre está disponível quando necessitei, ter disponibilizado os animais e as instalações do Laboratório de Pesquisa de Gado de Corte (LPGC - USP - Pirassununga).

Ao Prof. Dr. Alexandre Vaz Pires pela ajuda na realização das cirurgias de canulação dos animais e por sempre está disponível quando precisei. 
Ao Prof. Dr Ives Cláudio da Silva Bueno por aceitar participar como colaborador do projeto, viabilizando as análises de AGCC.

As Prof.(as) Dr.(as) Marta Miranda e Marta Alonso que foram minhas orientadoras no Doutorado Sanduiche realizado em Lugo - Espanha, deixo aqui meu muito obrigado por toda receptividade e orientação.

A Msc Juliana Aparecida por toda a ajuda na realização da parte prática da presente Tese, serei sempre grato.

Ao senhor Celso Schmidt e Tio Paulo pela amizade, companheirismo e acima de tudo pelo exemplo de pessoa do bem que vocês são, serei sempre grato por tudo que fizeram por mim. Ao Xandy, Amendoim, João, Maciano e Pedro por sempre estarem dispostos a ajudar e pela amizade durante os longos dias de trabalho.

Aos estagiários Ricardo (Viola), Fuleco, Bumbinha, Cintilante, Ana (Filhote), por toda a ajuda no decorrer do experimento e pelos momentos de descontração.

À Professora Dr. Maria Claudia Araripe Sucupira (Macau), pela sensibilidade de reconhecer quando precisamos de ajuda, pela sua disposição de sempre ajudar quando precisei e por sempre me motivar para um crescimento pessoal e profissional.

À Clara Satsuki Mori, pelo convívio diário, ajuda incondicional e resolução de vários problemas técnicos e pessoais. Agradeço por sua ajuda, paciência e espero contar com sua eterna amizade.

Ao amigo Prof. Dr. Raimundo Alves Barrêto Júnior, do Departamento de Ciências Animais da Universidade Federal Rural do Semiárido, pela ajuda durante todos esses anos de pósgraduação, em especial durante o meu Mestrado.

As pessoas de Maria de Fátima, Vivina Diógenes e Bia Loira pelo afeto, amizade, tenho vocês como Mãe.

As técnicas Creide, Claudia, Maria Helena, Dona Carmen, Dinha e aos técnicos Dinho e Agnaildo por todo o auxílio sempre que precisei, amizade e convívio. À secretária da pósgraduação, Adelaide Borges e Cida Freitas, pela paciência, agradável convívio, ajuda, compreensão e amizade. 
Aos amigos Enoch Brandão de Souza Meira Junior, Eduardo Marques, Mario Mexicano, Walter Fernandes, Kaio Barros, Paulo Carioca pela amizade (irmãos) desde que passei a morar aqui em São Paulo.

A Professora Alice Maria Melville Paiva Della Libera, pela constante atenção e orientação em todos os momentos da realização na minha residência.

Aos professores do Departamento de Clínica Médica da FMVZ-USP: Prof. Dra. Viviani Gomes, Prof. Dr. Fernando José Benesi, Prof. Dr. Fábio Celidonio Pogliane, Prof. Dra. Mitika Hagiwara, Prof. Dra. Lilian Gregory, Prof. Dr. Wilson Roberto Fernandes, Prof. Dra. Carla Barge Belli, Prof. Dra. Raquel Yvonne Arantes, Prof. Dra. Marcia Mery Kogika, Prof. Dra. Silvia Regina Ricci Lucas, Prof. Dr. Carlos Eduardo Larsson, Prof. Dra. Marcia Gomes, Prof. Dr. Marcio Bruneto, Prof. Dra. Maria Helena Matiko Akao Larsson pela convivência harmoniosa, conhecimentos transmitidos e pela amizade.

Aos amigos de pós-graduação: Carolina Harumi, Aline Morgado, Ronaldo Gargano, Bruno Leonardo, Carolina Shecara, Juliana Bombardelli, Gabriela Reis, Elisa Weiss, Juliana Junqueira, Mariane Franco, Natalia Gaeta, Camila Costa, Cinthia Costa, Vinicius Baldacim, Bruno Toledo, Camila Martin, Jean Ramos, Karen Nascimento, Natalia Sobreira, Carol dos Anjos, Bruna Stanigher, Fabio Sellera, Priscila Marques, Marcela Romanini, Debora Carvalho, Camila Freitas, Kamila Reis, Rodrigo Malzoni, Heloisa Bertagnon, Bruno Monteiro, Leandro Lipinski, Karen Nascimento, Fernanda Chicharo, Julio Spagnolo pelo agradável convívio, troca de conhecimentos e amizade.

Aos amigos de Pirrassununga Frodo, Rafa, Vicente, Carlos, Vitinho, Begônia, Flávio Perna, Mineiro, Severino, Nara, Vivi, Mel, Maria, Chibungo, Thiago Del Valle, Pablo, Caio, Comixão, Sacudo, Bumba, Fernanda são muito os nomes, mas quero agradecer pela amizade. Aos queridos companheiros de moradia Pedro Rubens, Adriano, Demetrio Godoy e Aurelio pelo convivio e amizade.

À Faculdade de Medicina Veterinária e Zootecnia da USP que oferece condições favoráveis para a execução de pesquisa e pela minha formação.

À FUNDAÇÃO DE AMPARO A PESQUISA DO ESTADO DE SÃO PAULO - FAPESP, pelo auxílio pesquisa, imprescindível ao desenvolvimento desta pesquisa. 
A todos que direto ou indiretamente de alguma maneira contribuíram para a execução deste trabalho.

E principalmente a todos os bovinos, que foram fundamentais para que este trabalho fosse realizado. 


\section{Oração a Nossa Senhora Aparecida}

Ó senhora minha, ó minha mãe, eu me ofereço todo a vós; e, em prova de minha devoção para convosco, eu vos consagro neste dia os meus olhos, os meus ouvidos, a minha boca, o meu coração e inteiramente todo o meu ser. E, guardai-me e defendeime, como coisa e propriedade vossa. Amém! 


\section{RESUMO}

OLIVEIRA, F. L. C. Avaliação comparativa de diferentes aditivos na prevenção da acidose láctica ruminal em bovinos de corte. [Comparative evaluation of different additives in the prevention of rumen lactic acidosis in beef cattle]. 2018. $150 \mathrm{f}$. Tese (Doutorado em Ciências) - Faculdade de Medicina Veterinária e Zootecnia, Universidade de São Paulo, São Paulo, 2018.

Objetivou-se compreender melhor o modelo de indução de acidose láctica ruminal (ALR) com sacarose destacando-se aspectos básicos da fermentação ruminal e suas consequências, assim como avaliação comparativa da eficácia de dois aditivos (Virginiamicina VM e Monensina MON), associados ou não, na prevenção desta enfermidade em bovinos adultos de corte. Para tal, foram utilizados 30 fêmeas da raça Nelore, providas de cânula ruminal, com cerca de 413 $\mathrm{kg}$ de peso corpóreo. Os animais foram mantidos em baias individuais e alimentados com dieta basal composta de $75 \%$ de feno de capim de coast-cross e de $25 \%$ de ração concentrada comercial, por 30 dias antes da indução de ALR. Durante esse período os bovinos foram distribuídos em cinco grupos iguais de seis animais cada, assim constituídos: controle (CON); MON 30 ppm; VM 25 ppm; VM 34 ppm e MON 30 ppm + VM 25 ppm. Os aditivos foram administrados numa mistura de $500 \mathrm{~g}$ fubá, antes do oferecimento do alimento. Em seguida, foi realizada indução individual de ALR com uso de sacarose de acordo com peso metabólico corrigido, administrada pela cânula ruminal. Foram obtidas amostras de conteúdo ruminal, sangue, urina e fezes, assim como realizado exame físico nos seguintes momentos: zero (basal) e após três, seis, 12 e 18 horas da indução. Foi realizada análise de variância (Teste F) dos dados que obedeceram à distribuição paramétrica, e utilizado o comando Proc mix para medidas repetidas no tempo de duas vias considerando os fatores tratamento, tempo e interação entre tratamento e tempo. Alguns dados foram submetidos ao teste T de Student. Os dados que não obedeceram a distribuição paramétrica foram avaliados pelos testes de Kruskal-Wallis e quiquadrado. Para o estudo da relação entre duas variáveis foi determinado os índices de correlação e determinação. Ocorreu acidose ruminal intensa, por grande produção inicial de ácidos graxos de cadeia curta (AGCC), seguido de ácido láctico, com predomínio do isômero L sobre o D, os quais com a glicose gerada na fermentação provocaram aumento de osmolaridade nesse conteúdo. A acidose sistêmica foi de grau moderado em pequena parte dos bovinos, com presença de desidratação num expressivo número de animais. Boa parte dos bovinos tratados $(n=15)$ apresentavam depressão nervosa e desidratação. Ocorreu pontualmente um quadro de hipertermia no auge da fermentação ruminal. Os melhores resultados preventivos da ALR 
foram obtidos com a associação VM + MON, a qual postergou a produção de ácido láctico, quer seja pela menor produção deste, como pela conversão de ácido láctico L em ácidos acético e propiônico. Ao término do experimento essa associação promoveu maior $\mathrm{pH}$ e menor acúmulo de ácido láctico L, assim como viabilizou que um menor número de animais necessitassem ser tratados, em relação ao grupo controle. As duas diferentes doses de VM tiveram resultados intermediários, seguidos da MON, a qual não se recomenda como único aditivo com fins de prevenção da ALR.

Palavras-chave: Ácido láctico. Nelore. Sacarose. Virginiamicina. Monensina. 


\begin{abstract}
OLIVEIRA, F. L. C. Comparative evaluation of different additives in the prevention of rumen lactic acidosis in beef cattle. [Avaliação comparativa de diferentes aditivos na prevenção da acidose láctica ruminal em bovinos de corte]. 2018. 150 f. Tese (Doutorado em Ciências) - Faculdade de Medicina Veterinária e Zootecnia, Universidade de São Paulo, São Paulo, 2018.
\end{abstract}

The objective was to better understand the induction model of rumen lactic acidosis (RLA) with sucrose, highlighting the basic aspects of ruminal fermentation and its consequences, as well as comparative evaluation of the efficacy of two additives (Virginiamycin VM and Monensin MON), associated or not, in the prevention of acidosis in adult beef cattle. For this purpose, 30 Nellore ruminally-cannulated females were used, with average body weight of about $413 \mathrm{~kg}$. The animals were kept in individual stalls and fed a basal diet composed of $75 \%$ coast-cross grass hay and $25 \%$ commercial concentrated feed for 30 days prior to RLA induction. During this period the cattle were distributed into five equal groups of six animals each, as follows: control (CON); MON 30 ppm; VM 25 ppm; VM 34 ppm and MON 30 ppm + VM 25 ppm. The additives were provided in a $500 \mathrm{~g}$ corn meal before the feed was offered. Subsequently, individual RLA induction with sucrose was performed according to corrected metabolic weight, via ruminal cannula. Samples of rumen contents, blood, urine and feces were collected, and physical examination at: zero (baseline) and after three, six, 12 and $18 \mathrm{~h}$ after induction. Variance analysis (Test F) of the data that obeyed the parametric distribution was performed, and the Proc mix command was used for repeated measurements in two-way time considering the factors treatment, time and interaction between treatment and time. Some data were submitted to Student's t-test. The data that did not obey the parametric distribution were evaluated by the Kruskal-Wallis and chi-square tests. The correlation and determination indices were determined for the study of the relationship between two variables.. A severe ruminal acidosis occurred due to the large initial production of short chain fatty acids (SCFA), followed by lactic acid, with predominance of the L over D-isomer, which with the glucose generated in the fermentation caused an increase in osmolarity in this content. Systemic acidosis was moderate in a small number of cattle, with dehydration in an expressive number of animals. Most treated cattle $(n=15)$ presented nervous depression and dehydration. A temporary hyperthermia occurred at the peak of ruminal fermentation. The best results of RLA prevention were obtained from VM + MON association, which postponed the lactic acid production, either 
by its lower production, or by the conversion of L-lactic acid in in acetic and propionic acids. At the end of the experiment, this association promoted greater $\mathrm{pH}$ and lower L-lactic acid accumulation, and a smaller number of animals needed to be treated, compared to the control group. The two different doses of VM had intermediate results, followed by MON, which is not recommended as a single additive for the RLA prevention.

Keywords: Lactic acid. Nellore. Sucrose. Virginiamycin. Monensin. 


\section{LISTA DE FIGURAS}

Figura 1 - Animais logo após a cirurgia de inclusão da cânula ruminal...................................53

Figura 2 - Animais canulados alojados em baias e presos por cabestro para facilitar o

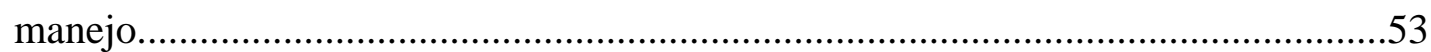




\section{LISTA DE TABELAS}

Tabela 1 - Valores médios e desvios padrão do $\mathrm{pH}$ do conteúdo ruminal nos bovinos dos grupos controle, monensina, virginiamicina (25 ppm), virginiamicina (34 ppm) e monensina + virginiamicina no decorrer do experimento - São Paulo - 2018

Tabela 2 - Valores de mediana da concentração de glicose ruminal (mM/L) nos bovinos dos grupos controle, monensina, virginiamicina $(25 \mathrm{ppm})$, virginiamicina (34 ppm) e monensina + virginiamicina no decorrer do experimento - São Paulo - 2018 .

Tabela 3 - Valores médios e desvios padrão da concentração de lactato - L ruminal (mM/L) nos bovinos dos grupos controle, monensina, virginiamicina (25 ppm), virginiamicina (34 ppm) e monensina + virginiamicina no decorrer do experimento - São Paulo 2018.

Tabela 4 - Valores médios e desvios padrão da concentração de lactato - D ruminal (mM/L) nos bovinos dos grupos controle, monensina, virginiamicina ( $25 \mathrm{ppm})$, virginiamicina (34 ppm) e monensina + virginiamicina no decorrer do experimento - São Paulo 2018.

Tabela 5 - Valores médios e desvios padrão da concentração de ácido láctico total do conteúdo ruminal (mM/L) nos bovinos dos grupos controle, monensina, virginiamicina (25 ppm), virginiamicina (34 ppm) e monensina + virginiamicina no decorrer do experimento - São Paulo - 2018.

Tabela 6 - Valores médios e desvios padrão da relação lactato L/D do conteúdo ruminal nos bovinos dos grupos controle, monensina, virginiamicina (25 ppm), virginiamicina (34 ppm) e monensina + virginiamicina no decorrer do experimento - São Paulo 2018 .

Tabela 7 - Valores médios e desvios padrão da concentração do acetato ruminal (mM/L) nos bovinos dos grupos controle, monensina, virginiamicina (25 ppm), virginiamicina (34 ppm) e monensina + virginiamicina no decorrer do experimento - São Paulo 2018 .

Tabela 8 - Valores médios e desvios padrão da concentração do propionato ruminal (mM/L) nos bovinos dos grupos controle, monensina, virginiamicina (25 ppm), virginiamicina (34 ppm) e monensina + virginiamicina no decorrer do experimento - São Paulo 2018. 
Tabela 9 - Valores médios e desvios padrão da concentração do butirato ruminal (mM/L) nos bovinos dos grupos controle, monensina, virginiamicina (25 ppm), virginiamicina (34 ppm) e monensina + virginiamicina no decorrer do experimento - São Paulo 2018 .

Tabela 10 - Valores médios e desvios padrão da concentração total de AGCC ruminal (mM/L) nos bovinos dos grupos controle, monensina, virginiamicina (25 ppm), virginiamicina (34 ppm) e monensina + virginiamicina no decorrer do experimento - São Paulo 2018

Tabela 11 - Valores médios e desvios padrão da relação acetato/propionato ruminal (mM/L) nos bovinos dos grupos controle, monensina, virginiamicina (25 ppm), virginiamicina $(34 \mathrm{ppm})$ e monensina + virginiamicina no decorrer do experimento - São Paulo 2018 .

Tabela 12 - Valores médios e desvios padrão da concentração do total de ácidos do conteúdo ruminal (mM/L) nos bovinos dos grupos controle, monensina, virginiamicina (25 ppm), virginiamicina $(34 \mathrm{ppm})$ e monensina + virginiamicina no decorrer do

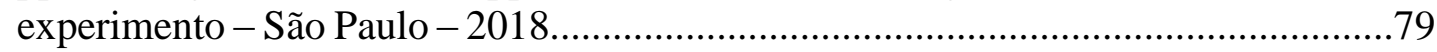

Tabela 13 - Valores médios e desvios padrão da osmolaridade ruminal (mOsm/L) nos bovinos dos grupos controle, monensina, virginiamicina (25 ppm), virginiamicina (34 ppm) e monensina + virginiamicina no decorrer do experimento - São Paulo 2018 .

Tabela 14 - Valores médios e desvios padrão do potencial de oxido-redução do conteúdo ruminal (mV) nos bovinos dos grupos controle, monensina, virginiamicina (25 ppm), virginiamicina (34 ppm) e monensina + virginiamicina no decorrer do experimento São Paulo - 2018.

Tabela 15 - Valores médios e desvios padrão da acidez titulável ruminal (UC) nos bovinos dos grupos controle, monensina, virginiamicina (25 ppm), virginiamicina (34 ppm) e monensina + virginiamicina no decorrer do experimento - São Paulo - 2018.

Tabela 16 - Valores médios e desvios padrão do pH sanguíneo nos bovinos dos grupos controle, monensina, virginiamicina $(25 \mathrm{ppm})$, virginiamicina $(34 \mathrm{ppm})$ e monensina + virginiamicina no decorrer do experimento - São Paulo - 2018.

Tabela 17 - Valores médios e desvios padrão do déficit da concentração de excesso de ácidobase nos bovinos dos grupos controle, monensina, virginiamicina (25 ppm), virginiamicina (34 ppm) e monensina + virginiamicina no decorrer do experimento São Paulo - 2018. 
Tabela 18 - Valores médios e desvios padrão do déficit da concentração de bicarbonato sanguíneo (mM/L) nos bovinos dos grupos controle, monensina, virginiamicina (25 ppm), virginiamicina $(34 \mathrm{ppm})$ e monensina + virginiamicina no decorrer do

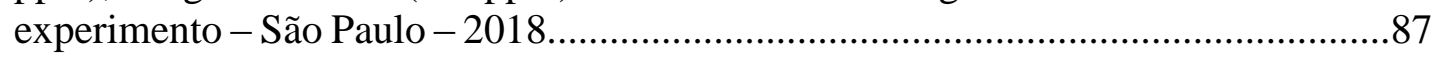

Tabela 19 - Valores médios e desvios padrão da concentração do lactato - L plasmático (mM/L) nos bovinos dos grupos controle, monensina, virginiamicina (25 ppm), virginiamicina (34 ppm) e monensina + virginiamicina no decorrer do experimento - São Paulo 2018

Tabela 20 - Valores médios e desvios padrão da concentração do lactato - D plasmático $(\mathrm{mM} / \mathrm{L})$ nos bovinos dos grupos controle, monensina, virginiamicina (25 ppm), virginiamicina (34 ppm) e monensina + virginiamicina no decorrer do experimento São Paulo - 2018 .

Tabela 21 - Valores médios e desvios padrão da osmolaridade sérica (mOsm/L) nos bovinos dos grupos controle, monensina, virginiamicina (25 ppm), virginiamicina (34 ppm) e monensina + virginiamicina no decorrer do experimento - São Paulo - 2018.

Tabela 22 - Valores médios e desvios padrão do déficit do volume globular (\%) nos bovinos dos grupos controle, monensina, virginiamicina ( $25 \mathrm{ppm})$, virginiamicina (34 ppm) e monensina + virginiamicina no decorrer do experimento - São Paulo - 2018.

Tabela 23 - Valores médios e desvios padrão do déficit de volume plasmático (\%) nos bovinos dos grupos controle, monensina, virginiamicina (25 ppm), virginiamicina (34 ppm) e monensina + virginiamicina no decorrer do experimento - São Paulo - 2018.

Tabela 24 - Valores médios e desvios padrão da glicose plasmática $(\mathrm{mM} / \mathrm{L})$ nos bovinos dos grupos controle, monensina, virginiamicina ( $25 \mathrm{ppm})$, virginiamicina (34 ppm) e monensina + virginiamicina no decorrer do experimento - São Paulo - 2018. .95

Tabela 25 - Valores médios e desvios padrão do $\mathrm{pH}$ de fezes na $12^{\mathrm{a}}$ e/ou $18^{\mathrm{a}} \mathrm{h}$ dos animais com ou sem muco nas fezes sem distinção de grupos - São Paulo - 2018

Tabela 26 - Valores médios e desvios padrão da concentração de lactato - D na $18^{\mathrm{a}} \mathrm{h}$ dos animais tratados e dos não tratados sem distinção de grupos - São Paulo - 2018........98

Tabela 27 - Valores médios e desvios padrão da frequência cardíaca (mpm) nos bovinos dos grupos controle, monensina, virginiamicina (25 ppm), virginiamicina (34 ppm) e monensina + virginiamicina no decorrer do experimento - São Paulo - 2018.........99 
Tabela 28 - Valores médios e desvios padrão da frequência respiratória (bpm) nos bovinos dos grupos controle, monensina, virginiamicina (25 ppm), virginiamicina (34 ppm) e monensina + virginiamicina no decorrer do experimento - São Paulo 2018 .

Tabela 29 - Valores médios e desvios padrão da temperatura retal $\left({ }^{\circ} \mathrm{C}\right)$ nos bovinos dos grupos controle, monensina, virginiamicina (25 ppm), virginiamicina (34 ppm) e monensina + virginiamicina no decorrer do experimento - São Paulo - 2018. 102

Tabela 30 - Valores médios e desvios padrão do movimento ruminal (3 min.) nos bovinos dos grupos controle, monensina, virginiamicina $(25 \mathrm{ppm})$, virginiamicina (34 ppm) e monensina + virginiamicina no decorrer do experimento - São Paulo - 2018. 103

Tabela 31 - Valores médios e desvios padrão do pH da urina nos bovinos dos grupos controle, monensina, virginiamicina $(25 \mathrm{ppm})$, virginiamicina $(34 \mathrm{ppm})$ e monensina + virginiamicina no decorrer do experimento - São Paulo - 2018. 104

Tabela 32 - Valores médios e desvios padrão da densidade urinaria nos bovinos dos grupos controle, monensina, virginiamicina (25 ppm), virginiamicina (34 ppm) e monensina + virginiamicina no decorrer do experimento - São Paulo - 2018. 106

Tabela 33 - Valores médios e desvios padrão do $\mathrm{pH}$ fecal nos bovinos dos grupos controle, monensina, virginiamicina $(25 \mathrm{ppm})$, virginiamicina $(34 \mathrm{ppm})$ e monensina + virginiamicina no decorrer do experimento - São Paulo - 2018.

Tabela 34 - Coeficientes de correlação entre as diferentes variáveis dos animais submetidos à indução da acidose láctica ruminal por sacarose 116

Tabela 35 - Coeficientes de correlação entre as diferentes variáveis dos animais submetidos à indução da acidose láctica ruminal por sacarose. 117

Tabela 36 - Coeficientes de correlação entre as diferentes variáveis dos animais submetidos à indução da acidose láctica ruminal por sacarose. 118 


\section{LISTA DE GRÁFICOS}

Gráfico 1 - Valores médios do $\mathrm{pH}$ do conteúdo ruminal nos bovinos dos grupos controle, monensina, virginiamicina (25 ppm), virginiamicina $(34 \mathrm{ppm})$ e monensina + virginiamicina no decorrer do experimento - São Paulo - 2018.

Gráfico 2 - Valores de mediana da concentração de glicose ruminal (mM/L) nos bovinos dos grupos controle, monensina, virginiamicina $(25 \mathrm{ppm})$, virginiamicina (34 ppm) e monensina + virginiamicina no decorrer do experimento - São Paulo - 2018. .65

Gráfico 3 - Valores médios da concentração de lactato - L ruminal (mM/L) nos bovinos dos grupos controle, monensina, virginiamicina (25 ppm), virginiamicina (34 ppm) e monensina + virginiamicina no decorrer do experimento - São Paulo - 2018. .66

Gráfico 4 - Valores médios da concentração de lactato - D ruminal (mM/L) nos bovinos dos grupos controle, monensina, virginiamicina (25 ppm), virginiamicina (34 ppm) e monensina + virginiamicina no decorrer do experimento - São Paulo - 2018. .68

Gráfico 5 - Valores médios da concentração do total de lactato ruminal (mM/L) nos bovinos dos grupos controle, monensina, virginiamicina ( $25 \mathrm{ppm})$, virginiamicina (34 ppm) e monensina + virginiamicina no decorrer do experimento - São Paulo - 2018.

Gráfico 6 - Valores médios da relação lactato L/D do conteúdo ruminal nos bovinos dos grupos controle, monensina, virginiamicina (25 ppm), virginiamicina (34 ppm) e monensina + virginiamicina no decorrer do experimento - São Paulo - 2018. .71

Gráfico 7 - Valores médios da concentração de acetato ruminal (mM/L) nos bovinos dos grupos controle, monensina, virginiamicina (25 ppm), virginiamicina (34 ppm) e monensina + virginiamicina no decorrer do experimento - São Paulo - 2018.

Gráfico 8 - Valores médios da concentração de propionato ruminal (mM/L) nos bovinos dos grupos controle, monensina, virginiamicina (25 ppm), virginiamicina (34 ppm) e monensina + virginiamicina no decorrer do experimento - São Paulo - 2018.............74

Gráfico 9 - Valores médios da concentração de butirato ruminal (mM/L) nos bovinos dos grupos controle, monensina, virginiamicina (25 ppm), virginiamicina (34 ppm) e monensina + virginiamicina no decorrer do experimento - São Paulo - 2018 .

Gráfico 10 - Valores médios da concentração do total de AGCC ruminal (mM/L) nos bovinos dos grupos controle, monensina, virginiamicina ( $25 \mathrm{ppm})$, virginiamicina (34 ppm) e monensina + virginiamicina no decorrer do experimento - São Paulo - 2018. 
Gráfico 11 - Valores médios da relação acetato/propionato ruminal nos bovinos dos grupos controle, monensina, virginiamicina ( $25 \mathrm{ppm})$, virginiamicina (34 ppm) e monensina + virginiamicina no decorrer do experimento - São Paulo - 2018.

Gráfico 12 - Valores médios da concentração do total de ácidos orgânicos do conteúdo ruminal $(\mathrm{mM} / \mathrm{L})$ nos bovinos dos grupos controle, monensina, virginiamicina (25 ppm), virginiamicina (34 ppm) e monensina + virginiamicina no decorrer do experimento São Paulo - 2018 .

Gráfico 13 - Valores médios da osmolaridade ruminal (mOsm/L) nos bovinos dos grupos controle, monensina, virginiamicina (25 ppm), virginiamicina (34 ppm) e monensina + virginiamicina no decorrer do experimento - São Paulo - 2018.

Gráfico 14 - Valores médios do potencial de oxido-redução ruminal $(\mathrm{mV})$ nos bovinos dos grupos controle, monensina, virginiamicina $(25 \mathrm{ppm})$, virginiamicina (34 ppm) e monensina + virginiamicina no decorrer do experimento - São Paulo - 2018 . 82

Gráfico 15 - Valores médios da acidez titulável ruminal (UC) nos bovinos dos grupos controle, monensina, virginiamicina $(25 \mathrm{ppm})$, virginiamicina $(34 \mathrm{ppm})$ e monensina + virginiamicina no decorrer do experimento - São Paulo - 2018.

Gráfico 16 - Valores médios do pH sanguíneo nos bovinos dos grupos controle, monensina, virginiamicina $(25 \mathrm{ppm})$, virginiamicina $(34 \mathrm{ppm})$ e monensina + virginiamicina no decorrer do experimento - São Paulo - 2018.

Gráfico 17 - Valores médios do déficit da concentração de excesso de ácido-base nos bovinos dos grupos controle, monensina, virginiamicina (25 ppm), virginiamicina (34 ppm) e monensina + virginiamicina no decorrer do experimento - São Paulo - 2018.........86

Gráfico 18 - Valores médios do déficit da concentração de bicarbonato sanguíneo (mM/L) nos bovinos dos grupos controle, monensina, virginiamicina (25 ppm), virginiamicina (34 ppm) e monensina + virginiamicina no decorrer do experimento - São Paulo 2018.

Gráfico 19 - Valores médios da concentração do lactato - L plasmático (mM/L) nos bovinos dos grupos controle, monensina, virginiamicina (25 ppm), virginiamicina (34 ppm) e monensina + virginiamicina no decorrer do experimento - São Paulo - 2018.

Gráfico 20 - Valores médios da concentração do lactato - D plasmático (mM/L) nos bovinos dos grupos controle, monensina, virginiamicina ( $25 \mathrm{ppm})$, virginiamicina (34 ppm) e monensina + virginiamicina no decorrer do experimento - São Paulo - 2018. 
Gráfico 21 - Valores médios da osmolaridade sérica $(\mathrm{mOsm} / \mathrm{L})$ nos bovinos dos grupos controle, monensina, virginiamicina (25 ppm), virginiamicina (34 ppm) e monensina + virginiamicina no decorrer do experimento - São Paulo - 2018.

Gráfico 22 - Valores médios do volume globular (\%) nos bovinos dos grupos controle, monensina, virginiamicina $(25 \mathrm{ppm})$, virginiamicina $(34 \mathrm{ppm})$ e monensina + virginiamicina no decorrer do experimento - São Paulo - 2018.

Gráfico 23 - Valores médios do déficit de volume plasmático (\%) nos bovinos dos grupos controle, monensina, virginiamicina (25 ppm), virginiamicina (34 ppm) e monensina + virginiamicina no decorrer do experimento - São Paulo - 2018.

Gráfico 24 - Valores médios da glicose plasmática (mM/L) nos bovinos dos grupos controle, monensina, virginiamicina $(25 \mathrm{ppm})$, virginiamicina $(34 \mathrm{ppm})$ e monensina + virginiamicina no decorrer do experimento - São Paulo - 2018

Gráfico 25 - Valores médios da frequência cardíaca ( $\mathrm{mpm}$ ) nos bovinos dos grupos controle, monensina, virginiamicina $(25 \mathrm{ppm})$, virginiamicina $(34 \mathrm{ppm})$ e monensina + virginiamicina no decorrer do experimento - São Paulo - 2018. 100

Gráfico 26 - Valores médios da frequência respiratória (bpm) nos bovinos dos grupos controle, monensina, virginiamicina $(25 \mathrm{ppm})$, virginiamicina $(34 \mathrm{ppm})$ e monensina + virginiamicina no decorrer do experimento - São Paulo - 2018.

Gráfico 27 - Valores médios da temperatura retal $\left({ }^{\circ} \mathrm{C}\right)$ nos bovinos dos grupos controle, monensina, virginiamicina $(25 \mathrm{ppm})$, virginiamicina $(34 \mathrm{ppm})$ e monensina + virginiamicina no decorrer do experimento - São Paulo - 2018.

Gráfico 28 - Valores médios do movimento ruminal (3 min.) nos bovinos dos grupos controle, monensina, virginiamicina $(25 \mathrm{ppm})$, virginiamicina $(34 \mathrm{ppm})$ e monensina + virginiamicina no decorrer do experimento - São Paulo - 2018. .104

Gráfico 29 - Valores médios do pH da urina nos bovinos dos grupos controle, monensina, virginiamicina $(25 \mathrm{ppm})$, virginiamicina $(34 \mathrm{ppm})$ e monensina + virginiamicina no decorrer do experimento - São Paulo - 2018. 105

Gráfico 30 - Valores médios da densidade urinaria nos bovinos dos grupos controle, monensina, virginiamicina $(25 \mathrm{ppm})$, virginiamicina $(34 \mathrm{ppm})$ e monensina + virginiamicina no decorrer do experimento - São Paulo - 2018.

Gráfico 31 - Valores médios do $\mathrm{pH}$ fecal nos bovinos dos grupos controle, monensina, virginiamicina (25 ppm), virginiamicina (34 ppm) e monensina + virginiamicina no decorrer do experimento - São Paulo - 2018. 
Gráfico 32 - Relação entre $\mathrm{pH}$ e a concentração de glicose (mM/L) do conteúdo ruminal dos bovinos no decorrer do experimento, sem distinção de grupos - São Paulo 2018.

Gráfico 33 - Relação entre lactato - L (mM/L) e a concentração de acetato (mM/L) do conteúdo ruminal dos bovinos na $3^{\mathrm{a}} \mathrm{h}$ do grupo VM + MON - São Paulo - 2018.

Gráfico 34 - Relação entre lactato - L (mM/L) e a concentração de acetato $(\mathrm{mM} / \mathrm{L})$ do conteúdo ruminal dos bovinos na $6^{\mathrm{a}} \mathrm{h}$ do grupo $\mathrm{VM}+\mathrm{MON}-\mathrm{São}$ Paulo - 2018

Gráfico 35 - Relação entre lactato - L ( $\mathrm{mM} / \mathrm{L})$ e a concentração de acetato $(\mathrm{mM} / \mathrm{L})$ do conteúdo ruminal dos bovinos na $3^{\mathrm{a}} \mathrm{h}$ do grupo CON, MON, VM 25 E VM 34 - São Paulo 2018.

Gráfico 36 - Relação entre a concentração de lactato -L (mM/L) e propionato do conteúdo ruminal $(\mathrm{mM} / \mathrm{L})$ nos bovinos, considerados os dados disponíveis das duas variáveis no grupo VM + M, com exceção do tempo basal - São Paulo - 2018 113

Gráfico 37 - Relação entre a concentração de lactato -L (mM/L) e propionato do conteúdo ruminal (mM/L) nos bovinos, considerados os dados disponíveis das duas variáveis no grupo C, M, VM 25 e VM34, com exceção do tempo basal - São Paulo - 2018...114

Gráfico 38 - Relação entre pH e a concentração de propionato (mM/L) do conteúdo ruminal dos bovinos na $6^{\mathrm{a}} \mathrm{h}$ do experimento sem distinção de grupo. - São Paulo 2018 . 


\section{LISTA DE QUADROS}

Quadro 1 - Ocorrências clínicas constatadas nos animais no decorrer da experimentação - São

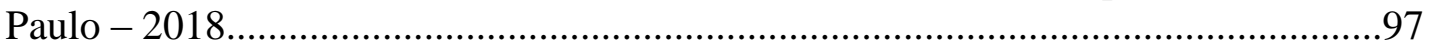




\section{SÚMARIO}

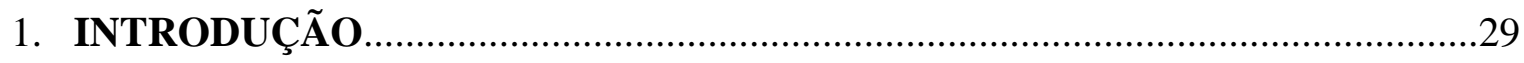

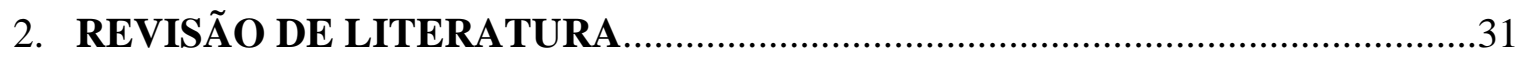

2.1 ENTENDENDO O AMBIENTE RUMINAL.................................................

2.2 ENTENDENDO A ACIDOSE LÁCTICA RUMINAL (ALR)..........................36

2.3 ADITIVOS NA ALIMENTAÇÃO DE RUMINANTES..................................42

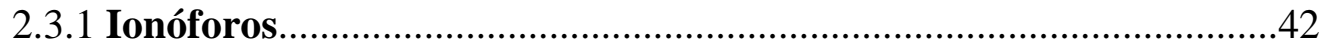

2.3.2 Virginiamicina

2.4 ENTENDENDO O MODELO DE INDUÇÃO DA ALR COM USO DE

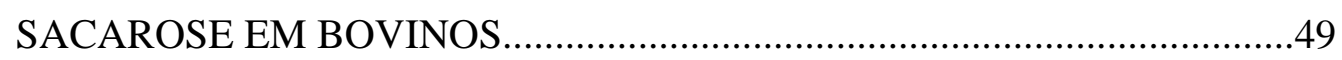

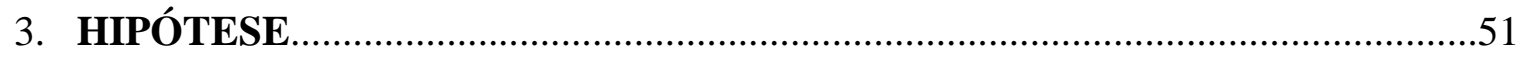

4. OBJETIVOS

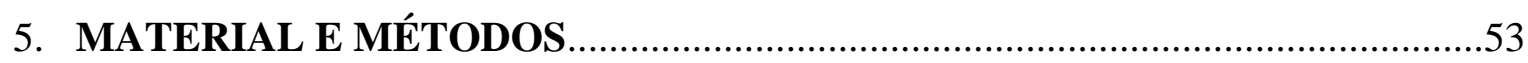

5.1 ANIMAIS E ALIMENTAÇÃO.................................................................

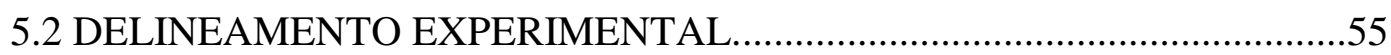

5.3 INDUÇÃO DA ACIDOSE LÁCTICA RUMINAL .........................................55

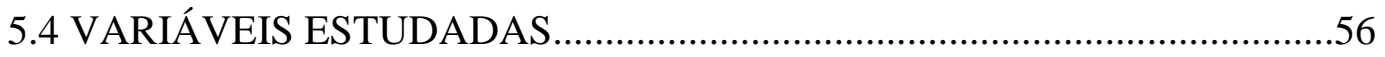

5.4.1 Exame clínico geral...........................................................................56

5.4.2 Coleta e processamento das amostras de fluido ruminal...................56

5.4.3 Coleta e processamento das amostras de sangue..................................57

5.4.4 Coleta e processamento das amostras de urina...................................59

5.4.5 Coleta e processamento das amostras de fezes....................................59

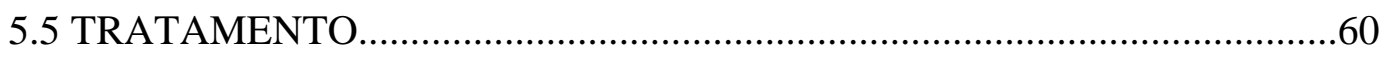

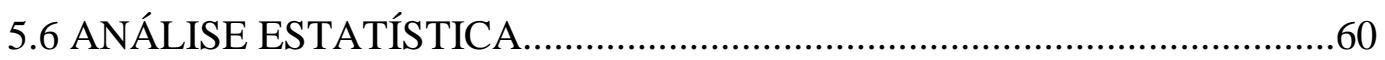

6. RESULTADOS

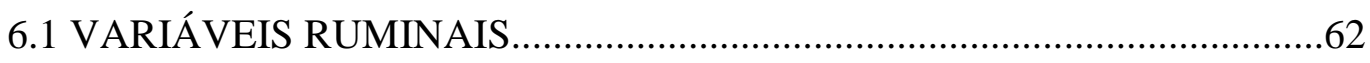

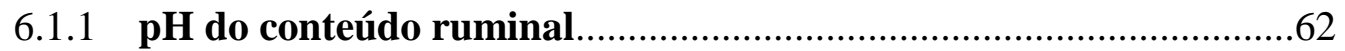

6.1.2 Concentração de glicose ruminal.......................................................64

6.1.3 Concentração de lactato - L ruminal................................................65

6.1.4 Concentração de lactato - D ruminal................................................66

6.1.5 Concentração de ácido láctico total do conteúdo ruminal................68

6.1.6 Relação lactato L/D no conteúdo ruminal...........................................69 


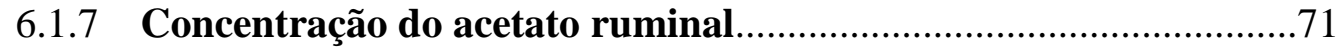

6.1.8 Concentração do propionato ruminal.............................................72

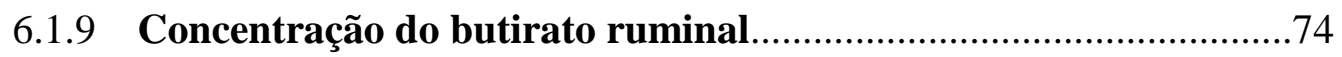

6.1.10 Concentração do total de AGCC ruminal......................................75

6.1 .11 Relação acetato/propionato ruminal............................................77

6.1.12 Concentração total de ácidos orgânicos ruminais............................78

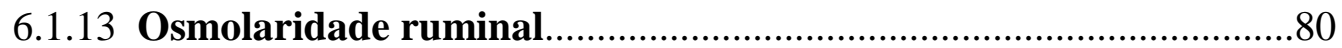

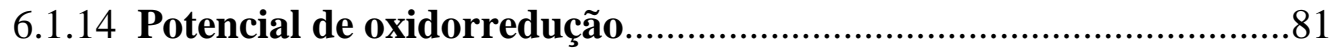

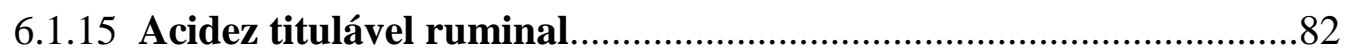

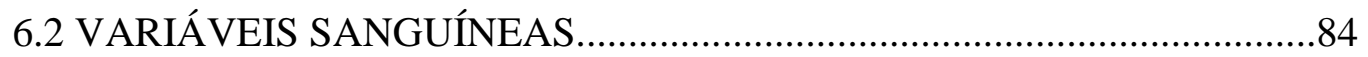

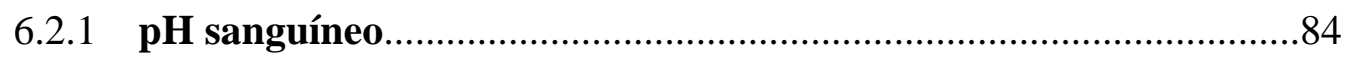

6.2.2 Concentração de excesso de ácido-base...........................................85

6.2.3 Concentração de bicarbonato sanguíneo........................................86

6.2.4 Concentração de lactato - L plasmático...........................................88

6.2.5 Concentração de lactato - D plasmático..........................................89

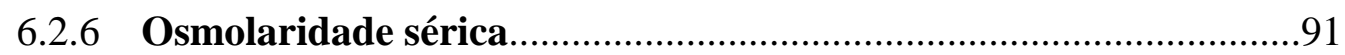

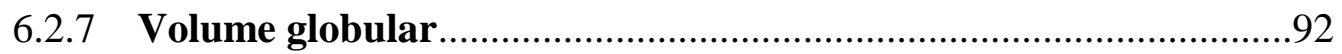

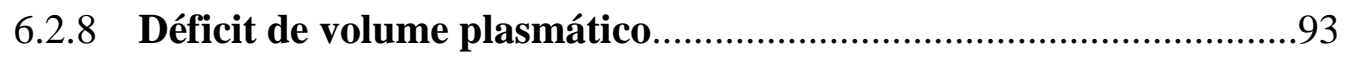

6.2.9 Concentração de glicose plasmática................................................95

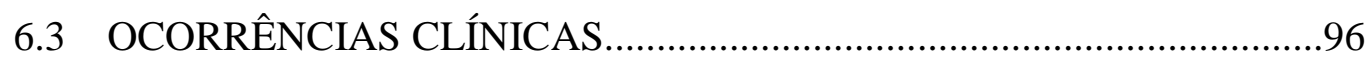

6.4 VARIÁVEIS CLÍNICAS.....................................................................99

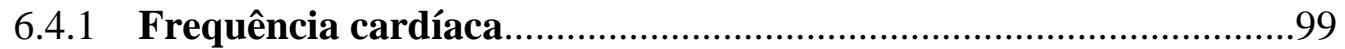

6.4.2 Frequência respiratória...............................................................100

6.4.3 Temperatura retal................................................................. 101

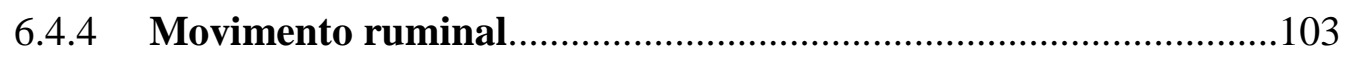

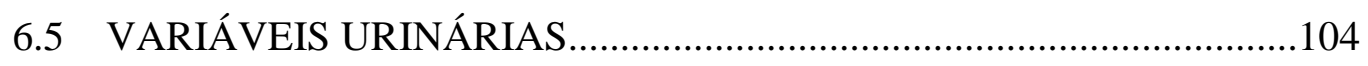

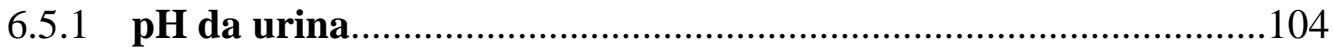

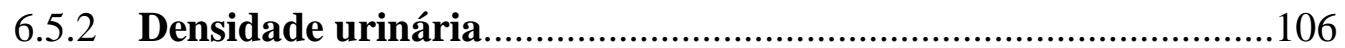

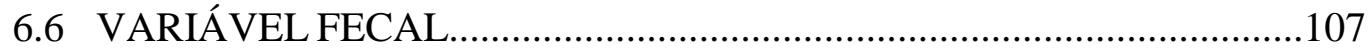

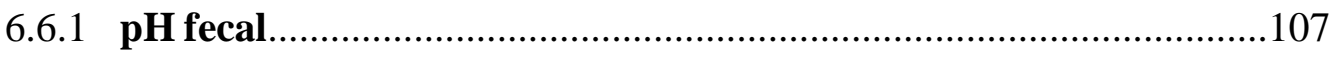

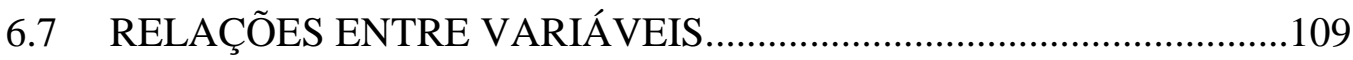

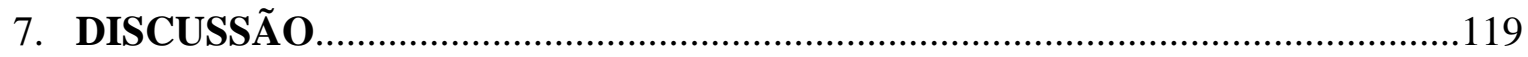

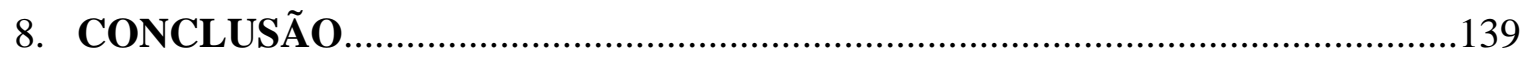




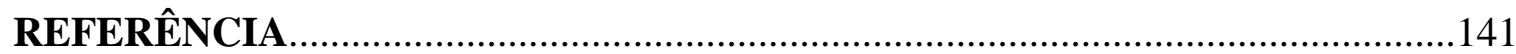




\section{INTRODUÇÃO}

Segundo o IBGE (2016) o Brasil possui 218,23 milhões de bovinos constituindo assim o maior rebanho comercial do mundo e o principal exportado desta carne com vendas que superam os US\$ 5,3 bilhões. Essa atividade pecuária é de grande importância econômica para a nação empregando no momento 1,6 milhões de pessoas na cadeia produtiva.

A pecuária de corte bovina nacional tem apresentado melhora em sua produtividade média. Até o final da década de 70, a esmagadora maioria dos rebanhos bovinos era submetida ao sistema extensivo de criação. De lá para cá, houve um aumento gradual na utilização de sistemas semi-intensivos ou intensivos e no ano de 2017 estimou-se que 5 milhões de bovinos tenham sido confinados (Anuário DBO, 2018).

A premissa dos confinadores é a obtenção de rápido ganho de peso, em um curto espaço de tempo, empregando-se para tal dietas ricas em carboidratos solúveis (ORTOLANI et al., 2010). Porém, essas diretrizes podem gerar aumento de doenças metabólicas como a acidose ruminal. Um grande levantamento do manejo conduzido nos mais expressivos confinamentos nacionais identificou que a acidose ruminal é a segunda principal doença nos bovinos confinados, sendo responsável por $36 \%$ das enfermidades, só perdendo para o complexo respiratório bovino (MILLEN et al., 2009).

Esses quadros de acidose ruminal, são causados por ingestão exagerada de dietas ricas em carboidratos solúveis, em especial de grãos ricos em amido, as quais são oferecidas sem uma adequada adaptação gradativa a esses alimentos, que geram no rúmen uma grande produção de ácidos graxos de cadeia curta, e em casos severos destacado incremento na síntese de ácido láctico, os quais promovem substancial queda no $\mathrm{pH}$ ruminal, aumento de osmolaridade ruminal, síndrome desidratação, diarreia, acidose metabólica, entre outros 
sintomas, levando nos casos graves os bovinos à morte (DUNLOP, 1972; OWENS, 1998; MARUTA; ORTOLANI, 2002; ORTOLANI et al., 2010; HERNÁNDEZ et al., 2014).

Existem várias formas de prevenção de quadro de acidose, estando entre a prioritárias as mudanças no manejo dietético, em especial no período inicial do confinamento, assim como o emprego de vários tipos de aditivos que diminuam a excessiva fermentação dos carboidratos solúveis no rúmen, tamponamento dos ácidos produzidos, entre outras formas de atuação (MILLEN et al., 2009).

Devido à grande complexidade do tema, quer seja ele da doença em si, como as suas formas de prevenção, abordar-se-á essa temática na revisão de literatura no capítulo a seguir. 


\section{REVISÃO DE LITERATURA}

\subsection{ENTENDENDO O AMBIENTE RUMINAL}

Os animais desenvolveram diferentes maneiras para extrair dos alimentos os nutrientes necessários para a manutenção dos processos biológicos. Todos os mamíferos herbívoros dependem de uma relação simbiótica com microrganismos habitantes do seu trato gastrointestinal. Por meio dessa relação, os ruminantes obtêm os nutrientes necessários através de processos fermentativos que ocorrem no rúmen, uma vez que, nesse processo, a o suprimento de 60 a $80 \%$ da energia dietética desses animais e a maior parte da proteína necessária é advinda da proteína microbiana, sendo está de alto valor biológico (BERCHIELLI, et al., 2011; FLINT, 1997).

O rúmen é um ambiente anaeróbico, constituído por uma variada microbiota que inclui bactérias, protozoários e fungos. Esses microrganismos são capazes de utilizar carboidratos (os principais carboidratos que compõem a dieta de ruminantes são a celulose, hemicelulose, os amidos, os monossacarídeos e os polissacarídeos) provenientes da alimentação como substrato para a fermentação, produzindo ácidos orgânicos (sendo os principais os ácidos graxos de cadeia curta que são o ácido acético, butírico e propiônico (AGCC), além de outros ácidos em menores quantidades como o fórmico, succínico, ácido láctico e pequenas quantidades de etanol), os quais são utilizados pelo animal e pela microbiota respectivamente (NAGARAJA; TITGEMEYER, 2007) O metabolismo fermentativo ruminal também produz gases como hidrogênio $\left(\mathrm{H}_{2}\right)$ e metano $\left(\mathrm{CH}_{4}\right)$ (DIJKSTRA, et al., 2005).

A composição do conteúdo ruminal é dependente de dois fatores principais: a composição da ingesta e a população de microrganismos. É esta inter-relação entre os grupos de microrganismos, os produtos metabólitos e substratos de crescimento microbiano que 
determinam a composição do conteúdo ruminal (HUNGATE, 1960). Para o perfeito funcionamento desse ecossistema, é necessário que o $\mathrm{pH}$ permaneça dentro de uma faixa ótima, pois quando ocorre alteração, determinadas populações de microrganismos se sobrepõem em detrimento a outras, culminando em possíveis distúrbios metabólicos (MOURINO et al., 2001; RUSSELL; RYCHLIK, 2001). Em situações de equilíbrio, o pH ruminal deve-se manter numa faixa de 5,9 a 7,1 (ORTOLANI, 1980). Nessa faixa ocorre eficiente degradação de celulose e proteínas, assim como a desaminação, enquanto em $\mathrm{pH}$ inferior estas funções são afetadas (LEWY; EMERY, 1962; MOULD et al., 1983).

O pH ruminal sofre alteração nictemeral, além de ser influenciado pela ingestão de carboidratos, tempo de alimentação com concentrado, utilização de fontes de fibras, forma física da dieta, produção de agentes tamponantes e produção e utilização de ácidos graxos orgânicos (KRAUSE et al., 2002; NAGARAJA; TITGEMEYER, 2007).

Os AGCC e o ácido láctico são os principais produtos provenientes da fermentação ruminal capazes de reduzir o $\mathrm{pH}$ ruminal. Os principais AGCC produzidos no rúmen são o ácido acético (54-71\%), propiônico (16-31\%) e butírico (8-11\%), sendo essa produção influenciada pela relação volumoso:concentrado da dieta (ANNISON; ARMSTRONG, 1970). Os AGCC não se acumulam facilmente no rúmen devido seu alto pKa de 4,9, portanto são ácidos fracos, com maior capacidade de associação e são rapidamente absorvidos pelo rúmen, diferentemente do ácido láctico que possui menor pKa de 3,9, sendo mais forte, com menor capacidade de dissociação, se acumulando no rúmen (NAGARAJA; TITGEMEYER, 2007). No rúmen há produção de dois isômeros do ácido láctico o L (+) e o D (-), no entanto, quando há redução do pH ruminal o lactato - D é produzido em maior escala (DUNLOP, 1972; GIESECKE; STANGASSINGER, 1980).

As bactérias do rúmen podem ser classificadas como "produtoras de lactato" ou "consumidoras de lactato." O equilíbrio entre estes dois grupos determina se o lactato se 
acumulará ou não no rúmen. Produtos finais de cepas bacterianas podem mudar dependendo da disponibilidade de substrato (RUSSELL; HINO, 1985). As espécies consumidoras de lactato são sensíveis ao pH baixo, enquanto a maioria dos produtores de lactato não são. Em condições anaeróbias, o piruvato é convertido em lactato para regenerar o NAD utilizada na glicólise. Sob condições normais, o lactato não se acumula no rúmen em concentrações acima de $5 \mathrm{mM} / \mathrm{L}$ (SLYTER, 1976).

Embora o rúmen esteja constantemente sujeito a sofrer reduções de $\mathrm{pH}$, existem sistemas tamponantes que ajudam a manter o $\mathrm{pH}$ na faixa fisiológica. Os principais agentes tamponantes são encontrados na saliva $(\mathrm{pH}=8,0)$, como carbonatos e fosfatos (COUNOTTE et al., 1979). A capacidade tampão dos fosfatos provenientes da saliva residem no fato deles possuírem alto pKa $(7,21)$, e uma capacidade tamponante de cerca de 80\% em pH 8,21 a 6,21. Considerando um pH ruminal de 6,2 ou menos, cerca de $80 \%$ da capacidade tamponante é utilizada quando a saliva é misturada com o conteúdo ruminal (ASCHENBACH et al., 2010).

Diferentemente dos fosfatos, a capacidade tampão dos carbonatos $\left(\mathrm{HCO}_{3}^{-}, \mathrm{H}_{2} \mathrm{CO}_{3}\right)$ não é apenas explicada pelo valor do seu pKa $(3,8)$, pois esse tampão faz parte de um sistema duplo aberto, onde $\mathrm{o}_{2} \mathrm{CO}_{3}$ pode ser proveniente da saliva ou formado no ambiente ruminal. $\mathrm{O}$ $\mathrm{H}_{2} \mathrm{CO}_{3}$ salivar pode facilmente se dissociar em $\mathrm{HCO}_{3}^{-} \mathrm{e} \mathrm{H}^{+}$, no entanto, carbonatos também podem ser produzidos a partir da reação do $\mathrm{CO}_{2}$ dissolvido no conteúdo ruminal com a $\mathrm{H}_{2} \mathrm{O}$, formando $\mathrm{H}_{2} \mathrm{CO}_{3}$ em meio aquoso, apesar de ser o mesmo composto proveniente da saliva, este tem um pKa eficaz de 6,1 (SEGEL, 1979; ASCHENBACH et al., 2010). O epitélio ruminal também contribui no tamponamento, devido a produção de íons bicarbonato e pela capacidade de absorver AGCC que possuem alto pKa (GäBEL; ASCHENBACH, 2007).

Os AGCC possuem dupla ação, embora contribuam para a redução do pH, também contribuem como agente tamponante. Isso ocorre devido à capacidade desses ácidos liberarem prótons, quando se dissociam no ambiente ruminal (GäBEL; ASCHENBACH, 2006). 
Aschenbach et al. (2010), utilizando a equação de Henderson-Hasselbalch e considerando que os AGCC possuem pKa= 4,8, mostraram que maior porcentagem de AGCC (99\%) dissociam seus prótons em $\mathrm{pH}$ ruminal maior $(6,8)$, enquanto menor porcentagem de AGCC (1\%) sofrem dissociação em pH baixo $(2,8)$. Assim, os AGCC comportam-se como substâncias tampões que podem liberar prótons quando há aumento do $\mathrm{pH}$ e ligam prótons quando há redução do $\mathrm{pH}$ (ASCHENBACH et al., 2010). Segundo Nakamura et al. (1971) os ácidos graxos de cadeia curta, em especial o acetato, $40 \%$ é formado via lactato e em menor escala o propionato que também é formado por lactato quando este último está presente em grande quantidade.

$\mathrm{O} \mathrm{NH}_{3}$ também contribui para o tamponamento ruminal. $\mathrm{O}$ nitrogênio alimentar é utilizado pelas bactérias ruminais produzindo amônia, a qual é absorvida pela parede ruminal (OBARA et al., 1991), no fígado esse composto é metabolizado em ureia. A ureia produzida no fígado pode ser reintroduzida no rúmen por secreção epitelial e salivar (MARINI et al., 2003). No rúmen a ureia é reconvertida pela uréase bacteriana em $\mathrm{NH}_{3}$, composto este que possui alto $\mathrm{pKa}(9,21) . \mathrm{O} \mathrm{NH}_{3}$ ruminal se liga em quantidade equimolar aos íons $\mathrm{H}^{+}$formando $\mathrm{NH}_{4}^{+}$que é rapidamente removido do rúmen (ASCHENBACH et al., 2010).

A ingestão de carboidratos de rápida fermentação, pode ocasionar alterações no pH ruminal. Sendo observado que reduções prolongadas do $\mathrm{pH}$ ruminal para menos de 6,0, propicia o crescimento de bactérias amilolítica, enquanto as bactérias celulolíticas têm sua atividade inibida (KRAJCARSKI-HUNT et al., 2002). Quando o pH ruminal cai para 5,8, ocorre redução da concentração de bicarbonato, e a capacidade tampão constitui uma ameaça para a microbiota ruminal e para o animal, ocorre proliferação das bactérias utilizadoras de lactato e aumento na produção de AGCC (BANNINK et al., 2008). Assim, o pH de 5,8 é o primeiro limiar de vulnerabilidade do epitélio ruminal, devido a mudanças na composição microbiana e há possibilidade de ocorrer resposta inflamatória (GOZHO et al., 2005). Se o pH cair para valores em torno de 5,0, ocorre morte de protozoários e crescimento da população de bactérias 
produtoras de ácido láctico, principalmente Streptococcus bovis, sendo este o segundo limiar de vulnerabilidade do epitélio ruminal, pois há comprometimento da função de transporte do epitélio ruminal (ASCHENBACH; GäBEL, 2000).

É sabido que cada população microbiana ruminal específica ocupa um nicho. Quando as condições mudam quer sejam pela alteração da dieta, quer seja pela adição de compostos a uma dieta já existente, alguns microrganismos têm seu crescimento inibido, apresentando um número populacional tão reduzido que sua contribuição para o metabolismo ruminal torna-se irrisório (BARAN et al., 1986). Em contrapartida, outras espécies podem apresentar um crescimento populacional significativo, dependente da presença do substrato de crescimento. Esse é o princípio pelo qual se realizam as adaptações a dietas com maior ou menor quantidade de concentrado, e também é o princípio pelo qual se utilizam aditivos na dieta de ruminantes. Como desdobramento deste princípio de estabilidade do sistema microbiano ruminal tem-se os distúrbios fermentativos como as acidoses.

São descritos dois tipos de acidose ruminal: a primeira de grau mais moderado causada por excesso de ácidos graxos de cadeia curta (AGCC), em especial pelo ácido propiônico (pKa 4,8), também denominada pelos norte-americanos de acidose ruminal subaguda (SARA), cujo $\mathrm{pH}$ ruminal diminui abaixo dos valores considerados normais $(5,9-7,1)$, permanecendo entre 5,8 a 5,2 por no mínimo 5 horas, quando nem sempre são constatados sintomas clínicos evidentes (ORTOLANI, 1980; OWENS, 1998; KRAUSE; OETZEL, 2006; NAGARAJA; TITGEMEYER, 2007; ZEBELI, et al; 2012 ).

Além, desse tipo supracitado existe outra categoria mais grave da enfermidade, conhecida como acidose láctica ruminal (ALR), em que além do excesso de AGCC, produzido nos primórdios do quadro, também é gerado grande quantidade de ácido láctico, o qual provoca intensa redução no pH (abaixo de 5,1) devido ao grande potencial de acidez desse composto $(\mathrm{pKa}=3,7)$. 
No tópico seguinte será revisado a enfermidade metabólica (Acidose Láctica Ruminal ALR) que é o foco do presente trabalho, que tem como gênese o aumento na oferta de carboidratos solúveis, com consequente comprometimento da saúde animal.

\subsection{ENTENDENDO A ACIDOSE LÁCTICA RUMINAL (ALR)}

Doenças metabólicas e digestivas em ruminantes são quadros que apresentam complexas relações de causalidade. Distúrbios como acidose ruminal vem acometendo os animais ruminantes desde que estes foram domesticados. Entretanto, a prevalência desses transtornos tem aumentado com o advento de sistemas de manejo intensificados, onde a alimentação concentrada e uso intensivo de grãos processados tornou-se uma premissa para que se obtenha o máximo de ganho de peso dentro do menor tempo possível (BENTON, 2010).

No manejo nutricional de confinamento, é uma prática comum realizar a transição dos animais alimentados em pasto para dietas de alto concentrado através de um período de adaptação o mais rápido possível (DUCKETT et al., 1993). A adaptação às dietas de terminação é um processo crítico que pode expor os animais a um elevado risco de acidose. (NAGARAJA; CHENGAPPA, 1998; VECHIATO, 2009).

A acidose láctica ruminal (ALR) foi descrita por REISET (1863), que estabeleceu que ruminantes não adaptados a uma dieta rica em grãos, sofriam de indigestões agudas e em muitos casos poderiam chegar a morte em 24 horas após a ingestão de grandes quantidades deste tipo de alimento. Posteriormente, McANALLY e PHILLIPSON (1942), esclareceram aspectos básicos da etiologia e da patogenia desta enfermidade, relacionando, pela primeira vez, a produção excessiva de ácido láctico no rúmen e as complicações decorrentes do seu acúmulo. 
A ALR é uma enfermidade típica de manejo alimentar incorreto ou inadequado. Entre as práticas mais observadas, destaca-se quando ruminantes criados extensivamente passam a receber em curto espaço de tempo dietas ricas em carboidratos não estruturais (de rápida fermentação), sem uma adequada adaptação, devido a um marcante aumento da produção de ácido láctico no interior do órgão (ORTOLANI, 1987; MARUTA; ORTOLANI, 2002a; OLIVEIRA, 2013) que usualmente atinge concentrações superiores a $120 \mathrm{mM} / \mathrm{L}$ de ácido. Também pode ocorrer quando os animais têm livre acesso a depósitos de ração concentrada, baixo oferecimento temporário de fibra dietética (fibra fisicamente efetiva), mudanças na umidade da dieta ou quando ocorre erros no oferecimento de ração proveniente de maquinas distribuidoras mal reguladas. Animais que recebem dietas hiperglucídicas quando estão sendo preparados para exposições também estão predispostos a terem ALR (DUNLOP, 1972; HOWARD, 1981; UNDERWOOD, 1992a; RADOSTITS et al., 2007; SNYDER; CREDILLE, 2017).

A mudança abrupta de uma dieta é o principal fator que determina o grau de perturbação da fermentação ruminal e potenciais distúrbios digestivos. Na ALR, a ingestão excessiva de alimentos ricos em carboidratos não estruturais de alta digestibilidade faz com que os microrganismos presentes alterem o balanço de fermentação, sendo seguido pelo ajuste das espécies microbianas às novas situações (VAN SOEST, 1994).

Rações concentradas oferecidas isoladamente também predispõem o surgimento da enfermidade, por outro lado, quando os concentrados são adequadamente misturados junto com os outros componentes fibrosos, a chance de ocorrência cai drasticamente. Quando os grãos são finamente moídos, prensados ou quebrados, existe maior exposição dos carboidratos não estruturais à microflora ruminal, em relação aos grãos inteiros, demonstrando com isso que o processamento dos grãos também influi no grau de severidade de ALR (RADOSTITS et al., 2007; SNYDER; CREDILLE, 2017). 
Segundo Dunlop (1972), fatores etológicos e ambientais podem favorecer a ocorrência de ALR, através do aumento de ingestão de alimentos. Pelo espírito competitivo, o consumo médio de concentrados é maior num animal mantido em grupo, num confinamento, do que isoladamente. Animais hierarquicamente mais fortes e glutões ingerem mais concentrados do que os demais. Mudança rápida do clima, de calor para o frio também estimula o consumo de concentrado. Animais que produzem menor quantidade de saliva ou que apresentem maior motilidade gastrointestinal são mais predispostos ao desenvolvimento da ALR.

Independentemente da causa inicial do incitamento, a patogênese da ALR é a mesma. Bactérias ruminais que digerem amido e açúcares proliferam e aumentam a taxa de fermentação de carboidratos. No animal normal, ou em animais com leve doença clínica, a capacidade de tamponamento ruminal e absorção de AGCC coincidi com a taxa de fermentação de carboidratos. Neste cenário, o pH ruminal permanecerá no intervalo normal entre 5,9 e 7,1 (ORTOLANI, 1980). Entretanto, quando a produção de AGCC e lactato excede a taxa de absorção, o pH ruminal começará a cair. Embora numerosos microorganismos tenham sido implicados no desenvolvimento da doença, a bactéria primária que acredita-se estar associada à progressão dos sinais clínicos é o Streptococcus bovis, devido a sua rápida taxa de divisão, capacidade de produzir mais ATP por unidade de tempo e tolerância a $\mathrm{pH}<5.5$, é o microrganismo que prepara o ambiente para a produção de ácido e piora dos sintomas. No entanto, o Streptococcus bovis é intolerante a um $\mathrm{pH}<4,5$. À medida que o pH diminui, a produção de lactato por Streptococcus bovis diminui, e o crescimento de Streptococcus bovis é retardado. Neste ponto, os Lactobacillus que toleram $\mathrm{pH}<4,5$ tornam-se os microorganismos dominantes no ambiente ruminal, contribuindo ainda mais para deprimir o $\mathrm{pH}$ ruminal, devido a maior produção de ácido láctico (OWENS, 1998; SNYDER e CREDILLE, 2017).

Segundo GOLDER et al. (2018) o genoma, metaboloma e microbioma bovino estão associados em animais submetidos a um desafio não ameaçador com amido e frutose, mas num 
desafio substancial é observado grande variação entre os animais, servindo de fundamentação as observações feitas. Os achados tidos por estes pesquisadores auxiliam na compreensão da ocorrência de variação inter-animal em respostas ao desafio fisiológico, tanto no campo como experimentalmente, fornecendo uma forte razão para uma grande área de estudo da variação natural da acidose ruminal. Os investigadores ainda sugerem que mais pesquisas são necessárias para determinar a herdabilidade de constituintes microbianos e respostas correlacionadas às mudanças fisiológicas e que no futuro marcadores de atividade ruminal podem auxiliar na identificação e manejo de animais predispostos a distúrbios ruminais.

Existem 2 formas quirais de lactato produzidas no rúmen: D e L. O isômero L é produzido por células de mamíferos e microorganismos, enquanto a forma $\mathrm{D}$ é produzida principalmente por microroganismos (OWENS, 1998). O lactato - L é facilmente metabolizado por células cardíacas de mamífero e tecido hepático. O lactato - D não é metabolizado de forma tão eficiente quanto o lactato - L acumulando-se na circulação. Esses dois isômeros são poderosos agentes corrosivos que podem causar sérios danos ao epitélio ruminal. Além disso, lactato e AGCC são osmoticamente ativos aumentando a osmolaridade ruminal e diminuindo a absorção desses ácidos, criando um ciclo que perpetua o acúmulo destes compostos e uma queda contínua no pH (OWENS, 1998; SNYDER e CREDILLE, 2017).

Como visto acima, essa acumulo de ácidos provoca uma grande redução no pH ruminal, aumentando consideravelmente a osmolaridade no conteúdo ruminal. Huber (1971) identificou em ovinos com ALR um aumento de osmolaridade do conteúdo ruminal, passando de 255 mOsm/L, em condições normais, para 402 mOsm/L durante o pico da ALR. Segundo esse supracitado autor nas condições dessa enfermidade a osmolaridade do rúmen passou a ser maior (em média $109 \mathrm{mOsm} / \mathrm{L}$ ) que a encontrada no sangue (em torno de $297 \mathrm{mOsm} / \mathrm{L}$ ). Essa diferença de osmolaridade entre os compartimentos provocou uma enorme migração de fluidos internos do corpo do animal para o rúmen. Como consequência a essa migração de fluidos que 
se instala nos ruminantes acidóticos se desenvolve um marcante quadro de desidratação (MENDES NETTO, 2000; ORTOLANI et al., 2010; RADOSTITS et al., 2007). Como demostrado por MARUTA (2000), os bovinos (zebuínos) apresentaram maior desidratação, causada pela maior passagem de fluidos do organismo para o rúmen, enquanto que bovinos (taurinos), tiveram maior acidose sistêmica, pela maior absorção de ácidos ruminais.

Osmolaridade ruminal acima de $300 \mathrm{mOsm} / \mathrm{L}$ é detectada pela parede do rúmen e reticulo e é responsável pela inibição da ingestão de alimento, enquanto valores acima de 350mOsm/L promovem inibição da digestão bacteriana de fibra e amido (CARTER; GROVUM, 1990). Durante a ALR existe uma pequena, mas significativa absorção de ácido láctico produzido no rúmen, o que pode produzir uma destacada acidose metabólica nos animais (MARUTA; ORTOLANI, 2002b).

Alguns estudos demonstram que embora a concentração de glicose ruminal seja normalmente baixa no rúmen, nos episódios de acidose os teores de glicose ruminal pode superar o sanguíneo (SLYTER, 1976).

Como já mencionado anteriormente, a digestão microbiana dos alimentos no rúmen converte carboidratos em ácidos orgânicos, os quais são removidos primariamente por absorção. Enquanto a taxa de absorção não supera a taxa de produção, a fermentação ruminal é estável e o pH fica na faixa fisiológica (NAGARAJA; LECHTENBER, 2007). Quando há um aumento súbito, os mecanismos de eliminação do ácido láctico pelo organismo do animal não são suficientes para manter o nível normal, ocorrendo assim o acúmulo deste ácido, tendo como consequência a marcada queda de $\mathrm{pH}$ e o aumento da osmolaridade ruminal, o que afeta negativamente a absorção e produção de endotoxina e amidas como a histamina que também desempenham um papel nos efeitos fisiológicos da doença, que incluem estase ruminal, diarreia e desidratação, acidose sistêmica e, em casos agudos, insuficiência respiratória, cardiovascular e renal (HUBER, 1976; OWENS, 1998; SNYDER; CREDILLE, 2017). 
Embora a ALR seja normalmente causada por erros de manejo, é importante considerar seu potencial efeito devastador na saúde animal podendo levar o animal à morte. No entanto, quando o animal consegue se recuperar do quadro agudo pode ocorrer complicações que afetam diretamente a produtividade animal, como a ocorrência secundaria de úlceras gastrointestinais, rumenite, laminite, podendo ocorrer ainda polioencefalomalacia, devido a deficiência de vitamina $\mathrm{B}_{1}$, decorrente da diminuição das bactérias sintetizadoras de tiamina e aumento das produtoras de tiaminases (UNDERWOOD, 1992b). O sistema nervoso também pode ser envolvido nos casos de ALR, e os principais sinais incluem depressão, opistótono, pressão da cabeça contra obstáculos e rigidez extensora. Podendo ser observado também tremores e fasciculações musculares (UNDERWOOD, 1992b).

O diagnóstico da ALR baseia-se na história de exposição a alimentos ricos em carboidratos de rápida digestão, sinais clínicos e testes diagnósticos, particularmente a análise do líquido ruminal. Embora a apresentação clínica da ALR possa mimetizar a apresentação de outras doenças (mastite, metrite, peritonite), a indicação dos animais, a falta de sinais referentes a outros sistemas do corpo e os resultados da análise do líquido ruminal geralmente pode ajudar o médico veterinário a fazer um diagnóstico preciso e desenvolver um plano terapêutico. Portanto, um exame completo de todo o animal é necessário para excluir outras síndromes e é um componente essencial para detectar animais com acidose (SNYDER; CREDILLE, 2017).

O prognóstico para os animais com ALR depende da duração e gravidade dos sinais clínicos. Testes diagnósticos auxiliares desempenham um papel importante na avaliação da gravidade da doença e desenvolvimento de planos de tratamento, e seu uso deve ser considerado se for economicamente viável. Animais com pH sanguíneo menor que 7,18, pH ruminal menor de 4,5, alterações graves do sistema nervoso central e anúria têm menos probabilidade de sobreviver do que animais com alterações menos severas (UNDERWOOD, 1992a). 
A prevenção da ALR geralmente está relacionada as práticas de manejo que antecipam o desenvolvimento da doença individualmente nos animais. Em animais não adaptados a dietas de alto concentrado, o acesso a alimentos facilmente digeríveis deve ser restrito. Mudanças súbitas no alimentação devem ser evitadas, e, se mudanças forem feitas, elas devem ser feitas gradualmente, pois a adaptação dos microrganismos do rúmen a novas dietas pode levar várias semanas. O espaço do cocho deve ser adequado para permitir que todos os animais tenham acesso a ração sem excesso de competição. Além disso, monitorar o nível de ração nos cochos é de fundamental importância para garantir que os animais não fiquem excessivamente famintos e se empanturrem quando a ração estiver novamente disponível. Os aditivos alimentares, como os antimicrobianos, bicarbonatos e calcários, podem reduzir a gravidade e a incidência da doença quando usados adequadamente (SNYDER; CREDILLE, 2017).

Dentre estes, os antibióticos monensina e virginiamicina vêm sendo utilizados, isoladamente, de maneira preventiva contra a ALR, necessitando assim de maiores estudos da associação dos dois. Sendo assim, uma revisão destes aditivos será feita para melhor compreensão de uma das hipóteses da presente Tese.

\subsection{ADITIVOS NA ALIMENTAÇÃO DE RUMINANTES}

\subsubsection{Ionóforos}

Os ionóforos (grego, ion "o que vai"; phoros, "carregador") são compostos que aumentam a permeabilidade das membranas lipídicas biológicas ou artificiais para íons específicos. A molécula de monensina é um poliéter carboxílico que se liga a íons metálicos e os carreia através da membrana celular (PRESSMAN, 1982). A monensina tem um grupamento carboxílico exposto, devendo ser não-protonado para favorecer seu movimento livremente 
através da membrana celular. A ligação sequencial de íons metálicos e prótons permite a monensina agir como metal/próton antiporte. O grupamento carboxílico tem um $\mathrm{pKa}$ ligeiramente alcalino, sendo a monensina mais hábil em inibir bactérias (Streptococcus bovis, por exemplo), quando o pH é ácido (CHOW; RUSSELL, 1990). Ionóforos, como a monensina sódica, são compostos produzidos por bactérias, sobretudo do grupo Streptomyces cinnamonensis, que, sendo altamente lipofílicos e tóxicos a muitos microrganismos, são definidos como antibióticos (HANEY; HOEHN, 1967).

A monensina sódica é, dentre os 120 ionóforos existentes, o composto mais estudado e empregado na rotina veterinária (CORAH, 1991), sendo o aditivo mais pesquisado em dietas de ruminantes, que, no Brasil, seu uso em dietas para gado de corte confinado é a que mais prevalece (OLIVEIRA; MILLEN, 2014). Nas últimas décadas, grande quantidade de artigos foi compilada em diversas revisões de literatura sobre seu mecanismo de ação (SCHELLING, 1984), efeitos nos padrões de fermentação ruminal (PAGE, 2003; TEDESCHI et al., 2003; ELLIS et al., 2012), produção de metano (PAGE, 2003; TEDESCHI et al., 2003; APPUHAMY et al., 2013) e metabolismo animal (PAGE, 2003; DUFFIELD et al., 2003).

A ação da monensina sobre as bactérias está relacionado com um mecanismo chamado de bomba iônica, que regula o balanço químico entre o meio interno e externo da célula. Em condições normais, as bactérias mantêm a concentração de $\mathrm{K}^{+}$no interior da célula muito mais alto que no meio externo e expelem prótons e $\mathrm{Na}^{+}$. Esse mecanismo é necessário não só para a síntese de proteína, como também para tamponar o $\mathrm{pH}$ intracelular por meio do mecanismo de troca de $\mathrm{K}^{+} / \mathrm{H}^{+}$. A monensina ao se ligar à membrana celular das bactéria e protozoários e provavelmente de fungos no rúmen, facilitam o movimento dos cátions através da membrana celular, então ocorre a troca de um cátion monovalente por um próton. Assim sendo, essa reação culmina em uma reduzida concentração intracelular de $\mathrm{K}^{+}$, baixo $\mathrm{pH}$ e maior concentração intracelular de $\mathrm{Na}^{+}$. Nesse caso, as bactérias Gram positivas são forçadas a utilizar os sistemas 
de transporte celular para dissipar $\mathrm{o}^{+}$e o $\mathrm{Na}^{+}$intracelular na tentativa de manter o equilíbrio na célula. As bombas de $\mathrm{Na}^{+} / \mathrm{K}^{+}$ATPase ou próton ATPase permitem que o organismo expulse $\mathrm{H}^{+}$com o gasto de 1 ATP por próton. Esse processo, juntamente com a baixa concentração de $\mathrm{K}^{+}$intracelular, reduz as reservas energéticas e a taxa de síntese de proteína com consequente menor capacidade de divisão celular. Como consequência, a bomba iônica não opera eficientemente, provocando um desequilíbrio e, em virtude de uma maior concentração de cátions dentro da célula, ocorre aumento da pressão osmótica, a água penetra em excesso e com isso a célula incha, tendendo a romper-se. Desse modo, as bactérias sensíveis acabam morrendo ou assumem um nicho sem expressão ruminal (BERCHIELLI et al., 2011; SCHELLING, 1984).

As bactérias ruminais Gram negativas são mais resistentes aos ionóforos que as Gram positivas, em virtude do seu envoltório celular ser constituído por uma parede celular e uma membrana externa de proteção, formada por proteínas, lipoproteínas e lipopolissacarídeos, a qual contém porinas com tamanho limite de, aproximadamente, 600 Da. A maioria dos ionóforos é maior que $600 \mathrm{Da}$ e, consequentemente, não passa através das porinas, tornando as células impermeáveis aos ionóforos. Por outro lado, as bactérias Gram positivas possuem apenas uma camada espessa de peptidioglicano, por ser porosa, não impede a ação da monensina. No entanto, os ionóforos podem aumentar o fluxo de íons em algumas bactérias Gram negativas que se comportam como Gram positivas, principalmente em altas concentrações desse aditivo. Além disso, com o passar do tempo, espécies Gram negativas, originalmente resistentes aos ionóforos, podem tornar-se sensíveis, e certas bactérias Gram positivas podem desenvolver resistência aos ionóforos (BERCHIELLI et al., 2011).

Os ruminantes absorvem aproximadamente $50 \%$ da monensina administrada por via oral, após sua absorção, essa molécula circula por todo o corpo não se acumulando preferencialmente em nenhum tecido específico. Essa molécula sofre rápido metabolismo 
hepático. Seus metabólitos compreendem moléculas de monensina desmetiladas, hidroxiladas, descarboxiladas e outras formas. Os metabólitos avaliados têm muito pouca atividade biológica. A monensina e seus metabólitos são excretados principalmente na bile e aparecem nas fezes. Cerca de $1 \%$ é excretado na urina de mamíferos. Bovinos e ovinos excretam 40 a $50 \%$ da dose de monensina na forma original. Aparentemente a maior parte da monensina absorvida é metabolizada, a molécula original nas fezes representa em grande parte a monensina que não foi absorvida (HATCH, 1992).

Citam-se como vantagens na utilização da monensina em gado de corte, que ela age selecionando as bactérias Gram negativas (RUSSELL; WALLACE, 1997), com isso a produção de ácidos graxos de cadeia curta é modificada, ocorrendo diminuição da proporção molar dos ácidos acético e butírico (MCGUFFEY et al., 2001), com consequente redução das produções dos gases metano - $\mathrm{CH}_{4}$ e carbônico - $\mathrm{CO}_{2}$ (BAGG, 1997), e aumento da proporção de ácido propiônico (BADAWY et al., 1996), seguido por elevação das concentrações de propionato hepático e dos níveis de glicose sanguínea (MAAS et al., 2001). Outros efeitos benéficos da monensina, em nível ruminal, é o controle do lactato, graças à inibição do Streptococcus bovis - uma das principais bactérias causadoras da ALR (OWENS, 1998), a elevação do pH ruminal, sobretudo em dietas com alta porcentagem de grãos (RUSSELL, 1996), e a diminuição da concentração de amônia ruminal, em decorrência da menor degradação de peptídeos e aminoácidos no rúmen, que posteriormente são digeridos e absorvidos no intestino delgado (HEGAZY; ELIAS, 1997). Ressalta-se também que a monensina promove redução de 5 a $6 \%$ no consumo de matéria seca em bovinos de corte alimentados com dietas com alto teor de concentrado (SCHELLING, 1984).

Estudos in vitro e in vivo demonstraram que a monensina atua na diminuição das bactérias Gram positivas que têm suas populações aumentadas durante a ALR (NAGARAJA et al., 1981; NAGARAJA et al., 1987). Contudo, estudos recentes em ovinos submetidos à ALR 
experimental demonstraram que a monensina atua de forma preventiva até a $12^{\mathrm{a}}$ hora do processo, mas não impediu que a acidose manifesta-se em momentos posteriores (REIS, 2011). Esse resultado indica a necessidade da associação da monensina com algum outro composto mais eficiente, quando situações de risco de ALR estejam presentes em ruminantes.

\subsubsection{Virginiamicina}

Esse antibiótico é da classe das estreptograminas produzidas por uma linhagem mutante de Streptomyces virginae, originalmente encontrada em solos belgas, composta de dois peptolídeos chamados fator $\mathrm{M}(\mathrm{C} 28 \mathrm{H} 35 \mathrm{~N} 3 \mathrm{O} 7)$ de peso molecular de 525 e fator $\mathrm{S}$ (C43H49N7O10) de peso molecular de 823, que possuem um efeito sinérgico quando combinados à razão de 4:1, respectivamente M:S (PAGE, 2003).

Conforme Cocito (1979), a virginiamicina apresenta atividade principalmente contra bactérias Gram positivas, tanto aeróbicas quanto anaeróbicas, mas não apresenta efeito sobre a maioria das bactérias Gram negativas em função da impermeabilidade da parede celular. No interior das células, ambos os fatores se ligam especifica e irreversivelmente a subunidades $50 \mathrm{~S}$ dos ribossomos, inibindo a formação de ligações peptídicas durante a síntese proteica bacteriana. Processos metabólicos são interrompidos dentro da célula, o que causa redução no crescimento (bacteriostase) ou morte da célula bacteriana (atividade bactericida). Quando pequenas concentrações de virginiamicina entram em contato com a parede celular bacteriana por curtos períodos, inibe seu crescimento continuamente após a retirada do antibacteriano, e este efeito é conhecido por bacteriopausa. Então este antibiótico inibe a síntese proteica da célula bacteriana no ribossomo, ao dificultar a formação dos enlaces peptídicos.

GOTTSCHALL et al. (1988) observou in vitro que a virginiamicina (VM) foi extensivamente metabolizada no conteúdo ruminal de bovinos. Notou também que a atividade 
antimicrobiana da VM diminuiu rapidamente com uma meia-vida inicial de aproximadamente 8 horas. Em contraste, em pH quase neutro, a VM manteve sua atividade completa por pelo menos 24 horas. Esses mesmos autores isolaram quatro metabólitos e todos foram derivados da redução do principal componente da virginiamicina, o fator M. O componente menor, o fator S, não foi metabolizado no fluido ruminal, tendo as vias metabólicas envolvidas incluindo a redução de $\mathrm{C}=\mathrm{C}$ e $\mathrm{C}=0$, bem como desidroxilação. Verificaram também que todos os metabolitos tinham menos atividade antimicrobiana do que o fator parental M. Além dos metabolitos, eles também isolaram dois produtos de decomposição do fator M após a incubação de VM apenas em tampão. Estes dois produtos resultam da desidratação do fator M e mostrou interconverter à temperatura ambiente.

Nagaraja e Taylor (1987) demonstraram que a virginiamicina consegue prevenir "in vitro" a acidose láctica em ruminantes por diminuir em mais de $50 \%$, em relação ao grupo controle, as populações de Lactobacillus sp. Além disso, esse antibiótico reduz as populações de bactérias que produzem $\mathrm{H}_{2}$ e consequentemente metano. Porém, os microrganismos que produzem ácido propiônico são pouco susceptíveis à virginiamicina. Posteriormente, Coe et al. (1999) promoveram uma indução de ALR em bovinos e trataram no tempo zero com virginiamicina ou monensina. A virginiamicina não permitiu que ocorresse uma redução drástica do pH ruminal (maior pH na 3, 6, 9 e 12 horas após a administração dos carboidratos) no decorrer da indução, assim como a elevação dos teores de ácido láctico (2 mM/L), mesmo assim os animais apresentaram um quadro de acidose subaguda (acidose por ácidos graxos de cadeia curta). Por outro lado, a monensina sódica teve uma ação preventiva bem menor (só apresentou aumento de $\mathrm{pH}$ as 6 horas após a indução), em especial quanto à redução das concentrações de ácido láctico (15,8 mM/L) no rúmen. Segundo esses mesmos autores, de modo em geral a VM foi mais efetiva que a monensina no controle de Lactobacillus e Streptococcus bovis. 
Nagaraja et al. 1987 e Page, 2003 afirmam em seus trabalhos que a virginiamicina é mais efetiva em reduzir a produção de lactato do conteúdo ruminal e, consequentemente, a incidência de acidose ruminal e de abscessos hepáticos.

Reis (2011) testou a ação preventiva contra a ALR da monensina sódica em ovinos e verificou que esse aditivo não permitiu uma queda acentuada do pH ruminal, em relação ao grupo controle, até a $12^{\mathrm{a}}$ hora de experimento, se igualando a este grupo a partir daí, ou seja, não promoveu uma redução significativa nos teores de ácido láctico, sugerindo que este composto teria uma ação maior contra o Streptococcus bovis e não contra o Lactobacillus sp. Esse autor não testou o efeito da associação destes dois aditivos na prevenção da ALR.

A combinação de antibióticos tem sido estudada como possibilidade de potencializar os benefícios obtidos individualmente com cada aditivo. Silva et al. (2004) estudou a combinação de salinomicina com VM para avaliar ganho de peso diário (GPD). Sitta (2011) avaliou o uso isolado e/ou combinações entre monensina, VM e salinomicina para mensurar consumo de matéria seca (MS) e eficiência alimentar. Camilo et al. (2014) compararam dietas contendo monensina, combinação de monensina e VM e virginiamicina sozinha para avaliar consumo de MS, GPD e eficiência alimentar. Coe et al. (1999) e Golder et al. (2014) que são os trabalhos clássicos do uso de virginiamicina e monensina na prevenção da ALR, não usam estes aditivos combinados. Como é possível observar, muitos trabalhos fazem a associação de diferentes aditivos para avaliar a melhora do desempenho de bovinos, mas não fazem essa associação para uma possível ação sinérgica de virginiamicina e monensina na prevenção da ALR, necessitando com isso maiores estudos a respeito. 


\section{EM BOVINOS}

Usualmente, os modelos de indução de acidose empregavam doses fixas de sacarose por quilograma de peso corpóreo em bovinos e ovinos. Porém, Ortolani (1995) constatou que esse modelo tradicional poderia levar falhas e a uma acidose fatal quando empregado em bovinos com pesos superiores a $500 \mathrm{~kg}$. Com o fito de solucionar essa falha o mesmo autor comparou a forma tradicional por dose fixa de sacarose, o que empregava correção por peso metabólico e por peso metabólico corrigido, concluindo que esta última apresentava os melhores resultados expressos pela fórmula $\mathrm{y}=1057+43,1 \times \mathrm{PV}^{0,75}$, onde y é a dose sacarose calculada e $\mathrm{PV}^{0,75} \mathrm{o}$ peso metabólico do animal. Mesmo assim, em trabalhos futuros de indução de ALR o grupo de Ortolani passou a empregar esse modelo, porém com doses finais reduzidas em $15 \%$ a $20 \%$ da dose calculada, para evitar possível quadros drásticos da enfermidade.

Assim sendo, esse modelo passou a ser adotado na reprodução de ALR tanto em aulas práticas de graduação como em várias pesquisas sobre o assunto (MENDES NETTO, 1997; MARUTA, 2000, LEAL et al., 2007; RODRIGUES, 2009; ORTOLANI et al., 2010).

Revendo esses trabalhos constatou-se que os mesmos poderiam ser aprimorados para uma melhor compreensão desse importante modelo, pois faltavam dados gerais como: fermentação ruminal e suas consequências nas primeiras 10 h de indução, análise dos ácidos graxos de cadeia curta (AGCC), teores de glicose ruminal, potencial de oxido-redução e total de ácidos ruminais. Tal elucidação poderia esclarecer o papel dos AGCC no desenvolvimento da acidose ruminal e o possível efeito que estes em conjunto com o ácido láctico e a glicose poderiam ter sobre o aumento da osmolaridade ruminal.

Embora o trabalho de MARUTA (2000) contemplasse a análise de lactato D nos vários fluidos, constatou-se que a técnica empregada pelo autor não era a mais adequada, podendo ser 
substituída por um método mais preciso, como por exemplo a atividade enzimática específica. Nesse trabalho brasileiro obteve-se uma razão de ácido láctico L e D ruminal próximo de 1, contrariando o que trabalhos clássicos tem constatado, ou seja, de uma razão no máximo 2:1. (DUNLOP; HAMMOND, 1965; DUNLOP, 1972; OWENS, 1998). Tal esclarecimento sobre a produção desses isômeros ainda necessita ser melhor averiguado.

Os trabalhos resultantes do modelo de indução com sacarose também não especificaram a relação dos sintomas que mais estiveram envolvidos com a necessidade de tratamento (MENDES NETTO, 1997; MARUTA, 2000, LEAL et al., 2007; RODRIGUES, 2009; ORTOLANI et al., 2010). 


\section{HIPÓTESES}

Pressupõem-se que o modelo de indução de ALR, com sacarose, desenvolva acidose ruminal inicialmente por acúmulo de AGCC, seguido de ácido láctico, com predomínio do isômero L, obtendo um ápice de osmolaridade quando a somatória de ácidos orgânicos e glicose seja máxima. Acredita-se que o modelo provoque moderada acidose sistêmica, com quadro mais pronunciado de desidratação;

Trabalha-se com a hipótese que a associação de virginiamicina e monensina possa atura de maneira mais eficaz na prevenção da acidose que o uso destes aditivos isolados, por possivelmente diminuir a produção de acidose em geral, em especial do ácido láctico. 


\section{OBJETIVOS}

Acompanhar as alterações principais no metabolismo ruminal e as consequências sistêmicas provocadas pelo modelo de indução de ALR com uso de sacarose;

Estudar a ação isolada ou associada de virginiamicina e de monensina na prevenção de ALR em bovinos de corte. 


\section{MATERIAL E MÉTODOS}

\subsection{ANIMAIS E ALIMENTAÇÃO}

Foram utilizados 30 bovinos, de dois anos de idade da raça Nelore, providos de cânula ruminal, com cerca de $413 \pm 35,86 \mathrm{~kg}$ de peso vivo. Para facilitar o manejo e identificação dos animais, estes foram numerados com brincos identificados.

Sessenta dias antes do início do período experimental, todos os animais receberam aplicação de endectocida a base de moxidectina $\left(\right.$ Cydectin ${ }^{\circledR}$ injetável na dose de $1 \mathrm{~mL}$ para cada 50kg), aplicada por via subcutânea, além de aplicação de dose de vacina contra clostridioses (Sintoxan Polivalente ${ }^{\circledR}$, Merial, Campinas/SP, Brasil), seguida de reforço 30 dias após a primeira imunização.

Os animais foram submetidos à cirurgia de implantação de cânula ruminal de silicone $\left(\mathrm{Khel}^{\circledR}\right.$, São Carlos-SP, Brasil). Após os procedimentos cirúrgicos, os bovinos passaram por período de adaptação as instalações e ao manejo alimentar por um período de 30 dias e foram alocados em baias individuais nas dependências do Centro de Pesquisa de Gado de Corte da Universidade de São Paulo (FMVZ - USP), Campus Pirassununga.

Durante todo período experimental os animais foram alimentados com dieta basal calculada em $2,7 \%$ do peso vivo, composta de $75 \%$ da matéria seca de feno (capim Cynodon dactylon (L) Pers - Coast cross) e de $25 \%$ de ração concentrada comercial contendo $14 \%$ de proteína bruta, a qual foi fornecida uma vez ao dia. Os bovinos foram suplementados com $80 \mathrm{~g}$ de sal mineralizado por dia, contendo macro e microelementos e tiveram livre acesso à água. 


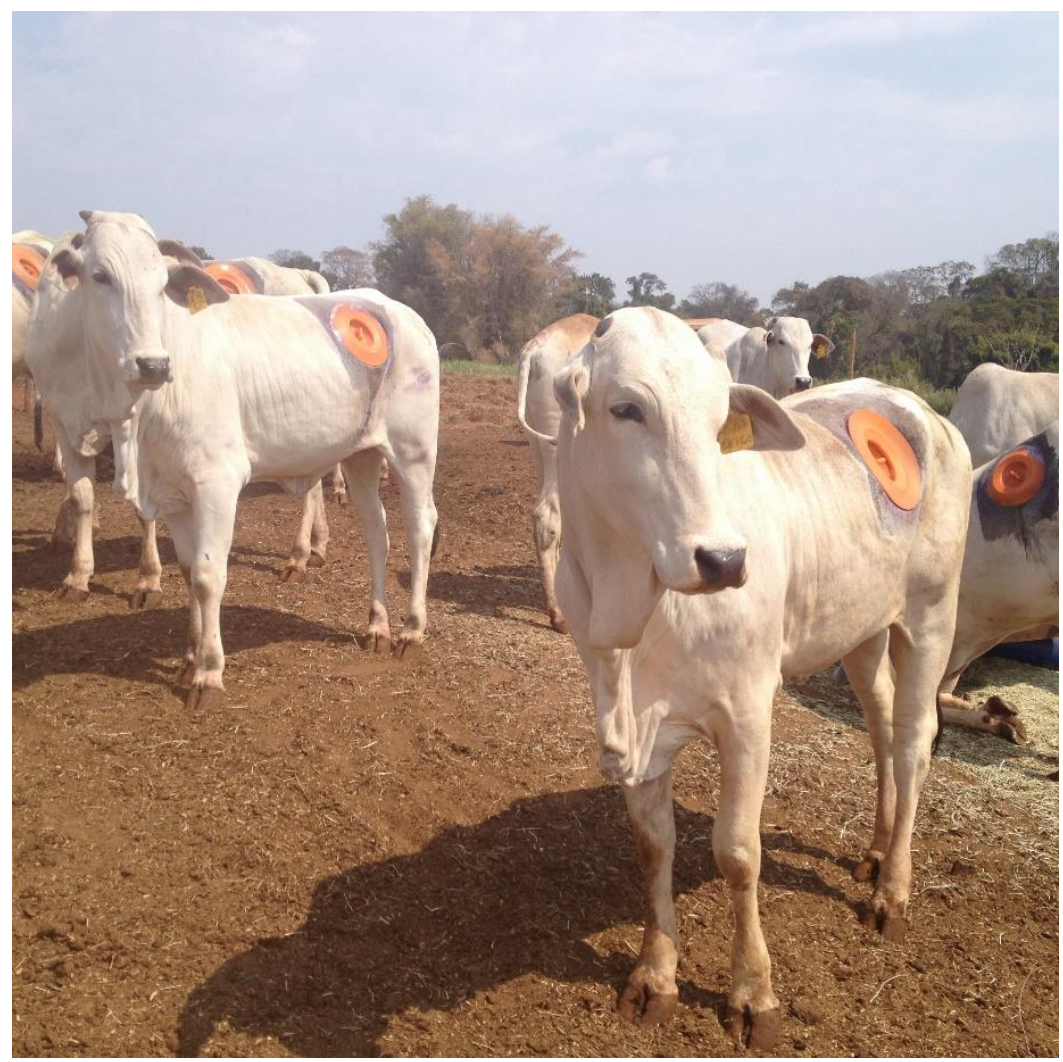

Fonte: (OLIVEIRA, F. L. C, 2018)

Figura 1 - Animais logo após a cirurgia de inclusão da cânula ruminal.

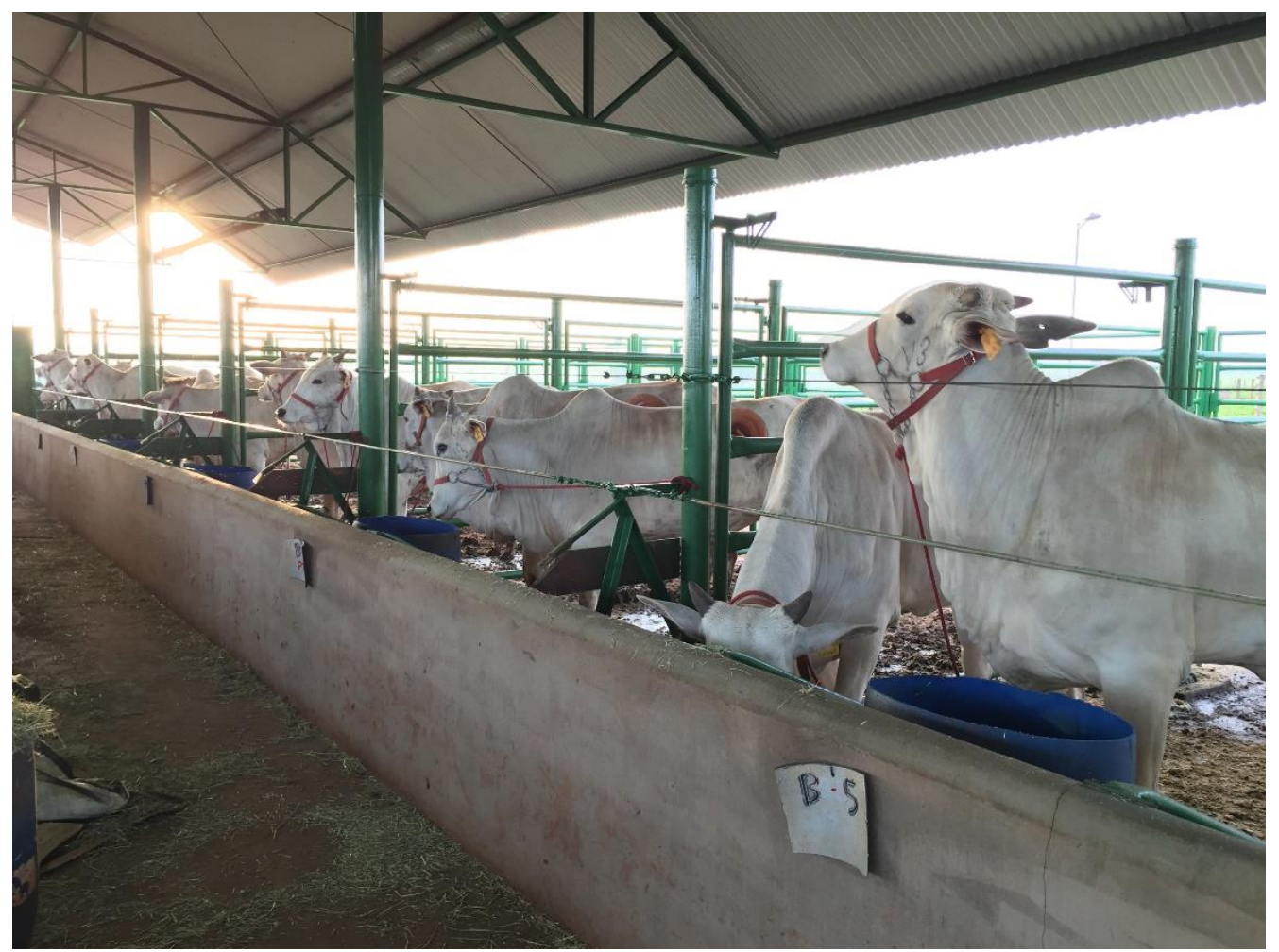

Fonte: (OLIVEIRA, F. L. C, 2018)

Figura 2 - Animais canulados alojados em baias e presos por cabresto para facilitar o manejo. 


\subsection{DELINEAMENTO EXPERIMENTAL}

Os 30 animais foram submetidos a um delineamento multifatorial inteiramente casualizado, em que, após o período de adaptação, os animais foram distribuídos aleatoriamente em cinco grupos iguais com seis animais cada, assim constituídos:

- CONTROLE (CON)

- $\quad$ MONENSINA 30 ppm (MON)

- VIRGINIAMICINA 25 ppm (VM 25)

- $\quad$ VIRGINIAMICINA 34 ppm (VM 34)

- VIRGINIAMICINA 25 ppm + MONENSINA 30 ppm (VM + MON)

O grupo controle $(\mathrm{CON})$ recebeu apenas a dieta basal supracitada. A monensina sódica e a virginiamicina foram fornecidas misturadas em $500 \mathrm{~g}$ de fubá de milho (antes do fornecimento da alimentação diária, para garantir a ingestão completa do aditivo), para simular uma situação real de alimentação.

\subsection{INDUÇÃO DA ACIDOSE LÁCTICA RUMINAL AGUDA}

Após 30 dias do oferecimento da dieta básica e dos aditivos supracitados foi realizada indução experimental de acidose láctica ruminal, em todos os animais, por meio da administração de sacarose (açúcar cristal), diretamente no rúmen, de acordo com protocolo clássico estabelecido por Ortolani (1995) para bovinos, $\left(\mathrm{y}=1057+43,1\right.$ x $\mathrm{PV}^{0,75}$, onde y é a dose sacarose calculada e $\mathrm{PV}^{0,75}$ o peso metabólico do animal), reduzido de $20 \%$ da dose calculada, para evitar possível quadros drásticos da enfermidade. 


\subsection{VARIÁVEIS ESTUDADAS}

Foi realizado exame físico, coletadas de conteúdo ruminal, de amostras de sangue, urina e fezes no decorrer do estudo nos seguintes tempos: Basal (T0) imediatamente antes da administração da sacarose; após início da administração do açúcar, decorridas 3 horas (T3h); 6 horas (T6h); 12 horas (T12h); 18 horas (T18h) após início da administração da sacarose, quando todo substrato já tinha se exaurido (ORTOLANI, 1995).

\subsubsection{Exame clínico geral}

O exame clínico dos animais foi realizado de acordo com recomendações de Dirksen (1993), dando ênfase na aferição das variáveis vitais: frequência cardíaca, frequência respiratória, movimento ruminal e temperatura.

\subsubsection{Coleta e processamento das amostras de fluido ruminal}

Nos momentos já mencionados, foram obtidas amostras de fluido ruminal para avaliação das seguintes variáveis: pH, potencial de oxirredução (POR), acidez titulável (AcT), lactato - L (levógiro) e D (dextrogiro), glicose, osmolaridade e ácidos graxos de cadeia curta (AGCC) como o ácido acético, propiônico e butírico. Com essas análises foi possível calcular o valor relativo de AGCC, relação acetato/propionato, total de ácidos orgânicos (não está somado o lactato - D), total de ácido láctico e relação lactato L/D.

As amostras de conteúdo ruminal foram coletadas diretamente do rúmen nas regiões: cranial, medial e caudal. O conteúdo foi rapidamente coado em um tecido de algodão e o fluido 
utilizado para análise imediata do pH ruminal, POR e acidez titulável, sendo imediatamente armazenada uma alíquota (sempre em duplicata) a $-20^{\circ} \mathrm{C}$ para determinação do lactato L e D, glicose, osmolaridade e AGCC.

A análise do pH e potencial de oxi-redução (POR) foram realizadas em pHmetro de bancada (DM-22, Digimed ${ }^{\circledR}$ Analítica Ltda, São Paulo/SP, Brasil), com sensibilidade de 0,01 graus, previamente calibrado segundo instruções do fabricante. A acidez titulável foi determinado adicionando-se duas gotas de fenolftaleína (10\% em álcool metílico) em $10 \mathrm{ml}$ de conteúdo ruminal e a mistura foi titulada com hidróxido de sódio $(\mathrm{NaOH}-0,1 \%)$, até se tornar cor de carne. O volume de $\mathrm{NaOH}$ exigido (em ml) é multiplicado por 10 e esse resultado é expresso em unidades clínicas (UC), segundo conceitua Rosemberg (1993).

O lactato - L e a glicose foram determinados por kit comercial (Randox® - Randox Laboratories, Reino Unido) em analisador bioquímico automático modelo RX Daytona (Randox® - Randox Laboratories, Reino Unido) e a osmolaridade em osmômetro por ponto de congelamento (modelo The Advanced Micro Osmometer 3300. AdvancedTM). O lactato - D foi medido por ensaios enzimáticos (D - Lactate Assay Kit; k667-100; BioVision; USA).

De cada amostra da fase líquida do fluido ruminal coletada, uma alíquota de $50 \mathrm{~mL}$ foi centrifugada a $3.500 \mathrm{rpm}$ por 15 minutos e 1,6 mL do sobrenadante foi adicionado $0,4 \mathrm{~mL}$ de ácido fórmico para determinação dos ácidos graxos voláteis. A determinação dos AGCC foi realizada através de cromatografia gasosa segundo metodologia de Erwin et al. (1961).

\subsubsection{Coleta e processamento das amostras de sangue}

Amostras de sangue foram coletadas em tubos de coleta a vácuo (Becton, Dickinson and Company, modelo Vacutainer ${ }^{\circledR}$, São Paulo-SP, Brasil) com capacidade de 8,5 mL sem anticoagulante, para a obtenção do soro, e tubos de $5 \mathrm{~mL}$ contendo fluoreto de sódio e ácido 
dietilenodiamino tetra-acético (EDTA) (Becton, Dickinson and Company, modelo Vacutainer ${ }^{\circledR}$, São Paulo-SP, Brasil). Estas amostras foram obtidas por meio de punctura da veia jugular externa.

Após cada coleta de sangue, os tubos com anticoagulante foram imediatamente homogeneizados e mantidos em refrigeração a $4^{\circ} \mathrm{C}$ para serem posteriormente processados. Ao passo que os tubos sem anticoagulante eram mantidos à temperatura ambiente até que proviesse seu processamento.

No laboratório, os tubos com sangue, para obtenção de soro e plasma eram centrifugados a 1400 x $g$ por 10 min, onde foram acondicionadas, em duas alíquotas, em microtubos plásticos Eppendorf ${ }^{\circledR}$ e congelados a $-20^{\circ} \mathrm{C}$, sendo descongeladas uma única vez para cada análise realizada. As amostras de soro foram utilizadas para determinação da osmolaridade sérica, sendo realizada pelo mesmo método já mencionado para o fluido ruminal. Enquanto que as amostras de plasma fluoretado foi utilizado para determinação das concentrações de ácido láctico - L e D e glicose. Os teores de lactato L e glicose sérico foram determinados utilizando kits comerciais Randox ${ }^{\circledR}\left(\operatorname{Randox}^{\circledR}\right.$ - Randox Laboratories, Reino Unido) em analisador bioquímico automático modelo RX Daytona (Randox ${ }^{\circledR}$ - Randox Laboratories, Reino Unido). O lactato - D foi medido por ensaios enzimáticos (D - Lactate Assay Kit; k667-100; BioVision; USA). No experimento em questão não foi possível fazer análise do lactato-D na $3^{\mathrm{a}}$ hora, por questões de preço do kit e indisponibilidade de verba.

As amostras de sangue nos tubos com EDTA foram utilizadas para determinação do volume globular. A partir dos valores do volume globular, foi calculado o déficit de volume plasmático segundo Kaneko et al. (1997) que relacionam o volume globular do momento zero (VG1) com os obtidos nos tempos subsequentes (VG2), de acordo com a expressão:

DVP: $\{[$ VG1 (1-VG2) / VG2 * (1-VG1)] -1 $\} * 100$ 
Onde VG1 = VG inicial no tempo 0` expresso com uma casa após a virgula

VG2= VG em outros tempos expressos com uma casa após a vírgula.

Para análise hemogasométrica o sangue total arterial foi coletado da artéria auricular em seringas de $3 \mathrm{~mL}$ contendo heparina sódica. Dessa amostra foram obtidos os valores do $\mathrm{pH}$ sanguíneo, concentração de bicarbonato $\left(\mathrm{HCO}_{-3}\right)$ e excesso ácido básico (EAB) utilizando analisador portátil (i-STAT, Abbott ${ }^{\circledR}$ Point of Care, Illinois, USA) e cartuchos ECG8+ (Abbott ${ }^{\circledR}$ Point of Care, Illinois, USA).

\subsubsection{Coleta e processamento das amostras de urina}

Nos mesmos tempos acima mencionados, foi coletado uma amostra de urina em copo coletor e imediatamente foi analisado o $\mathrm{pH}$ e a densidade urinaria. $\mathrm{O} \mathrm{pH}$ foi realizado em pHmetro de bancada (DM-22, Digimed ${ }^{\circledR}$ Analítica Ltda, São Paulo/SP, Brasil). A densidade foi analisada por refratômetro (Atago ${ }^{\circledR}$ T2, NE Clinical, Atago Brasil Ltda., Ribeirão Preto/SP, Brasil).

\subsubsection{Coleta e processamento das amostras de fezes}

Semelhante as variáveis supracitadas, foi coletado uma amostra de fezes em copo coletor e imediatamente foi analisado o $\mathrm{pH}$. O pH foi realizado em pHmetro de bancada (DM22, Digimed ${ }^{\circledR}$ Analítica Ltda, São Paulo/SP, Brasil). 


\subsection{TRATAMENTO}

Todos os animais que manifestaram quadro clínico severo de ALR foram tratados, com uso de 5 mL/kg P.C., de solução hipertônica de cloreto de sódio 7,5\% (IV), seguida de infusão de $20 \mathrm{~mL} / \mathrm{kg}$ P.C. solução salina isotônica (IV); retirada de parte do conteúdo ruminal e adicionado conteúdo de um animal saudável e administração de 4 L de água no rúmen, segundo protocolo descrito por Rodrigues et al. (2011). Não foi necessário a correção do estado ácidobásico dos animais com bicarbonato de sódio $(8,4 \%)$ já que nenhum apresentou pH sanguíneo menor que 7,18 como pré estabelecido para o uso de alcalinizante nesse estudo.

\subsection{ANÁLISE ESTATÍSTICA}

A análise estatística foi processada com auxílio do programa estatístico computadorizado SAS 9.3 (2012) e Minitab release 14.

Os dados obtidos durante o período experimental foram analisados quanto a sua distribuição normal pelo teste de Kolgomorov-Sminorv e avaliada a homogeneidade das variâncias (SIEGEL, 1975). Os dados que obedeceram à distribuição paramétrica foram submetidos a análise de variância (Teste F) utilizando o procedimento PROC MIXED (SAS 9.3, 2012), para medidas repetidas no tempo, sendo estudado para cada variável o efeito de tratamento, tempo e interação entre tratamento e tempo. Sendo considerado o critério de Akaike (AIC) para a escolha da melhor estrutura de covariância. Para comparações pontuais entre duas variáveis utilizou-se o teste t de Student. 
Para avaliação do movimento ruminal (MR) os dados foram transformados usando a fórmula: $\sqrt{X}+\sqrt{X}+1$, segundo recomendação de Reis (2003), devido a existência de números nulos e inferior a 10, sendo em seguida empregado teste estatístico paramétrico supracitado.

Quando os dados exibiram distribuição não paramétrica, foi aplicado o de Teste Kruskal-Wallis, complementado por teste de Mann-Whitney. O teste de Qui-quadrado foi utilizado para avaliar os sinais clínicos (depressão nervosa, desidratação e acidose sistêmica) e a necessidade de tratamento entre os grupos estudados.

Foi considerada significativa as diferenças cujo valor de "P" foi igual ou inferior a 0,05 , e tendência para valores de "P" entre 0,06 e 0,1 .

Para estudar a influência das relações entre duas variáveis foram calculados os coeficientes de correlação (r) e o coeficiente de determinação $\left(\mathrm{R}^{2}\right)$ pelo teste de Spearman. Ficou estabelecido que existiu uma correlação de alta intensidade entre as variáveis quando $\mathrm{r} \geq$ 0,60; média intensidade quando $0,30<\mathrm{r}<0,60$; e de baixa intensidade quando $\mathrm{r} \leq 0,30$, considerando também que o nível de significância obtido nas correlações seja igual ou inferior a 5\% (LITTLE; HILLS, 1978). 


\section{RESULTADOS}

Os resultados obtidos durante o experimento estão expressos por meio das médias e desvios padrão obtidos para as diferentes variáveis estudadas, e foram alocados em tabelas e gráficos com a finalidade de facilitar a leitura deste capítulo.

\subsection{VARIÁVEIS RUMINAIS}

\subsection{1 pH do conteúdo ruminal}

Na tabela 1 estão apresentados os resultados médios e desvios padrão do pH do conteúdo ruminal no decorrer do experimento, e no gráfico 1 está ilustrado o comportamento desta variável.

Tabela 1 - Valores médios e desvios padrão do $\mathrm{pH}$ do conteúdo ruminal nos bovinos dos grupos controle, monensina, virginiamicina $(25 \mathrm{ppm})$, virginiamicina $(34 \mathrm{ppm})$ e monensina + virginiamicina no decorrer do experimento - São Paulo - 2018.

\begin{tabular}{cccccc}
\hline & T0 & T3 & T6 & T12 & T18 \\
\hline CON & $7,01 \pm 0,10^{\mathrm{a}}$ & $5,25 \pm 0,08^{\mathrm{Bb}}$ & $4,57 \pm 0,08^{\mathrm{Bc}}$ & $4,24 \pm 0,10^{\mathrm{d}}$ & $4,04 \pm 0,11^{\mathrm{Ce}}$ \\
MON & $6,94 \pm 0,11^{\mathrm{a}}$ & $5,46 \pm 0,10^{\mathrm{ABb}}$ & $4,72 \pm 0,07^{\mathrm{Abc}}$ & $4,38 \pm 0,18^{\mathrm{d}}$ & $4,24 \pm 0,11^{\mathrm{BCd}}$ \\
VM 25 & $7,03 \pm 0,10^{\mathrm{a}}$ & $5,41 \pm 0,15^{\mathrm{ABb}}$ & $4,60 \pm 0,12^{\mathrm{Abc}}$ & $4,39 \pm 0,12^{\mathrm{cd}}$ & $4,27 \pm 0,08^{\mathrm{ABd}}$ \\
VM 34 & $6,96 \pm 0,03^{\mathrm{a}}$ & $5,47 \pm 0,10^{\mathrm{ABb}}$ & $4,79 \pm 0,14^{\mathrm{Abc}}$ & $4,46 \pm 0,11^{\mathrm{d}}$ & $4,24 \pm 0,06^{\mathrm{ABe}}$ \\
VM + MON & $6,95 \pm 0,09^{\mathrm{a}}$ & $5,59 \pm 0,17^{\mathrm{Ab}}$ & $4,91 \pm 0,30^{\mathrm{Ab}}$ & $4,44 \pm 0,14^{\mathrm{c}}$ & $4,35 \pm 0,12^{\mathrm{Ac}}$ \\
\hline
\end{tabular}

Fonte: (OLIVEIRA, F.L.C, 2018)

Efeito de tratamento $=0,0188$; Efeito de tempo <.0001; Interação entre trat*tempo <.0001.

Notas: Letras maiúsculas distintas nas colunas significam diferença estatística entre os grupos.

Letras minúsculas distintas nas linhas significam diferenças dentro de cada grupo. 
Não existiu diferença no $\mathrm{pH}$ no tempo basal e na $12^{\mathrm{a}} \mathrm{h}$ entre os grupos. Porém, na $3^{\mathrm{a}}$ h e na $6^{a} h$ a associação $V M+M O N$ foi superior ao controle, ocorrendo o mesmo fato na $6^{a}$ h nos outros grupos em relação ao controle. No auge da acidose (T18), a associação VM + MON foi significativamente superior ao controle e à monensina, e os grupos VM 34 e VM 25 superiores ao controle. Enquanto que no grupo controle e no grupo VM 34 a diminuição do $\mathrm{pH}$ ruminal foi significativa e constante em cada um dos tempos estudados, nos grupos MON, VM 25 e VM + MON isto ocorreu até a $12^{\mathrm{a}} \mathrm{h}$. Existiu uma nítida interação significativa entre o tratamento e o tempo de coleta $(\mathrm{P}<0,0001)$.

Gráfico 1 - Valores médios do $\mathrm{pH}$ do conteúdo ruminal nos bovinos dos grupos controle, monensina, virginiamicina $(25 \mathrm{ppm})$, virginiamicina $(34 \mathrm{ppm})$ e monensina + virginiamicina no decorrer do experimento - São Paulo - 2018.

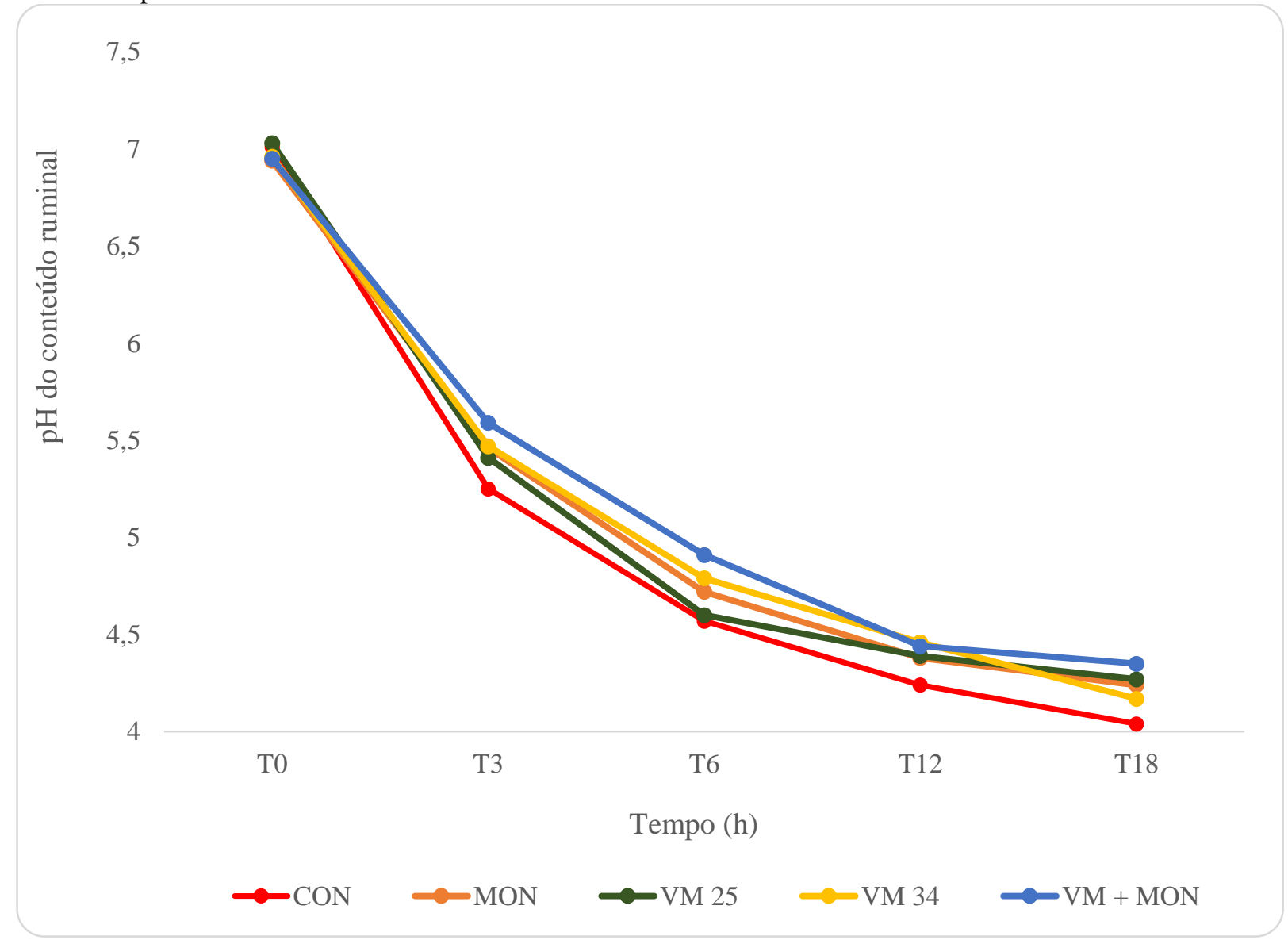

Fonte: (OLIVEIRA, F.L.C, 2018) 


\subsubsection{Concentração de glicose do conteúdo ruminal}

Na tabela 2 estão apresentados os resultados de mediana da concentração de glicose do conteúdo ruminal.

Tabela 2 - Valores de mediana da concentração de glicose ruminal (mM/L) nos bovinos dos grupos controle, monensina, virginiamicina $(25 \mathrm{ppm})$, virginiamicina $(34 \mathrm{ppm})$ e monensina + virginiamicina no decorrer do experimento - São Paulo - 2018.

\begin{tabular}{cccccc}
\hline & T0 & T3 & T6 & T12 & T18 \\
\hline CON & $0,12^{\mathrm{d}}$ & $99,24^{\mathrm{a}}$ & $52,62^{\mathrm{b}}$ & $27,91^{\mathrm{c}}$ & $0,80^{\mathrm{BCd}}$ \\
MON & $0,28^{\mathrm{d}}$ & $107,14^{\mathrm{a}}$ & $57,14^{\mathrm{b}}$ & $31,14^{\mathrm{c}}$ & $0,64^{\mathrm{Cd}}$ \\
VM 25 & $0,16^{\mathrm{c}}$ & $94,90^{\mathrm{a}}$ & $46,45^{\mathrm{ab}}$ & $26,79^{\mathrm{ab}}$ & $15,0^{\mathrm{ABb}}$ \\
VM 34 & $0,15^{\mathrm{d}}$ & $120,91^{\mathrm{a}}$ & $75,31^{\mathrm{ab}}$ & $38,80^{\mathrm{bc}}$ & $19,40^{\mathrm{Ac}}$ \\
VM + MON & $0,18^{\mathrm{c}}$ & $51,92^{\mathrm{a}}$ & $39,41^{\mathrm{a}}$ & $17,29^{\mathrm{ab}}$ & $10,77^{\mathrm{ABb}^{* *}}$ \\
\hline
\end{tabular}

Fonte: (OLIVEIRA, F.L.C, 2018)

Efeito de tratamento $=0,003 ;$ Efeito de tempo $=0,0052$

Notas: Letras maiúsculas distintas nas colunas significam diferença estatística entre os grupos.

Letras minúsculas distintas nas linhas significam diferença dentro de cada grupo.

A análise entre os grupos identificou que não houve diferença na concentração de glicose ruminal no tempo basal e na $3^{\mathrm{a}}, 6^{\mathrm{a}}$ e $12^{\mathrm{a}} \mathrm{h}$, porém isto ocorreu na $18^{\mathrm{a}}$ em que o tratamento VM 34 foi superior ao CON e ao MON; neste mesmo tempo há uma tendência do tratamento VM 25 e VM + MON de diferirem do CON, tendo $\mathrm{p}=0,06$ e $\mathrm{p}=0,09$ respectivamente. Dentro de cada grupo, nota-se que no CON, MON, VM 25 e VM 34 há um pico na $3^{\mathrm{a}} \mathrm{h}$ havendo uma diminuição progressiva nas demais; no VM + MON essa superioridade é notada na $3^{\mathrm{a}}$ e $6^{\mathrm{a}} \mathrm{h}$. 
Gráfico 2 - Valores de mediana da concentração de glicose ruminal (mM/L) nos bovinos dos grupos controle, monensina, virginiamicina $(25 \mathrm{ppm})$, virginiamicina $(34 \mathrm{ppm})$ e monensina + virginiamicina no decorrer do experimento - São Paulo - 2018.

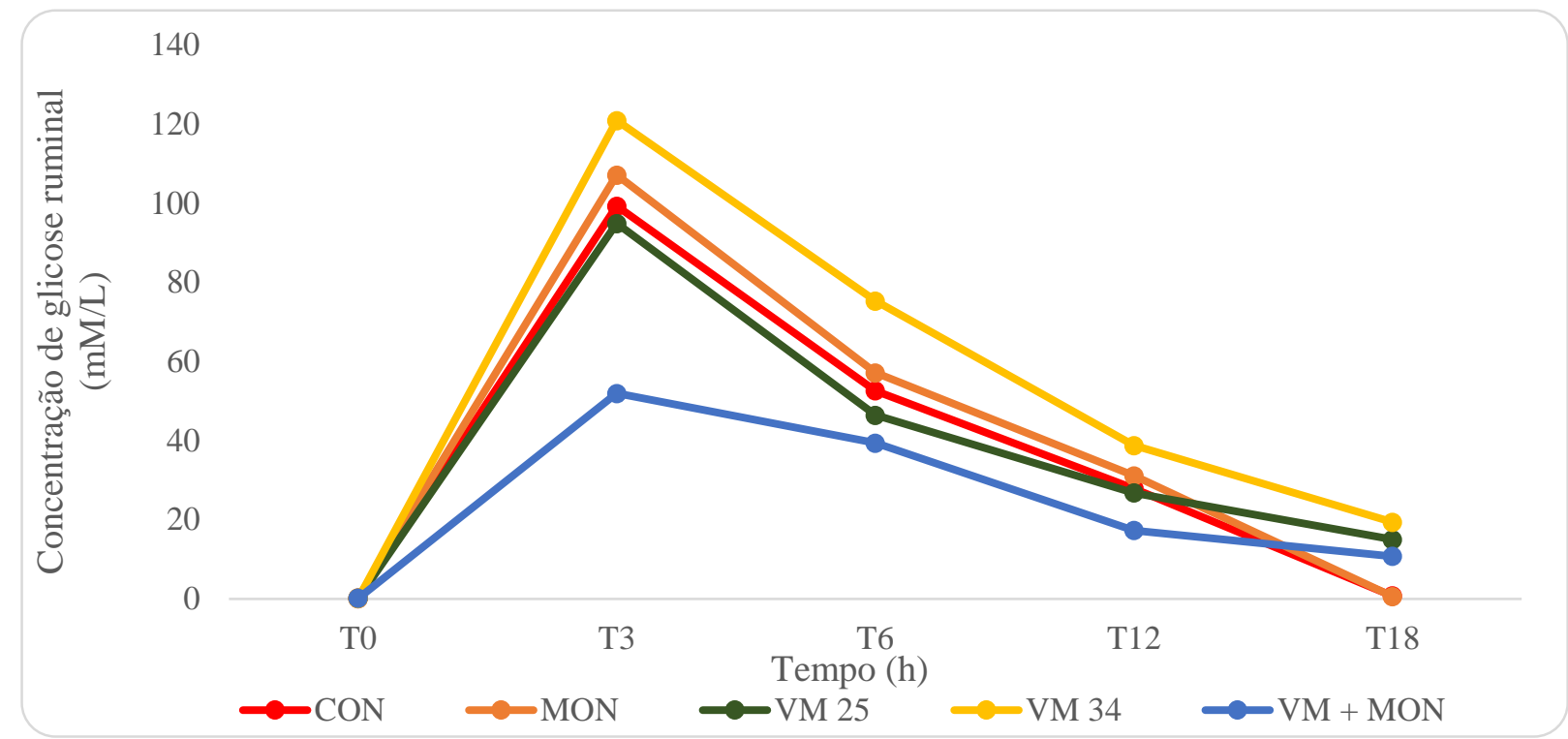

Fonte: (OLIVEIRA, F.L.C, 2018)

\subsubsection{Concentração de lactato - L ruminal}

Na tabela 3 estão apresentados os resultados médios e desvios padrão do lactato - L ruminal no decorrer do experimento, e no gráfico 3 está ilustrado o comportamento desta variável.

Tabela 3 - Valores médios e desvios padrão da concentração de lactato - L ruminal (mM/L) nos bovinos dos grupos controle, monensina, virginiamicina $(25 \mathrm{ppm})$, virginiamicina $(34 \mathrm{ppm})$ e monensina + virginiamicina no decorrer do experimento - São Paulo - 2018.

\begin{tabular}{cccccc}
\hline & T0 & T3 & T6 & T12 & T18 \\
\hline CON & $0,08 \pm 0,01^{\mathrm{d}}$ & $21,79 \pm 5,98^{\mathrm{Ac}}$ & $56,18 \pm 4,48^{\mathrm{Ab}}$ & $67,93 \pm 6,32^{\mathrm{a}}$ & $71,17 \pm 7,12^{\mathrm{Aa}}$ \\
MON & $0,07 \pm 0,008^{\mathrm{c}}$ & $12,32 \pm 6,11^{\mathrm{Ac}}$ & $43,68 \pm 20,07^{\mathrm{Ab}}$ & $62,18 \pm 11,79^{\mathrm{ab}}$ & $67,71 \pm 3,12^{\mathrm{ABa}}$ \\
VM 25 & $0,09 \pm 0,02^{\mathrm{c}}$ & $18,87 \pm 6,44^{\mathrm{Ab}}$ & $54,03 \pm 12,02^{\mathrm{Aa}}$ & $56,74 \pm 7,10^{\mathrm{a}}$ & $60,91 \pm 5,96^{\mathrm{Ba}}$ \\
VM 34 & $0,08 \pm 0,01^{\mathrm{d}}$ & $15,67 \pm 5,08^{\mathrm{Ac}}$ & $43,66 \pm 9,71^{\mathrm{Ab}}$ & $56,70 \pm 14,14^{\mathrm{ab}}$ & $62,04 \pm 5,47^{\mathrm{ABa}}$ \\
VM + MON & $0,08 \pm 0,01^{\mathrm{c}}$ & $2,46 \pm 2,20^{\mathrm{Bc}}$ & $22,30 \pm 5,89^{\mathrm{Bb}}$ & $54,91 \pm 7,01^{\mathrm{a}}$ & $61,04 \pm 3,92^{\mathrm{Ba}}$ \\
\hline
\end{tabular}

Fonte: (OLIVEIRA, F.L.C, 2018)

Efeito de tratamento $=0,0005$; Efeito de tempo <.0001; Interação entre trat*tempo <.0001

Notas: Letras maiúsculas distintas nas colunas significam diferença estatística entre os grupos.

Letras minúsculas distintas nas linhas significam diferença dentro de cada grupo. 
Identicamente ao $\mathrm{pH}$ ruminal, no momento basal e na $12^{\mathrm{a}} \mathrm{h}$ os teores de ácido láctico-L foram semelhantes entre os tratamentos. Nos tempos T3 e T6 a associação VM + MON gerou menores concentrações desse ácido em relação a todos os tratamentos. No final do estudo, os tratamentos VM + MON e VM 25 apresentaram menores teores de ácido láctico que o controle. A análise dentro de cada grupo identificou que, com exceção do tratamento VM + MON e MON, ocorreu aumento constante desses teores até a $12^{\mathrm{a}} \mathrm{h}$, se mantendo semelhante na T18 em todos os grupos. Tal qual o pH ruminal existiu interação entre o tratamento e o tempo de coleta.

Gráfico 3 - Valores médios da concentração de lactato - L ruminal (mM/L) nos bovinos dos grupos controle, monensina, virginiamicina $(25 \mathrm{ppm})$, virginiamicina $(34 \mathrm{ppm})$ e monensina + virginiamicina no decorrer do experimento - São Paulo - 2018.

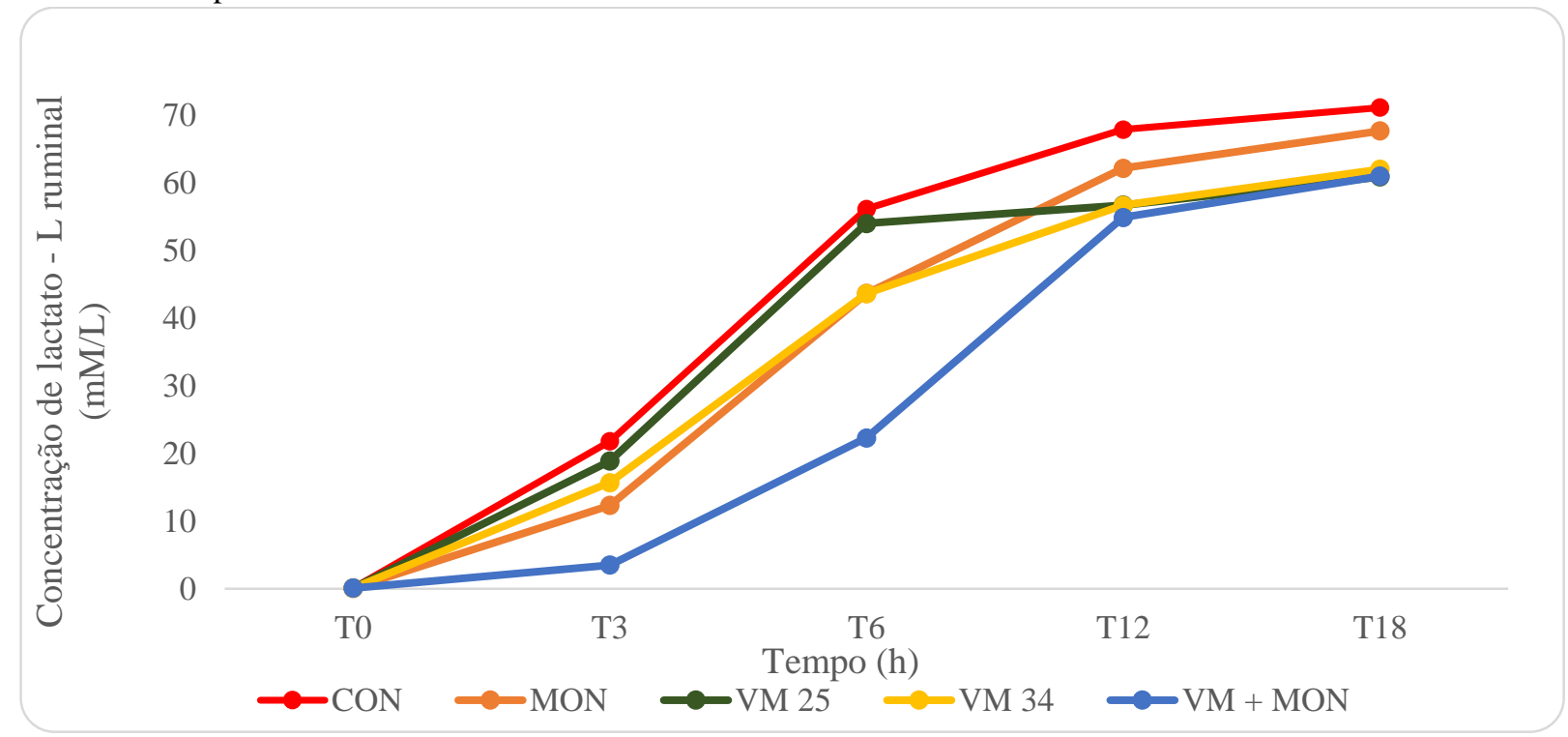

Fonte: (OLIVEIRA, F.L.C, 2018)

\subsubsection{Concentração de lactato - D ruminal}

Na tabela 4 estão apresentados os resultados médios e desvios padrão do lactato - D ruminal no decorrer do experimento, e no gráfico 4 está ilustrado o comportamento desta variável. 
Tabela 4 - Valores médios e desvios padrão da concentração de lactato - D ruminal (mM/L) nos bovinos dos grupos controle, monensina, virginiamicina $(25 \mathrm{ppm})$, virginiamicina $(34 \mathrm{ppm})$ e monensina + virginiamicina no decorrer do experimento - São Paulo - 2018.

\begin{tabular}{cccccc}
\hline & T0 & T3 & T6 & T12 & T18 \\
\hline CON & $0,14 \pm 0,06^{\mathrm{Ab}}$ & - & $5,00 \pm 1,44^{\mathrm{BCb}}$ & $16,59 \pm 8,37^{\mathrm{a}}$ & $17,90 \pm 3,59^{\mathrm{ABa}}$ \\
MON & $0,04 \pm 0,01^{\mathrm{Bd}}$ & - & $6,38 \pm 2,77^{\mathrm{BCc}}$ & $15,48 \pm 1,53^{\mathrm{a}}$ & $10,7 \pm 2,64^{\mathrm{Bb}}$ \\
VM 25 & $0,09 \pm 0,06^{\mathrm{Ab}}$ & - & $8,36 \pm 1,70^{\mathrm{ABb}}$ & $17,21 \pm 4,11^{\mathrm{a}}$ & $20,65 \pm 7,03^{\mathrm{Aa}}$ \\
VM 34 & $0,05 \pm 0,0^{\mathrm{Bb}}$ & - & $4,41 \pm 1,24^{\mathrm{Cb}}$ & $16,07 \pm 2,69^{\mathrm{a}}$ & $12,18 \pm 4,09^{\mathrm{Ba}}$ \\
VM + MON & $0,05 \pm 0,04^{\mathrm{Bb}}$ & - & $0,46 \pm 0,12^{\mathrm{Db}}$ & $16,43 \pm 4,53^{\mathrm{a}}$ & $20,61 \pm 2,98^{\mathrm{Aa}}$ \\
\hline
\end{tabular}

Fonte: (OLIVEIRA, F.L.C, 2018)

Efeito de tratamento $=0,012$; Efeito de tempo <.0001

Notas: Letras maiúsculas distintas nas colunas significam diferença estatística entre os grupos.

Letras minúsculas distintas nas linhas significam diferença dentro de cada grupo.

Não existiu diferença na concentração de lactato - D ruminal na $12^{\mathrm{a}} \mathrm{h}$ entre os grupos, no tempo basal nota-se que o CON e VM 25 possuem valores superiores aos demais grupos; observando a $6^{\mathrm{a}} \mathrm{h}$ percebe-se que o $\mathrm{VM}+\mathrm{MON}$ produziu menor concentração desse ácido em relação a todos os grupos e que o VM 25 gerou mais ácido que o VM 34; na $18^{\mathrm{a}}$ h o VM + MON e o VM 25 apresentaram maiores teores desse ácido que o MON e VM 34. Dentro de cada grupo, nos tratamentos CON, VM 25, VM 34 e VM + MON o tempo basal e a $6^{\mathrm{a}} \mathrm{h}$ possuem valores inferiores quando comparado a $12^{\mathrm{a}}$ e $18^{\mathrm{a}} \mathrm{h}$; no grupo VM 25 detectou-se que existiu um aumento constante até o final do experimento. 
Gráfico 4 - Valores médios da concentração de lactato - D (mM/L) ruminal nos bovinos dos grupos controle, monensina, virginiamicina (25 ppm), virginiamicina (34 ppm) e monensina + virginiamicina no decorrer do experimento - São Paulo - 2018.

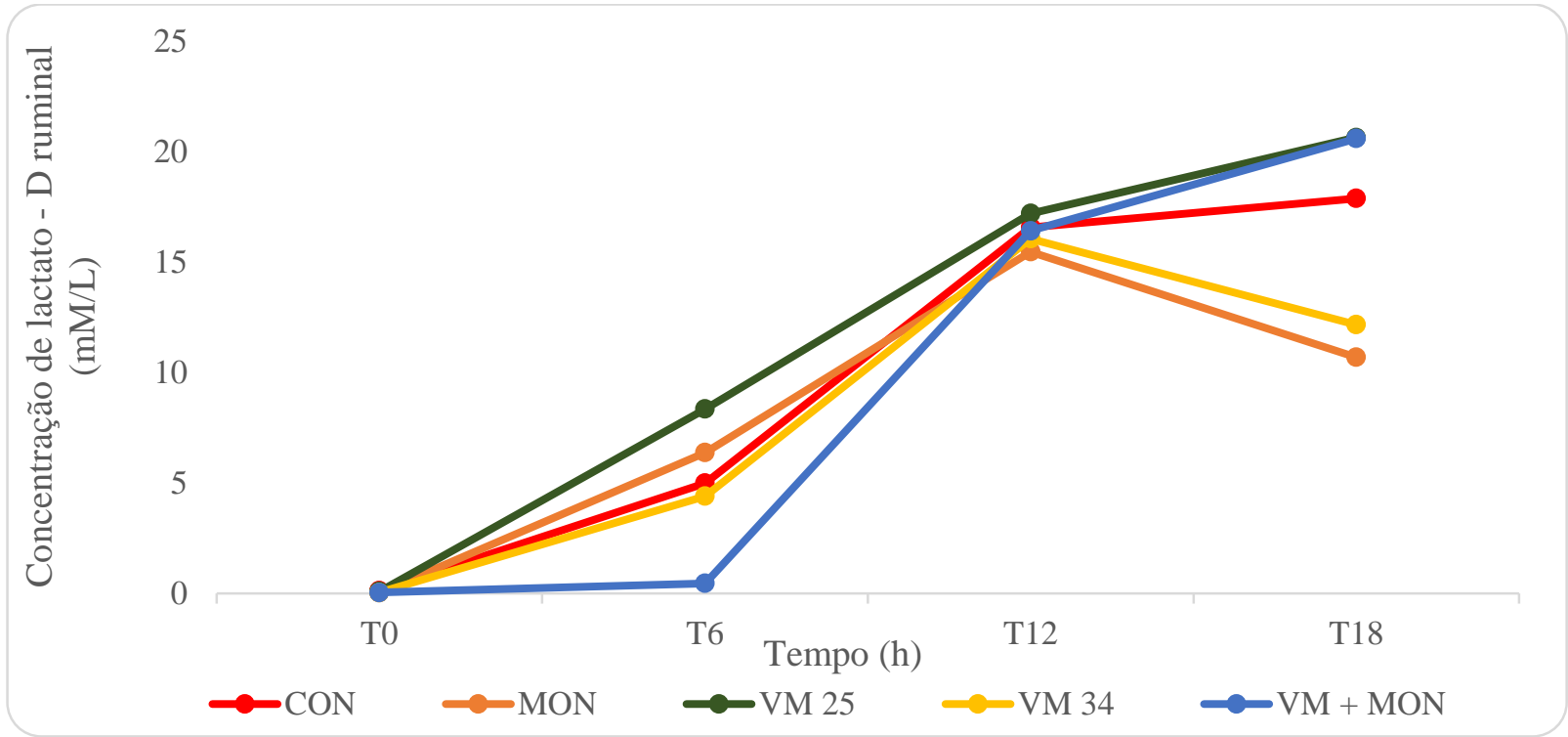

Fonte: (OLIVEIRA, F.L.C, 2018)

\subsubsection{Concentração do total de lactato do conteúdo ruminal}

Na tabela 5 estão apresentados os resultados médios e desvios padrão do total de lactato ruminal no decorrer do experimento, e no gráfico 5 está ilustrado o comportamento desta variável.

Tabela 5 - Valores médios e desvios padrão da concentração do total de lactato ruminal (mM/L) nos bovinos dos grupos controle, monensina, virginiamicina $(25 \mathrm{ppm})$, virginiamicina (34 ppm) e monensina + virginiamicina no decorrer do experimento - São Paulo - 2018.

\begin{tabular}{cccccc}
\hline & T0 & T3 & T6 & T12 & T18 \\
\hline CON & $0,24 \pm 0,02^{\mathrm{Ac}}$ & - & $60,62 \pm 5,77^{\mathrm{Ab}}$ & $83,67 \pm 12,14^{\mathrm{a}}$ & $89,07 \pm 8,61^{\mathrm{Aa}}$ \\
MON & $0,12 \pm 0,02^{\mathrm{Bc}}$ & - & $57,62 \pm 8,53^{\mathrm{Ab}}$ & $80,93 \pm 9,60^{\mathrm{a}}$ & $74,13 \pm 9,80^{\mathrm{ABa}}$ \\
VM 25 & $0,18 \pm 0,06^{\mathrm{ABc}}$ & - & $61,22 \pm 11,47^{\mathrm{Ab}}$ & $73,13 \pm 9,55^{\mathrm{ab}}$ & $81,23 \pm 11,68^{\mathrm{ABa}}$ \\
VM 34 & $0,15 \pm 0,03^{\mathrm{Bc}}$ & - & $50,76 \pm 7,63^{\mathrm{Ab}}$ & $69,07 \pm 13,20^{\mathrm{a}}$ & $70,57 \pm 11,41^{\mathrm{Ba}}$ \\
VM + MON & $0,13 \pm 0,05^{\mathrm{Bc}}$ & - & $22,21 \pm 6,42^{\mathrm{Bb}}$ & $70,76 \pm 9,76^{\mathrm{a}}$ & $81,65 \pm 4,56^{\mathrm{ABa}}$ \\
\hline
\end{tabular}

Fonte: (OLIVEIRA, F.L.C, 2018)

Efeito de tratamento $=0,031$; Efeito de tempo $<.0001$

Notas: Letras maiúsculas distintas nas colunas significam diferença estatística entre os grupos.

Letras minúsculas distintas nas linhas significam diferença dentro de cada grupo. 
Não houve diferença na $12^{\mathrm{a}} \mathrm{h}$ entre os grupos, no tempo basal o grupo CON possui maior valor que o MON, VM 34 e VM + MON; na $6^{\mathrm{a}} \mathrm{h}$ o tratamento $\mathrm{VM}+\mathrm{MON}$ se diferencia dos demais e na $18^{\mathrm{a}} \mathrm{h}$ o VM 34 apresenta menor valor em relação ao CON. Fazendo-se uma análise dentro de cada grupo, nota-se que houve em todos os grupos, uma maior produção de ácido láctico total no conteúdo ruminal no decorrer do tempo.

Gráfico 5 - Valores médios da concentração total de lactato ruminal (mM/L) nos bovinos dos grupos controle, monensina, virginiamicina $(25 \mathrm{ppm})$, virginiamicina $(34 \mathrm{ppm})$ e monensina + virginiamicina no decorrer do experimento - São Paulo - 2018.

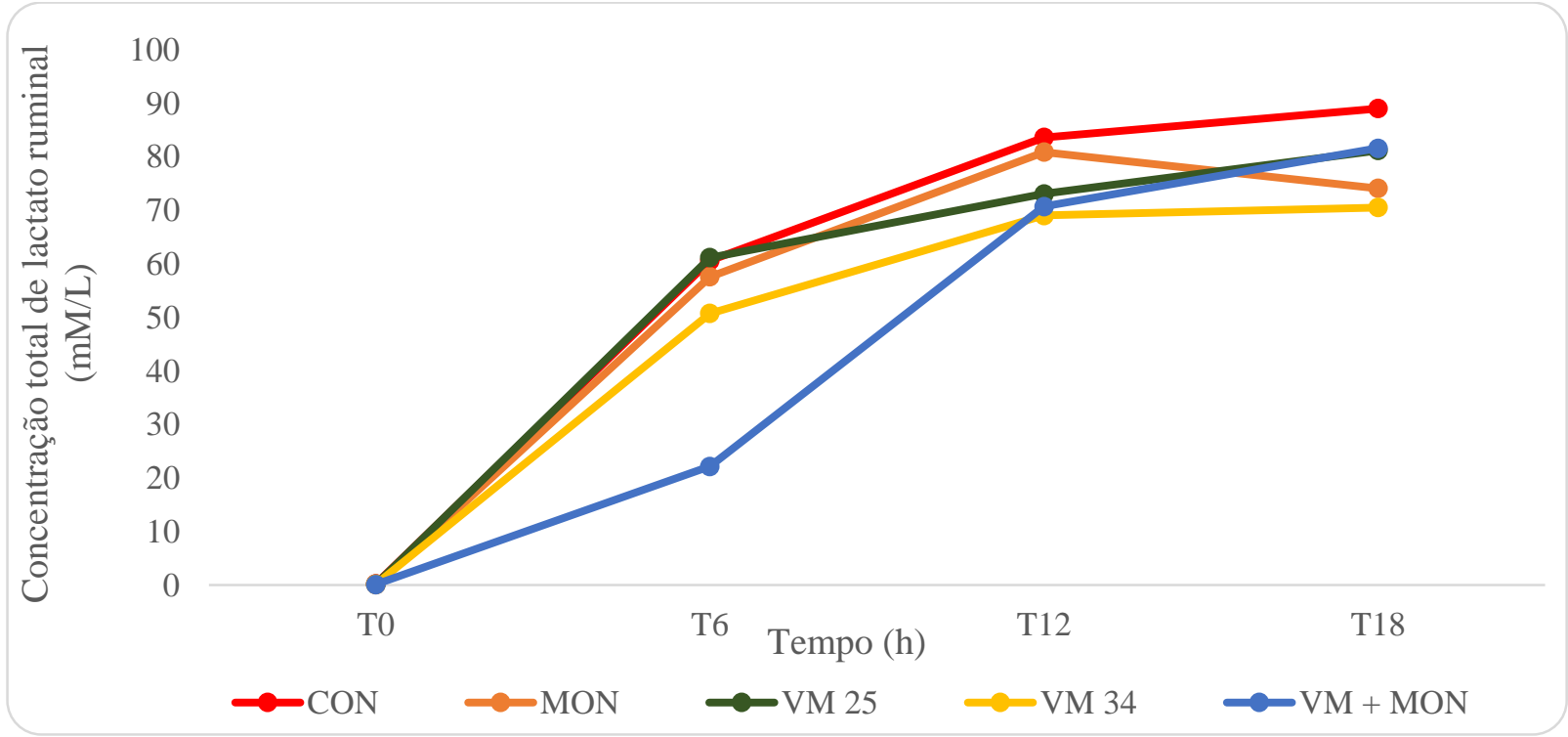

Fonte: (OLIVEIRA, F.L.C, 2018)

\subsubsection{Relação de lactato $L / D$ ruminal}

Na tabela 6 estão apresentados os resultados médios e desvios padrão da relação lactato L/D do conteúdo ruminal no decorrer do experimento, e no gráfico 6 está ilustrado o comportamento desta variável. 
Tabela 6 - Valores médios e desvios padrão da relação lactato L/D do conteúdo ruminal nos bovinos dos grupos controle, monensina, virginiamicina (25 ppm), virginiamicina (34 ppm) e monensina + virginiamicina no decorrer do experimento - São Paulo - 2018.

\begin{tabular}{cccccc}
\hline & T0 & T3 & T6 & T12 & T18 \\
\hline CON & $1,10 \pm 1,17^{\mathrm{b}}$ & - & $11,76 \pm 3,14^{\mathrm{Ba}}$ & $4,64 \pm 1,50^{\mathrm{b}}$ & $4,11 \pm 0,93^{\mathrm{ABb}}$ \\
MON & $1,86 \pm 0,58^{\mathrm{c}}$ & - & $9,31 \pm 4,19^{\mathrm{Ba}}$ & $4,26 \pm 0,77^{\mathrm{bc}}$ & $6,35 \pm 2,27^{\mathrm{Aab}}$ \\
VM 25 & $1,24 \pm 0,73^{\mathrm{b}}$ & - & $6,76 \pm 2,82^{\mathrm{Ba}}$ & $3,42 \pm 1,11^{\mathrm{b}}$ & $3,14 \pm 0,90^{\mathrm{Bb}}$ \\
VM 34 & $1,41 \pm 0,42^{\mathrm{b}}$ & - & $11,27 \pm 3,90^{\mathrm{Ba}}$ & $3,33 \pm 0,70^{\mathrm{b}}$ & $5,20 \pm 1,73^{\mathrm{ABb}}$ \\
VM + MON & $2,03 \pm 0,82^{\mathrm{b}}$ & - & $50,08 \pm 23,09^{\mathrm{Aa}}$ & $3,55 \pm 1,29^{\mathrm{b}}$ & $3,03 \pm 0,62^{\mathrm{Bb}}$ \\
\hline Fon
\end{tabular}

Fonte: (OLIVEIRA, F.L.C, 2018)

Efeito de tratamento $=0,003 ;$ Efeito de tempo $=0,001$

Notas: Letras maiúsculas distintas nas colunas significam diferença estatística entre os grupos.

Letras minúsculas distintas nas linhas significam diferença dentro de cada grupo.

Não existiu diferença entre os grupos no tempo basal e na $12^{\mathrm{a}} \mathrm{h}$, percebe-se que na $6^{\mathrm{a}}$ h o $\mathrm{VM}+\mathrm{MON}$ possui maior valor em relação aos demais e na $18^{\mathrm{a}} \mathrm{h}$ o $\mathrm{VM} 25$ e $\mathrm{VM}+\mathrm{MON}$ têm menor relação que o MON. Analisando cada grupo separadamente, nota-se que no CON, VM 25, VM 34, VM + MON e MON na $6^{\mathrm{a}} \mathrm{h}$ está havendo uma maior relação lactato L/D em relação aos demais tempos e no tratamento MON menores valores são observados no tempo basal e na $12^{\mathrm{a}} \mathrm{h}$. 
Gráfico 6 - Valores médios da relação lactato L/D do conteúdo ruminal (mM/L) nos bovinos dos grupos controle, monensina, virginiamicina $(25 \mathrm{ppm})$, virginiamicina $(34 \mathrm{ppm})$ e monensina + virginiamicina no decorrer do experimento - São Paulo - 2018.

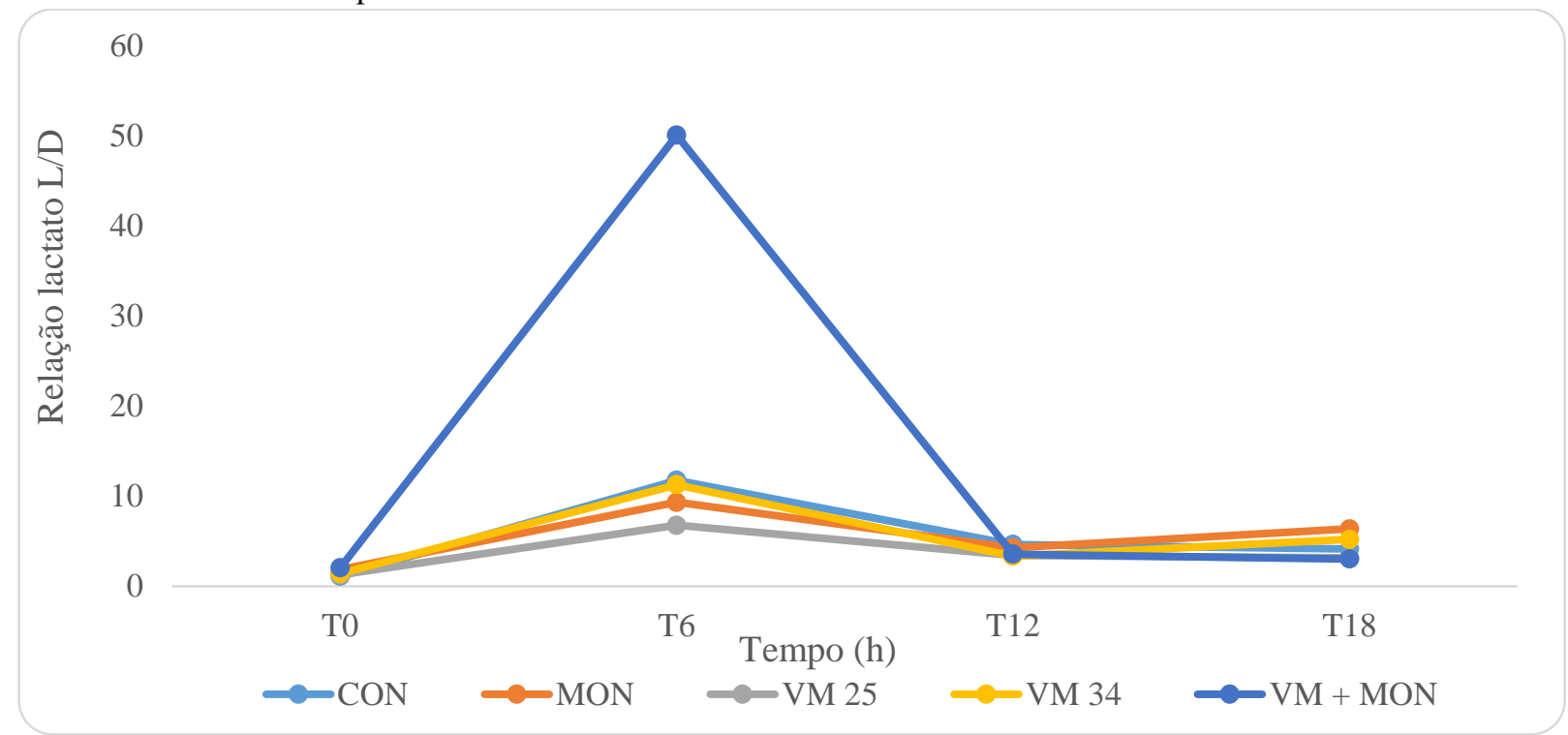

Fonte: (OLIVEIRA, F.L.C, 2018)

\subsubsection{Concentração de acetato ruminal}

Na tabela 7 estão apresentados os resultados médios e desvios padrão do acetato do conteúdo ruminal no decorrer do experimento, e no gráfico 7 está ilustrado o comportamento desta variável.

Tabela 7 - Valores médios e desvios padrão da concentração do acetato ruminal (mM/L) nos bovinos dos grupos controle, monensina, virginiamicina (25 ppm), virginiamicina (34 ppm) e monensina + virginiamicina no decorrer do experimento - São Paulo - 2018.

\begin{tabular}{cccccc}
\hline & T0 & T3 & T6 & T12 & T18 \\
\hline CON & $52,38 \pm 6,06^{\mathrm{b}}$ & $103,98 \pm 30,92^{\mathrm{a}}$ & $55,53 \pm 11,68^{\mathrm{Bb}}$ & $34,08 \pm 5,30^{\mathrm{bc}}$ & $18,69 \pm 3,33^{\mathrm{c}}$ \\
MON & $54,56 \pm 8,98^{\mathrm{ab}}$ & $84,32 \pm 24,97^{\mathrm{a}}$ & $57,19 \pm 15,36^{\mathrm{ABab}}$ & $35,54 \pm 12,78^{\mathrm{b}}$ & $28,85 \pm 18,50^{\mathrm{b}}$ \\
VM 25 & $47,75 \pm 10,91^{\mathrm{bc}}$ & $85,61 \pm 18,69^{\mathrm{a}}$ & $65,18 \pm 12,55^{\mathrm{ABab}}$ & $31,82 \pm 11,87^{\mathrm{c}}$ & $30,40 \pm 10,92^{\mathrm{c}}$ \\
VM 34 & $56,90 \pm 10,92^{\mathrm{cd}}$ & $100,93 \pm 16,42^{\mathrm{a}}$ & $67,16 \pm 20,44^{\mathrm{ABb}}$ & $33,90 \pm 9,95^{\mathrm{cd}}$ & $27,29 \pm 8,94^{\mathrm{d}}$ \\
VM + MON & $47,83 \pm 9,25^{\mathrm{b}}$ & $103,13 \pm 25,29^{\mathrm{a}}$ & $81,62 \pm 8,93^{\mathrm{Aa}}$ & $39,71 \pm 11,29^{\mathrm{b}}$ & $29,20 \pm 11,66^{\mathrm{b}}$ \\
\hline Fo
\end{tabular}

Fonte: (OLIVEIRA, F.L.C, 2018)

Efeito de tratamento $=0,6633 ;$ Efeito de tempo <.0001; Interação entre trat*tempo <0,0144;

Notas: Letras maiúsculas distintas nas colunas significam diferença estatística entre os grupos.

Letras minúsculas distintas nas linhas significam diferença dentro de cada grupo. 
Não existiu diferença na concentração de ácido acético no tempo basal, na $3^{\mathrm{a}}, 12^{\mathrm{a}}$ e $18^{\mathrm{a}}$ h entre os grupos, porém na $6^{\mathrm{a}} \mathrm{h}$ o grupo VM + MON foi superior ao controle. Dentro de cada grupo, houve um pico na $3^{\text {a }}$ hora, havendo uma diminuição progressiva nos demais tempos. Existiu uma nítida relação significativa entre o tratamento e o tempo de coleta $(\mathrm{p}<0,0144)$.

Gráfico 7 - Valores médios da concentração do acetato ruminal (mM/L) nos bovinos dos grupos controle, monensina, virginiamicina $(25 \mathrm{ppm})$, virginiamicina $(34 \mathrm{ppm})$ e monensina + virginiamicina no decorrer do experimento - São Paulo - 2018.

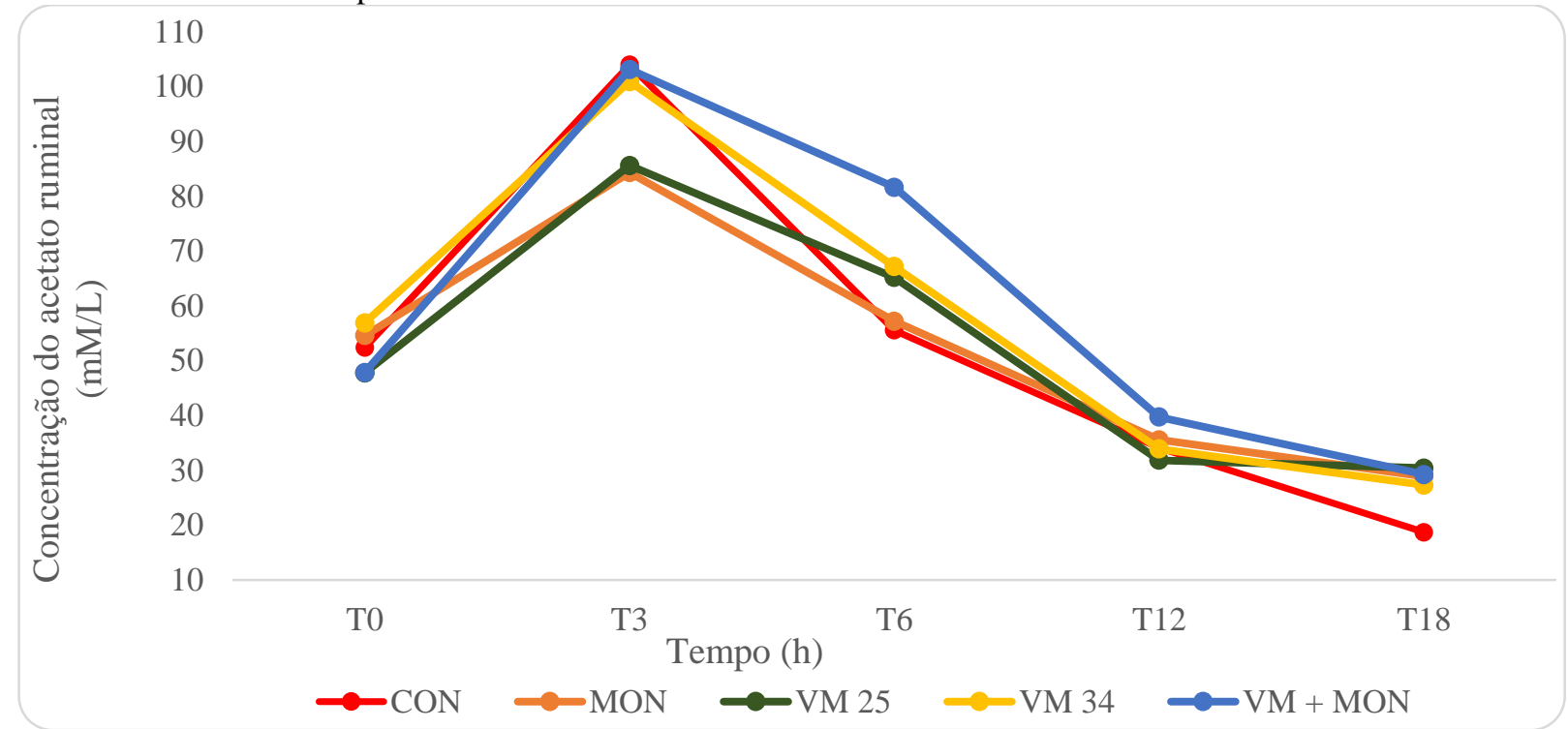

Fonte: (OLIVEIRA, F.L.C, 2018)

\subsubsection{Concentração de propionato ruminal}

Na tabela 8 estão apresentados os resultados médios e desvios padrão do propionato do conteúdo ruminal no decorrer do experimento, e no gráfico 8 está ilustrado o comportamento desta variável. 
Tabela 8 - Valores médios e desvios padrão da concentração do propionato ruminal (mM/L) nos bovinos dos grupos controle, monensina, virginiamicina $(25 \mathrm{ppm})$, virginiamicina (34 ppm) e monensina + virginiamicina no decorrer do experimento - São Paulo - 2018.

\begin{tabular}{cccccc}
\hline & T0 & T3 & T6 & T12 & T18 \\
\hline CON & $13,29 \pm 1,64^{\mathrm{Aba}}$ & $13,84 \pm 4,49^{\mathrm{a}}$ & $5,39 \pm 1,88^{\mathrm{Bb}}$ & $9,46 \pm 5,19^{\mathrm{ab}}$ & $4,95 \pm 3,56^{\mathrm{Bb}}$ \\
MON & $15,18 \pm 2,26^{\mathrm{Aab}}$ & $19,88 \pm 7,25^{\mathrm{a}}$ & $12,32 \pm 3,75^{\mathrm{ABab}}$ & $11,21 \pm 7,68^{\mathrm{ab}}$ & $7,25 \pm 5,03^{\mathrm{ABb}}$ \\
VM 25 & $9,30 \pm 1,71^{\mathrm{Cab}}$ & $14,93 \pm 6,70^{\mathrm{a}}$ & $7,87 \pm 2,43^{\mathrm{Bb}}$ & $13,30 \pm 4,81^{\mathrm{ab}}$ & $12,74 \pm 2,77^{\mathrm{Aab}}$ \\
VM 34 & $11,28 \pm 1,78^{\mathrm{BC}}$ & $15,64 \pm 6,99$ & $13,43 \pm 5,81^{\mathrm{AB}}$ & $13,67 \pm 3,42$ & $10,18 \pm 2,56^{\mathrm{AB}}$ \\
VM + MON & $13,42 \pm 2,41^{\mathrm{ABab}}$ & $20,89 \pm 4,70^{\mathrm{a}}$ & $19,74 \pm 8,04^{\mathrm{Aab}}$ & $15,24 \pm 1,95^{\mathrm{ab}}$ & $12,13 \pm 2,68^{\mathrm{Ab}}$ \\
\hline
\end{tabular}

Fonte: (OLIVEIRA, F.L.C, 2018)

Efeito de tratamento $=0,0041 ;$ Efeito de tempo <.0001; Interação entre trat*tempo <0,0001;

Notas: Letras maiúsculas distintas nas colunas significam diferença estatística entre os grupos.

Letras minúsculas distintas nas linhas significam diferença dentro de cada grupo.

Não teve diferença na concentração de ácido propiônico na $3^{\mathrm{a}}$ e $12^{\mathrm{a}} \mathrm{h}$ entre os grupos. No tempo basal os grupos VM 25 e 34 foram inferiores ao do controle; na $6^{\mathrm{a}} \mathrm{h}$ o grupo VM + MON teve maior concentração em relação aos grupos CON e VM 25, ao passo que na $18^{\mathrm{a}} \mathrm{h}$ os grupos VM 25 e VM + MON foram maiores que o grupo CON. Na análise dos resultados dentro de cada grupo, nos bovinos CON detectou-se maior concentração de ácido propiônico no tempo basal e $3^{\mathrm{a}} \mathrm{h}$ em relação a $6^{\mathrm{a}}$ e $18^{\mathrm{a}} \mathrm{h}$; nos grupos $\mathrm{MON}$ e $\mathrm{VM}+\mathrm{MON}$ maiores teores foram detectados na $3^{\mathrm{a}} \mathrm{h}$ em relação à $18^{\mathrm{a}}$; no grupo VM 25 a concentração de propionato foi superior na $3^{\mathrm{a}}$ em comparação à $6^{\mathrm{a}} \mathrm{h}$. Não ocorreu diferença dentro do grupo VM 34. Teve uma nítida relação significativa entre o tratamento e o tempo de coleta $(\mathrm{p}<0,0001)$. 
Gráfico 8 - Valores médios da concentração do propionato ruminal (mM/L) nos bovinos dos grupos controle, monensina, virginiamicina $(25 \mathrm{ppm})$, virginiamicina $(34 \mathrm{ppm})$ e monensina + virginiamicina no decorrer do experimento - São Paulo - 2018.

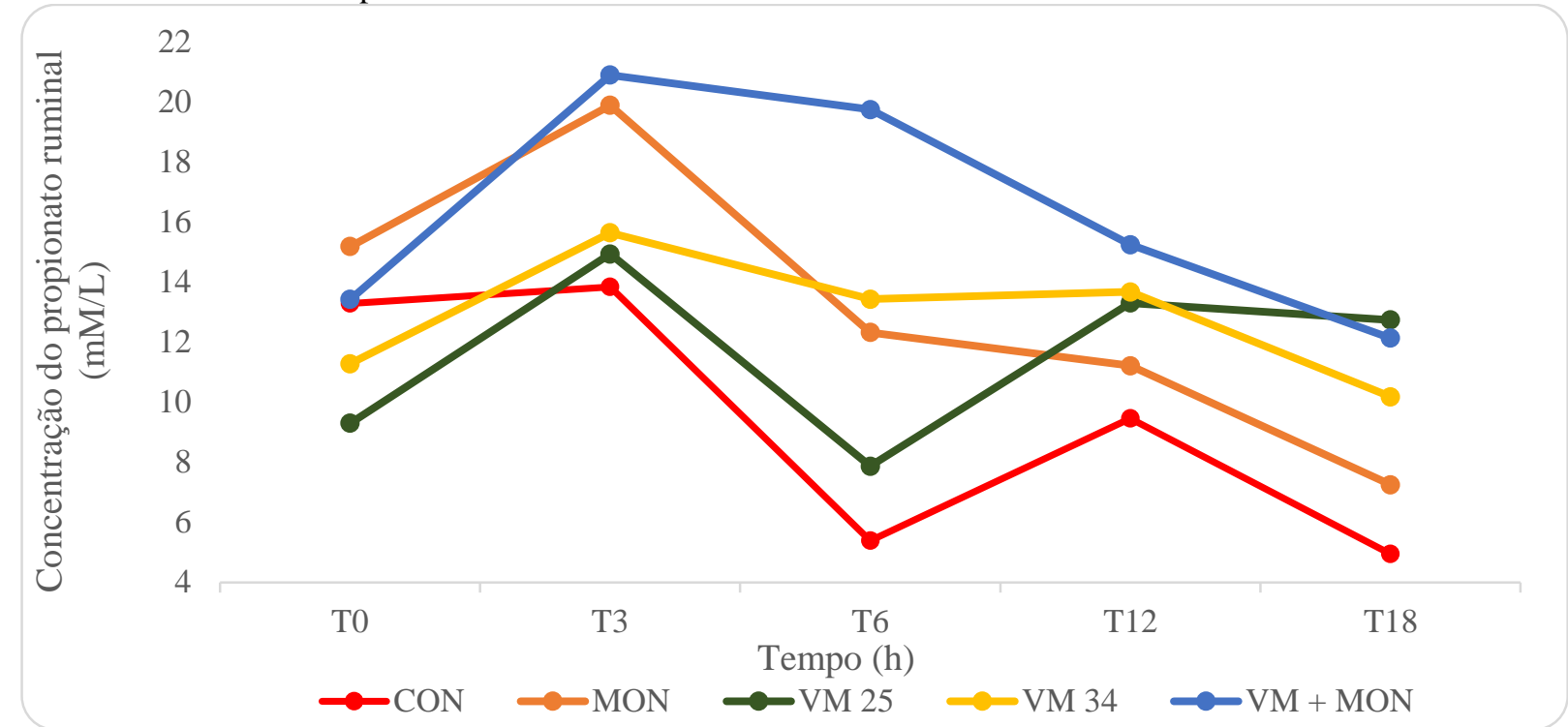

Fonte: (OLIVEIRA, F.L.C, 2018)

\subsubsection{Concentração de butirato ruminal}

Na tabela 9 estão apresentados os resultados médios e desvios padrão do butirato ruminal no decorrer do experimento, e no gráfico 9 está ilustrado o comportamento desta variável.

Tabela 9 - Valores médios e desvios padrão da concentração do butirato ruminal (mM/L) nos bovinos dos grupos controle, monensina, virginiamicina (25 ppm), virginiamicina (34 ppm) e monensina + virginiamicina no decorrer do experimento - São Paulo - 2018.

\begin{tabular}{cccccc}
\hline & T0 & T3 & T6 & T12 & T18 \\
\hline CON & $6,97 \pm 0,90^{\mathrm{b}}$ & $11,35 \pm 2,21^{\mathrm{a}}$ & $3,76 \pm 0,79^{\mathrm{c}}$ & $1,00 \pm 0,22^{\mathrm{d}}$ & $0,04 \pm 0,1^{\mathrm{d}}$ \\
MON & $6,66 \pm 1,49^{\mathrm{b}}$ & $9,90 \pm 2,13^{\mathrm{a}}$ & $6,68 \pm 1,82^{\mathrm{b}}$ & $1,15 \pm 0,41^{\mathrm{c}}$ & $0,59 \pm 0,47^{\mathrm{c}}$ \\
VM 25 & $6,34 \pm 1,98^{\mathrm{ab}}$ & $9,42 \pm 3,50^{\mathrm{a}}$ & $5,34 \pm 2,77^{\mathrm{b}}$ & $0,77 \pm 0,65^{\mathrm{c}}$ & $0,60 \pm 0,54^{\mathrm{c}}$ \\
VM 34 & $7,24 \pm 1,62^{\mathrm{a}}$ & $10,40 \pm 1,38^{\mathrm{a}}$ & $6,92 \pm 3,81^{\mathrm{a}}$ & $0,69 \pm 0,30^{\mathrm{b}}$ & $0,47 \pm 0,28^{\mathrm{b}}$ \\
VM + MON & $6,01 \pm 2,86^{\mathrm{b}}$ & $11,91 \pm 2,65^{\mathrm{a}}$ & $6,89 \pm 1,85^{\mathrm{b}}$ & $0,85 \pm 0,56^{\mathrm{c}}$ & $0,19 \pm 0,32^{\mathrm{c}}$ \\
\hline
\end{tabular}

Fonte: (OLIVEIRA, F.L.C, 2018)

Efeito de tratamento $=0,7112$; Efeito de tempo <.0001; Interação entre trat*tempo <0,0488;

Notas: Letras maiúsculas distintas nas colunas significam diferença estatística entre os grupos.

Letras minúsculas distintas nas linhas significam diferença dentro de cada grupo. 
Não houve diferenças entre os grupos quanto à concentração de butirato ruminal. Dentro de cada grupo, nos seguintes tratamentos CON, MON, VM 25 e VM + MON ocorreu um aumento de butirato na $3^{\mathrm{a}} \mathrm{h}$ com diminuição progressiva no decorrer do tempo; no grupo VM 34 este valor máximo transcorreu na $3^{\mathrm{a}} \mathrm{h}$. Existiu uma nítida relação significativa entre o tratamento e o tempo de coleta $(\mathrm{p}<0,0488)$

Gráfico 9 - Valores médios da concentração do butirato ruminal (mM/L) nos bovinos dos grupos controle, monensina, virginiamicina $(25 \mathrm{ppm})$, virginiamicina $(34 \mathrm{ppm})$ e monensina + virginiamicina no decorrer do experimento - São Paulo - 2018.

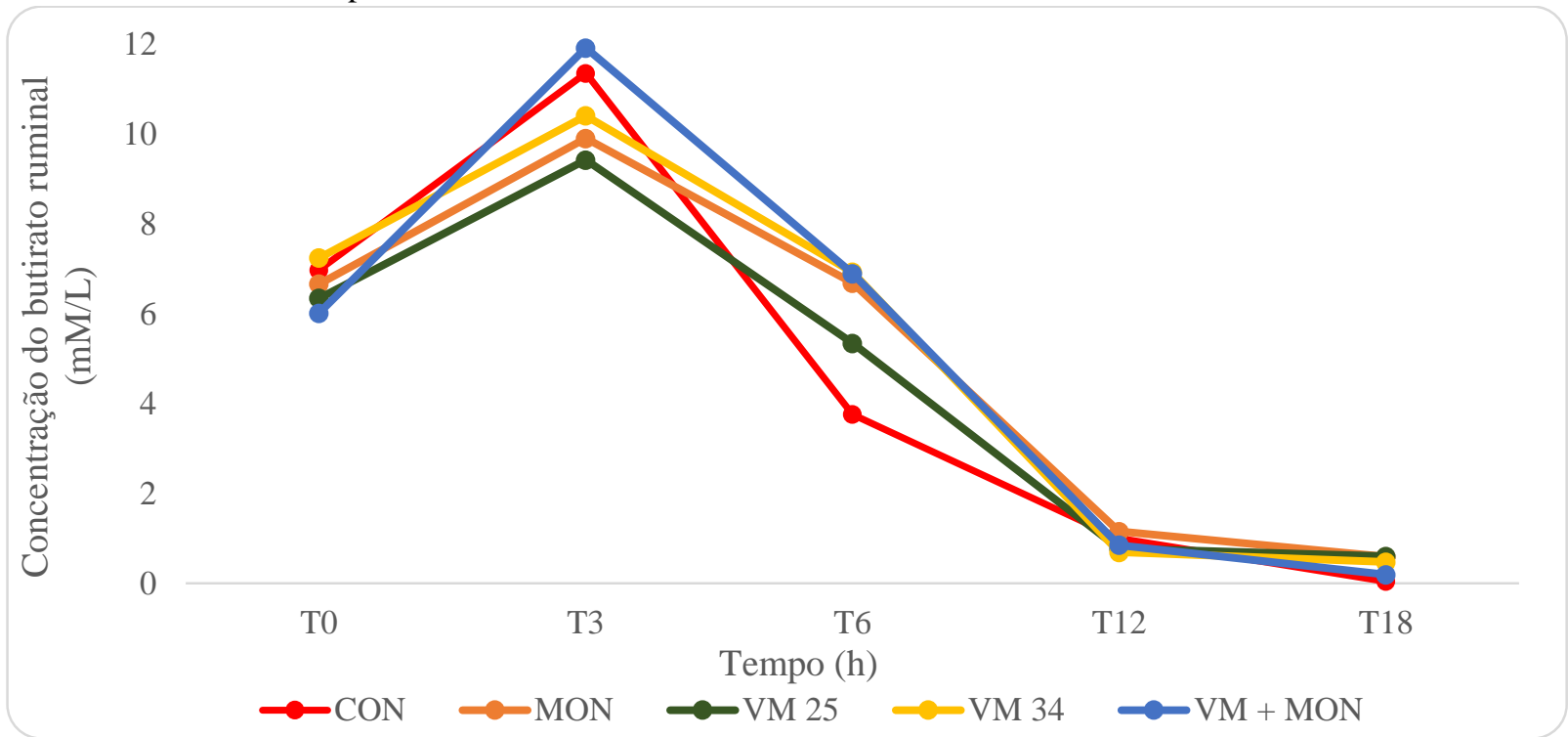

Fonte: (OLIVEIRA, F.L.C, 2018)

\subsubsection{Concentração total de AGCC ruminal}

Na tabela 10 estão apresentados os resultados médios e desvios padrão do total de AGCC do conteúdo ruminal no decorrer do experimento, e no gráfico 10 está ilustrado o comportamento desta variável. 
Tabela 10 - Valores médios e desvios padrão da concentração total de AGCC ruminal (mM/L) nos bovinos dos grupos controle, monensina, virginiamicina (25 ppm), virginiamicina (34 ppm) e monensina + virginiamicina no decorrer do experimento - São Paulo - 2018.

\begin{tabular}{cccccc}
\hline & T0 & T3 & T6 & T12 & T18 \\
\hline CON & $77,95 \pm 9,46^{\mathrm{b}}$ & $135,24 \pm 39,98^{\mathrm{a}}$ & $66,65 \pm 14,93^{\mathrm{Bb}}$ & $47,91 \pm 7,39^{\mathrm{bc}}$ & $26,68 \pm 5,30^{\mathrm{c}}$ \\
MON & $81,39 \pm 11,99^{\mathrm{ab}}$ & $119,59 \pm 34,34^{\mathrm{a}}$ & $77,73 \pm 20,03^{\mathrm{Bab}}$ & $63,46 \pm 36,14^{\mathrm{b}}$ & $40,50 \pm 24,95^{\mathrm{b}}$ \\
VM 25 & $67,36 \pm 15,76^{\mathrm{bc}}$ & $114,28 \pm 21,07^{\mathrm{a}}$ & $80,94 \pm 15,38^{\mathrm{Bb}}$ & $47,52 \pm 16,52^{\mathrm{c}}$ & $45,24 \pm 14,40^{\mathrm{c}}$ \\
VM 34 & $79,86 \pm 14,58^{\mathrm{b}}$ & $134,44 \pm 27,20^{\mathrm{a}}$ & $79,41 \pm 14,07^{\mathrm{Bb}}$ & $53,34 \pm 15,50^{\mathrm{bc}}$ & $40,34 \pm 10,47^{\mathrm{c}}$ \\
VM + MON & $72,22 \pm 14,19^{\mathrm{b}}$ & $141,81 \pm 26,74^{\mathrm{a}}$ & $113,37 \pm 18,61^{\mathrm{Aa}}$ & $62,05 \pm 17,74^{\mathrm{b}}$ & $45,35 \pm 19,16^{\mathrm{b}}$ \\
\hline
\end{tabular}

Fonte: (OLIVEIRA, F.L.C, 2018)

Efeito de tratamento = 0,3873; Efeito de tempo <.0001; Interação entre trat*tempo <0,0016;

Notas: Letras maiúsculas distintas nas colunas significam diferença estatística entre os grupos.

Letras minúsculas distintas nas linhas significam diferença dentro de cada grupo.

Não existiu diferença na concentração total de AGCC no tempo basal, $3^{\mathrm{a}}, 12^{\mathrm{a}}$ e $18^{\mathrm{a}} \mathrm{h}$ entre os grupos, havendo uma maior concentração na $6^{\mathrm{a}} \mathrm{h}$ no grupo $\mathrm{VM}+\mathrm{MON}$ em relação aos demais. Nos tratamentos CON, VM 25 e VM 34 verificou-se um maior valor na $3^{\text {a }}$, persistindo uma diminuição progressiva nos demais tempos. No grupo MON constatou-se uma maior produção de ácidos na $3^{\mathrm{a}} \mathrm{h}$ em comparação a $12^{\mathrm{a}}$ e $18^{\mathrm{a}}$ e no grupo $\mathrm{VM}+\mathrm{MON}$ este fenômeno ocorreu entre a $3^{\mathrm{a}}$ e $6^{\mathrm{a}} \mathrm{h}$ em relação as demais. Houve uma nítida relação significativa entre o tratamento e o tempo de coleta $(\mathrm{p}<0,0016)$. 
Gráfico 10 - Valores médios da concentração total de AGCC ruminal (mM/L) nos bovinos dos grupos controle, monensina, virginiamicina $(25 \mathrm{ppm})$, virginiamicina $(34 \mathrm{ppm})$ e monensina + virginiamicina no decorrer do experimento - São Paulo - 2018.

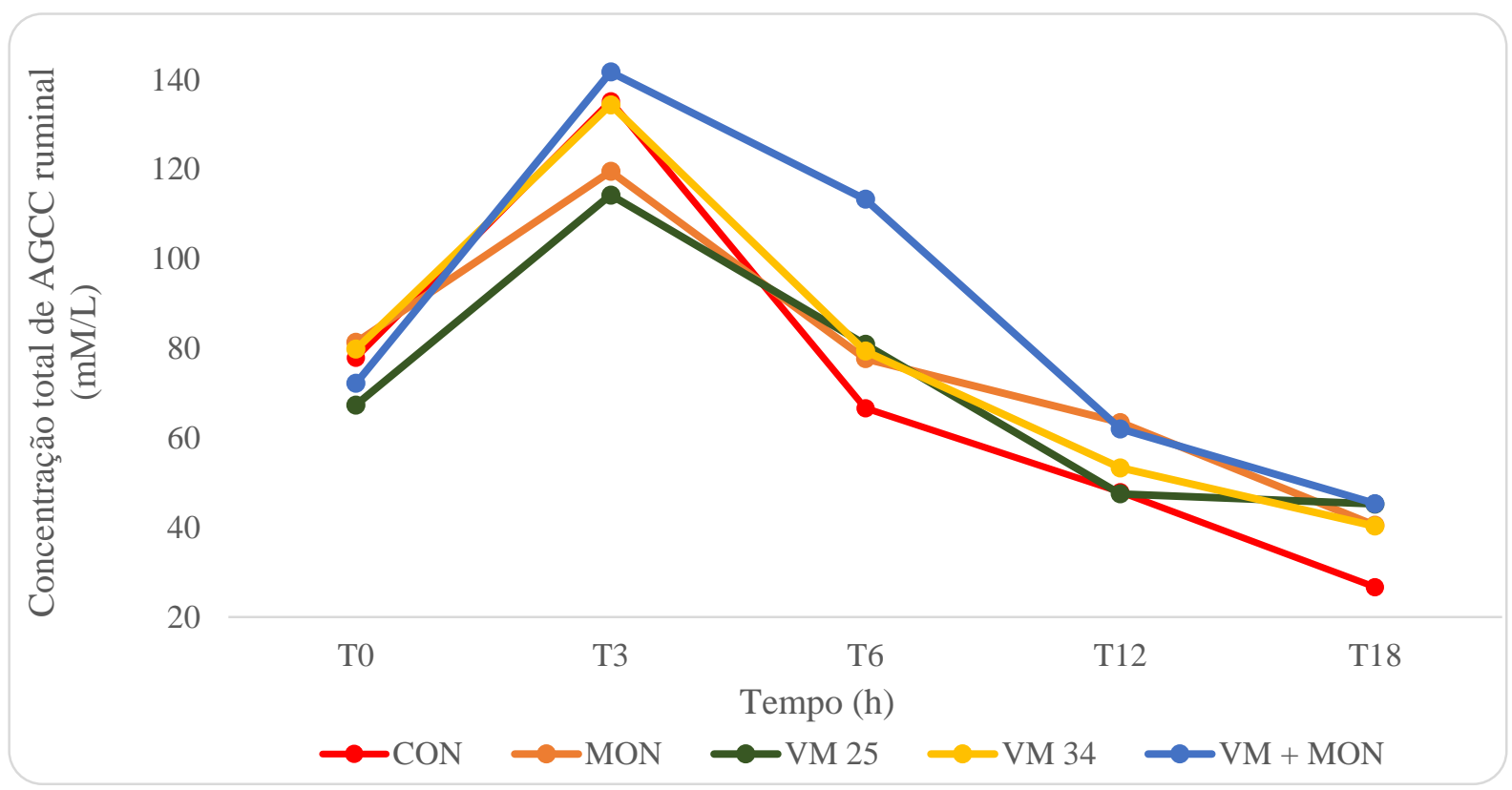

Fonte: (OLIVEIRA, F.L.C, 2018)

\subsubsection{Relação acetato/propionato ruminal}

Na tabela 11 estão apresentados os resultados médios e desvios padrão da relação acetato/propionato ruminal no decorrer do experimento, e no gráfico 11 está ilustrado o comportamento desta variável.

Tabela 11 - Valores médios e desvios padrão da relação acetato/propionato ruminal nos bovinos dos grupos controle, monensina, virginiamicina (25 ppm), virginiamicina (34 ppm) e monensina + virginiamicina no decorrer do experimento - São Paulo - 2018.

\begin{tabular}{|c|c|c|c|c|c|}
\hline & T0 & $\mathrm{T} 3$ & T6 & $\mathrm{T} 12$ & T18 \\
\hline $\mathrm{CON}$ & $3,96 \pm 0,35^{\mathrm{Bc}}$ & $7,63 \pm 1,06^{\mathrm{Ab}}$ & $11,06 \pm 3,22^{\mathrm{Aa}}$ & $2,57 \pm 0,33^{c}$ & $2,13 \pm 0,25^{\mathrm{c}}$ \\
\hline MON & $3,61 \pm 0,50^{\mathrm{B}}$ & $4,43 \pm 1,14^{\mathrm{B}}$ & $5,46 \pm 1,33^{\mathrm{BC}}$ & $4,28 \pm 2,06$ & $4,12 \pm 2,03$ \\
\hline VM 25 & $5,10 \pm 0,30^{\mathrm{A}}$ & $6,51 \pm 2,64^{\mathrm{AB}}$ & $8,90 \pm 2,85^{\mathrm{AB}}$ & $2,51 \pm 0,62$ & $2,33 \pm 0,52$ \\
\hline VM 34 & $5,05 \pm 0,38^{\mathrm{Aab}}$ & $7,11 \pm 1,84^{\mathrm{ABa}}$ & $5,46 \pm 2,06^{\mathrm{BCa}}$ & $2,56 \pm 0,87^{\mathrm{c}}$ & $2,75 \pm 0,82^{\mathrm{bc}}$ \\
\hline $\mathrm{VM}+\mathrm{MON}$ & $3,61 \pm 0,61^{\mathrm{Babc}}$ & $5,11 \pm 1,54^{\mathrm{ABa}}$ & $4,75 \pm 1,98^{\mathrm{Cab}}$ & $2,63 \pm 0,78^{b c}$ & $2,41 \pm 0,79^{c}$ \\
\hline
\end{tabular}

Fonte: (OLIVEIRA, F.L.C, 2018)

Efeito de tratamento = 0,0099; Efeito de tempo <.0001; Interação entre trat*tempo <0,0003;

Notas: Letras maiúsculas distintas nas colunas significam diferença estatística entre os grupos.

Letras minúsculas distintas nas linhas significam diferença dentro de cada grupo. 
Não houve diferença na relação acetato/propionato na $12^{\mathrm{a}}$ e $18^{\mathrm{a}} \mathrm{h}$ entre os grupos, no tempo basal os grupos VM 25 e 34 possuem uma maior relação aos demais. Na $3^{\mathrm{a}} \mathrm{h}$ o CON têm uma maior relação que o tratamento MON e na $6^{\mathrm{a}} \mathrm{h}$ os grupos $\mathrm{MON}$, VM 34 e VM + MON têm uma menor relação que o CON. Na análise de cada grupo, no CON uma maior relação acetato/propionato é observado na $6^{\mathrm{a}}$ em relação as demais, no tratamento VM 34 na $3^{\mathrm{a}}$ e $6^{\mathrm{a}} \mathrm{h}$ foi onde se ressaltou está maior correlação; no grupo VM + MON foi notado esse aumento na $3^{\mathrm{a}}$ h. Não ocorreu diferença dentro do grupo MON e VM 25. Existiu uma nítida relação significativa entre o tratamento e o tempo de coleta $(\mathrm{p}<0,0003)$.

Gráfico 11 - Valores médios da relação acetato/propionato ruminal nos bovinos dos grupos controle, monensina, virginiamicina $(25 \mathrm{ppm})$, virginiamicina $(34 \mathrm{ppm})$ e monensina + virginiamicina no decorrer do experimento - São Paulo - 2018.

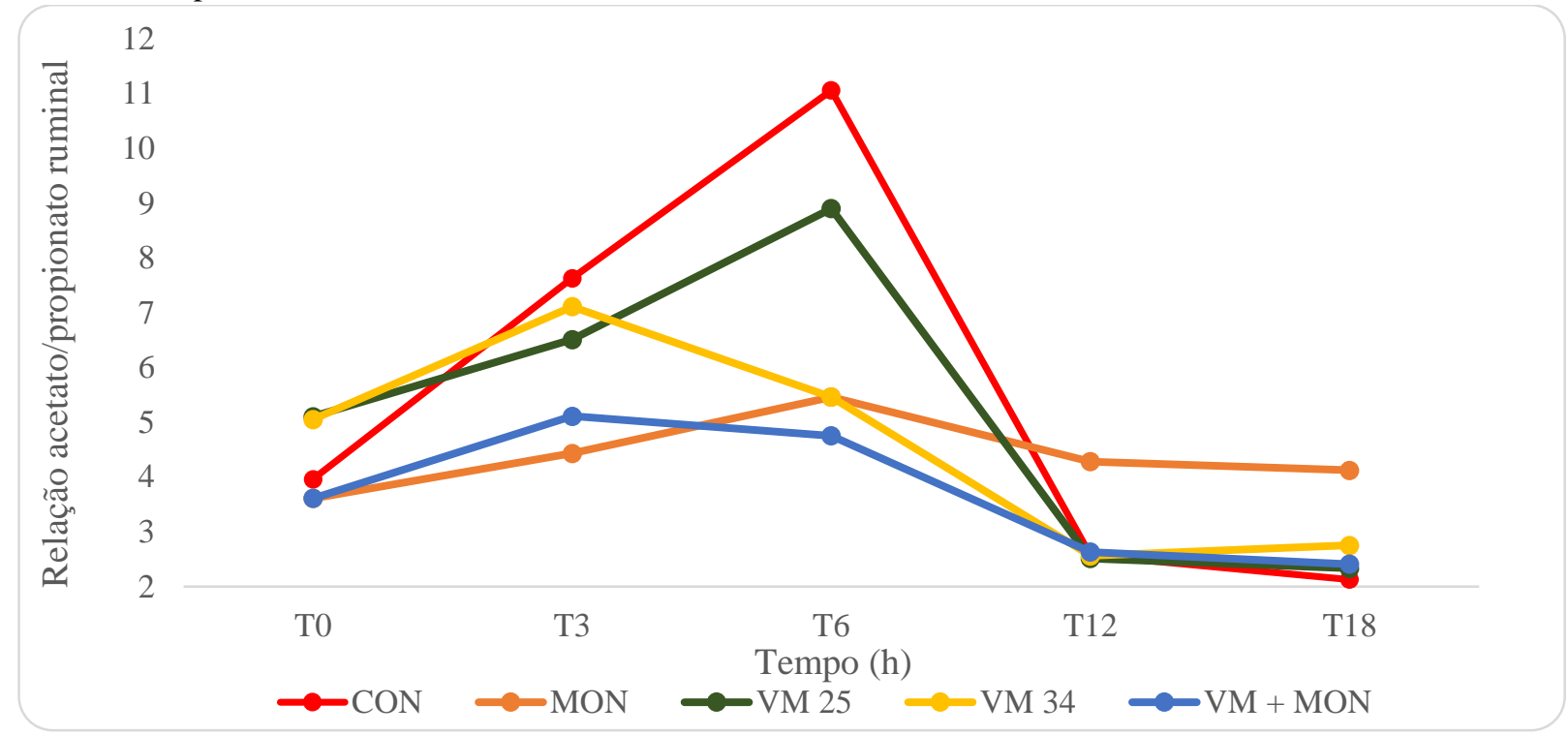

Fonte: (OLIVEIRA, F.L.C, 2018)

\subsubsection{Total de ácidos orgânicos do conteúdo ruminal}

Na tabela 12 estão apresentados os resultados médios e desvios padrão do total de ácidos orgânicos do conteúdo ruminal $(\mathrm{mM} / \mathrm{L})$ no decorrer do experimento, e no gráfico 12 está ilustrado o comportamento desta variável. 
Tabela 12 - Valores médios e desvios padrão do total de ácidos orgânicos do conteúdo ruminal (mM/L) nos bovinos dos grupos controle, monensina, virginiamicina (25 ppm), virginiamicina (34 ppm) e monensina + virginiamicina no decorrer do experimento - São Paulo - 2018.

\begin{tabular}{|c|c|c|c|c|c|}
\hline & T0 & $\mathrm{T} 3$ & T6 & $\mathrm{T} 12$ & T18 \\
\hline $\mathrm{CON}$ & $78,0 \pm 9,5^{\mathrm{d}}$ & $157,0 \pm 40,0^{\mathrm{a}}$ & $122,8 \pm 17,5^{\mathrm{bc}}$ & $115,8 \pm 10,4^{\mathrm{bc}}$ & $97,9 \pm 6,4^{\mathrm{cd}}$ \\
\hline MON & $81,5 \pm 12,0^{b}$ & $131,9 \pm 30,8^{a}$ & $133,3 \pm 24,5^{\mathrm{a}}$ & $125,6 \pm 29,3^{\mathrm{a}}$ & $104,4 \pm 29,8^{\mathrm{ab}}$ \\
\hline VM 25 & $67,5 \pm 15,8^{b}$ & $133,2 \pm 25,0^{\mathrm{a}}$ & $135,0 \pm 23,2^{\mathrm{a}}$ & $104,3 \pm 19,0^{\mathrm{a}}$ & $106,2 \pm 13,9^{a}$ \\
\hline VM 34 & $80,0 \pm 14,6^{\mathrm{d}}$ & $150,1 \pm 24,0^{\mathrm{ab}}$ & $134,3 \pm 26,1^{b c}$ & $110,0 \pm 25,2^{\mathrm{cd}}$ & $99,5 \pm 13,1^{\mathrm{cd}}$ \\
\hline $\mathrm{VM}+\mathrm{MON}$ & $72,3 \pm 14,2^{\mathrm{d}}$ & $145,3 \pm 28,8^{\mathrm{ab}}$ & $135,7 \pm 17,7^{\mathrm{bc}}$ & $117,0 \pm 16,4^{\mathrm{bc}}$ & $106,4 \pm 19,8^{\mathrm{cd}}$ \\
\hline
\end{tabular}

Fonte: (OLIVEIRA, F.L.C, 2018)

Efeito de tratamento = 0,363; Efeito de tempo <.0001

Notas: Letras maiúsculas distintas nas colunas significam diferença estatística entre os grupos.

Letras minúsculas distintas nas linhas significam diferença dentro de cada grupo.

Não houve diferenças entre os grupos quanto o total de ácidos do conteúdo ruminal. Analisando cada grupo, percebe-se que no CON têm uma maior concentração na $3^{\mathrm{a}} \mathrm{h}$ em relação as demais; no MON e VM + MON maiores valores são observados na $3^{\mathrm{a}}, 6^{\mathrm{a}}$ e $12^{\mathrm{a}} \mathrm{h}$ comparandose ao tempo basal; no VM 25 todos os tempos são maiores que o T0 e no tratamento VM 34 essa superioridade foi observada na $3^{\mathrm{a}}$ e $6^{\mathrm{a}}$ quando comparado ao tempo basal.

Gráfico 12 - Valores médios do total de ácidos orgânicos do conteúdo ruminal (mM/L) nos bovinos dos grupos controle, monensina, virginiamicina (25 ppm), virginiamicina (34 ppm) e monensina + virginiamicina no decorrer do experimento - São Paulo - 2018.

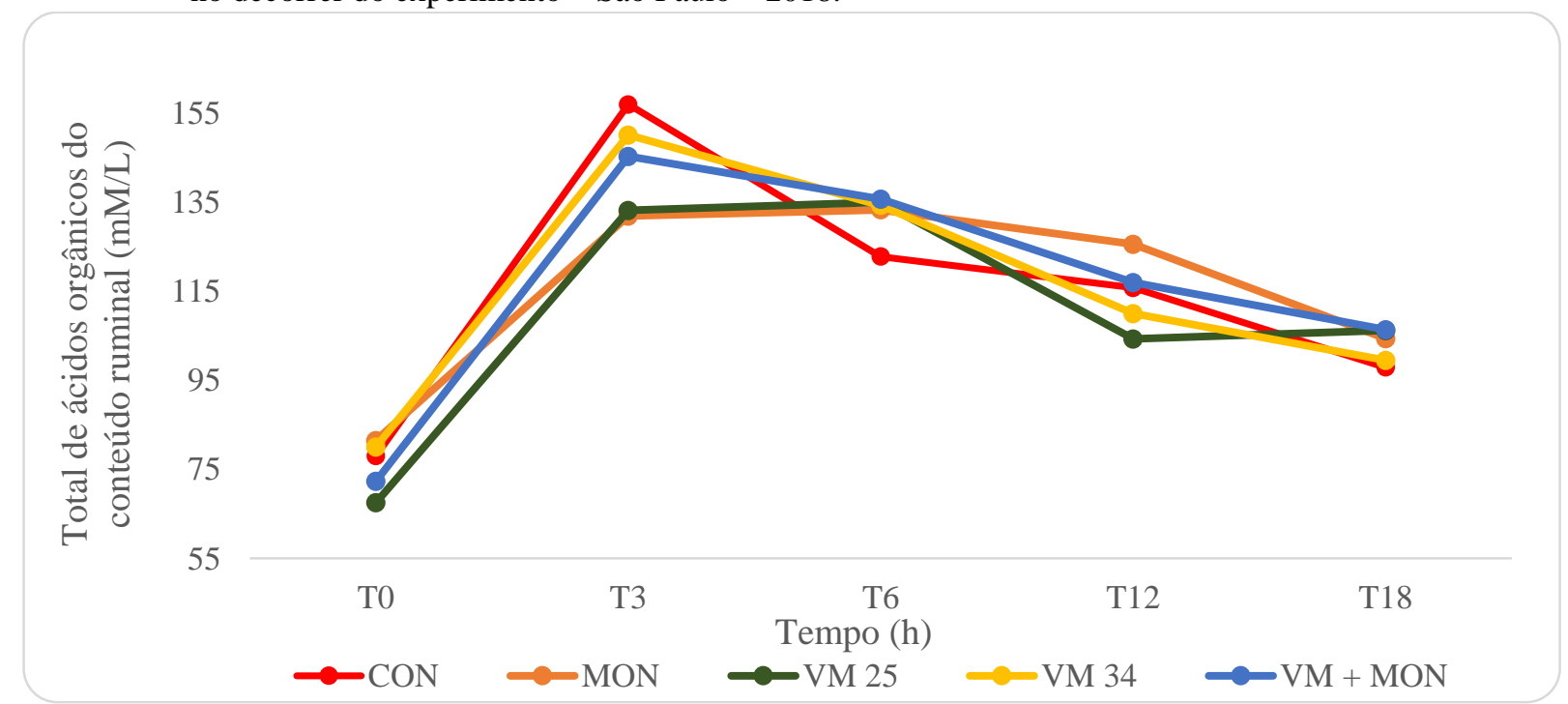

Fonte: (OLIVEIRA, F.L.C, 2018) 


\subsubsection{Osmolaridade do conteúdo ruminal}

Na tabela 13 estão apresentados os resultados médios e desvios padrão da osmolaridade ruminal no decorrer do experimento, e no gráfico 13 está ilustrado o comportamento desta variável.

Tabela 13 - Valores médios e desvios padrão da osmolaridade ruminal (mOsm/L) nos bovinos dos grupos controle, monensina, virginiamicina (25 ppm), virginiamicina (34 ppm) e monensina + virginiamicina e monensina + virginiamicina no decorrer do experimento - São Paulo - 2018.

\begin{tabular}{cccccc}
\hline & T0 & T3 & T6 & T12 & T18 \\
\hline CON & $281,20 \pm 9,74^{\mathrm{b}}$ & $390,16 \pm 78,99^{\mathrm{a}}$ & $326,50 \pm 29,50^{\mathrm{ab}}$ & $299,33 \pm 26,75^{\mathrm{Bb}}$ & $303,83 \pm 17,75^{\mathrm{b}}$ \\
MON & $271,66 \pm 4,08^{\mathrm{c}}$ & $397,83 \pm 87,68^{\mathrm{a}}$ & $377,33 \pm 43,06^{\mathrm{ab}}$ & $340,33 \pm 24,72^{\text {Aabc }}$ & $301,33 \pm 40,73^{\mathrm{bc}}$ \\
VM 25 & $285,33 \pm 10,96$ & $325,33 \pm 53,64$ & $317,33 \pm 59,41$ & $297,00 \pm 21,08^{\mathrm{B}}$ & $297,16 \pm 26,92$ \\
VM 34 & $283,16 \pm 23,77^{\mathrm{b}}$ & $383,33 \pm 58,10^{\mathrm{a}}$ & $346,50 \pm 69,34^{\mathrm{ab}}$ & $308,50 \pm 20,91^{\mathrm{Bab}}$ & $299,66 \pm 25,09^{\mathrm{b}}$ \\
VM + MON & $295,20 \pm 4,91$ & $372,16 \pm 71,33$ & $339,83 \pm 60,15$ & $305,66 \pm 26,44^{\mathrm{B}}$ & $295,66 \pm 18,58$ \\
\hline
\end{tabular}

Fonte: (OLIVEIRA, F.L.C, 2018)

Efeito de tratamento = 0,0759; Efeito de tempo <.0001; Interação entre trat*tempo $=0,0730$

Notas: Letras maiúsculas distintas nas colunas significam diferença estatística entre os grupos. Letras minúsculas distintas nas linhas significam diferença dentro de cada grupo.

Não houve diferença na osmolaridade do conteúdo ruminal no tempo basal, na $3^{\mathrm{a}}, 6^{\mathrm{a}} \mathrm{e}$ $18^{\mathrm{a}} \mathrm{h}$ entre os grupos; na $12^{\mathrm{a}} \mathrm{h}$ no grupo MON observou-se uma maior osmolaridade em relação aos demais. Feito uma análise dentro de cada grupo, observou-se que no CON, MON e VM 34 um maior valor de osmolaridade se deu na $3^{\mathrm{a}} \mathrm{h}$ não ocorreu diferença dentro do grupo VM 25 e VM + MON. Não houve relação significativa entre o tratamento e o tempo de coleta $(\mathrm{p}<$ 0,0730). 
Gráfico 13 - Valores médios da osmolaridade ruminal (mOsm/L) nos bovinos dos grupos controle, monensina, virginiamicina $(25 \mathrm{ppm})$, virginiamicina $(34 \mathrm{ppm})$ e monensina + virginiamicina no decorrer do experimento - São Paulo - 2018.

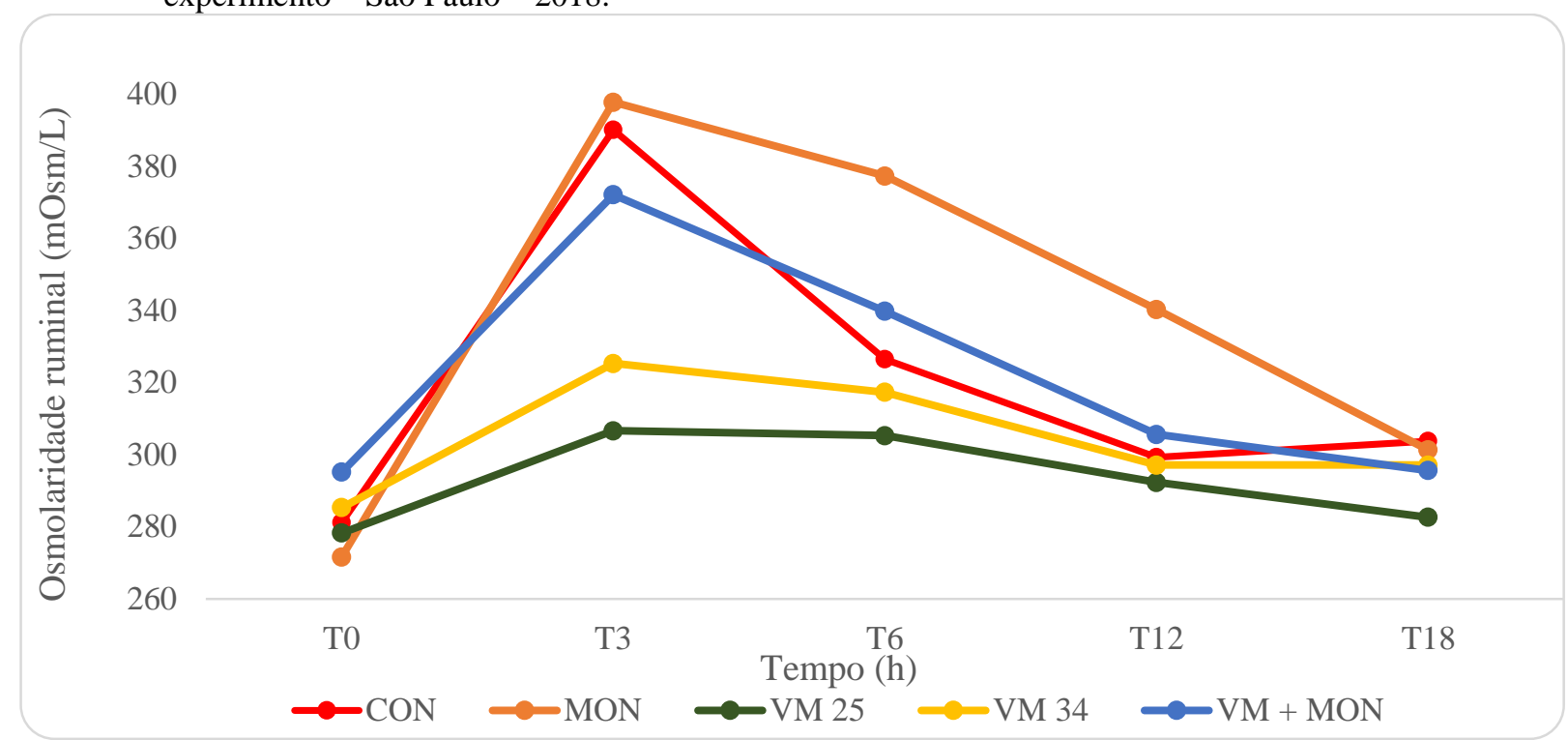

Fonte: (OLIVEIRA, F.L.C, 2018)

\subsubsection{Potencial de óxidorredução (POR) do conteúdo ruminal}

Na tabela 14 estão apresentados os resultados médios e desvios padrão do potencial de oxido-redução do conteúdo ruminal no decorrer do experimento, e no gráfico 14 está ilustrado o comportamento desta variável.

Tabela 14 - Valores médios e desvios padrão do potencial de oxidorredução $(\mathrm{mV})$ nos bovinos dos grupos controle, monensina, virginiamicina $(25 \mathrm{ppm})$, virginiamicina $(34 \mathrm{ppm})$ e monensina + virginiamicina no decorrer do experimento - São Paulo - 2018.

\begin{tabular}{cccccc}
\hline & T0 & T3 & T6 & T12 & T18 \\
\hline CON & $-3,36 \pm 3,76^{\mathrm{d}}$ & $101,48 \pm 4,15^{\mathrm{Ac}}$ & $142,18 \pm 6,59^{\mathrm{Ab}}$ & $163,23 \pm 7,25^{\mathrm{Aa}}$ & $174,05 \pm 14,17^{\mathrm{a}}$ \\
MON & $0,86 \pm 7,87^{\mathrm{d}}$ & $92,40 \pm 8,51^{\mathrm{ABc}}$ & $135,88 \pm 5,45^{\mathrm{ABb}}$ & $161,92 \pm 6,57^{\mathrm{ABa}}$ & $162,55 \pm 12,66^{\mathrm{a}}$ \\
VM 25 & $-4,56 \pm 4,89^{\mathrm{d}}$ & $90,83 \pm 10,46^{\mathrm{ABc}}$ & $137,83 \pm 5,71^{\mathrm{ABb}}$ & $154,00 \pm 7,62^{\mathrm{ABCa}}$ & $161,40 \pm 8,83^{\mathrm{a}}$ \\
VM 34 & $-2,26 \pm 7,66^{\mathrm{d}}$ & $87,50 \pm 8,05^{\mathrm{ABc}}$ & $128,03 \pm 9,81^{\mathrm{Bb}}$ & $148,65 \pm 8,93^{\mathrm{BCa}}$ & $161,18 \pm 13,10^{\mathrm{a}}$ \\
VM + & $-3,78 \pm 6,16^{\mathrm{d}}$ & $82,03 \pm 12,97^{\mathrm{Bc}}$ & $125,76 \pm 9,63^{\mathrm{Bc}}$ & $143,96 \pm 10,19^{\mathrm{Cab}}$ & $153,03 \pm 10,04^{\mathrm{a}}$ \\
MON & & & & &
\end{tabular}

Fonte: (OLIVEIRA, F.L.C, 2018)

Efeito de tratamento $=0,0279 ;$ Efeito de tempo <.0001; Interação entre trat*tempo $=0,0158$;

Notas: Letras maiúsculas distintas nas colunas significam diferença estatística entre os grupos.

Letras minúsculas distintas nas linhas significam diferença dentro de cada grupo. 
Entre os grupos não existiu diferença no potencial de oxidorredução do conteúdo ruminal no tempo basal e $18^{\mathrm{a}} \mathrm{h}$; na $3^{\mathrm{a}} \mathrm{h}$ o tratamento $\mathrm{VM}+\mathrm{MON}$ apresenta um menor valor em relação ao CON; na $6^{\mathrm{a}}$ e $12^{\mathrm{a}} \mathrm{h}$ houve uma diminuição do POR nos grupos VM 34 e VM + MON em relação ao CON. Em todos os grupos, percebe-se que maiores valores são observados na $12^{\mathrm{a}}$ e $18^{\mathrm{a}} \mathrm{h}$ em comparação as demais. Existiu uma nítida relação significativa entre o tratamento e o tempo de coleta $(\mathrm{p}<0,0158)$.

Gráfico 14 - Valores médios do potencial de oxidorredução nos bovinos dos grupos controle, monensina, virginiamicina $(25 \mathrm{ppm})$, virginiamicina $(34 \mathrm{ppm})$ e monensina + virginiamicina no decorrer do experimento - São Paulo - 2018.

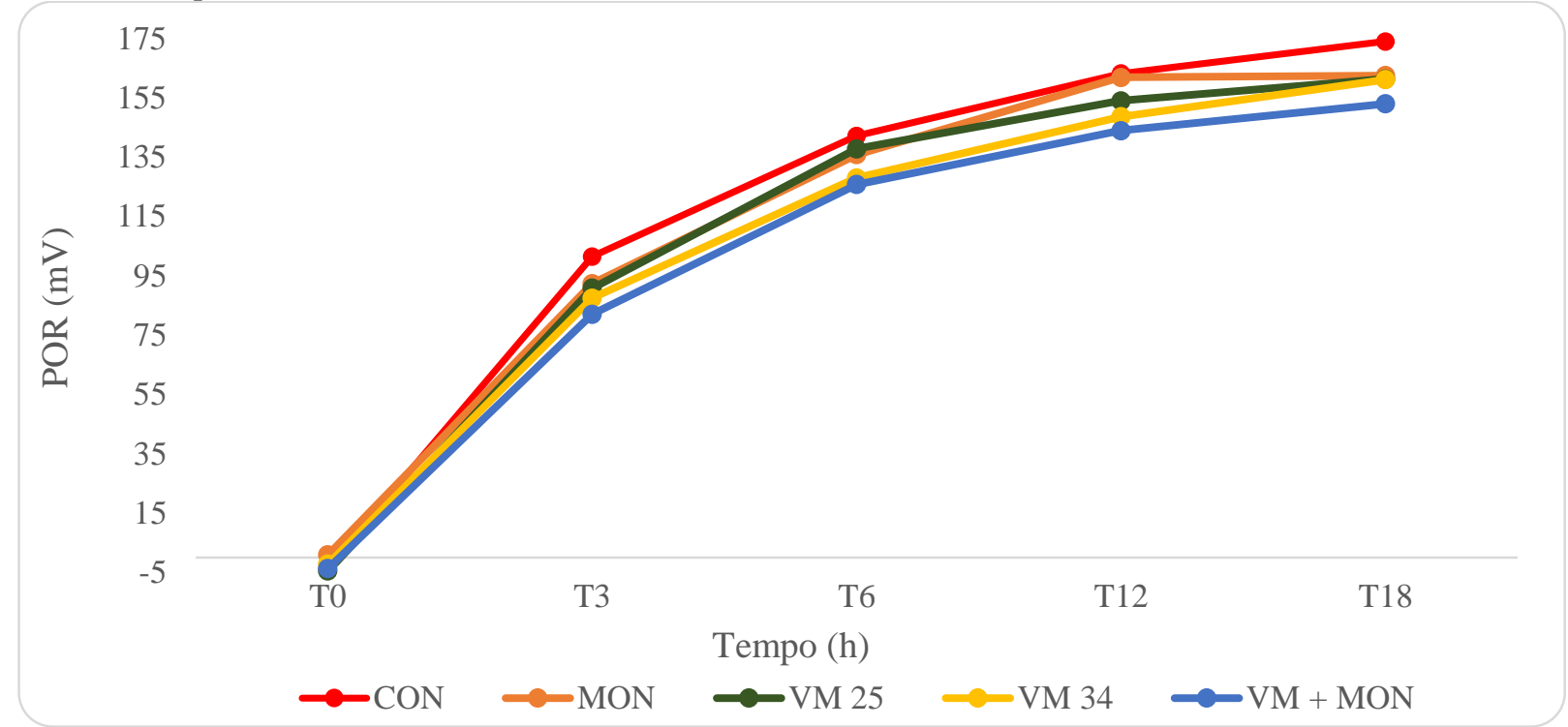

Fonte: (OLIVEIRA, F.L.C, 2018)

\subsubsection{Acidez titulável ruminal}

Na tabela 15 estão apresentados os resultados médios e desvios padrão da acidez titulável ruminal no decorrer do experimento, e no gráfico 15 está ilustrado o comportamento desta variável. 
Tabela 15 - Valores médios e desvios padrão da acidez titulável ruminal (UC) nos bovinos dos grupos controle, monensina, virginiamicina $(25 \mathrm{ppm})$, virginiamicina $(34 \mathrm{ppm})$ e monensina + virginiamicina no decorrer do experimento - São Paulo - 2018.

\begin{tabular}{cccccc}
\hline & T0 & T3 & T6 & T12 & T18 \\
\hline CON & $24,78 \pm 1,31^{\mathrm{d}}$ & $39,15 \pm 2,58^{\mathrm{c}}$ & $49,36 \pm 3,16^{\mathrm{c}}$ & $74,35 \pm 2,82^{\mathrm{Aab}}$ & $80,76 \pm 3,69^{\mathrm{Aa}}$ \\
MON & $23,63 \pm 1,83^{\mathrm{c}}$ & $42,46 \pm 2,08^{\mathrm{b}}$ & $61,15 \pm 6,76^{\mathrm{a}}$ & $71,61 \pm 2,55^{\mathrm{Aa}}$ & $77,11 \pm 3,80^{\mathrm{ABa}}$ \\
VM 25 & $23,98 \pm 0,62^{\mathrm{d}}$ & $34,98 \pm 2,19^{\mathrm{c}}$ & $49,50 \pm 1,50^{\mathrm{b}}$ & $56,75 \pm 1,93^{\mathrm{Bb}}$ & $70,28 \pm 3,02^{\mathrm{ABa}}$ \\
VM 34 & $23,78 \pm 0,81^{\mathrm{d}}$ & $37,26 \pm 1,46^{\mathrm{c}}$ & $49,36 \pm 1,89^{\mathrm{b}}$ & $56,11 \pm 1,20^{\mathrm{Bab}}$ & $64,76 \pm 2,75^{\mathrm{Ba}}$ \\
VM + MON & $23,53 \pm 1,02^{\mathrm{b}}$ & $36,53 \pm 2,45^{\mathrm{b}}$ & $56,15 \pm 2,30^{\mathrm{a}}$ & $59,26 \pm 2,76^{\mathrm{Ba}}$ & $65,18 \pm 2,54^{\mathrm{Ba}}$ \\
\hline
\end{tabular}

Fonte: (OLIVEIRA, F.L.C, 2018)

Efeito de tratamento $=0,0015 ;$ Efeito de tempo <.0001; Interação entre trat*tempo $<0,0001$;

Notas: Letras maiúsculas distintas nas colunas significam diferença estatística entre os grupos.

Letras minúsculas distintas nas linhas significam diferença dentro de cada grupo.

Não teve diferença na acidez titulável do conteúdo ruminal no tempo basal, $3^{\mathrm{a}}$ e $6^{\mathrm{a}} \mathrm{h}$ entre os grupos; na $12^{\mathrm{a}} \mathrm{h}$ o CON e MON apresentaram maiores valores em relação aos demais; observou-se que na $18^{\mathrm{a}} \mathrm{h}$ os grupos VM 34 e VM + MON exibiram menores valores se comparado ao CON. Percebe-se ao analisar todos os grupos, que está havendo um aumento progressivo no decorrer dos tempos. Existiu uma nítida relação significativa entre o tratamento e o tempo de coleta $(\mathrm{p}<0,0001)$.

Gráfico 15 - Valores médios da acidez titulável nos bovinos dos grupos controle, monensina, virginiamicina (25 ppm), virginiamicina (34 ppm) e monensina + virginiamicina no decorrer do experimento - São Paulo -2018 .

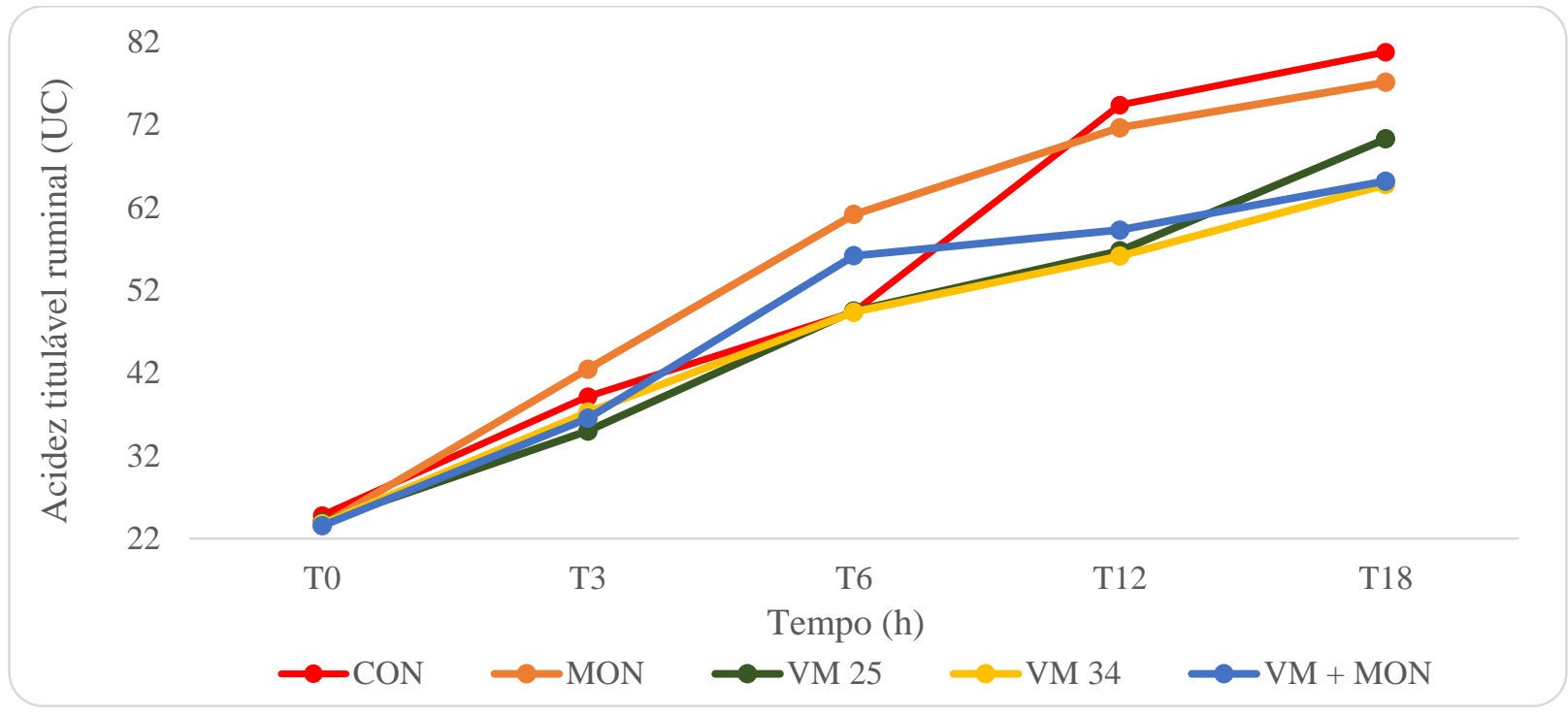

Fonte: (OLIVEIRA, F.L.C, 2018) 


\subsection{VARIÁVEIS SANGUÍNEAS}

\subsection{1 pH sanguíneo}

Na tabela 16 estão apresentados os resultados médios e desvios padrão do pH sanguíneo no decorrer do experimento, e no gráfico 16 está ilustrado o comportamento desta variável.

Tabela 16 - Valores médios e desvios padrão do pH sanguíneo nos bovinos dos grupos controle, monensina, virginiamicina $(25 \mathrm{ppm})$, virginiamicina $(34 \mathrm{ppm})$ e monensina + virginiamicina no decorrer do experimento - São Paulo - 2018.

\begin{tabular}{cccccc}
\hline & T0 & T3 & T6 & T12 & T18 \\
\hline CON & $7,43 \pm 0,05^{\mathrm{a}}$ & $7,42 \pm 0,04^{\mathrm{a}}$ & $7,40 \pm 0,05^{\mathrm{ab}}$ & $7,30 \pm 0,06^{\mathrm{b}}$ & $7,30 \pm 0,08^{\mathrm{b}}$ \\
MON & $7,43 \pm 0,01^{\mathrm{a}}$ & $7,44 \pm 0,02^{\mathrm{a}}$ & $7,43 \pm 0,03^{\mathrm{a}}$ & $7,34 \pm 0,08^{\mathrm{b}}$ & $7,31 \pm 0,04^{\mathrm{b}}$ \\
VM 25 & $7,37 \pm 0,08^{\mathrm{ab}}$ & $7,43 \pm 0,02^{\mathrm{a}}$ & $7,43 \pm 0,04^{\mathrm{a}}$ & $7,31 \pm 0,06^{\mathrm{b}}$ & $7,28 \pm 0,07^{\mathrm{b}}$ \\
VM 34 & $7,43 \pm 0,05^{\mathrm{a}}$ & $7,44 \pm 0,03^{\mathrm{a}}$ & $7,43 \pm 0,03^{\mathrm{a}}$ & $7,31 \pm 0,05^{\mathrm{b}}$ & $7,33 \pm 0,05^{\mathrm{b}}$ \\
VM + MON & $7,42 \pm 0,04$ & $7,43 \pm 0,04$ & $7,43 \pm 0,07$ & $7,37 \pm 0,09$ & $7,36 \pm 0,06$ \\
\hline
\end{tabular}

Fonte: (OLIVEIRA, F.L.C, 2018)

Efeito de tratamento $=0,3756$; Efeito de tempo <.0001; Interação entre trat*tempo $=0,4107$

Notas: Letras maiúsculas distintas nas colunas significam diferença estatística entre os grupos.

Letras minúsculas distintas nas linhas significam diferença dentro de cada grupo.

Não houve diferença desta variável entre os grupos estudados, em cada um dos momentos avaliados. Observando-se cada grupo, percebe-se que no grupo $\mathrm{C}$ a partir da $6^{\mathrm{a}} \mathrm{h}$ houve uma diminuição do pH sanguíneo; já no tratamento MON e VM 34 este decréscimo se dá a partir da $12^{\mathrm{a}} \mathrm{h}$; no grupo VM 25 maiores valores são observados na $3^{\mathrm{a}}$ e $6^{\mathrm{a}} \mathrm{h}$ em relação a $12^{\mathrm{a}}$ e $18^{\mathrm{a}}$ h e no VM + MON não teve diferença dentro do grupo. Não houve relação significativa entre o tratamento e o tempo de coleta $(\mathrm{p}<0,4107)$. 
Gráfico 16 - Valores médios do pH sanguíneo nos bovinos dos grupos controle, monensina, virginiamicina (25 ppm), virginiamicina (34 ppm) e monensina + virginiamicina no decorrer do experimento - São Paulo -2018 .

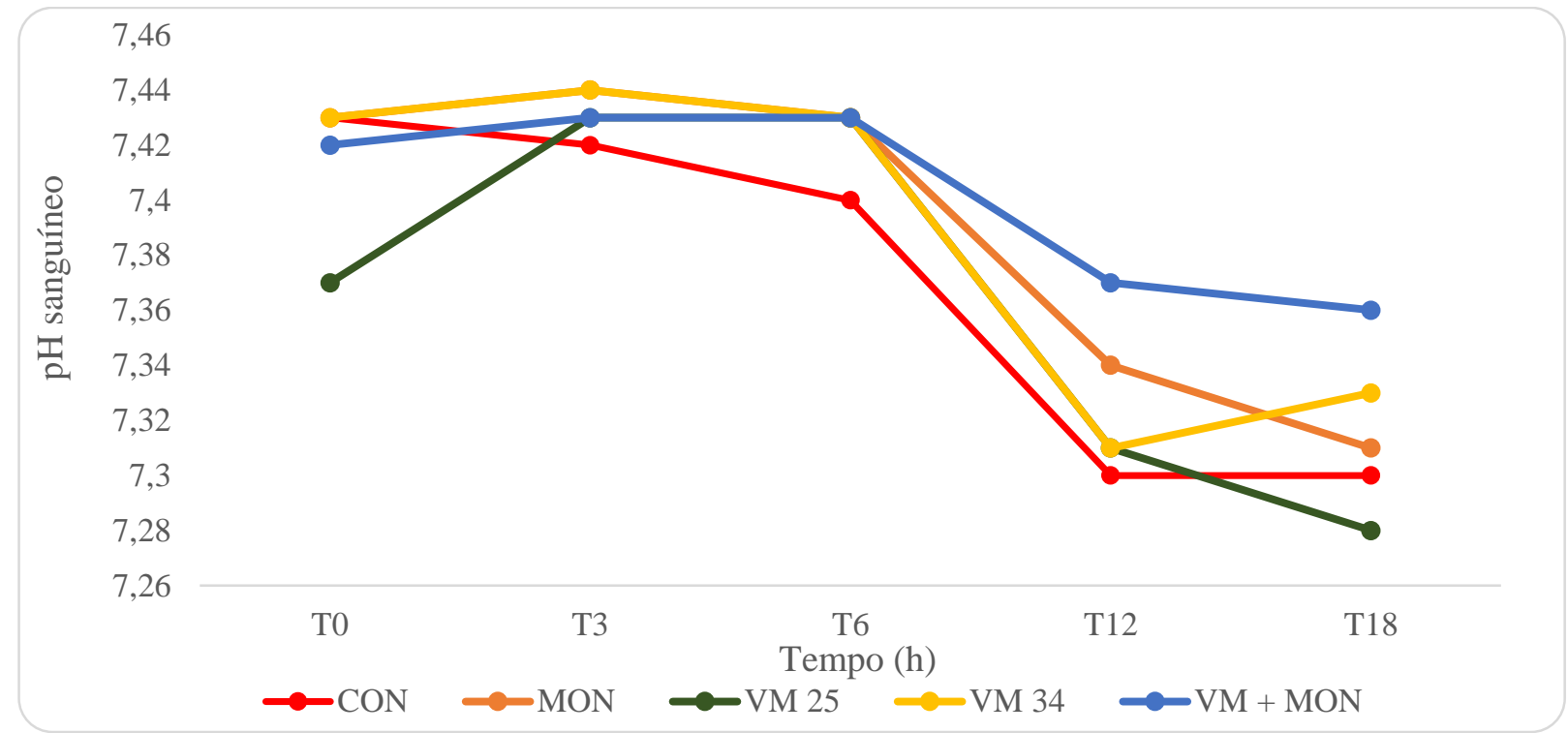

Fonte: (OLIVEIRA, F.L.C, 2018)

\subsubsection{Concentração de excesso de ácido-base (EAB)}

Na tabela 17 estão apresentados os resultados médios e desvios padrão da concentração de excesso de ácido-base no decorrer do experimento, e no gráfico 17 está ilustrado o comportamento desta variável.

Tabela 17 - Valores médios e desvios padrão do déficit da concentração de excesso de ácido-base nos bovinos dos grupos controle, monensina, virginiamicina (25 ppm), virginiamicina (34 ppm) e monensina + virginiamicina no decorrer do experimento - São Paulo - 2018.

\begin{tabular}{|c|c|c|c|c|c|}
\hline & 0 & $\mathrm{~T} 3$ & T6 & $\mathrm{T} 12$ & T18 \\
\hline $\mathrm{CON}$ & $0,83 \pm 2,04^{\mathrm{a}}$ & $1,50 \pm 4,41^{\mathrm{a}}$ & $-1,50 \pm 3,01^{a b}$ & $-10,33 \pm 4,71^{\mathrm{c}}$ & $-8,33 \pm 5,12^{b c}$ \\
\hline MON & $-1,16 \pm 1,72^{\mathrm{ab}}$ & $1,66 \pm 3,55^{\mathrm{a}}$ & $1,66 \pm 6,25^{\mathrm{a}}$ & $-6,00 \pm 9,23^{\mathrm{ab}}$ & $-10,00 \pm 4,81^{b}$ \\
\hline VM 25 & $2,16 \pm 2,13^{\mathrm{ab}}$ & $4,66 \pm 2,06^{\mathrm{a}}$ & $1,83 \pm 5,60^{\mathrm{ab}}$ & $-8,66 \pm 2,06^{c}$ & $-7,00 \pm 4,00^{c}$ \\
\hline VM 34 & $-0,75 \pm 2,62^{\mathrm{ab}}$ & $2,83 \pm 3,97^{\mathrm{a}}$ & $1,33 \pm 4,32^{\mathrm{a}}$ & $-9,50 \pm 4,92^{b c}$ & $-13,33 \pm 6,28^{c}$ \\
\hline $\mathrm{VM}+\mathrm{MON}$ & $0 \pm 3,46^{\mathrm{abc}}$ & $3,83 \pm 4,35^{\mathrm{a}}$ & $1,50 \pm 5,64^{\mathrm{ab}}$ & $-7,66 \pm 5,12^{\mathrm{bc}}$ & $-9,50 \pm 4,72^{\mathrm{c}}$ \\
\hline
\end{tabular}

Fonte: (OLIVEIRA, F.L.C, 2018)

Efeito de tratamento: 0,7009; efeito de tempo: <.0001; interação entre trat*tempo: 0,3986

Notas: Letras maiúsculas distintas nas colunas significam diferença estatística entre os grupos.

Letras minúsculas distintas nas linhas significam diferença dentro de cada grupo. 
Não teve diferença desta variável entre os grupos estudados. Analisando cada grupo individualmente, percebe-se que no $\mathrm{CON}$ o tempo basal e a $3^{\mathrm{a}} \mathrm{h}$ possuem maiores valores comparando-se a $12^{\mathrm{a}}$ e $18^{\mathrm{a}} \mathrm{h}$; no tratamento MON detectou-se menor valor na $18^{\mathrm{a}} \mathrm{h}$ em relação a $3^{\mathrm{a}}$ e $6^{\mathrm{a}} \mathrm{h}$; nos grupos VM 25 e VM + MON observa-se na $3^{\mathrm{a}} \mathrm{h}$ valor superior a $12^{\mathrm{a}}$ e $18^{\mathrm{a}} \mathrm{h}$ e no VM 34 está superioridade está na $3^{\mathrm{a}}$ e $6^{\mathrm{a}} \mathrm{h}$ confrontando-se a $12^{\mathrm{a}}$ e $18^{\mathrm{a}} \mathrm{h}$. Não teve relação significativa entre o tratamento e o tempo de coleta $(\mathrm{p}<0,3986)$.

Gráfico 17 - Valores médios da concentração de excesso de ácido-base nos bovinos dos grupos controle, monensina, virginiamicina $(25 \mathrm{ppm})$, virginiamicina $(34 \mathrm{ppm})$ e monensina + virginiamicina no decorrer do experimento - São Paulo - 2018.

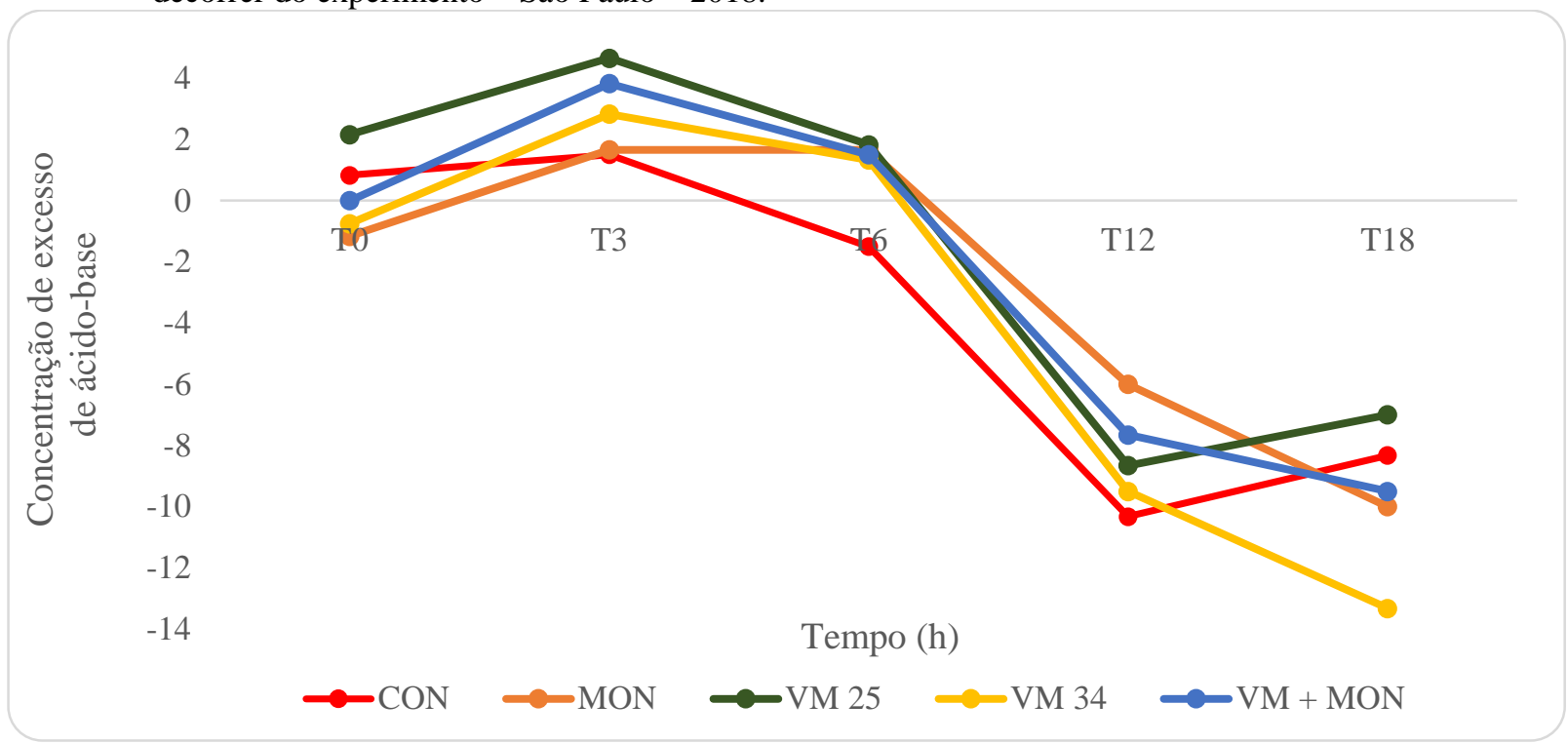

Fonte: (OLIVEIRA, F.L.C, 2018)

\subsubsection{Concentração de bicarbonato sanguíneo}

Na tabela 18 estão apresentados os resultados médios e desvios padrão de concentração de bicarbonato sanguíneo no decorrer do experimento, e no gráfico 18 está ilustrado o comportamento desta variável. 
Tabela 18 - Valores médios e desvios padrão da concentração de bicarbonato sanguíneo (mM/L) nos bovinos dos grupos controle, monensina, virginiamicina $(25 \mathrm{ppm})$, virginiamicina $(34 \mathrm{ppm})$ e monensina + virginiamicina no decorrer do experimento - São Paulo - 2018.

\begin{tabular}{cccccc}
\hline \multicolumn{2}{c}{ T0 } & \multicolumn{2}{c}{ T3 } & T12 & T18 \\
\hline CON & $24,73 \pm 1,61^{\mathrm{ab}}$ & $27,08 \pm 3,01^{\mathrm{a}}$ & $22,68 \pm 2,46^{\mathrm{abc}}$ & $15,81 \pm 3,63^{\mathrm{d}}$ & $17,71 \pm 3,84^{\mathrm{cd}}$ \\
MON & $23,08 \pm 1,88^{\mathrm{ab}}$ & $25,51 \pm 3,64^{\mathrm{a}}$ & $25,31 \pm 5,80^{\mathrm{ab}}$ & $17,46 \pm 7,59^{\mathrm{ab}}$ & $16,10 \pm 4,04^{\mathrm{b}}$ \\
VM 25 & $26,15 \pm 2,08^{\mathrm{a}}$ & $28,16 \pm 2,11^{\mathrm{a}}$ & $25,58 \pm 5,07^{\mathrm{a}}$ & $17,28 \pm 1,71^{\mathrm{b}}$ & $18,58 \pm 3,48^{\mathrm{b}}$ \\
VM 34 & $23,16 \pm 5,21^{\mathrm{abc}}$ & $26,71 \pm 3,62^{\mathrm{a}}$ & $25,30 \pm 4,05^{\mathrm{ab}}$ & $16,43 \pm 4,34^{\mathrm{cd}}$ & $13,50 \pm 5,21^{\mathrm{d}}$ \\
VM + MON & $24,43 \pm 2,85^{\mathrm{ab}}$ & $28,20 \pm 3,26^{\mathrm{a}}$ & $27,15 \pm 5,43^{\mathrm{a}}$ & $20,35 \pm 5,88^{\mathrm{ab}}$ & $17,31 \pm 4,23^{\mathrm{b}}$ \\
\hline
\end{tabular}

Fonte: (OLIVEIRA, F.L.C, 2018)

Efeito de tratamento: 0,5743; efeito de tempo: <.0001; interação entre trat*tempo: 0,5568

Notas: Letras maiúsculas distintas nas colunas significam diferença estatística entre os grupos.

Letras minúsculas distintas nas linhas significam diferença dentro de cada grupo.

Não existiu diferença na concentração de bicarbonato plasmático entre os grupos estudados. Ao analisar cada grupo separadamente, no CON e VM 34 maior concentração foi observada na $3^{\mathrm{a}} \mathrm{h}$ em relação a $12^{\mathrm{a}}$ e $18^{\mathrm{a}} \mathrm{h}$; no tratamento $\mathrm{M}$ a $3^{\mathrm{a}} \mathrm{h}$ foi superior a $18^{\mathrm{a}} \mathrm{h}$; no grupo VM 25 percebe-se menores valores na $12^{\mathrm{a}}$ e $18^{\mathrm{a}} \mathrm{h}$ em relação às demais e o $\mathrm{VM}+\mathrm{MON}$ a $3^{\mathrm{a}} \mathrm{e}$ $6^{\mathrm{a}} \mathrm{h}$ possuem valores elevados comparando-se com a $18^{\mathrm{a}} \mathrm{h}$. Não existiu relação significativa entre o tratamento e o tempo de coleta $(\mathrm{p}<0,5568)$.

Gráfico 18 - Valores médios da concentração de bicarbonato sanguíneo (mM/L) nos bovinos dos grupos controle, monensina, virginiamicina $(25 \mathrm{ppm})$, virginiamicina $(34 \mathrm{ppm})$ e monensina + virginiamicina no decorrer do experimento - São Paulo - 2018.

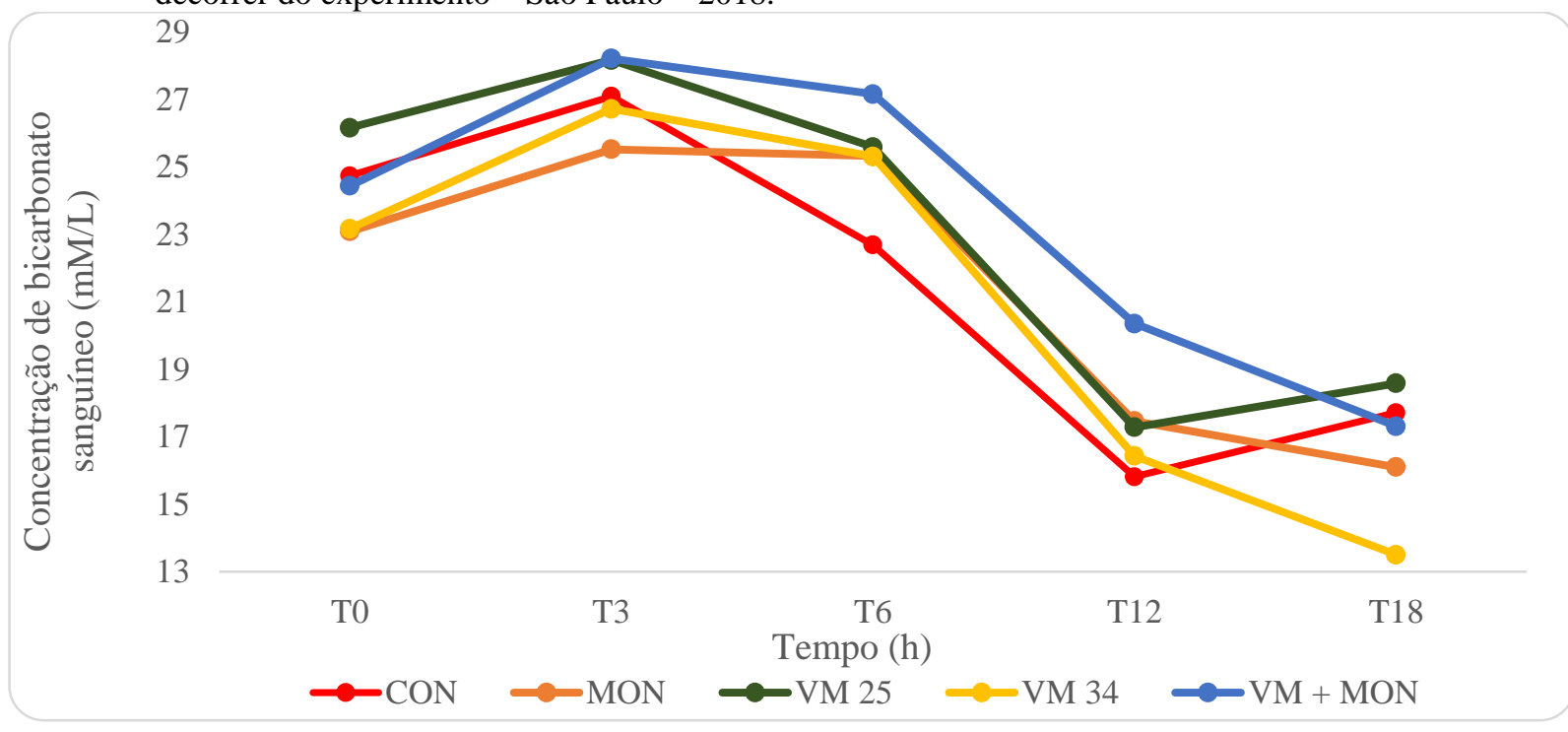

Fonte: (OLIVEIRA, F.L.C, 2018) 


\subsubsection{Concentração de lactato - L plasmático}

Na tabela 19 estão apresentados os resultados médios e desvios padrão da concentração do lactato - L plasmático no decorrer do experimento, e no gráfico 19 está ilustrado o comportamento desta variável.

Tabela 19 - Valores médios e desvios padrão da concentração do lactato - L plasmático (mM/L) nos bovinos dos grupos controle, monensina, virginiamicina $(25 \mathrm{ppm})$, virginiamicina (34 ppm) e monensina + virginiamicina no decorrer do experimento - São Paulo - 2018.

\begin{tabular}{cccccc}
\hline & T0 & T3 & T6 & T12 & T18 \\
CON & $2,53 \pm 1,18^{\mathrm{ab}}$ & $3,58 \pm 1,95^{\mathrm{a}}$ & $2,21 \pm 0,93^{\mathrm{ab}}$ & $1,61 \pm 0,31^{\mathrm{b}}$ & $1,75 \pm 0,69^{\mathrm{ab}}$ \\
MON & $1,65 \pm 0,43$ & $2,66 \pm 1,25$ & $2,41 \pm 1,15$ & $1,88 \pm 0,74$ & $1,26 \pm 0,32$ \\
VM 25 & $2,28 \pm 0,76$ & $3,13 \pm 2,26$ & $3,61 \pm 1,93$ & $2,73 \pm 3,09$ & $1,73 \pm 0,82$ \\
VM 34 & $2,76 \pm 0,66^{\mathrm{ab}}$ & $3,30 \pm 0,70^{\mathrm{a}}$ & $2,68 \pm 0,76^{\mathrm{ab}}$ & $1,75 \pm 0,73^{\mathrm{bc}}$ & $1,46 \pm 0,53^{\mathrm{c}}$ \\
VM + MON & $1,66 \pm 0,49^{\mathrm{ab}}$ & $2,56 \pm 1,12^{\mathrm{a}}$ & $1,80 \pm 0,69^{\mathrm{ab}}$ & $1,20 \pm 0,47^{\mathrm{b}}$ & $1,21 \pm 0,22^{\mathrm{b}}$ \\
\hline
\end{tabular}

Fonte: (OLIVEIRA, F.L.C, 2018)

Efeito de tratamento $=0,3116$; Efeito de tempo <.0001; Interação entre trat*tempo $=0,0438$

Notas: Letras maiúsculas distintas nas colunas significam diferença estatística entre os grupos.

Letras minúsculas distintas nas linhas significam diferença dentro de cada grupo.

Não houve diferença entre os grupos quanto à concentração de lactato - L plasmático. Feito uma análise dentro de cada grupo, nota-se que no $\mathrm{CON}$ a $3^{\mathrm{a}} \mathrm{h}$ tem uma maior concentração quando comparando a $12^{\mathrm{a}} \mathrm{h}$, maior valor é observado na $3^{\mathrm{a}} \mathrm{h}$ em relação $12^{\mathrm{a}}$ e $18^{\mathrm{a}} \mathrm{h}$ no tratamento VM 34. No grupo VM + MON menores valores são observados na $12^{\mathrm{a}}$ e $18^{\mathrm{a}} \mathrm{h}$ quando confrontado a $3^{\mathrm{a}}$ h. Não ocorreu diferença dentro do grupo MON e VM 25. Houve uma nítida relação significativa entre o tratamento e o tempo de coleta $(\mathrm{p}<0,0438)$. 
Gráfico 19 - Valores médios da concentração do lactato - L plasmático nos bovinos dos grupos controle, monensina, virginiamicina $(25 \mathrm{ppm})$, virginiamicina $(34 \mathrm{ppm})$ e monensina + virginiamicina no decorrer do experimento - São Paulo - 2018.

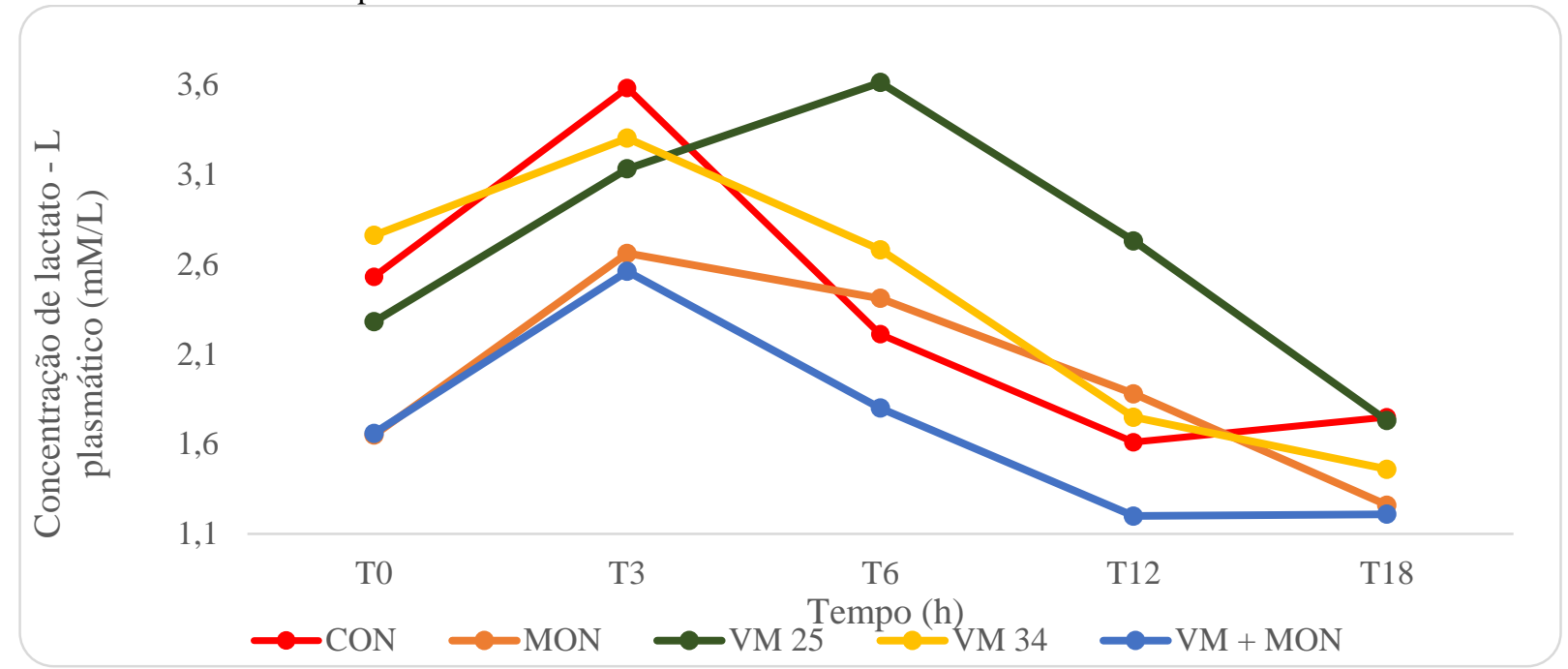

Fonte: (OLIVEIRA, F.L.C, 2018)

\subsubsection{Concentração de lactato - D plasmático}

Na tabela 20 estão apresentados os resultados médios e desvios padrão da concentração do lactato - D plasmático no decorrer do experimento, e no gráfico 20 está ilustrado o comportamento desta variável.

Tabela 20 - Valores médios e desvios padrão da concentração do lactato - D plasmático (mM/L) nos bovinos dos grupos controle, monensina, virginiamicina $(25 \mathrm{ppm})$, virginiamicina (34 ppm) e monensina + virginiamicina no decorrer do experimento - São Paulo - 2018.

\begin{tabular}{cccccc}
\hline & T0 & T3 & T6 & T12 & T18 \\
CON & $0,29 \pm 0,18^{\mathrm{b}}$ & - & $0,24 \pm 0,16^{\mathrm{b}}$ & $0,80 \pm 0,51^{\mathrm{b}}$ & $2,49 \pm 0,71^{\mathrm{a}}$ \\
MON & $0,16 \pm 0,06^{\mathrm{b}}$ & - & $0,38 \pm 0,26^{\mathrm{b}}$ & $0,94 \pm 0,77^{\mathrm{b}}$ & $3,35 \pm 1,12^{\mathrm{a}}$ \\
VM 25 & $0,32 \pm 0,20^{\mathrm{b}}$ & - & $0,32 \pm 0,28^{\mathrm{b}}$ & $0,8 \pm 0,40^{\mathrm{b}}$ & $2,31 \pm 1,29^{\mathrm{a}}$ \\
VM 34 & $0,50 \pm 0,24^{\mathrm{b}}$ & - & $0,18 \pm 0,10^{\mathrm{b}}$ & $1,10 \pm 0,83^{\mathrm{b}}$ & $2,59 \pm 1,09^{\mathrm{a}}$ \\
VM + MON & $0,30 \pm 0,15^{\mathrm{b}}$ & - & $0,25 \pm 0,19^{\mathrm{b}}$ & $0,27 \pm 0,25^{\mathrm{b}}$ & $1,48 \pm 0,92^{\mathrm{a}}$ \\
\hline
\end{tabular}

Fonte: (OLIVEIRA, F.L.C, 2018)

Efeito de tratamento $=0,125$; Efeito de tempo <.0001;

Notas: Letras maiúsculas distintas nas colunas significam diferença estatística entre os grupos.

Letras minúsculas distintas nas linhas significam diferença dentro de cada grupo. 
Não houve diferenças significativas entre os grupos quanto a concentração de lactato - D plasmático. Analisando cada grupo separadamente, nota-se que todos apresentam o mesmo comportamento, que é uma produção constante desse ácido, tendo um aumento significativo na $18^{\mathrm{a}} \mathrm{h}$.

Gráfico 20 - Valores médios da concentração do lactato - D plasmático $(\mathrm{mM} / \mathrm{L})$ nos bovinos dos grupos controle, monensina, virginiamicina $(25 \mathrm{ppm})$, virginiamicina $(34 \mathrm{ppm})$ e monensina + virginiamicina no decorrer do experimento - São Paulo - 2018

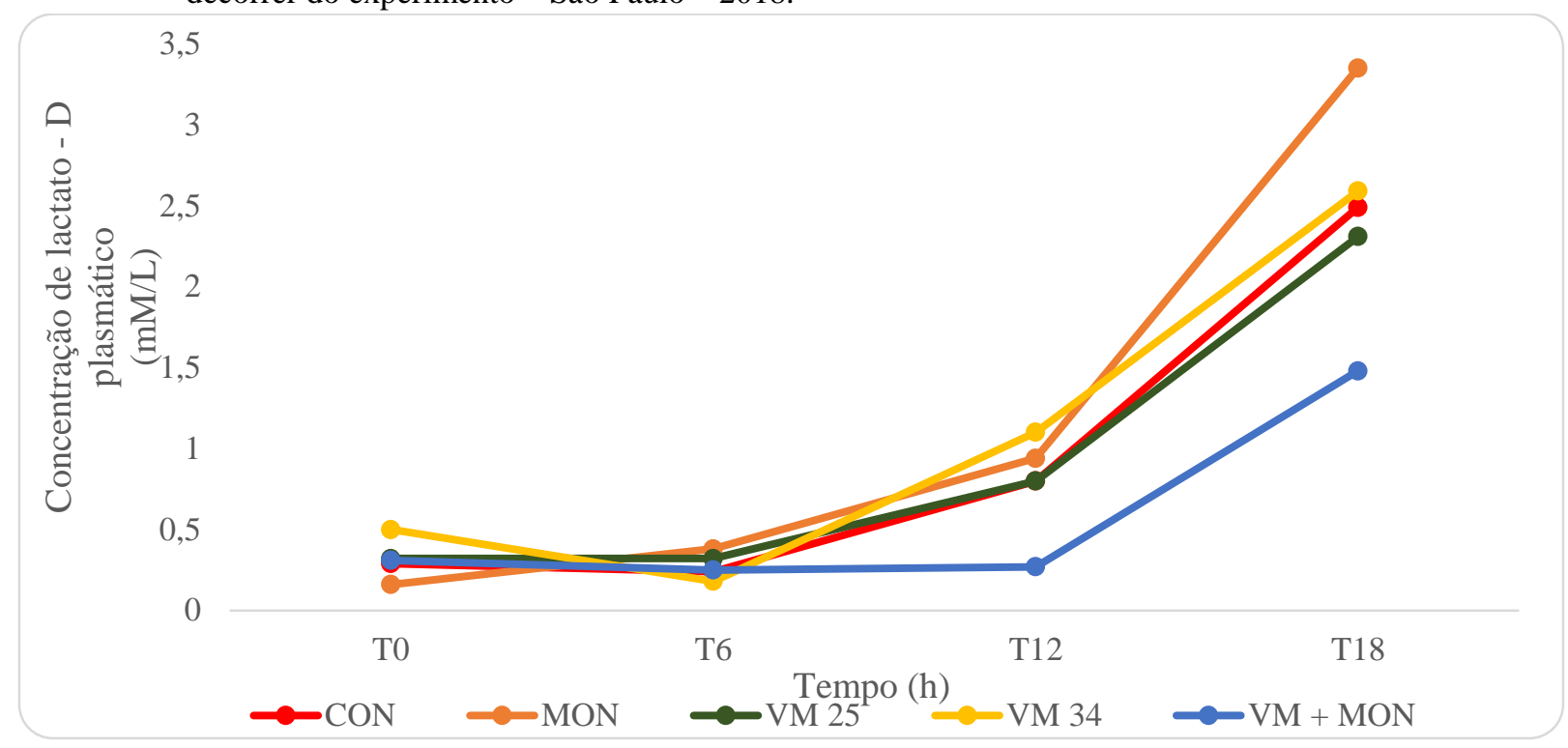

Fonte: (OLIVEIRA, F.L.C, 2018) 


\subsubsection{Osmolaridade sérica}

Na tabela 21 estão apresentados os resultados médios e desvios padrão da osmolaridade sérica no decorrer do experimento, e no gráfico 21 está ilustrado o comportamento desta variável.

Tabela 21 - Valores médios e desvios padrão da osmolaridade sérica (mOsm/L) nos bovinos dos grupos controle, monensina, virginiamicina $(25 \mathrm{ppm})$, virginiamicina $(34 \mathrm{ppm})$ e monensina + virginiamicina no decorrer do experimento - São Paulo - 2018.

\begin{tabular}{cccccc}
\hline & T0 & T3 & T6 & T12 & T18 \\
\hline CON & $280,33 \pm 7,63^{\mathrm{b}}$ & $308,00 \pm 6,35^{\mathrm{a}}$ & $306,66 \pm 4,63^{\mathrm{ABa}}$ & $288,00 \pm 7,04^{\mathrm{b}}$ & $284,83 \pm 9,66^{\mathrm{b}}$ \\
MON & $279,50 \pm 9,31^{\mathrm{c}}$ & $306,66 \pm 7,28^{\mathrm{a}}$ & $298,16 \pm 15,01^{\mathrm{BCab}}$ & $290,40 \pm 1,81^{\mathrm{bc}}$ & $282,16 \pm 5,26^{\mathrm{c}}$ \\
VM 25 & $278,33 \pm 7,11^{\mathrm{c}}$ & $306,66 \pm 6,71^{\mathrm{a}}$ & $305,33 \pm 8,31^{\mathrm{ABa}}$ & $292,33 \pm 5,81^{\mathrm{b}}$ & $282,66 \pm 5,81^{\mathrm{bc}}$ \\
VM 34 & $282,83 \pm 4,91^{\mathrm{c}}$ & $308,66 \pm 10,78^{\mathrm{ab}}$ & $312,00 \pm 8,14^{\mathrm{Aa}}$ & $293,00 \pm 9,75^{\mathrm{bc}}$ & $289,50 \pm 14,57^{\mathrm{c}}$ \\
VM + MON & $276,66 \pm 2,25^{\mathrm{c}}$ & $302,50 \pm 6,12^{\mathrm{a}}$ & $292,00 \pm 10,13^{\mathrm{Cab}}$ & $287,00 \pm 10,52^{\mathrm{bc}}$ & $283,00 \pm 10,01^{\mathrm{bc}}$ \\
\hline
\end{tabular}

Fonte: (OLIVEIRA, F.L.C, 2018)

Efeito de tratamento $=0,0718$; Efeito de tempo <.0001; Interação entre trat*tempo $=0,3775$

Notas: Letras maiúsculas distintas nas colunas significam diferença estatística entre os grupos.

Letras minúsculas distintas nas linhas significam diferença dentro de cada grupo.

Avaliando entre os grupos, observou-se que na $6^{\mathrm{a}} \mathrm{h}$ a osmolaridade sérica dos grupos

CON, VM 25 e VM 34 foi superior ao VM + MON e que o tratamento MON foi inferior ao

VM 34. Nos demais tempos não existiu diferença. Dentro de cada grupo, observa-se no CON e VM 25 valores superiores na $3^{\mathrm{a}}$ e $6^{\mathrm{a}} \mathrm{h}$ em relação as demais; no VM 34 ocorreu um pico na $6^{\mathrm{a}}$ h havendo decréscimo nos tempos subsequentes; já no MON e VM + MON está superioridade acontece na $3^{\mathrm{a}} \mathrm{h}$ com uma diminuição progressiva nas demais. Não teve relação significativa entre o tratamento e o tempo de coleta $(\mathrm{p}<0,3775)$. 
Gráfico 21 - Valores médios da osmolaridade sérica (mOsm/L) nos bovinos dos grupos controle, monensina, virginiamicina $(25 \mathrm{ppm})$, virginiamicina $(34 \mathrm{ppm})$ e monensina + virginiamicina no decorrer do experimento - São Paulo - 2018.

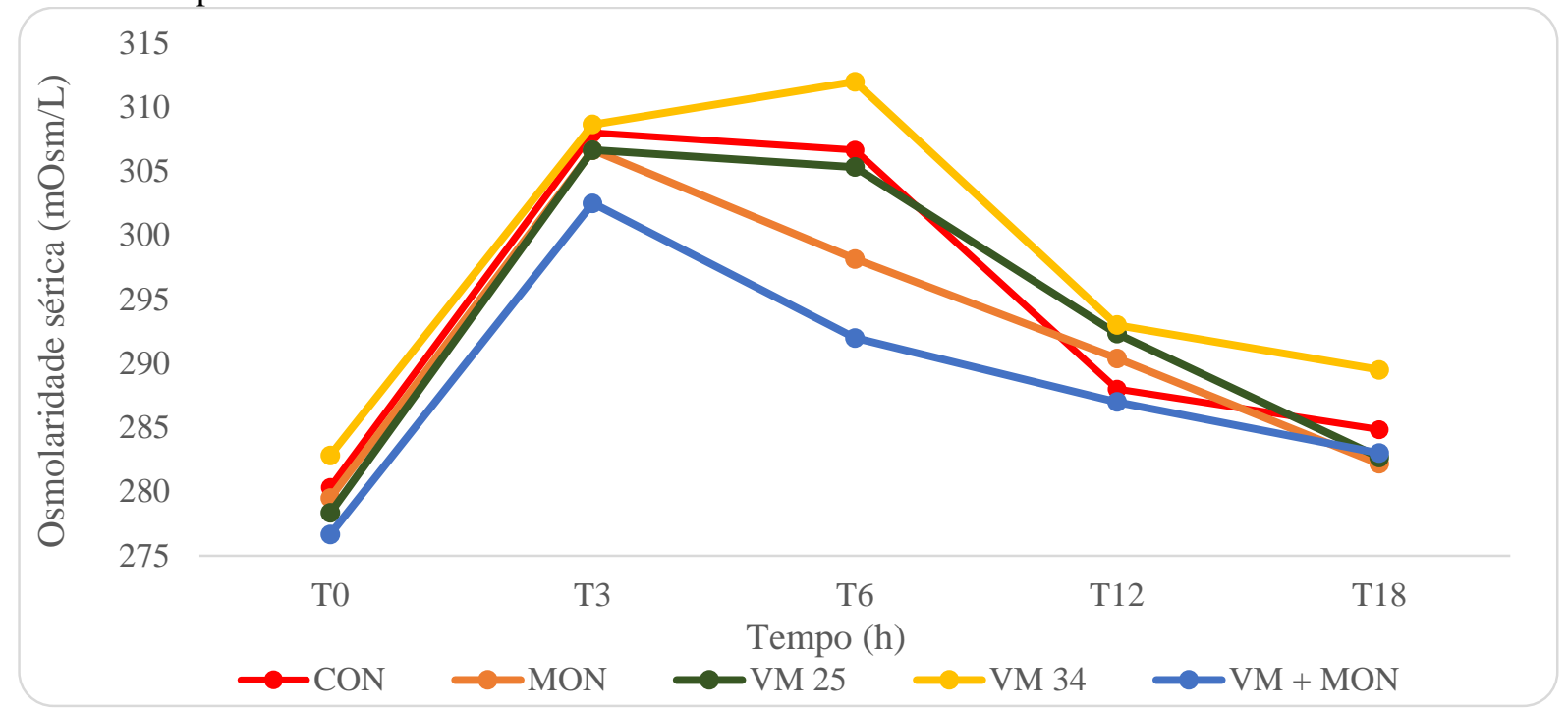

Fonte: (OLIVEIRA, F.L.C, 2018)

\subsubsection{Volume globular (VG)}

Na tabela 22 estão apresentados os resultados médios e desvios padrão do volume globular no decorrer do experimento, e no gráfico 22 está ilustrado o comportamento desta variável.

Tabela 22 - Valores médios e desvios padrão do volume globular (\%) nos bovinos dos grupos controle, monensina, virginiamicina $(25 \mathrm{ppm})$, virginiamicina $(34 \mathrm{ppm})$ e monensina + virginiamicina no decorrer do experimento - São Paulo - 2018.

\begin{tabular}{clllll}
\hline & T0 & T3 & T6 & T12 & T18 \\
CON & $36,50 \pm 1,87$ & $40,50 \pm 3,39$ & $40,66 \pm 1,87^{\mathrm{AB}}$ & $41,00 \pm 2,65$ & $45,33 \pm 8,21$ \\
MON & $35,83 \pm 0,98^{\mathrm{b}}$ & $39,00 \pm 3,52^{\mathrm{ab}}$ & $35,33 \pm 2,94^{\mathrm{Bb}}$ & $39,50 \pm 4,23^{\mathrm{ab}}$ & $41,66 \pm 3,38^{\mathrm{a}}$ \\
VM 25 & $35,50 \pm 2,42$ & $38,50 \pm 3,93$ & $37,83 \pm 3,86^{\mathrm{AB}}$ & $42,16 \pm 4,44$ & $42,00 \pm 5,17$ \\
VM 34 & $37,40 \pm 0,54$ & $42,16 \pm 4,53$ & $42,33 \pm 4,67^{\mathrm{A}}$ & $43,33 \pm 5,64$ & $45,50 \pm 5,43$ \\
VM + MON & $36,50 \pm 1,04$ & $38,33 \pm 4,36$ & $36,33 \pm 2,33^{\mathrm{AB}}$ & $39,66 \pm 5,31$ & $40,50 \pm 3,33$ \\
\hline
\end{tabular}

Fonte: (OLIVEIRA, F.L.C, 2018)

Efeito de tratamento $=0,1426$; Efeito de tempo <.0001; Interação entre trat*tempo $=0,0342$;

Notas: Letras maiúsculas distintas nas colunas significam diferença estatística entre os grupos.

Letras minúsculas distintas nas linhas significam diferença dentro de cada grupo. 
Não teve diferença no volume globular no tempo basal, $3^{\mathrm{a}}, 12^{\mathrm{a}}$ e $18^{\mathrm{a}} \mathrm{h}$ entre os grupos, na $6^{\text {a }}$ pode-se notar que o grupo VM 34 têm valor de VG superior ao MON. Dentro de cada grupo, percebe-se que no MON maiores percentuais de volume globular foi detectado na $18^{\mathrm{a}} \mathrm{h}$ em relação ao tempo basal e a $6^{\mathrm{a}}$ h. Nos tratamentos CON, VM 25, VM 34 e VM + MON não foram verificadas diferenças significativas na análise intra-grupo. Existiu uma nítida relação significativa entre o tratamento e o tempo de coleta $(\mathrm{p}<0,0342)$.

Gráfico 22 - Valores médios do volume globular (\%) nos bovinos dos grupos controle, monensina, virginiamicina $(25 \mathrm{ppm})$, virginiamicina (34 ppm) e monensina + virginiamicina no decorrer do experimento - São Paulo - 2018.

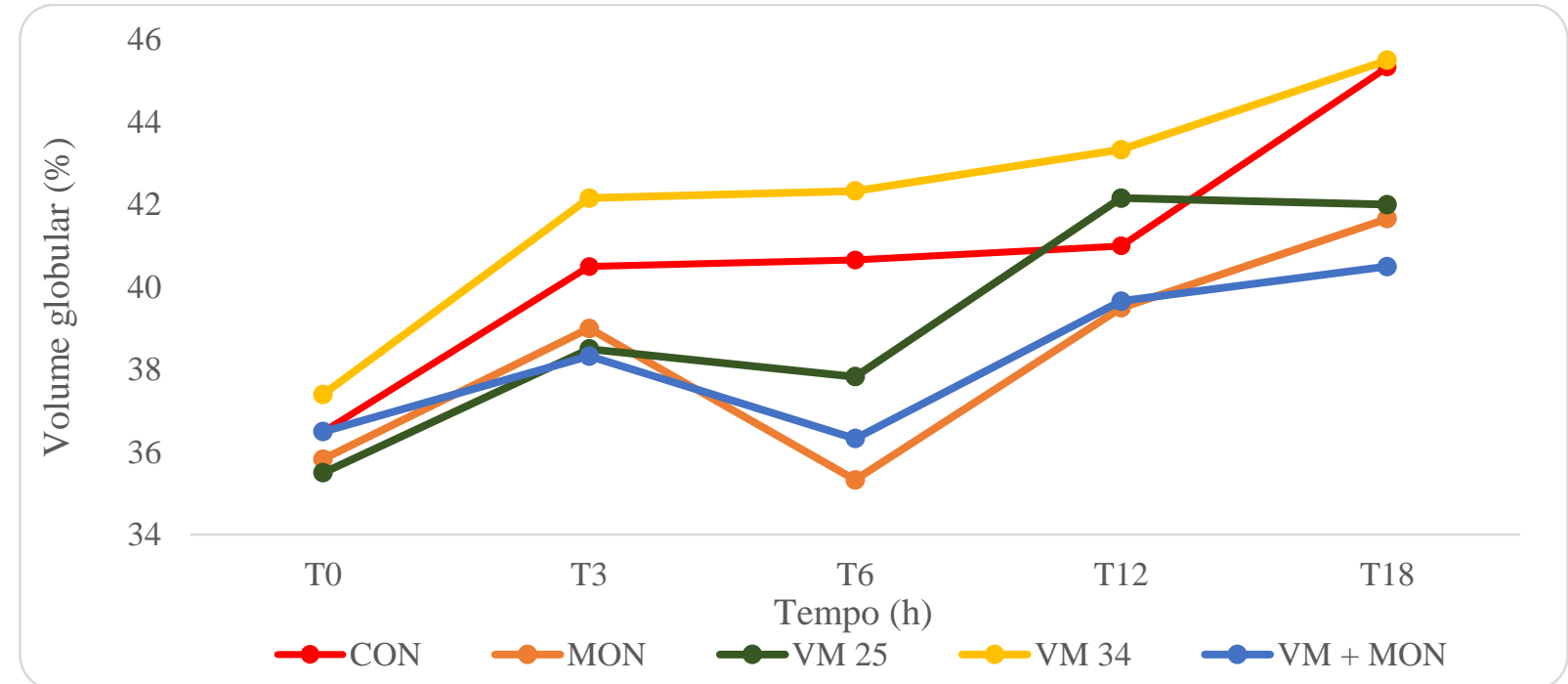

Fonte: (OLIVEIRA, F.L.C, 2018)

\subsubsection{Déficit de volume plasmático (DVP)}

Na tabela 23 estão apresentados os resultados médios e desvios padrão do déficit de volume plasmático no decorrer do experimento, e no gráfico 23 está ilustrado o comportamento desta variável. 
Tabela 23 - Valores médios e desvios padrão do déficit de volume plasmático (\%) nos bovinos dos grupos controle, monensina, virginiamicina $(25 \mathrm{ppm})$, virginiamicina $(34 \mathrm{ppm})$ e monensina + virginiamicina no decorrer do experimento - São Paulo - 2018.

\begin{tabular}{lccccc} 
& T0 & T3 & T6 & T12 & T18 \\
\hline CON & - & $-15,30 \pm 5,94$ & $-15,44 \pm 10,05^{\mathrm{B}}$ & $-17,67 \pm 16,77$ & $-28,27 \pm 18,94$ \\
MON & - & $-11,54 \pm 13,86^{\mathrm{ab}}$ & $3,21 \pm 14,22^{\mathrm{Aa}}$ & $-13,21 \pm 14,52^{\mathrm{ab}}$ & $-21,14 \pm 10,62^{\mathrm{b}}$ \\
VM 25 & - & $-11,69 \pm 7,65^{\mathrm{ab}}$ & $-8,83 \pm 11,53^{\mathrm{ABa}}$ & $-24,21 \pm 6,45^{\mathrm{b}}$ & $-23,31 \pm 9,84^{\mathrm{ab}}$ \\
VM 34 & - & $-17,68 \pm 6,03$ & $-20,26 \pm 12,38^{\mathrm{B}}$ & $-23,05 \pm 14,65$ & $-29,45 \pm 14,10$ \\
VM + MON & - & $-11,50 \pm 8,92$ & $1,02 \pm 7,31^{\mathrm{A}}$ & $-10,82 \pm 17,66$ & $-14,87 \pm 11,02$ \\
\hline
\end{tabular}

Fonte: (OLIVEIRA, F.L.C, 2018)

Efeito de tratamento $=0,1565$; Efeito de tempo $=<.0001 ;$ Interação entre trat*tempo $=0,0237$

Notas: Letras maiúsculas distintas nas colunas significam diferença estatística entre os grupos. Letras minúsculas distintas nas linhas significam diferença dentro de cada grupo.

Não houve diferença entre os grupos na $3^{\mathrm{a}}, 12^{\mathrm{a}}$ e $18^{\mathrm{a}} \mathrm{h}$. Na $6^{\mathrm{a}} \mathrm{h}$ o déficit de volume plasmático do grupo CON foi inferior aos tratamentos MON e VM + MON. Já dentro de cada grupo, pode-se notar no MON maior valor na $6^{\mathrm{a}} \mathrm{h}$ em relação a $18^{\mathrm{a}} \mathrm{h}$, no VM 25 esta superioridade é notada na $6^{\mathrm{a}} \mathrm{h}$ comparando-se com a $12^{\mathrm{a}} \mathrm{h}$. Não houve diferença entre os demais grupos nesta mesma análise. Houve uma nítida relação significativa entre o tratamento e o tempo de coleta $(\mathrm{p}<0,0237)$. 
Gráfico 23 - Valores médios do déficit de volume plasmático (\%) nos bovinos dos grupos controle, monensina, virginiamicina $(25 \mathrm{ppm})$, virginiamicina $(34 \mathrm{ppm})$ e monensina + virginiamicina no decorrer do experimento - São Paulo - 2018.

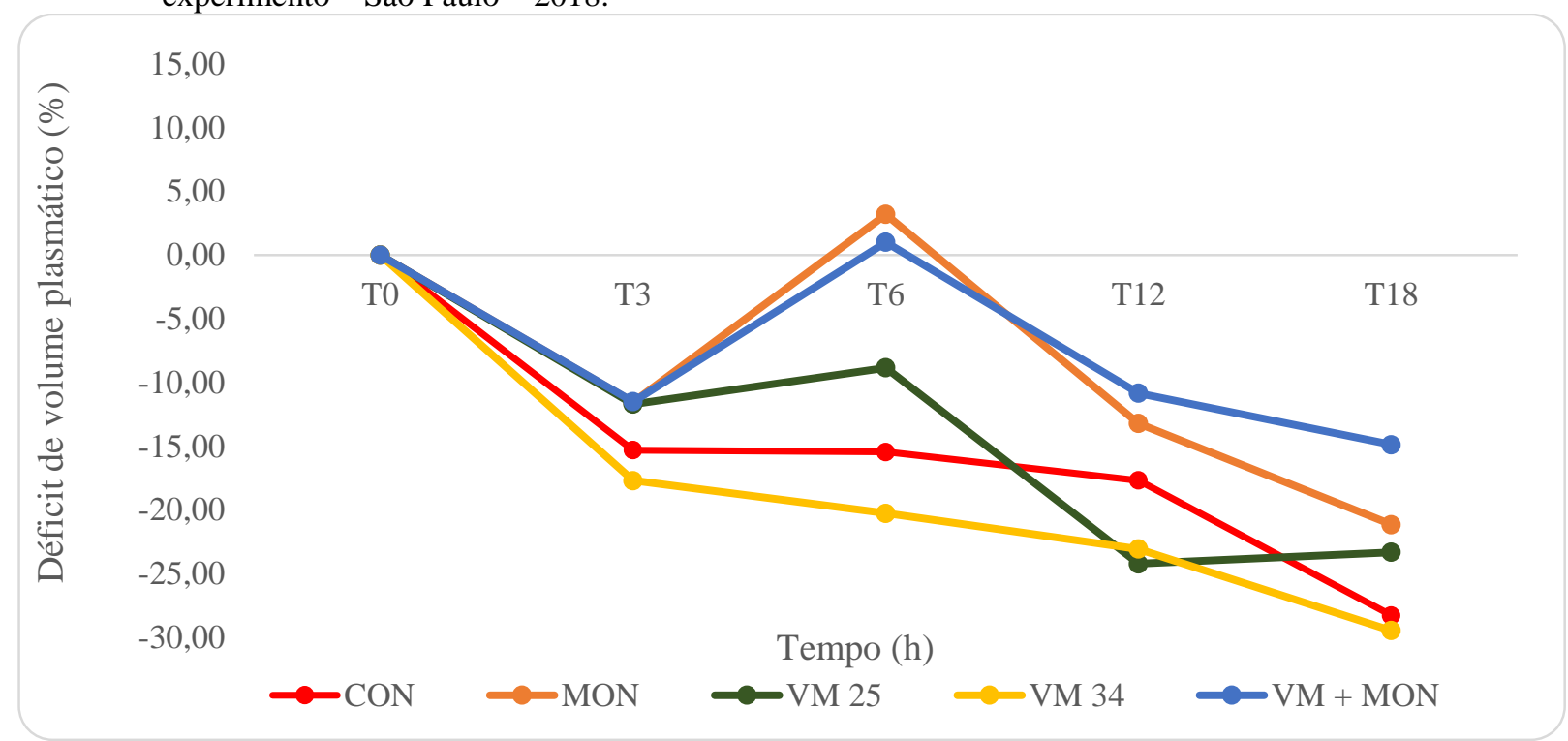

Fonte: (OLIVEIRA, F.L.C, 2018)

\subsubsection{Concentração da glicose plasmática}

Na tabela 24 estão apresentados os resultados médios e desvios padrão da pressão da glicose plasmática no decorrer do experimento, e no gráfico 24 está ilustrado o comportamento desta variável.

Tabela 24 - Valores médios e desvios padrão da concentração de glicose plasmática (mM/L) nos bovinos dos grupos controle, monensina, virginiamicina $(25 \mathrm{ppm})$, virginiamicina (34 ppm) e monensina + virginiamicina no decorrer do experimento - São Paulo - 2018.

\begin{tabular}{|c|c|c|c|c|c|}
\hline & T0 & $\mathrm{T} 3$ & T6 & $\mathrm{T} 12$ & T18 \\
\hline $\mathrm{CON}$ & $5,03 \pm 0,91^{\mathrm{AB}}$ & $11,45 \pm 2,48^{\mathrm{A}}$ & $8,83 \pm 2,10$ & $4,38 \pm 0,87$ & $4,53 \pm 0,77$ \\
\hline MON & $4,56 \pm 0,81^{\mathrm{AB}}$ & $6,71 \pm 2,33^{\mathrm{AB}}$ & $6,16 \pm 1,87$ & $4,28 \pm 1,23$ & $4,25 \pm 0,78$ \\
\hline VM 25 & $4,56 \pm 0,53^{\mathrm{AB}}$ & $10,93 \pm 4,37^{\mathrm{AB}}$ & $9,38 \pm 3,68$ & $4,66 \pm 1,13$ & $4,86 \pm 0,68$ \\
\hline VM 34 & $5,78 \pm 1,26^{\mathrm{A}}$ & $10,35 \pm 3,22^{\mathrm{AB}}$ & $8,65 \pm 2,18$ & $4,91 \pm 0,48$ & $5,21 \pm 1,07$ \\
\hline $\mathrm{VM}+\mathrm{MON}$ & $4,20 \pm 0,32^{\mathrm{B}}$ & $5,98 \pm 2,28^{\mathrm{B}}$ & $5,95 \pm 1,74$ & $3,75 \pm 0,54$ & $4,26 \pm 0,30$ \\
\hline
\end{tabular}

Fonte: (OLIVEIRA, F.L.C, 2018)

Efeito de tratamento: 0,0066; efeito de tempo: <0,1253; interação entre trat*tempo: 0,1547

Notas: Letras maiúsculas distintas nas colunas significam diferença estatística entre os grupos.

Letras minúsculas distintas nas linhas significam diferença dentro de cada grupo. 
Ao fazer uma análise entre os grupos, observa-se que no momento basal o tratamento VM 34 possui maior concentração de glicose plasmática que o $\mathrm{VM}+\mathrm{MON}$, já na $6^{\mathrm{a}} \mathrm{h}$ o $\mathrm{CON}$ apresenta maior concentração em relação ao $\mathrm{VM}+\mathrm{MON}$, não existindo diferença nos demais momentos avaliados. Não foram verificadas diferenças na análise dentro de todos os grupos, comparando cada grupo individualmente no decorrer do experimento. Houve uma nítida relação significativa entre o tratamento e o tempo de coleta $(\mathrm{p}<0,0017)$.

Gráfico 24 - Valores médios da concentração de glicose plasmática (mM/L) nos bovinos dos grupos controle, monensina, virginiamicina $(25 \mathrm{ppm})$, virginiamicina $(34 \mathrm{ppm})$ e monensina + virginiamicina no decorrer do experimento - São Paulo - 2018.

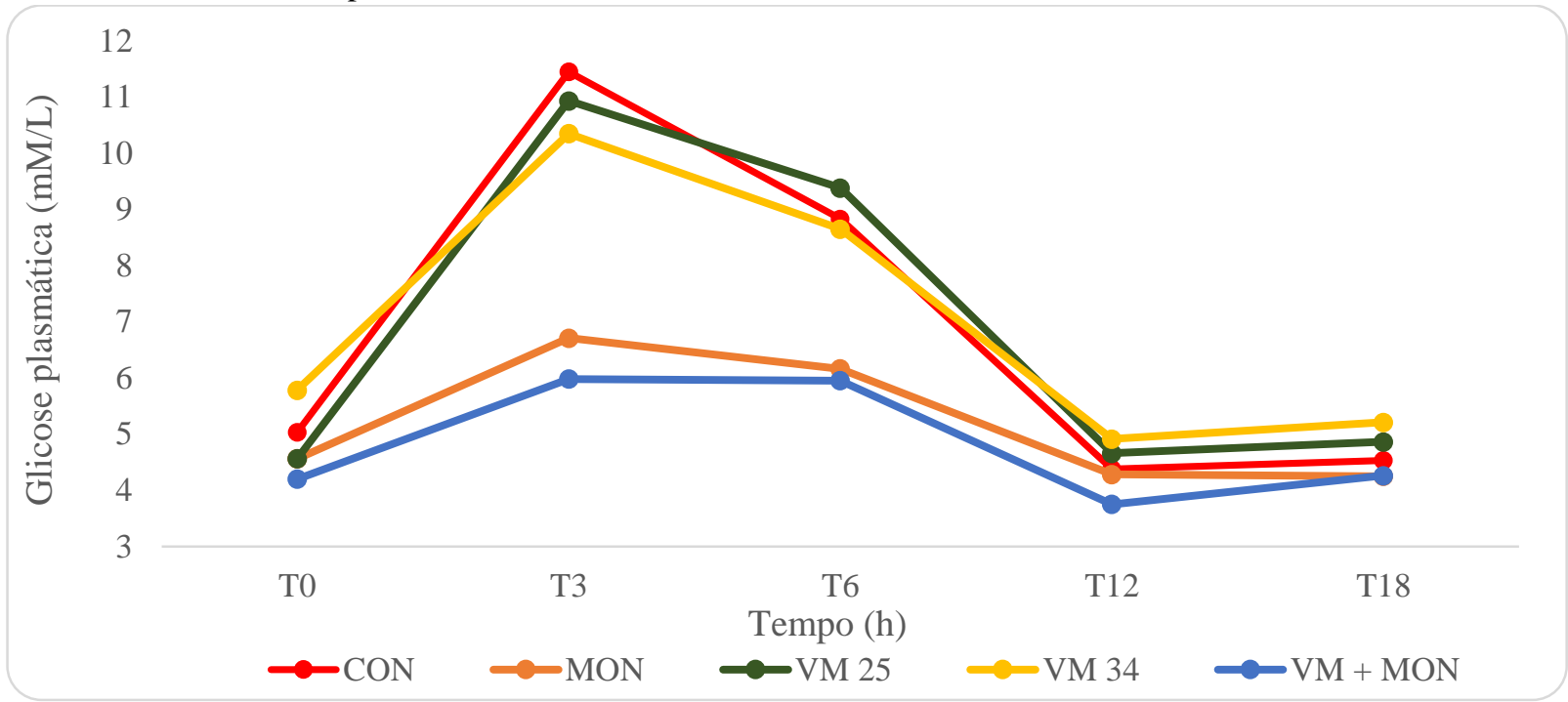

Fonte: (OLIVEIRA, F.L.C, 2018)

\subsection{OCORRÊNCIAS CLÍNICAS}

Todas as ocorrências clínicas observadas durante o decorrer do ensaio estão expostas no quadro 1. Todos os animais apresentaram diarreia, a qual tinha odor ácido, coloração acinzentada, não era continua e surgia quando os animais eram submetidos ao movimento; no decorrer do experimento os animais apresentaram muco nas fezes que era observada a partir da $18^{\mathrm{a}} \mathrm{h}$; em oito animais foi observado secreção nasal seromucosa, que na sua grande maioria era 
notado a partir da $18^{\mathrm{a}} \mathrm{h}$; todos os animais, com exceção de um, tiveram atonia ruminal, que foi notada a partir da $6^{\mathrm{a}} \mathrm{h}$; a desidratação acometeu $2 / 3$ dos animais, sendo classificada em três diferentes graus, de acordo com a intensidade; acidose sistémica foi constatada laboratorialmente em 1/3 dos animais, sendo necessário o tratamento em metade deles.

Quadro 1 - Ocorrências clínicas constatadas nos animais no decorrer da experimentação - São Paulo - 2018

\begin{tabular}{|c|c|c|c|c|c|}
\hline & CON & MON & VM25 & VM34 & VM+MON \\
\hline Diarreia & $6 / 6$ & $6 / 6$ & $6 / 6$ & $6 / 6$ & $5 / 6$ \\
\hline $\begin{array}{c}\text { Muco nas } \\
\text { fezes }\end{array}$ & $2 / 6$ & $2 / 6$ & $1 / 6$ & $1 / 6$ & $2 / 6$ \\
\hline $\begin{array}{c}\text { Secreção } \\
\text { nasal }\end{array}$ & $2 / 6$ & $2 / 6$ & $1 / 6$ & $1 / 6$ & $2 / 6$ \\
\hline Depressão & $5 / 6^{*}$ & $2 / 6$ & $3 / 6$ & $3 / 6$ & $1 / 6^{*}$ \\
\hline $\begin{array}{c}\text { Atonia } \\
\text { ruminal }\end{array}$ & $6 / 6$ & $6 / 6$ & $6 / 6$ & $6 / 6$ & $5 / 6$ \\
\hline $\begin{array}{c}\text { Desidratação } \\
\text { intensa }\end{array}$ & $2 / 6$ & $0 / 6$ & $0 / 6$ & $1 / 6$ & $0 / 6$ \\
\hline $\begin{array}{c}\text { Desidratação } \\
\text { moderada }\end{array}$ & $1 / 6$ & $1 / 6$ & $2 / 6$ & $2 / 6$ & $0 / 6$ \\
\hline $\begin{array}{c}\text { Desidratação } \\
\text { leve }\end{array}$ & $1 / 6$ & $3 / 6$ & $3 / 6$ & $2 / 6$ & $2 / 6$ \\
\hline $\begin{array}{c}\text { Acidose } \\
\text { sistémica }\end{array}$ & $3 / 6$ & $2 / 6$ & $1 / 6$ & $3 / 6$ & $1 / 6$ \\
\hline $\begin{array}{c}\text { Necessidade } \\
\text { de tratamento }\end{array}$ & $5 / 6^{*}$ & $3 / 6$ & $3 / 6$ & $3 / 6$ & $1 / 6^{*}$ \\
\hline
\end{tabular}

Fonte: (OLIVEIRA, F.L.C, 2018)

$*(p=0,0389)$

Constatou-se que a maioria dos animais (14/15) que manifestaram depressão tiveram que ser tratados $\left(\chi^{2}=22,533 ; \mathrm{p}<0,0001\right)$, assim como boa parte daqueles $(20 / 15)$ que se apresentavam desidratados $\left(\chi^{2}=11,627 ; \mathrm{p}<0,001\right)$ e uma parte expressiva $(8 / 15)$ com acidose sistêmica moderada $\left(\chi^{2}=5,4 ; \mathrm{p}=0,020\right)$. 


\subsection{1 pH de fezes na $12^{\mathrm{a}}$ e/ou $18^{\mathrm{a}} \mathrm{h}$ dos animais com ou sem muco nas fezes sem distinção de grupos}

Na tabela 25 estão apresentados os resultados médios e desvios padrão do pH de fezes na $12^{\mathrm{a}}$ e/ou $18^{\mathrm{a}} \mathrm{h}$ dos animais com ou sem muco nas fezes sem distinção de grupos.

Tabela 25 - Valores médios e desvios padrão do $\mathrm{pH}$ de fezes na $12^{\mathrm{a}} \mathrm{e} / \mathrm{ou} 18^{\mathrm{a}} \mathrm{h}$ dos animais com ou sem muco nas fezes sem distinção de grupos - São Paulo - 2018.

\begin{tabular}{cccccc}
\hline \multirow{2}{*}{ Grupos } & \multicolumn{2}{c}{ Muco nas fezes } & \multicolumn{2}{c}{ Sem muco nas fezes } & P \\
\cline { 2 - 6 } & Média & DP & Média & DP & \\
\hline pH das fezes & 5,22 & 0,05 & 5,63 & 0,12 & $\mathrm{P}<0,005$ \\
\hline
\end{tabular}

Fonte: (OLIVEIRA, F.L.C, 2018)

\subsubsection{Concentração de lactato - D na $18^{\mathrm{a}} \mathrm{h}$ dos animais tratados e dos não tratados sem distinção de grupos}

Na tabela 26 estão apresentados os resultados médios e desvios padrão da concentração de lactato - D na $18^{\mathrm{a}} \mathrm{h}$ dos animais tratados e dos não tratados sem distinção de grupos.

Tabela 26 - Valores médios e desvios padrão da concentração de lactato - D plasmático (mM/L) na $18^{\mathrm{a}} \mathrm{h}$ dos animais tratados e dos não tratados sem distinção de grupos - São Paulo - 2018.

\begin{tabular}{cccccc}
\hline \multirow{2}{*}{ Grupos } & \multicolumn{3}{c}{ Tratado } & \multicolumn{3}{c}{ Não Tratado } & P \\
\cline { 2 - 6 } & Média & DP & Média & DP & \\
\hline $\begin{array}{c}\text { Lactato }-\mathrm{D} \\
\text { Sanguíneo }\end{array}$ & 2,8 & 1,09 & 1,7 & 0,83 & $\mathrm{P}<0,015$ \\
\hline Fonte: (OLIVEIRA, F.L. & & & & &
\end{tabular}

Fonte: (OLIVEIRA, F.L.C, 2018) 


\subsection{VARIÁVEIS CLÍNICAS}

\subsubsection{Frequência cardíaca}

Na tabela 27 estão apresentados os resultados médios e desvios padrão na frequência cardíaca no decorrer do experimento, e no gráfico 27 está ilustrado o comportamento desta variável.

Tabela 27 - Valores médios e desvios padrão da frequência cardíaca (bpm) nos bovinos dos grupos controle, monensina, virginiamicina $(25 \mathrm{ppm})$, virginiamicina $(34 \mathrm{ppm})$ e monensina + virginiamicina no decorrer do experimento - São Paulo - 2018.

\begin{tabular}{cccccc}
\hline & T0 & T3 & T6 & T12 & T18 \\
\hline CON & $73,66 \pm 10,15^{\mathrm{b}}$ & $104,50 \pm 19,83^{\mathrm{ab}}$ & $110,16 \pm 14,14^{\mathrm{a}}$ & $95,83 \pm 20,73^{\mathrm{ab}}$ & $103,83 \pm 25,72^{\mathrm{ab}}$ \\
MON & $79,00 \pm 11,57^{\mathrm{b}}$ & $111,33 \pm 10,99^{\mathrm{a}}$ & $103,80 \pm 3,63^{\mathrm{a}}$ & $99,50 \pm 8,75^{\mathrm{ab}}$ & $101,83 \pm 17,41^{\mathrm{a}}$ \\
VM 25 & $73,66 \pm 11,20^{\mathrm{b}}$ & $100,50 \pm 12,61^{\mathrm{a}}$ & $111,16 \pm 17,98^{\mathrm{a}}$ & $96,33 \pm 18,12^{\mathrm{ab}}$ & $102,33 \pm 14,65^{\mathrm{a}}$ \\
VM 34 & $80,00 \pm 14,53^{\mathrm{b}}$ & $112,00 \pm 19,47^{\mathrm{a}}$ & $115,40 \pm 13,81^{\mathrm{a}}$ & $111,16 \pm 22,16^{\mathrm{ab}}$ & $104,50 \pm 18,54^{\mathrm{ab}}$ \\
VM + MON & $75,66 \pm 9,99^{\mathrm{b}}$ & $104,33 \pm 9,83^{\mathrm{a}}$ & $99,50 \pm 15,22^{\mathrm{a}}$ & $103,83 \pm 13,89^{\mathrm{a}}$ & $98,16 \pm 17,93^{\mathrm{ab}}$ \\
\hline FOn
\end{tabular}

Fonte: (OLIVEIRA, F.L.C, 2018)

Efeito de tratamento $=0,6584 ;$ Efeito de tempo <.0001; Interação entre trat*tempo $=0,8915$

Notas: Letras maiúsculas distintas nas colunas significam diferença estatística entre os grupos.

Letras minúsculas distintas nas linhas significam diferença dentro de cada grupo.

Não existiu diferença desta variável entre os grupos estudados. Analisando cada grupo em separado, percebe-se que no $\mathrm{CON}$ a $6^{\mathrm{a}} \mathrm{h}$ é superior ao tempo basal, no tratamento MON e VM 25 maiores valores são observados na $3^{\mathrm{a}}, 6^{\mathrm{a}}$ e $18^{\mathrm{a}} \mathrm{h}$ em relação ao T0. No VM 34 percebese menor valor no tempo basal comparando-se com a $3^{\mathrm{a}}$ e $6^{\mathrm{a}} \mathrm{h}$ e no $\mathrm{VM}+\mathrm{MON}$ o momento basal é inferior a $3^{\mathrm{a}}, 6^{\mathrm{a}}$ e $12^{\mathrm{a}} \mathrm{h}$. Não existiu relação significativa entre o tratamento e o tempo de coleta $(\mathrm{p}<0,8915)$.

Dos nove animais com batimento cardíaco com frequência acima de 130/min. seis deles $(66,7 \%)$ tiveram altas concentrações de lactato D no sangue $(\mathrm{p}=0,077)$. 
Gráfico 25 - Valores médios da frequência cardíaca $(\mathrm{mpm})$ nos bovinos dos grupos controle, monensina, virginiamicina $(25 \mathrm{ppm})$, virginiamicina $(34 \mathrm{ppm})$ e monensina + virginiamicina no decorrer do experimento - São Paulo - 2018.

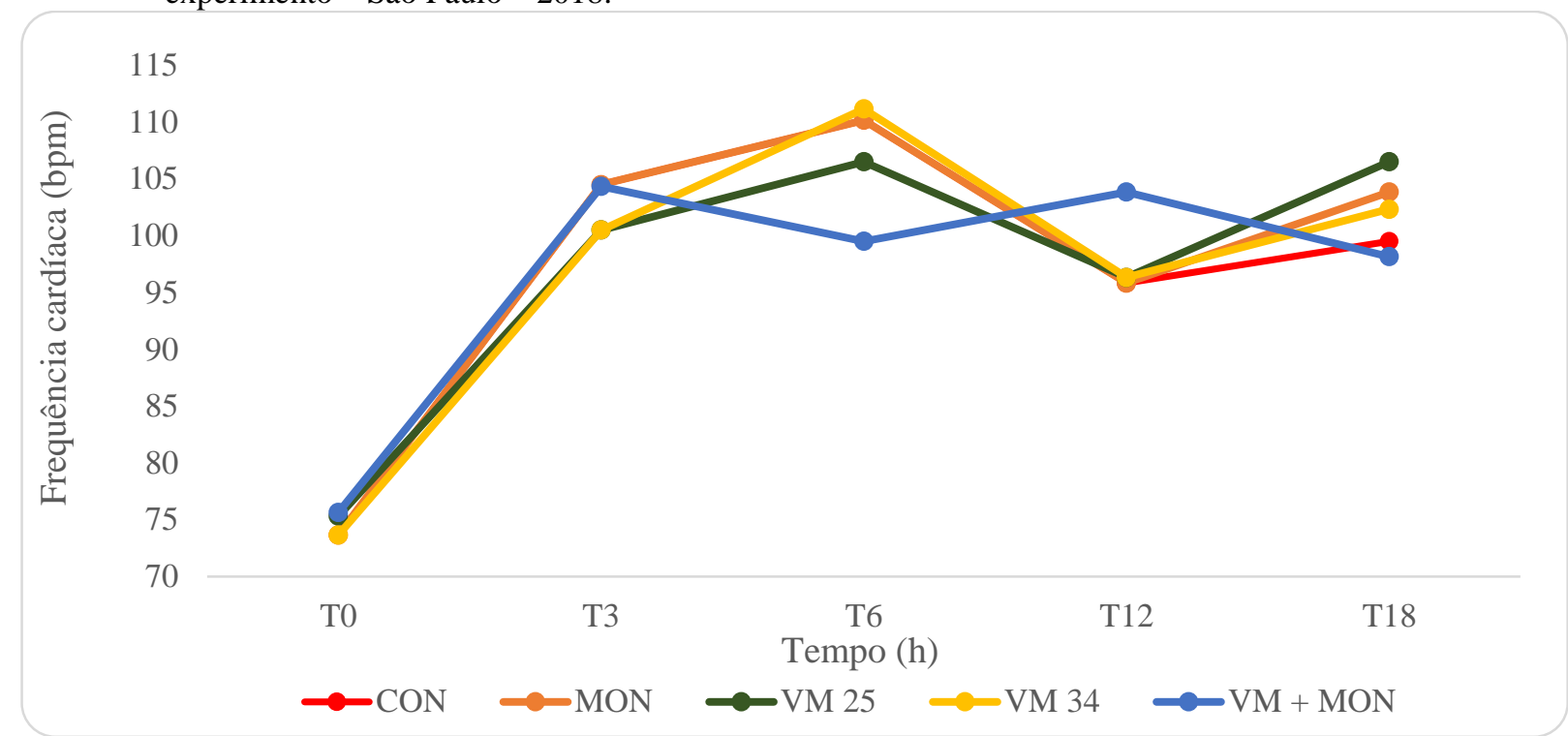

Fonte: (OLIVEIRA, F.L.C, 2018)

\subsubsection{Frequência respiratória}

Na tabela 28 estão apresentados os resultados médios e desvios padrão na frequência respiratória no decorrer do experimento, e no gráfico 28 está ilustrado o comportamento desta variável.

Tabela 28 - Valores médios e desvios padrão da frequência respiratória (mpm) nos bovinos dos grupos controle, monensina, virginiamicina (25 ppm), virginiamicina (34 ppm) e monensina + virginiamicina no decorrer do experimento - São Paulo - 2018.

\begin{tabular}{cccccc}
\hline & T0 & T3 & T6 & T12 & T18 \\
\hline CON & $34,16 \pm 9,21^{\mathrm{ab}}$ & $35,66 \pm 10,28^{\mathrm{ab}}$ & $41,83 \pm 9,66^{\mathrm{a}}$ & $29,66 \pm 8,11^{\mathrm{ab}}$ & $22,00 \pm 3,03^{\mathrm{b}}$ \\
MON & $25,00 \pm 7,00^{\mathrm{ab}}$ & $32,83 \pm 6,58^{\mathrm{ab}}$ & $33,66 \pm 9,89^{\mathrm{a}}$ & $28,50 \pm 6,65^{\mathrm{ab}}$ & $21,16 \pm 2,99^{\mathrm{b}}$ \\
VM 25 & $31,50 \pm 1,97^{\mathrm{ab}}$ & $30,16 \pm 4,21^{\mathrm{ab}}$ & $38,66 \pm 9,68^{\mathrm{a}}$ & $29,00 \pm 5,51^{\mathrm{b}}$ & $24,33 \pm 1,36^{\mathrm{b}}$ \\
VM 34 & $28,00 \pm 6,32^{\mathrm{ab}}$ & $39,50 \pm 11,57^{\mathrm{a}}$ & $40,83 \pm 13,94^{\mathrm{a}}$ & $27,00 \pm 7,97^{\mathrm{ab}}$ & $21,83 \pm 3,86^{\mathrm{b}}$ \\
VM + MON & $24,50 \pm 5,50$ & $30,83 \pm 9,21$ & $32,50 \pm 10,46$ & $33,16 \pm 6,61$ & $24,00 \pm 2,00$ \\
\hline
\end{tabular}

Fonte: (OLIVEIRA, F.L.C, 2018)

Efeito de tratamento $=0,6503$; Efeito de tempo <.0001; Interação entre trat*tempo $=0,0378$

Notas: Letras maiúsculas distintas nas colunas significam diferença estatística entre os grupos.

Letras minúsculas distintas nas linhas significam diferença dentro de cada grupo. 
Não existiu diferença significativa da frequência respiratória entre os grupos estudados, em cada um dos momentos avaliados. Dentro de cada grupo, nota-se que no CON e MON a $6^{\mathrm{a}} \mathrm{h}$ é superior a $18^{\mathrm{a}} \mathrm{h}$. No tratamento VM 25 maior valor é observado na $6^{\mathrm{a}} \mathrm{h}$ em relação a $12^{\mathrm{a}}$ e $18^{\mathrm{a}} \mathrm{h}$; no VM 34 a $18^{\mathrm{a}} \mathrm{h}$ têm menor valor comparando-se a $3^{\mathrm{a}}$ e $6^{\mathrm{a}} \mathrm{h}$ e no $\mathrm{VM}+\mathrm{MON}$ não foi verificado diferença intra-grupo. Teve uma nítida relação significativa entre o tratamento e o tempo de coleta $(\mathrm{p}<0,0378)$.

Gráfico 26 - Valores médios da frequência respiratória (bpm) nos bovinos dos grupos controle, monensina, virginiamicina $(25 \mathrm{ppm})$, virginiamicina $(34 \mathrm{ppm})$ e monensina + virginiamicina no decorrer do experimento - São Paulo - 2018.

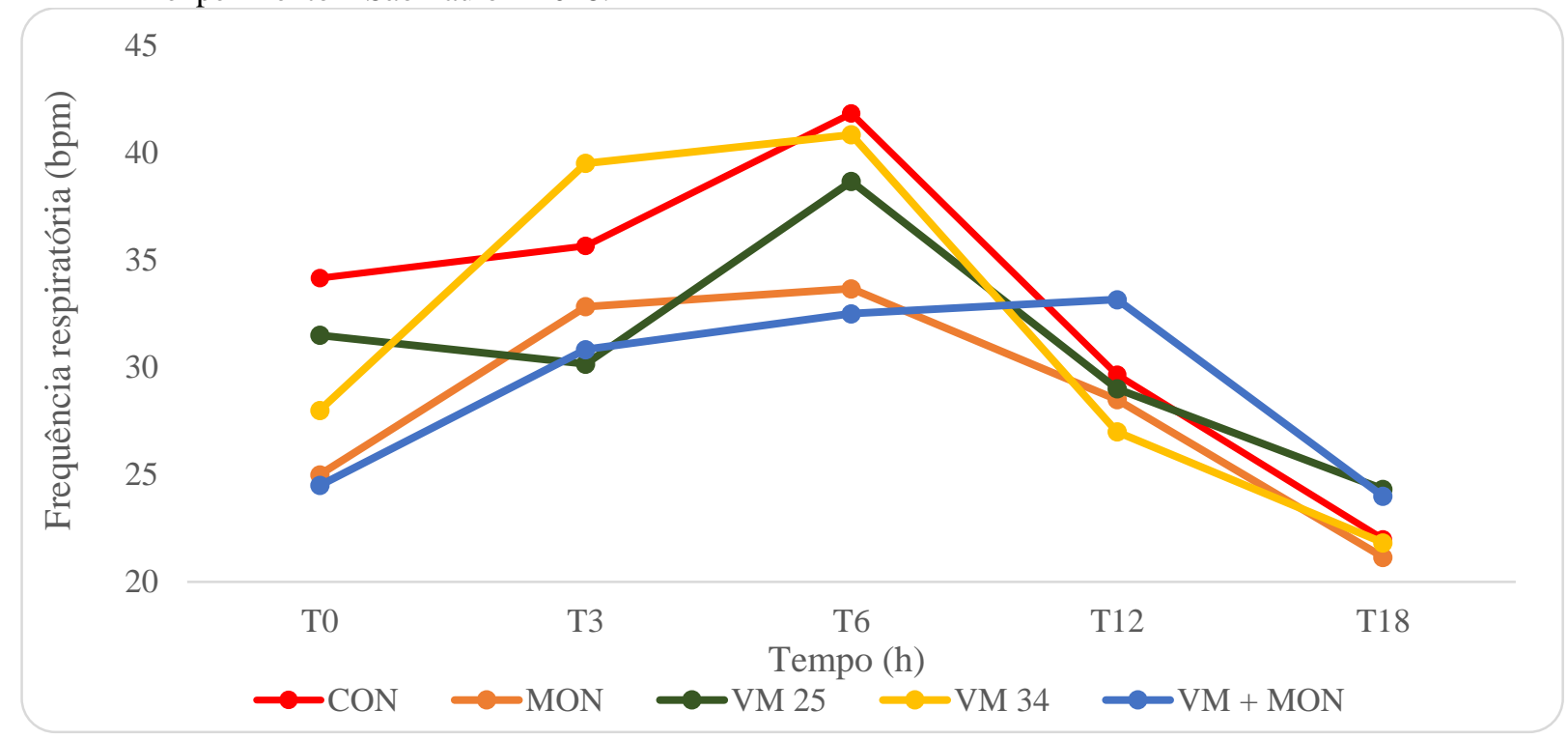

Fonte: (OLIVEIRA, F.L.C, 2018)

\subsubsection{Temperatura retal}

Na tabela 29 estão apresentados os resultados médios e desvios padrão da temperatura retal no decorrer do experimento, e no gráfico 29 está ilustrado o comportamento desta variável. 
Tabela 29 - Valores médios e desvios padrão da temperatura retal $\left({ }^{\circ} \mathrm{C}\right)$ nos bovinos dos grupos controle, monensina, virginiamicina $(25 \mathrm{ppm})$, virginiamicina $(34 \mathrm{ppm})$ e monensina + virginiamicina no decorrer do experimento - São Paulo - 2018.

\begin{tabular}{cccccc}
\hline & T0 & T3 & T6 & T12 & T18 \\
\hline COM & $38,50 \pm 0,24^{\mathrm{c}}$ & $39,36 \pm 0,27^{\mathrm{ab}}$ & $39,68 \pm 0,54^{\mathrm{a}}$ & $38,80 \pm 0,73^{\mathrm{bc}}$ & $38,20 \pm 0,39^{\mathrm{c}}$ \\
MON & $38,36 \pm 0,37^{\mathrm{b}}$ & $39,31 \pm 0,29^{\mathrm{a}}$ & $39,53 \pm 0,62^{\mathrm{a}}$ & $38,93 \pm 0,51^{\mathrm{ab}}$ & $38,36 \pm 0,29^{\mathrm{b}}$ \\
VM 25 & $38,78 \pm 0,53$ & $39,36 \pm 0,41$ & $39,80 \pm 0,93$ & $39,21 \pm 0,39$ & $38,30 \pm 0,45$ \\
VM 34 & $38,56 \pm 0,33^{\mathrm{bc}}$ & $39,18 \pm 0,30^{\mathrm{ab}}$ & $39,38 \pm 0,30^{\mathrm{a}}$ & $38,61 \pm 0,29^{\mathrm{bc}}$ & $38,35 \pm 0,56^{\mathrm{c}}$ \\
VM + MON & $38,65 \pm 0,30^{\mathrm{ab}}$ & $39,26 \pm 0,12^{\mathrm{a}}$ & $39,40 \pm 0,49^{\mathrm{a}}$ & $39,23 \pm 0,50^{\mathrm{a}}$ & $38,33 \pm 0,63^{\mathrm{b}}$ \\
\hline
\end{tabular}

Fonte: (OLIVEIRA, F.L.C, 2018)

Efeito de tratamento $=0,6529 ;$ Efeito de tempo <.0001; Interação entre trat*tempo $=0,6629$

Notas: Letras maiúsculas distintas nas colunas significam diferença estatística entre os grupos.

Letras minúsculas distintas nas linhas significam diferença dentro de cada grupo.

Não houve diferença significativa desta variável entre os tratamentos. Observando o comportamento de cada grupo, percebe-se que no CON e VM 34 há um pico na $6^{\mathrm{a}} \mathrm{h}$ tendo uma diminuição progressiva nos momentos subsequentes. No MON valores mais elevados são notados na $3^{\mathrm{a}}$ e $6^{\mathrm{a}} \mathrm{h}$ em relação ao tempo basal e a $12^{\mathrm{a}} \mathrm{h}$, no $\mathrm{VM}+\mathrm{MON}$ a $18^{\mathrm{a}} \mathrm{h}$ possui menor valor comparando-se com a $3^{\mathrm{a}}, 6^{\mathrm{a}}$ e $12^{\mathrm{a}} \mathrm{h}$. No grupo VM 25 nota-se que não houve diferença. Não existiu relação significativa entre o tratamento e o tempo de coleta $(\mathrm{p}<0,6629)$.

Gráfico 27 - Valores médios da temperatura retal $\left({ }^{\circ} \mathrm{C}\right)$ nos bovinos dos grupos controle, monensina, virginiamicina $(25 \mathrm{ppm})$, virginiamicina $(34 \mathrm{ppm})$ e monensina + virginiamicina no decorrer do experimento - São Paulo - 2018.

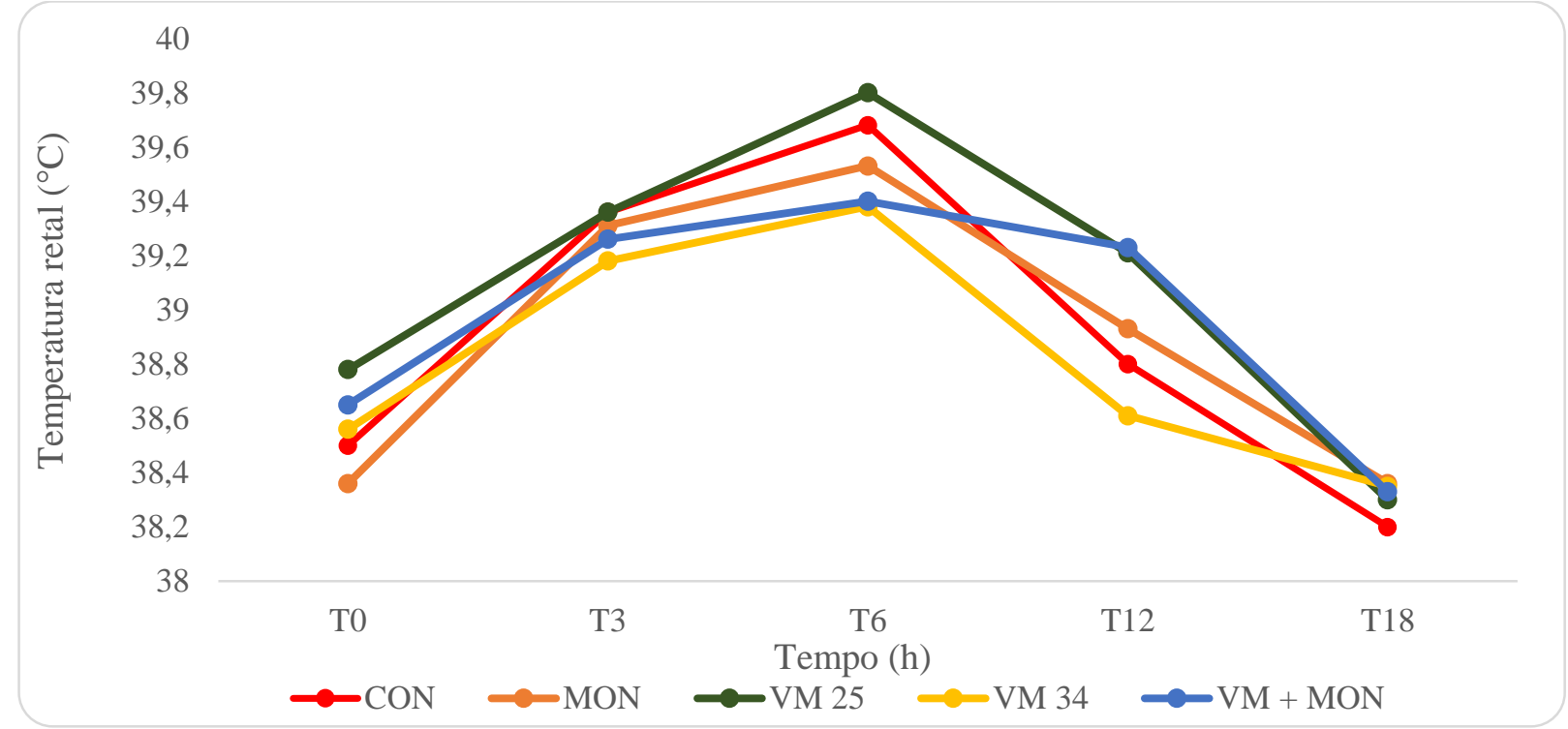

Fonte: (OLIVEIRA, F.L.C, 2018) 


\subsubsection{Movimento ruminal}

Na tabela 30 estão apresentados os resultados médios e desvios padrão do movimento ruminal no decorrer do experimento, e no gráfico 30 está ilustrado o comportamento desta variável.

Tabela 30 - Valores médios e desvios padrão do movimento ruminal (3 min.) nos bovinos dos grupos controle, monensina, virginiamicina (25 ppm), virginiamicina (34 ppm) e monensina + virginiamicina no decorrer do experimento - São Paulo - 2017.

\begin{tabular}{cccccc}
\hline & T0 & T3 & T6 & T12 & T18 \\
\hline CON & $2,8 \pm 0,6^{\mathrm{a}}$ & $2,2 \pm 06^{\mathrm{b}}$ & $1 \pm 0^{\mathrm{Bc}}$ & $1 \pm 0^{\mathrm{c}}$ & $1 \pm 0^{\mathrm{c}}$ \\
MON & $3,1 \pm 0,9^{\mathrm{a}}$ & $2,5 \pm 0,3^{\mathrm{a}}$ & $1,8 \pm 0,9^{\mathrm{ABbc}}$ & $1 \pm 0^{\mathrm{c}}$ & $1 \pm 0^{\mathrm{c}}$ \\
VM 25 & $2,7 \pm 0,4^{\mathrm{a}}$ & $2,5 \pm 0,8^{\mathrm{a}}$ & $1 \pm 0^{\mathrm{ABb}}$ & $1 \pm 0^{\mathrm{b}}$ & $1 \pm 0^{\mathrm{b}}$ \\
VM 34 & $2,9 \pm 0,5^{\mathrm{a}}$ & $2,9 \pm 0,5^{\mathrm{a}}$ & $1,2 \pm 0,6^{\mathrm{ABb}}$ & $1 \pm 0^{\mathrm{b}}$ & $1 \pm 0^{\mathrm{b}}$ \\
VM + MON & $2,6 \pm 0,5^{\mathrm{a}}$ & $2,5 \pm 0,3^{\mathrm{a}}$ & $1,9 \pm 0,7^{\mathrm{Aab}}$ & $1,2 \pm 0,6^{\mathrm{b}}$ & $1,2 \pm 0,6^{\mathrm{b}}$ \\
\hline
\end{tabular}

Fonte: (OLIVEIRA, F.L.C, 2018)

Efeito de tratamento $=0,021 ;$ Efeito de tempo $=<.0001$

Notas: Letras maiúsculas distintas nas colunas significam diferença estatística entre os grupos.

Letras minúsculas distintas nas linhas significam diferença dentro de cada grupo.

Compreensão dos dados convertidos (1=0 mov. $/ 3 \mathrm{~min} ; 1$ mov.=2,4/3min.; $2 \mathrm{mov} .=3,1 / 3 \mathrm{~min}$.; 3 mov. $=3,7 / 3 \mathrm{~min}$.; 4 mov. $=4,2 / 3 \mathrm{~min}$.)

Não teve diferença significativa do movimento ruminal entre os grupos. Observando cada grupo, percebe-se que no CON está havendo maior motilidade no tempo basal em comparação aos momentos subsequentes, já nos demais tratamentos este evento está acontecendo no tempo basal e $3^{\mathrm{a}} \mathrm{h}$. 
Gráfico 28 - Valores médios dos movimentos ruminais (3 min.) (dados reais, não transformados) nos bovinos dos grupos controle, monensina, virginiamicina $(25 \mathrm{ppm})$, virginiamicina $(34 \mathrm{ppm})$ e monensina + virginiamicina no decorrer do experimento - São Paulo - 2018.

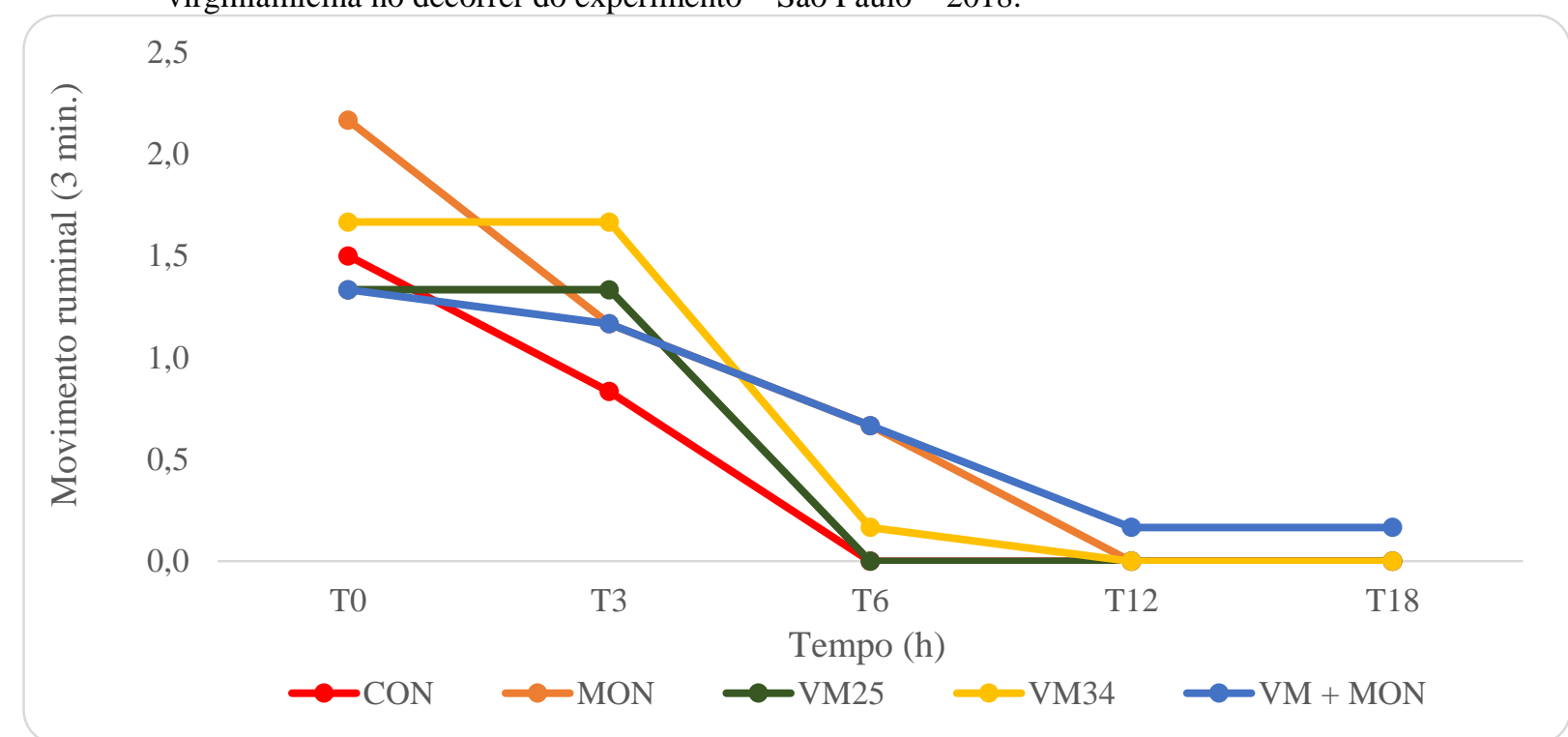

Fonte: (OLIVEIRA, F.L.C, 2018)

\subsection{VARIÁVEIS URINÁRIAS}

\subsection{1 pH da urina}

Na tabela 31 estão apresentados os resultados médios e desvios padrão do pH da urina no decorrer do experimento, e no gráfico 31 está ilustrado o comportamento desta variável.

Tabela 31 - Valores médios e desvios padrão do $\mathrm{pH}$ da urina nos bovinos dos grupos controle, monensina, virginiamicina $(25 \mathrm{ppm})$, virginiamicina $(34 \mathrm{ppm})$ e monensina + virginiamicina no decorrer do experimento - São Paulo - 2018.

\begin{tabular}{cccccc}
\hline & T0 & T3 & T6 & T12 & T18 \\
\hline COM & $6,09 \pm 0,86^{\mathrm{ab}}$ & $6,25 \pm 1,24^{\mathrm{ABba}}$ & $6,08 \pm 0,43^{\mathrm{ab}}$ & $5,80 \pm 0,21^{\mathrm{ab}}$ & $5,49 \pm 0,19^{\mathrm{b}}$ \\
MON & $5,62 \pm 0,26$ & $5,46 \pm 0,34^{\mathrm{B}}$ & $5,70 \pm 0,38$ & $5,78 \pm 0,27$ & $5,75 \pm 0,18$ \\
VM 25 & $5,96 \pm 1,05$ & $6,41 \pm 0,82^{\mathrm{AB}}$ & $6,49 \pm 1,04$ & $5,57 \pm 0,10$ & $5,63 \pm 0,33$ \\
VM 34 & $6,67 \pm 1,30^{\mathrm{ab}}$ & $7,12 \pm 1,19^{\mathrm{Aa}}$ & $6,52 \pm 1,13^{\mathrm{ab}}$ & $5,70 \pm 0,17^{\mathrm{ab}}$ & $5,49 \pm 0,16^{\mathrm{b}}$ \\
VM + MON & $6,63 \pm 0,96^{\mathrm{ab}}$ & $7,24 \pm 1,11^{\mathrm{Aa}}$ & $6,07 \pm 0,67^{\mathrm{ab}}$ & $5,98 \pm 0,36^{\mathrm{ab}}$ & $5,63 \pm 0,21^{\mathrm{b}}$ \\
\hline
\end{tabular}

Fonte: (OLIVEIRA, F.L.C, 2018)

Efeito de tratamento $=0,0257$ Efeito de tempo <.0001; Interação entre trat*tempo $=0,1051$

Notas: Letras maiúsculas distintas nas colunas significam diferença estatística entre os grupos.

Letras minúsculas distintas nas linhas significam diferença dentro de cada grupo. 
Fazendo uma análise entre os grupos, observa-se que o MON na $3^{\mathrm{a}} \mathrm{h}$ possui menor valor de pH urinário quando comparado ao CON, VM 34 e VM + MON, não havendo diferença nos demais tempos. Dentro de cada grupo, no tratamento CON, VM 34 e VM + MON percebe-se que na $3^{a}$ h houve um pico tendo uma diminuição progressiva nos demais tempos, no MON e VM 25 não foi observado diferença dentro do grupo. Não houve relação significativa entre o tratamento e o tempo de coleta $(\mathrm{p}<0,1051)$.

Gráfico 29 - Valores médios do pH da urina nos bovinos dos grupos controle, monensina, virginiamicina (25 $\mathrm{ppm})$, virginiamicina (34 ppm) e monensina + virginiamicina no decorrer do experimento - São Paulo -2018 .

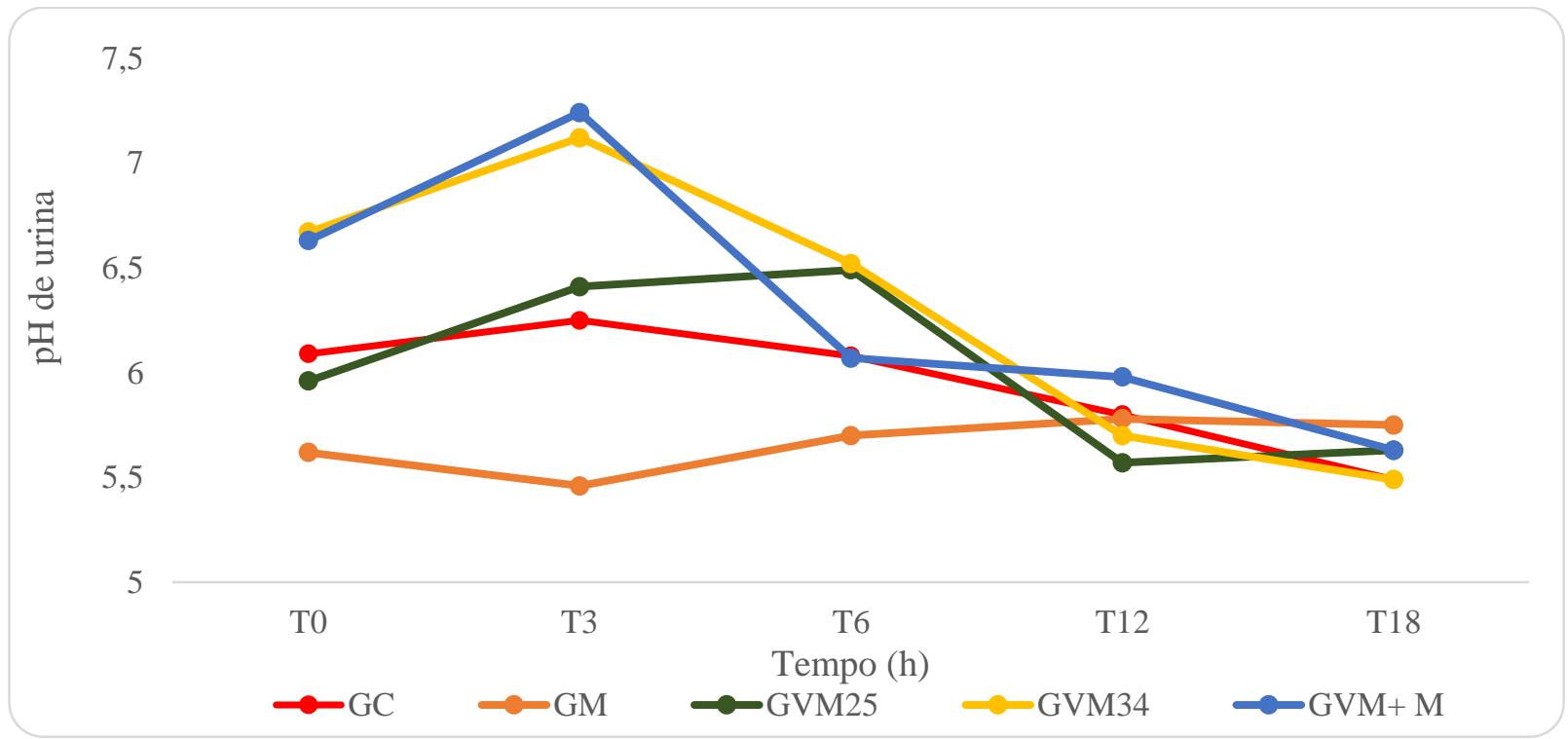

Fonte: (OLIVEIRA, F.L.C, 2018) 


\subsubsection{Densidade urinária}

Na tabela 32 estão apresentados os resultados médios e desvios padrão da densidade urinária no decorrer do experimento, e no gráfico 32 está ilustrado o comportamento desta variável.

Tabela 32 - Valores médios e desvios padrão da densidade urinária nos bovinos dos grupos controle, monensina, virginiamicina $(25 \mathrm{ppm})$, virginiamicina $(34 \mathrm{ppm})$ e monensina + virginiamicina no decorrer do experimento - São Paulo - 2018.

\begin{tabular}{cccccc}
\hline & T0 & T3 & T6 & T12 & T18 \\
\hline COM & $1014 \pm 7,78^{\mathrm{c}}$ & $1048 \pm 3,55^{\mathrm{a}}$ & $1051 \pm 3,57^{\mathrm{a}}$ & $1041 \pm 6,06^{\mathrm{ab}}$ & $1032 \pm 5,01^{\mathrm{b}}$ \\
MON & $1024 \pm 7,99^{\mathrm{b}}$ & $1047 \pm 7,06^{\mathrm{a}}$ & $1047 \pm 5,61^{\mathrm{a}}$ & $1041 \pm 10,63^{\mathrm{a}}$ & $1036 \pm 2,73^{\mathrm{ab}}$ \\
VM 25 & $1015 \pm 9,13^{\mathrm{c}}$ & $1038 \pm 9,49^{\mathrm{ab}}$ & $1046 \pm 3,91^{\mathrm{a}}$ & $1038 \pm 8,57^{\mathrm{ab}}$ & $1028 \pm 11,55^{\mathrm{bc}}$ \\
VM 34 & $1014 \pm 11,78^{\mathrm{c}}$ & $1040 \pm 9,39^{\mathrm{ab}}$ & $1045 \pm 6,15^{\mathrm{a}}$ & $1038 \pm 8,71^{\mathrm{ab}}$ & $1027 \pm 14,55^{\mathrm{bc}}$ \\
VM + MON & $1017 \pm 15,08^{\mathrm{b}}$ & $1041 \pm 6,54^{\mathrm{ab}}$ & $1048 \pm 3,94^{\mathrm{a}}$ & $1041 \pm 13,00^{\mathrm{ab}}$ & $1022 \pm 17,63^{\mathrm{b}}$ \\
\hline
\end{tabular}

Fonte: (OLIVEIRA, F.L.C, 2018)

Efeito de tratamento $=0,1651 ;$ Efeito de tempo <.0001; Interação entre trat*tempo $=0,9219$

Notas: Letras maiúsculas distintas nas colunas significam diferença estatística entre os grupos.

Letras minúsculas distintas nas linhas significam diferença dentro de cada grupo.

Não existiu diferença desta variável entre os grupos estudados, em cada um dos tempos avaliados. Na análise de cada grupo, no CON maior densidade urinaria é observada na $3^{\mathrm{a}}$ e $6^{\mathrm{a}}$ h; no MON está superioridade é constatada na $3^{\mathrm{a}}, 6^{\mathrm{a}}$ e $12^{\mathrm{a}} \mathrm{h}$ e nos tratamentos VM 25, VM 34 e VM + MON maior valor é notado na $6^{\mathrm{a}} \mathrm{h}$. Não houve relação significativa entre o tratamento e o tempo de coleta $(\mathrm{p}<0,9219)$. 
Gráfico 30 - Valores médios da densidade urinária nos bovinos dos grupos controle, monensina, virginiamicina (25 ppm), virginiamicina (34 ppm) e monensina + virginiamicina no decorrer do experimento - São Paulo - 2018.

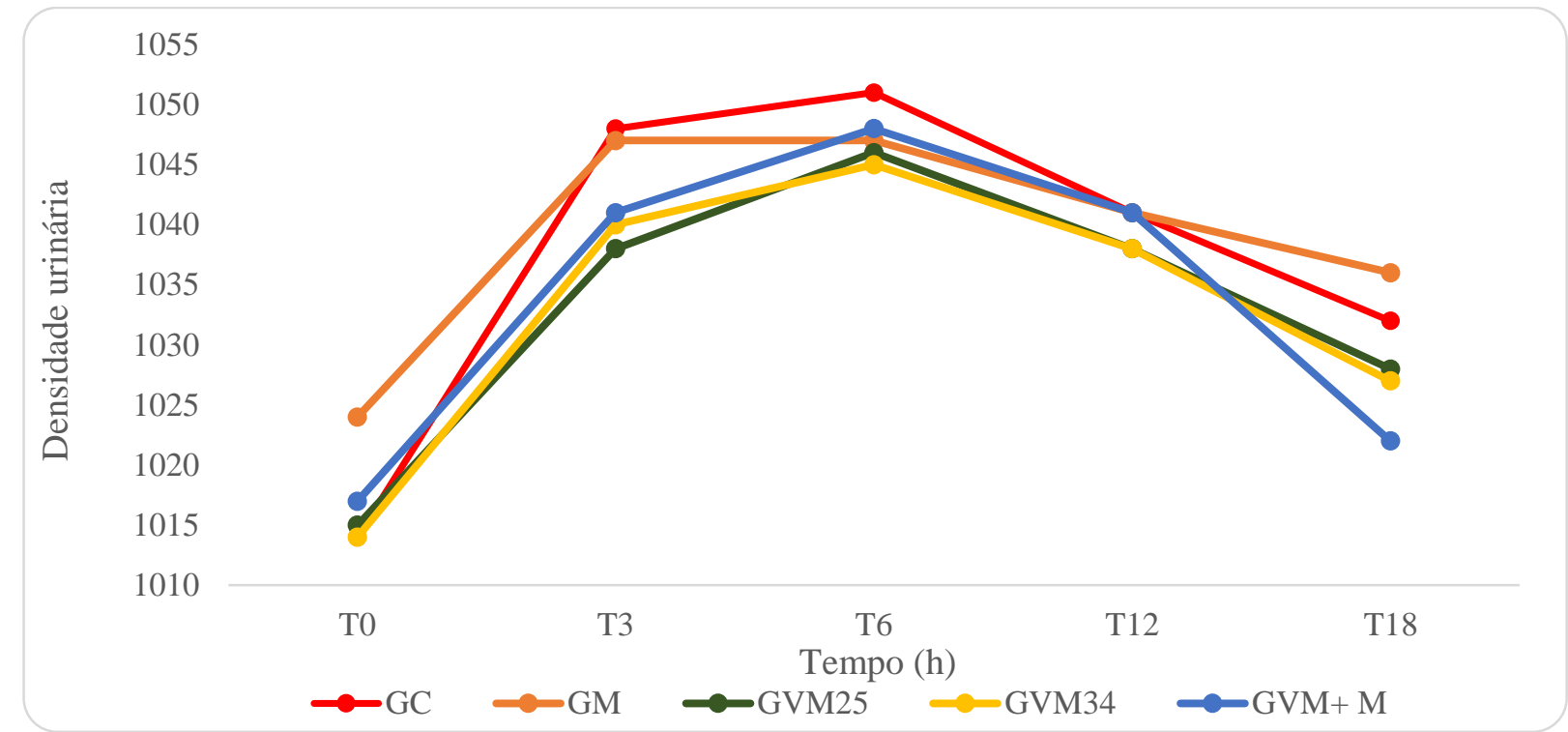

Fonte: (OLIVEIRA, F.L.C, 2018)

\subsection{VARIÁVEL FECAL}

\subsection{1 pH fecal}

Na tabela 33 estão apresentados os resultados médios e desvios padrão do pH fecal no decorrer do experimento, e no gráfico 33 está ilustrado o comportamento desta variável.

Tabela 33 - Valores médios e desvios padrão do $\mathrm{pH}$ fecal nos bovinos dos grupos controle, monensina, virginiamicina $(25 \mathrm{ppm})$, virginiamicina $(34 \mathrm{ppm})$ e monensina + virginiamicina no decorrer do experimento - São Paulo - 2018.

\begin{tabular}{cccccc}
\hline & T0 & T3 & T6 & T12 & T18 \\
\hline COM & $6,93 \pm 0,21^{\mathrm{a}}$ & $7,00 \pm 0,22^{\mathrm{a}}$ & $6,62 \pm 0,85^{\mathrm{a}}$ & $5,18 \pm 0,15^{\mathrm{b}}$ & $6,29 \pm 0,46^{\mathrm{a}}$ \\
MON & $6,73 \pm 0,30^{\mathrm{a}}$ & $6,98 \pm 0,42^{\mathrm{a}}$ & $6,88 \pm 0,20^{\mathrm{a}}$ & $5,55 \pm 0,48^{\mathrm{b}}$ & $5,96 \pm 0,58^{\mathrm{b}}$ \\
VM 25 & $6,91 \pm 0,32^{\mathrm{a}}$ & $7,08 \pm 0,27^{\mathrm{a}}$ & $6,84 \pm 0,66^{\mathrm{a}}$ & $5,72 \pm 0,75^{\mathrm{b}}$ & $6,30 \pm 0,90^{\mathrm{ab}}$ \\
VM 34 & $7,00 \pm 0,26^{\mathrm{a}}$ & $6,96 \pm 0,26^{\mathrm{a}}$ & $6,96 \pm 0,23^{\mathrm{a}}$ & $5,69 \pm 0,79^{\mathrm{b}}$ & $5,89 \pm 0,79^{\mathrm{b}}$ \\
VM + MON & $6,66 \pm 0,16^{\mathrm{a}}$ & $7,02 \pm 0,22^{\mathrm{a}}$ & $7,14 \pm 0,16^{\mathrm{a}}$ & $5,73 \pm 0,78^{\mathrm{b}}$ & $5,62 \pm 0,56^{\mathrm{b}}$ \\
\hline
\end{tabular}

Fonte: (OLIVEIRA, F.L.C, 2018)

Efeito de tratamento $=0,145 ;$ Efeito de tempo $=<.0001$

Notas: Letras maiúsculas distintas nas colunas significam diferença estatística entre os grupos.

Letras minúsculas distintas nas linhas significam diferença dentro de cada grupo. 
Não houve diferença entre os grupos em nenhum dos momentos avaliados. Analisando cada grupo individualmente, observa-se que no $\mathrm{CON}$ a $12^{\mathrm{a}} \mathrm{h}$ possui o menor valor em relação aos demais tempos; nos tratamentos MON, VM 34 e VM + MON o tempo basal, a $3^{\mathrm{a}}$ e $6^{\mathrm{a}} \mathrm{h}$ possuem valores superiores a $12^{\mathrm{a}}$ e $18^{\mathrm{a}} \mathrm{h}$ e no VM 25 maiores valores são notados no tempo basal, a $3^{\mathrm{a}}$ e $6^{\mathrm{a}} \mathrm{h}$ em relação a $12^{\mathrm{a}} \mathrm{h}$.

Gráfico 31 - Valores médios do pH fecal nos bovinos dos grupos controle, monensina, virginiamicina (25 ppm), virginiamicina $(34 \mathrm{ppm})$ e monensina + virginiamicina no decorrer do experimento - São Paulo - 2018.

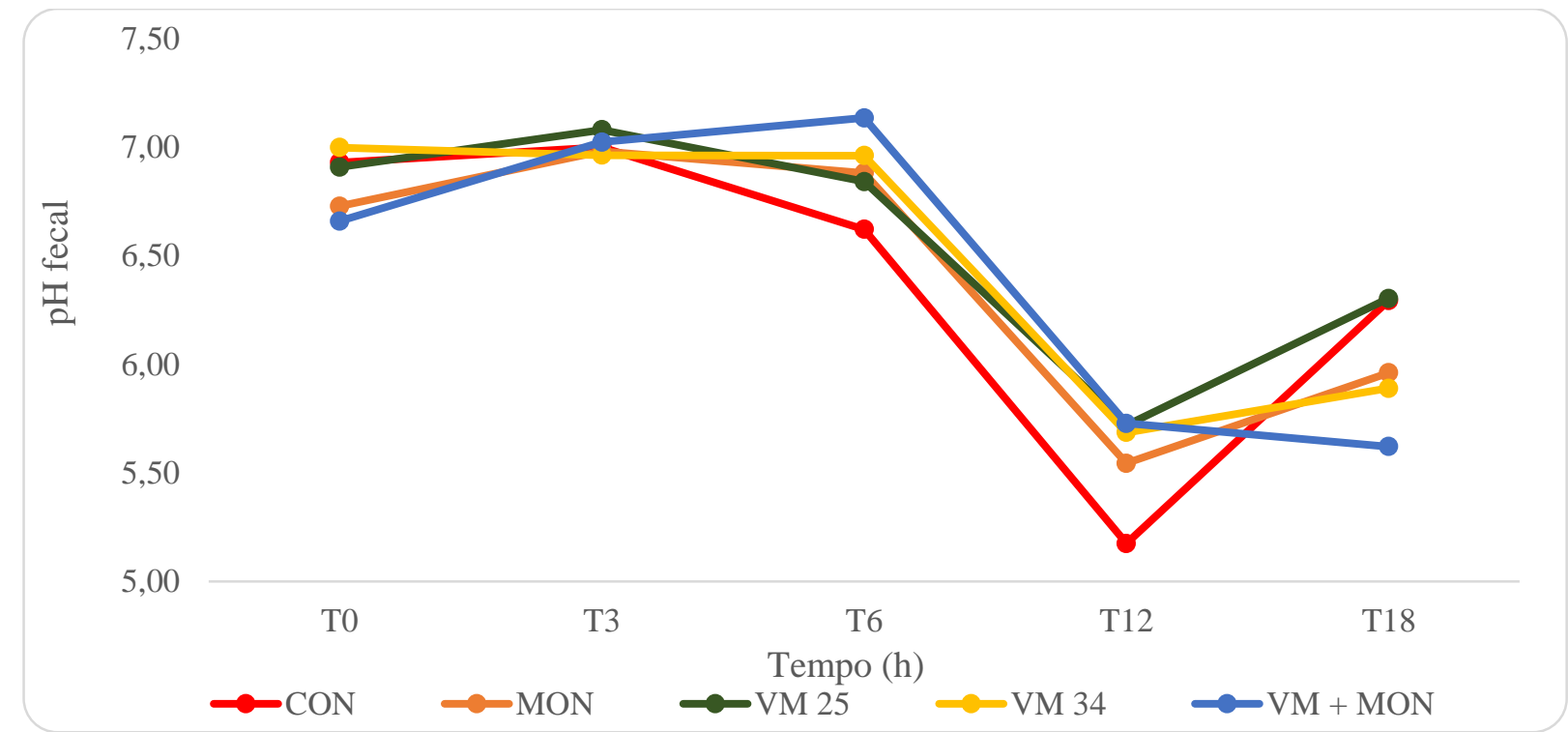

Fonte: (OLIVEIRA, F.L.C, 2018) 


\subsection{RELAÇÕES ENTRE VARIÁVEIS}

\subsubsection{Relação entre pH e concentração de glicose do conteúdo ruminal}

O gráfico 32 apresenta a correlação entre pH e concentração de glicose do conteúdo ruminal nos bovinos. Para esta análise foram considerados todos os dados disponíveis das duas variáveis sem distinção de grupo.

Gráfico 32 - Relação entre pH e a concentração de glicose (mM/L) do conteúdo ruminal dos bovinos no decorrer do experimento. - São Paulo - 2018.

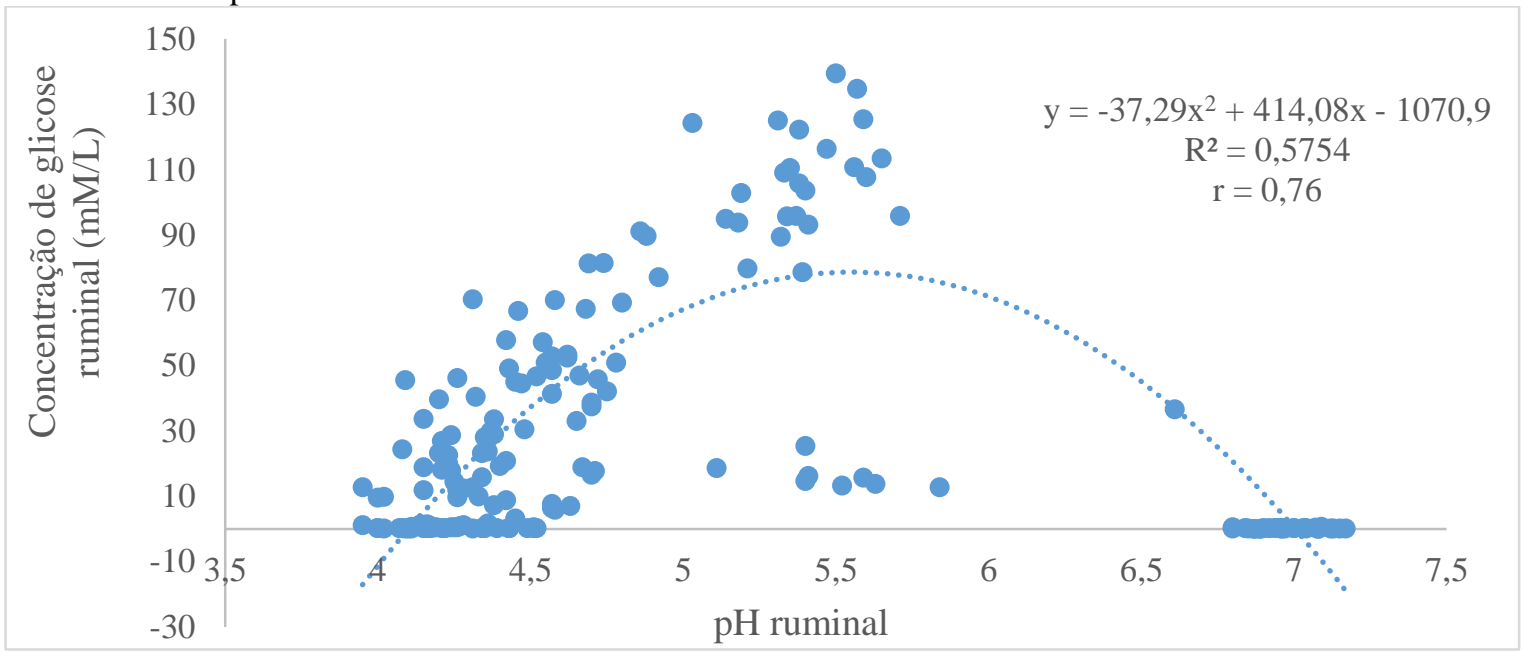

Fonte: (OLIVEIRA, F.L.C, 2018) 
6.7.2 Relação entre lactato - $L$ e concentração de acetato do conteúdo ruminal na $3^{\mathrm{a}}$ hora do grupo VM + MON

O gráfico 33 apresenta a correlação entre a concentração de lactato - L e acetato do conteúdo ruminal nos bovinos. Para esta análise foram considerados os dados disponíveis das duas variáveis na $3^{\mathrm{a}} \mathrm{h}$ do grupo $\mathrm{VM}+\mathrm{MON}$.

Gráfico 33 - Relação entre lactato - L (mM/L) e a concentração de acetato (mM/L) do conteúdo ruminal dos bovinos no decorrer da $3^{\mathrm{a}} \mathrm{h}$ do grupo VM + MON - São Paulo - 2018

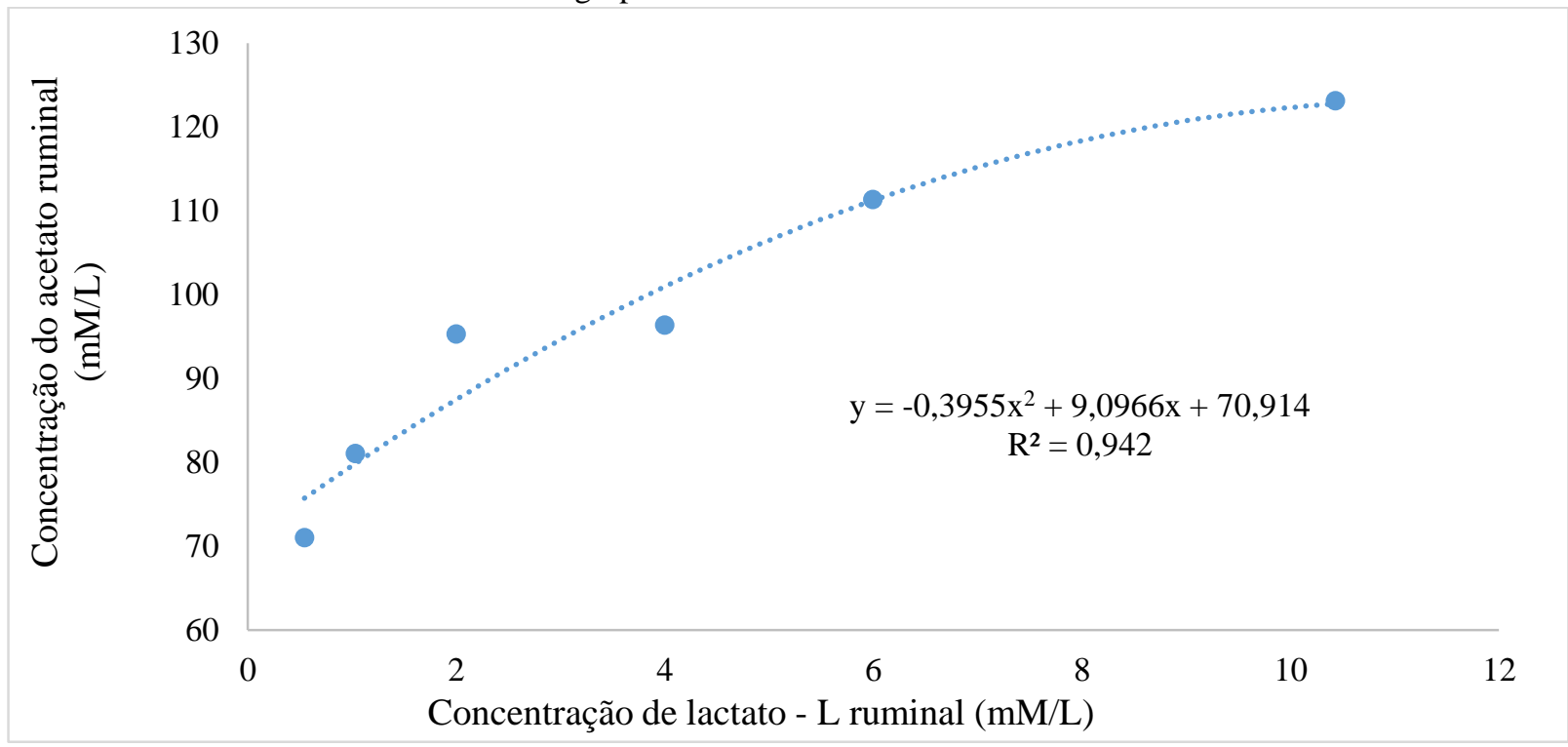

Fonte: (OLIVEIRA, F.L.C, 2018) 
6.7.3 Relação entre lactato - $L$ e concentração de acetato do conteúdo ruminal na $6^{a}$ hora do grupo VM + MON

O gráfico 34 apresenta a correlação entre a concentração de lactato - L e acetato do conteúdo ruminal nos bovinos. Para esta análise foram considerados os dados disponíveis das duas variáveis na $6^{\mathrm{a}} \mathrm{h}$ do grupo $\mathrm{VM}+\mathrm{MON}$.

Gráfico 34 - Relação entre lactato - L (mM/L) e a concentração de acetato (mM/L) do conteúdo ruminal dos bovinos no decorrer da $6^{\mathrm{a}} \mathrm{h}$ do grupo VM + MON - São Paulo - 2018

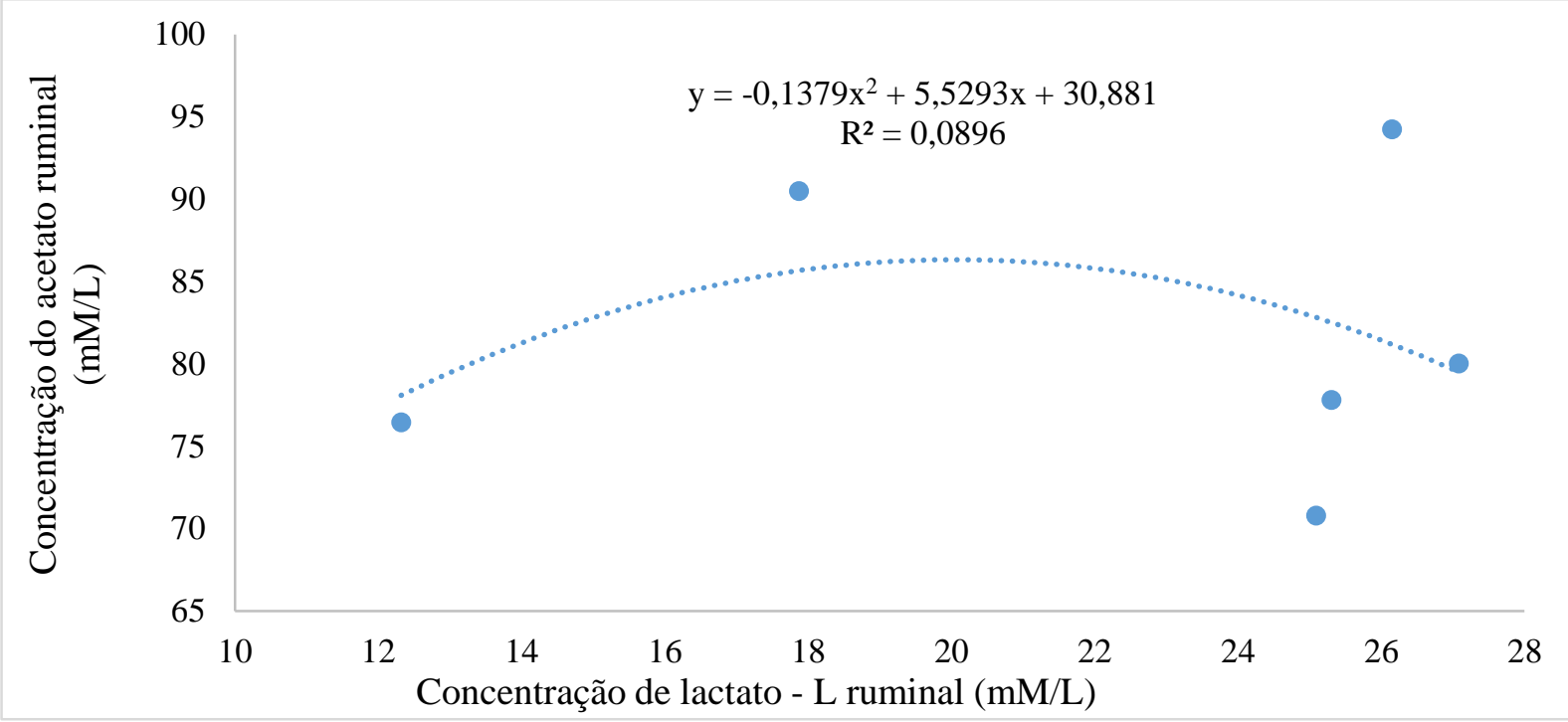

Fonte: (OLIVEIRA, F.L.C, 2018) 
6.7.4 Relação entre lactato - $L$ e concentração de acetato do conteúdo ruminal na $3^{\mathrm{a}}$ hora do grupo CON, MON, VM 25 E VM 34

O gráfico 35 apresenta a correlação entre a concentração de lactato - L e acetato do conteúdo ruminal nos bovinos. Para esta análise foram considerados os dados disponíveis das duas variáveis na $3^{\mathrm{a}} \mathrm{h}$ do grupo CON, MON, VM 25 E VM 34.

Gráfico 35 - Relação entre lactato - L (mM/L) e a concentração de acetato $(\mathrm{mM} / \mathrm{L})$ do conteúdo ruminal dos bovinos no decorrer da $3^{\mathrm{a}} \mathrm{h}$ do grupo CON, MON, VM 25 E VM 34 - São Paulo - 2018

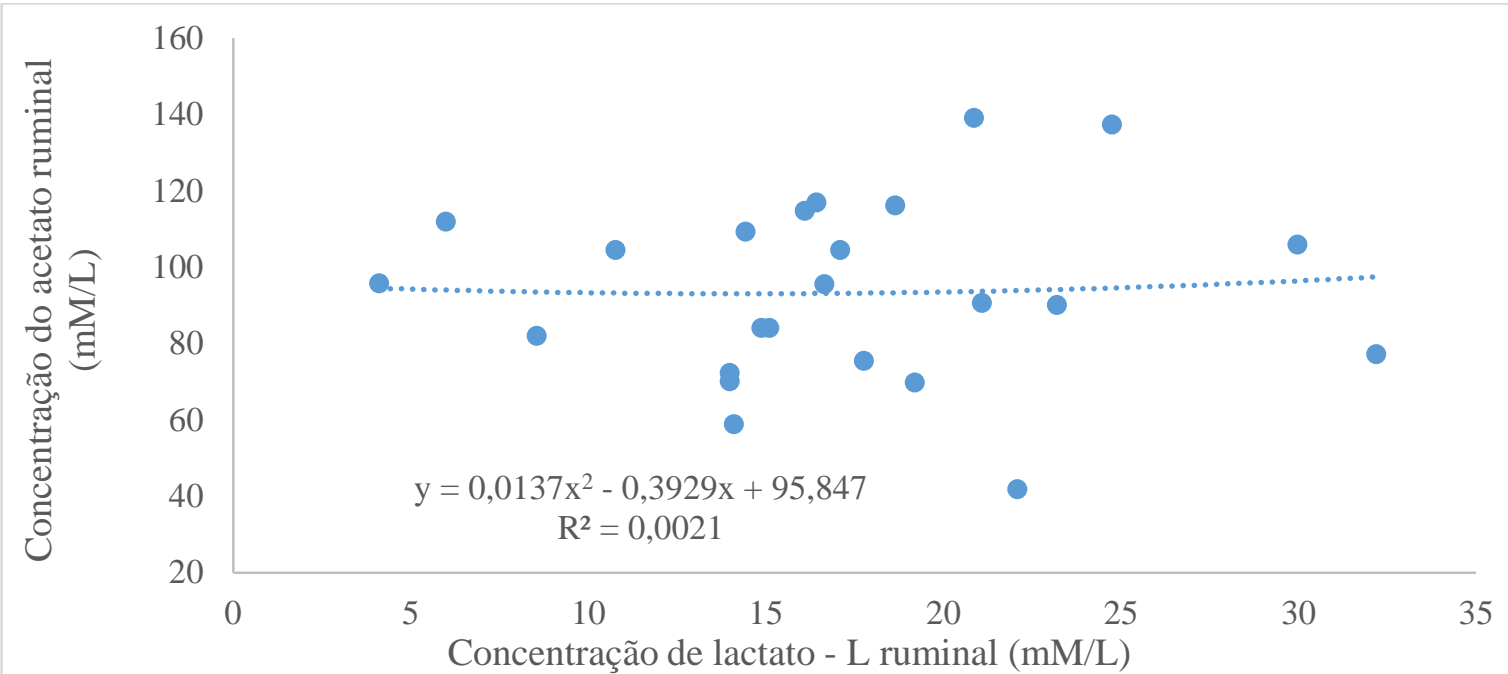

Fonte: (OLIVEIRA, F.L.C, 2018) 


\subsubsection{Relação entre a concentração de lactato - L e propionato do conteúdo ruminal no grupo VM + M, excluído o tempo basal}

O gráfico 36 apresenta a correlação entre a concentração de lactato -L e propionato do conteúdo ruminal nos bovinos. Para esta análise foram considerados os dados disponíveis das duas variáveis no grupo $\mathrm{VM}+\mathrm{M}$, com exceção do tempo basal que foi excluído.

Gráfico 36 - Relação entre a concentração de lactato - L (mM/L) e propionato do conteúdo ruminal (mM/L) nos bovinos, considerados os dados disponíveis das duas variáveis no grupo $\mathrm{VM}+\mathrm{M}$, com exceção do tempo basal - São Paulo - 2018.

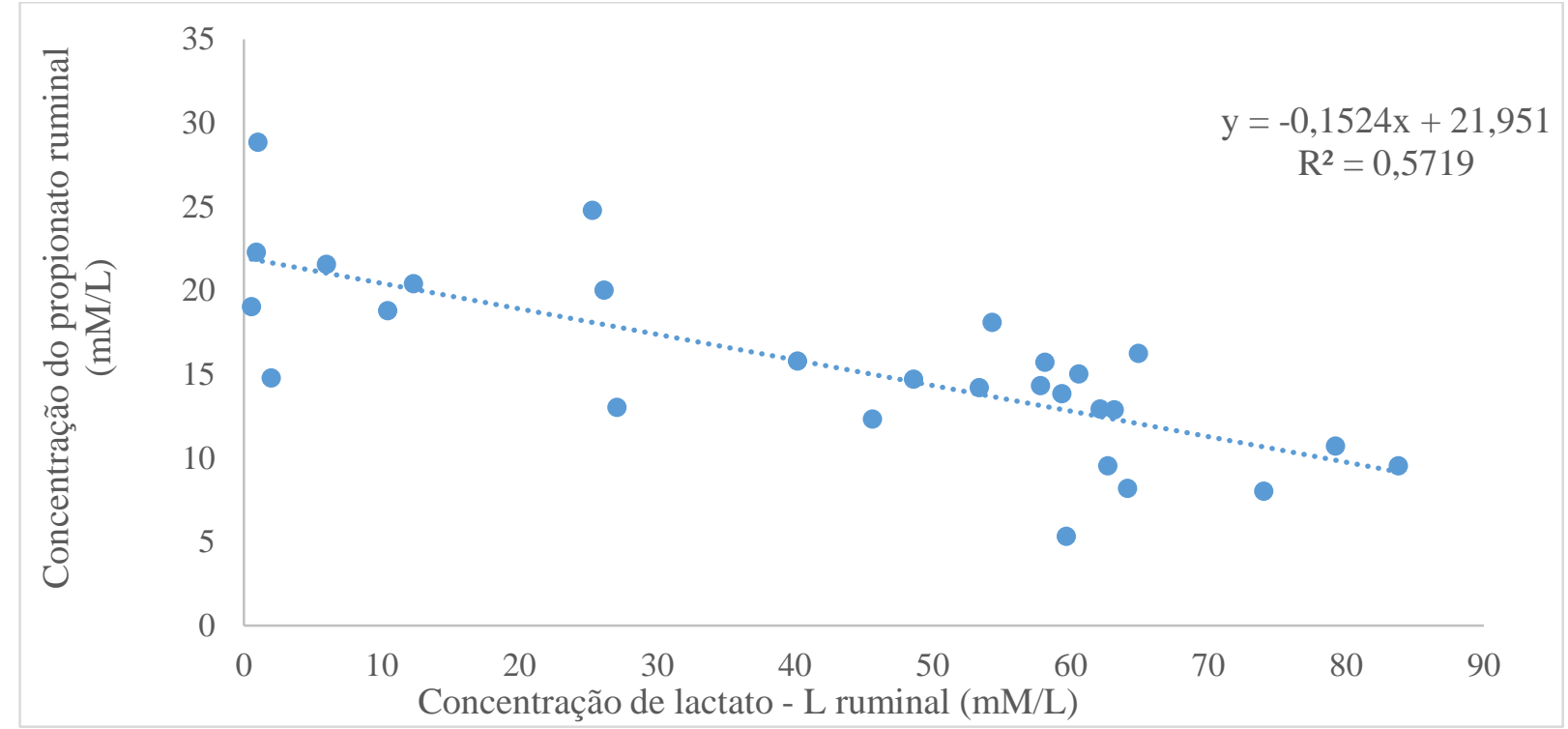

Fonte: (OLIVEIRA, F.L.C, 2018) 


\subsubsection{Relação entre a concentração de lactato - $L$ e propionato do conteúdo ruminal nos grupos C, M, VM 25 E VM 34, excluído o tempo basal}

O gráfico 37 apresenta a correlação entre a concentração de lactato - L e propionato do conteúdo ruminal nos bovinos. Para esta análise foram considerados todos os dados disponíveis das duas variáveis sem distinção de grupo, com exceção do tempo basal que foi excluído.

Gráfico 37 - Relação entre a concentração de lactato - L (mM/L) e propionato do conteúdo ruminal (mM/L) nos bovinos, considerados os dados disponíveis das duas variáveis no grupo C, M, VM 25 e VM34, com exceção do tempo basal - São Paulo - 2018.

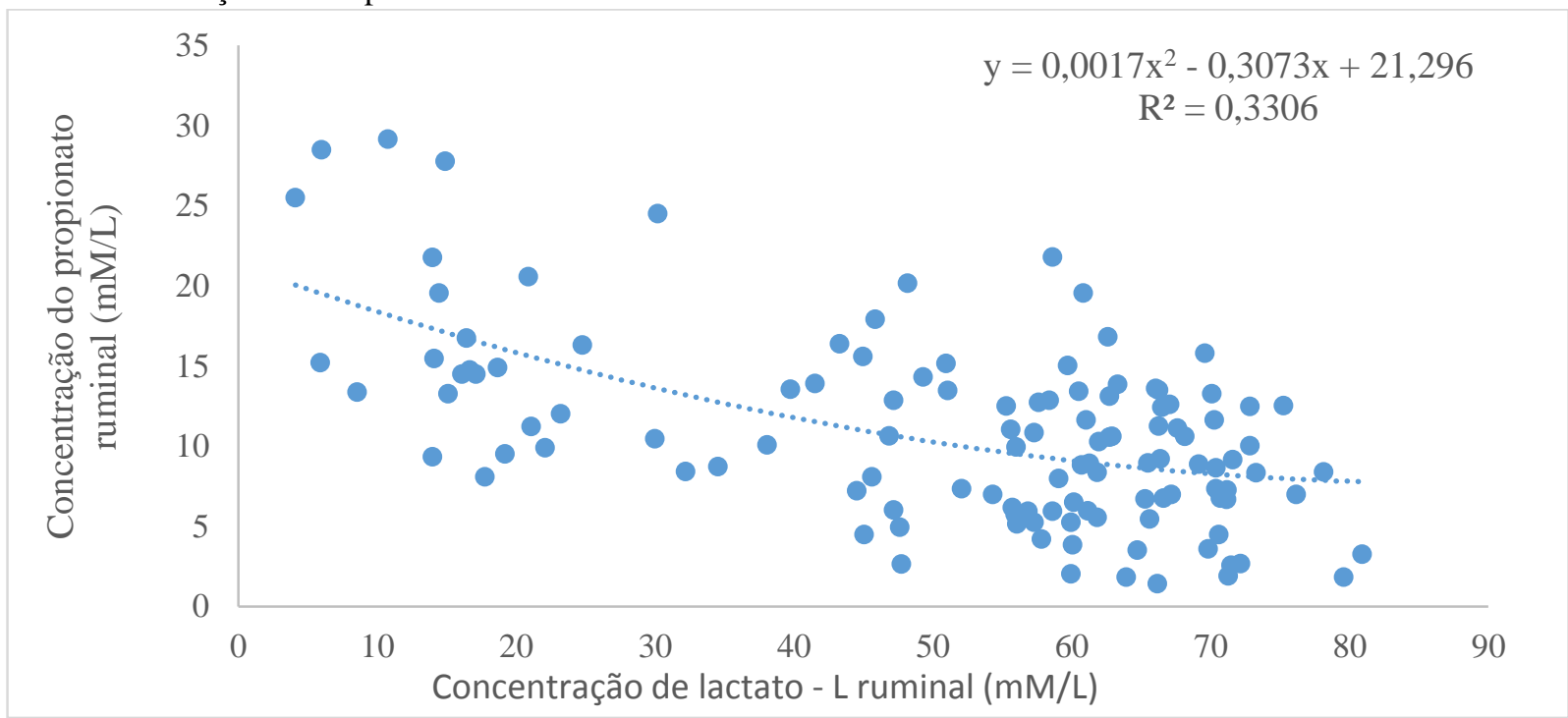

Fonte: (OLIVEIRA, F.L.C, 2018) 


\subsubsection{Relação entre pH e concentração de propionato do conteúdo ruminal na $6^{\mathrm{a}}$ hora}

O gráfico 38 apresenta a correlação entre pH e concentração de propionato do conteúdo ruminal nos bovinos. Para esta análise foram considerados os dados disponíveis das duas variáveis sem distinção de grupo, onde foi usado apenas os dados da $6^{\mathrm{a}}$ hora.

Gráfico 38 - Relação entre pH e a concentração de propionato (mM/L) do conteúdo ruminal dos bovinos no decorrer da $6^{\mathrm{a}} \mathrm{h}$ do experimento sem distinção de grupo. - São Paulo - 2018

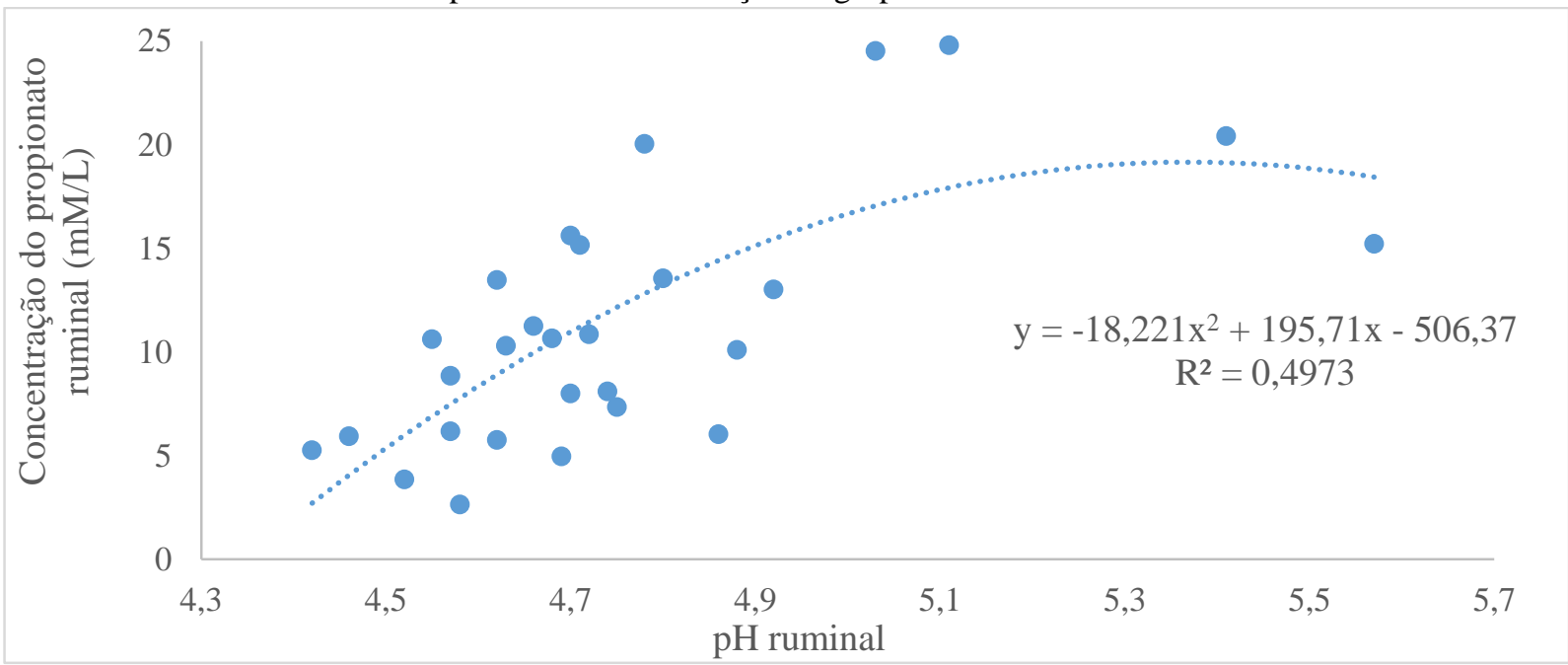

Fonte: (OLIVEIRA, F.L.C, 2018) 
Tabela 34. - Coeficientes de correlação entre as diferentes variáveis dos animais submetidos à indução da acidose láctica ruminal por sacarose.

\begin{tabular}{|c|c|c|c|c|c|c|c|c|c|c|c|c|c|c|}
\hline Variáveis & 1 & 2 & 3 & 4 & 5 & 6 & 7 & 8 & 9 & 10 & 11 & 12 & 13 & 14 \\
\hline $\mathrm{pH}(1)$ & 1 & $\begin{array}{c}0,76 \\
P<0,0001\end{array}$ & $\begin{array}{c}-0,88 \\
P<0,0001\end{array}$ & $\begin{array}{c}-0,72 \\
P<0,0001\end{array}$ & $\begin{array}{c}0,73 \\
P<0,0001\end{array}$ & - & - & - & $\begin{array}{c}-0,96 \\
P<0,0001\end{array}$ & - & - & - & - & - \\
\hline Glicose ruminal (2) & & 1 & - & - & - & - & $\begin{array}{c}0,47 \\
P<0,0001\end{array}$ & - & - & - & - & - & $\begin{array}{c}0,50 \\
P<0,0001\end{array}$ & - \\
\hline Lactato - L ruminal (3) & & & 1 & - & - & $\begin{array}{c}-0,63 \\
P<0,0001\end{array}$ & - & - & - & - & - & - & - & $\begin{array}{c}-0,32 \\
P<0,0001\end{array}$ \\
\hline Lactato - D ruminal (4) & & & & 1 & - & - & $\begin{array}{c}-0,35 \\
P=0,002\end{array}$ & - & - & - & - & - & - & - \\
\hline Total de AGCC (5) & & & & & 1 & - & - & - & - & $\begin{array}{c}-0,60 \\
P<0,0001\end{array}$ & - & $\begin{array}{c}0,54 \\
P<0,0001 \\
\end{array}$ & - & - \\
\hline Acetato ruminal (6) & & & & & & 1 & - & - & - & - & - & - & - & - \\
\hline Osmolaridade ruminal (7) & & & & & & & 1 & $\begin{array}{c}0,50 \\
P<0,0001\end{array}$ & - & - & - & - & - & - \\
\hline Total de ácidos ruminais (8) & & & & & & & & 1 & - & - & - & - & - & - \\
\hline POR (9) & & & & & & & & & 1 & - & - & - & - & - \\
\hline Acidez Titulável (10) & & & & & & & & & & 1 & - & - & - & - \\
\hline Lactato - D sanguíneo (11) & & & & & & & & & & & 1 & $\begin{array}{c}-0,63 \\
P<0,0001\end{array}$ & - & - \\
\hline pH sangue (12) & & & & & & & & & & & & 1 & - & $\begin{array}{c}0,31 \\
P<0,0001\end{array}$ \\
\hline Glicose sanguínea (13) & & & & & & & & & & & & & 1 & $\begin{array}{c}0,54 \\
P<0,0001\end{array}$ \\
\hline Lactato - L sanguíneo (14) & & & & & & & & & & & & & & 1 \\
\hline
\end{tabular}


Tabela 35. - Coeficientes de correlação entre as diferentes variáveis dos animais submetidos à indução da acidose láctica ruminal por sacarose.

\begin{tabular}{|c|c|c|c|c|c|c|c|c|c|c|c|c|c|c|}
\hline Variáveis & 1 & 2 & 3 & 4 & 5 & 6 & 7 & 8 & 9 & 10 & 11 & 12 & 13 & 14 \\
\hline Osmolaridade ruminal (1) & 1 & $\begin{array}{c}0,23 \\
P<0,005\end{array}$ & - & - & - & - & - & - & - & - & - & - & - & - \\
\hline DVP (2) & & 1 & $\begin{array}{c}-0,63 \\
P<0,0001\end{array}$ & - & - & - & - & - & - & - & - & - & $\begin{array}{c}-0,34 \\
P<0,0001\end{array}$ & - \\
\hline Lactato total do rúmen (3) & & & 1 & $\begin{array}{c}-0,54 \\
P<0,0001\end{array}$ & - & - & - & - & - & - & - & - & - & - \\
\hline $\mathrm{pH}$ fecal (4) & & & & 1 & - & - & - & - & - & - & - & - & - & - \\
\hline POR (5) & & & & & 1 & $\begin{array}{c}0,93 \\
P<0,0001\end{array}$ & - & - & - & - & - & - & - & - \\
\hline Lactato total do rúmen (6) & & & & & & 1 & $\begin{array}{c}0,86 \\
P<0,0001\end{array}$ & - & - & - & - & - & - & - \\
\hline Acidez titúlavel (7) & & & & & & & 1 & - & - & - & - & - & - & - \\
\hline Lactato L sanguíneo (8) & & & & & & & & 1 & $\begin{array}{c}0,31 \\
P<0,0001\end{array}$ & $\begin{array}{c}0,32 \\
P<0,0001\end{array}$ & - & - & - & - \\
\hline Bicarbonato (9) & & & & & & & & & 1 & - & - & - & - & - \\
\hline $\mathrm{EAB}(10)$ & & & & & & & & & & 1 & - & - & - & - \\
\hline $\mathrm{pH}$ ruminal (11) & & & & & & & & & & & 1 & $\begin{array}{c}0,80 \\
P<0,0001\end{array}$ & - & - \\
\hline Movimento de rúmen (12) & & & & & & & & & & & & 1 & - & - \\
\hline Frequência cardíaca (13) & & & & & & & & & & & & & 1 & $\begin{array}{c}0,50 \\
P<0,0001\end{array}$ \\
\hline Volume Globular (14) & & & & & & & & & & & & & & 1 \\
\hline
\end{tabular}


Tabela 36. - Coeficientes de correlação entre as diferentes variáveis dos animais submetidos à indução da acidose láctica ruminal por sacarose.

\begin{tabular}{|c|c|c|c|c|c|c|c|c|c|c|}
\hline Variáveis & 1 & 2 & 3 & 4 & 5 & 6 & 7 & 8 & 9 & 10 \\
\hline Glicose ruminal (1) & 1 & $\begin{array}{c}0,49 \\
P<0,0001\end{array}$ & - & - & - & - & $\begin{array}{c}0,59 \\
P<0,0001\end{array}$ & - & - & - \\
\hline Temperatura retal (2) & & 1 & - & - & - & - & - & - & - & - \\
\hline pH sanguíneo (3) & & & 1 & $\begin{array}{c}0,39 \\
P<0,0001\end{array}$ & - & - & - & - & - & - \\
\hline $\mathrm{pH}$ urina (4) & & & & 1 & $\begin{array}{c}0,48 \\
P<0,0001\end{array}$ & $\begin{array}{c}0,49 \\
P<0,0001\end{array}$ & - & - & - & - \\
\hline$A B E(5)$ & & & & & 1 & - & - & - & - & - \\
\hline Bicarbonato (6) & & & & & & 1 & - & - & - & - \\
\hline Densidade urinaria (7) & & & & & & & 1 & $\begin{array}{c}0,55 \\
P<0,0001\end{array}$ & $\begin{array}{c}0,13 \\
P=0,11\end{array}$ & $\begin{array}{c}0,53 \\
P<0,0001\end{array}$ \\
\hline $\begin{array}{c}\text { Osmolaridade sanguínea } \\
\text { (8) }\end{array}$ & & & & & & & & 1 & - & - \\
\hline DVP (9) & & & & & & & & & 1 & - \\
\hline $\begin{array}{l}\text { Total de ácidos orgânicos } \\
\text { (10) }\end{array}$ & & & & & & & & & & 1 \\
\hline
\end{tabular}




\section{DISCUSSÃO}

Esse capítulo será dividido em dois segmentos. No primeiro deles serão discutidos os resultados referentes aos efeitos gerais do modelo de indução de ALR sobre a acidose ruminal, sistêmica, quadro clínico e demais variáveis, independente dos tratamentos testados. No remanescente se abordará as influências causadas pelos diferentes tratamentos visando a prevenção da ALR.

\subsection{EFEITOS GERAIS DO MODELO DE INDUÇÃO}

O experimento atingiu suas metas e permitiu uma perfeita comparação entre os diferentes aditivos e trouxe importantes contribuições para o melhor entendimento do modelo experimental de ALR proposto por Ortolani (1995), visto que em empregos anteriores do protocolo não foram estudadas variáveis como os ácidos graxos de cadeia curta (AGCC), teores de glicose ruminal, potencial de oxido-redução e total de ácidos orgânicos ruminais, além do fato que até então não se tinha estudado estas e outras variáveis precocemente nas primeiras 12 h do protocolo (MENDES NETTO, 1997; MARUTA, 2000, LEAL et al., 2007; RODRIGUES, 2009).

Pode-se afirmar que a indução provocou ALR, no grupo controle, de grau intenso considerando que o $\mathrm{pH}$ ruminal atingiu em alguns momentos valores inferiores a 4,0 e acima de $10 \mathrm{~h}$, na maioria dos tratamentos, teores de lactato acima de $40 \mathrm{mM} / \mathrm{L}$, como caracterizado em importante revisão do assunto (OWENS et al., 1998).

A primeira constatação foi de que a acidose inicial que normalmente é decorrente de acúmulo de AGCC é bem mais curta que a enfermidade natural, que geralmente dura 8 a $10 \mathrm{~h}$ e que neste protocolo durou um pouco mais de 3h (OWENS, 1998). A segunda 
verificação foi que já na $3^{\mathrm{a}} \mathrm{h}$ ocorreu um aumento exponencial de ácido láctico $\mathrm{L}$ ruminal, enquanto que num quadro natural só se manifesta a partir da $12^{\mathrm{a}} \mathrm{h}$ (OWENS, 1998). Chama a atenção também o predomínio de ácido láctico $\mathbf{L}$ em relação ao seu isômero $\mathbf{D}$. Tudo indica que o substrato empregado no modelo brasileiro, a sacarose, favorece o crescimento de Lactobacillus ruminis que sintetiza primordialmente o isômero $\mathrm{L}$, em detrimento do Lactobacillus vitulinus que gera apenas a segunda forma (NAGARAJA; TITGEMEYER, 2007). A osmolaridade ruminal provocada pela acidose foi máxima na $3^{\mathrm{a}} \mathrm{h}$, quando ocorriam maiores teores de ácidos orgânicos totais e de glicose no rúmen.

A indução gerou rápida diminuição no pH ruminal em todos os tratamentos já na $\mathbf{3}^{\mathbf{a}} \mathbf{h}$ do processo, apresentando progressiva acidose, a qual culminou com os menores valores na $18^{\mathbf{a}} \mathbf{h}$ (Tabela 1; Gráfico 1), momento este em que se encerrou o experimento devido ao exaurimento do substrato, visto que o teor de glicose ruminal foi semelhante entre o tempo basal e a $18^{\mathrm{a}} \mathrm{h}$. Assim, a fermentação ruminal foi paralelamente acompanhada pela dinâmica do $\mathrm{pH}$ e pelo teor de glicose ruminal, o qual funcionou como um indicador da presença de substrato ainda a ser fermentado e o grau de utilização deste durante a acidose, visto que a correlação foi alta entre estas duas variáveis $\left(r=0,76 ; \mathrm{R}^{2}=0,5754\right.$, Tabela 34) (Tabela 2; Gráfico 2 e 32). O gráfico 32 representa uma quadrática. No tempo basal a glicose ruminal era mínima, quando a fermentação também o era. A sacarose foi altamente desdobrada em glicose quando o pH ruminal se encontrava em torno de 5,5 provocado pela produção inicial de AGCC, com alguma contribuição do lactato total, declinando em seguida assim que o pH foi se tornando menor, o que indicou que esse açúcar estava plenamente sendo convertido para ácido láctico. A literatura consultada é lacônica e vaga quanto a essa sequência cronológica dos eventos.

Quanto aos teores de glicose constatou-se no presente trabalho que, semelhante ao descrito por SLYTER (1976), essas concentrações no rúmen foram muito superiores as detectadas no sangue no auge de seus valores (Tabelas 2 e 24; Gráfico 2 e 24). 
Ocorreu um acúmulo de ácido acético na $3^{\mathbf{a}} \mathbf{h}$, praticamente dobrando sua concentração em relação ao tempo basal (Tabela 7; Gráfico 7). De acordo com a literatura clássica a diminuição do $\mathrm{pH}$ inferior a 6,2 bloqueia a atividade das bactérias celulolíticas, produtoras maiores de ácido acético (HUNGATE, 1966). Assim, a fermentação da sacarose não deveria produzir como produto final o ácido acético. Contudo, num experimento in vitro Russel e Hino (1985) verificaram que nas fases iniciais do processo fermentativo ruminal com excesso de glicose, quando o pH ainda está entre na casa do dígito 6,0, gerou-se uma produção abundante de ácido acético, o qual foi constatado no presente experimento na $3^{\mathrm{a}} \mathrm{h}$. Counette; Prinz (1981) identificaram que no processo inicial de acidose a lactato desidrogenase está plenamente ativa transformando o lactato LD primordialmente em acetato. De fato, existiu no presente trabalho uma alta correlação entre o acetato e o lactato - $L\left(r=-0,63 ; R^{2}=0,397\right.$; Tabela 34). Porém, no avançar do processo com $\mathrm{pH}$ inferior a 6,0 o lactato L é transformado em propionato, basicamente pela bactéria Megasphera elsdenii (Dunlop, 1972).

As concentrações de propionato ruminal (Tabela 8; Gráfico 8) estão aquém do esperado, visto que o modelo de indução deveria gerar uma acidose inicial por excesso de AGCC, em especial por acúmulo de ácido propiônico, fazendo com que a relação acetato:propionato, que normalmente é 3:1 diminuísse abaixo de 2:1 (DANSCHER et al., 2015). Contudo, isso não se realizou nesse experimento, pois no grupo controle a relação acetato: propionato variou de 6,6 a 8,7:1 na $3^{\text {a }} \mathrm{h}$ (Tabela 11; Gráfico 11). A mais provável explicação é que a repentina queda do $\mathrm{pH}$, nas primeiras $3 \mathrm{~h}$, fizeram com que ocorresse um acumulo de glicose (Tabela 2; Gráfico 2) e esta fosse convertida grandemente em frutose 1,6 difosfato e em seguida em piruvato, o qual nesse caso converte este último substrato diretamente a lactato, bloqueando a formação mais intensa de propionato devido ao baixo $\mathrm{pH}$ no meio (inferior a 4,5) (Russell; Hino, 1985). Além do mais, já foi devidamente explanado a superprodução de acetato nos primórdios da ALR. 
Uma informação adicional para melhor entendimento da presente alta produção de ácido acético e baixa de ácido propiônico é dada por Church (1988) o qual enfatiza que dietas ricas em forragem, como foi oferecida neste experimento, favorecem maior atividade de bactérias celulotíticas e sacarolíticas, gerando no processo acetato, enquanto rações ricas em amido e ou proteína estimulam a ação de bactérias amilolíticas e/ou proteolíticas com estímulo a produção de propionato.

Como esperado o butirato aumentou sua concentração na 3h da indução nos vários tratamentos (Tabela 9; Gráfico 9) diminuindo exponencialmente a seguir. À primeira vista, quando comparado ao comportamento do propionato os resultados parecem contraditórios. Mas em experimento de acidose in vitro Russell e Strobel (1988) comparou a produção desses dois ácidos numa faixa de 5,2 e 5,9, e identificou que num $\mathrm{pH}$ em torno de 5,4 (vide $3^{\mathrm{a}} \mathrm{h}$ Tabela 1) existia um bloqueio na produção de propionato e uma enorme síntese de butirato, oriundo a partir da transformação de lactato - L.

O modelo em questão identificou que a acidose ruminal foi causada primordialmente por acúmulo de ácido láctico $\mathbf{L}\left(\mathrm{r}=-0,88 ; \mathrm{R}^{2}=0,77\right)$ e $\mathbf{D}\left(\mathrm{r}=-0,72 ; \mathrm{R}^{2}=\right.$ 0,52; Tabela 34) tendo uma contribuição também significativa do total dos ácidos graxos de cadeia curta $\left(r=0,73 ; R^{2}=0,53\right.$; Tabela 34), como caracteriza Owens (1998).

O lactato $L$ e em menor grau o D são altamente produzidos no rúmen na ALR. O presente trabalho identificou que a razão lactato L/D (Tabela 6; Gráfico 6) foi superior $( \pm 4: 1)$ ao descrito pelo artigo clássico de Dunlop e Hammond (1965) que identificaram em torno de 2,8:1. Esse resultado inclusive contraria os dados de Maruta (2000), no mesmo modelo experimental, que identificou uma razão de 1:1, provavelmente, pois a metodologia empregada pelo brasileiro não tinha tamanha precisão com o método enzimático específico atualmente empregado. 
No trabalho norte-americano os pesquisadores utilizaram na indução da ALR milho (amido) e nesse caso sacarose. Três fatores interferem positivamente na produção de lactato D. O primeiro é a fonte de carboidrato solúvel. Quanto mais fermentescível for o amido maior a produção do isômero D, sendo máxima quando o substrato é o trigo (DUNLOP, 1972). Altos teores de proteína dietética, associado a elevadas quantidades de carboidratos solúveis, favorecem a produção desse isômero (Counette; Prinz, 1981). Finalmente, quando o pH ruminal cai abaixo de 4,2 existe um incremento de produção para D (Dunlop, 1972). Esse último fator ocorreu no presente trabalho, pois existiu uma alta correlação negativa entre $\mathrm{pH}$ do rúmen e lactato - D ( $\mathrm{r}=-0,72 ; \mathrm{R}^{2}=0,52$; Tabela 34$)$. Analisando-se pontualmente dados de amostras ruminais dos teores de lactato D cujo $\mathrm{pH}$ era inferior ou igual 4,2 versus $\mathrm{pH}$ entre 4,21 e 4,99, constatou-se maior média para a primeira condição $(15,8 \pm 6,2 \times 11 \pm 7$; $\mathrm{p}=0,003)$ confirmando que num pH inferior a 4,2 existe maior produção de lactato $D$ ruminal.

Como esperado a indução de ALR provocou aumento significativo da osmolaridade no conteúdo ruminal (Tabela 13; Gráfico 13), atingindo em $10 \%$ dos casos valores superiores a $400 \mathrm{mOsm} / \mathrm{L}$ e numa ocasião acima de 500 mOsm/L. Em três $(\mathrm{CON}$; MON e VM 34) dos cinco tratamentos a maior média de osmolaridade foi constatada na $3^{\mathrm{a}} \mathrm{h}$, quando a concentração de ácidos produzidos no rúmen também foi superior e coincidentemente a glicose ruminal também se expressava numericamente maior (Tabela 12 e 2). A literatura é concorde que o incremento na osmolaridade na ALR é causado pelo excesso de produção de ácidos fortes e suas devidas ionizações dentro do rúmen. Contudo, o coeficiente de determinação no presente trabalho entre a osmolaridade e a concentração total de ácidos foi aquém da expectativa $\left(r=0,50 ; R^{2}=0,25\right.$; Tabela 34$)$. $O$ teor de glicose ruminal colaborou com $22 \%\left(r=0,47 ; R^{2}=0,22 ;\right.$ Tabela 34$)$ na osmolaridade. A concentração de lactato $-D$ contribuiu com $12 \%\left(r=-0,35 ; R^{2}=0,12\right.$ : Tabela 34$)$. Porém, os demais $41 \%$ causadores dos valores médios de osmolaridade não conseguiram ser detalhados. Possivelmente, esteja ligado aos íons 
H+ livres, fruto da dissociação dos ácidos ruminais cuja influência maior é dependente do respectivo pKa e do pH ruminal em cada momento da análise cronológica da indução.

O potencial de oxirredução (Tabela 14; Gráfico 14) foi francamente positivo durante a ALR, apresentando uma altíssima correlação negativa com o pH ruminal ( $r$ = - 0,96; $\mathrm{R}^{2}=0,92$; Tabela 34) e positiva com o lactato total $\left(\mathrm{r}=0,93 ; \mathrm{R}^{2}=0,87\right.$; Tabela 35). Poucos trabalhos identificam os valores normais de POR, destacando entre eles os de Baldwin e Emery (1960) e de Marden et al. (2005) que variaram de $-65 \mathrm{mV}$ a $-180 \mathrm{mV}$. No tempo basal no presente trabalho encontrou-se valores que variaram de $-15 \mathrm{a}+10 \mathrm{mV}$, fora dos valores de referência supracitados. Todos os estudos a respeito identificaram que amostras obtidas de bovinos canulados apresentaram valores muito mais altos de POR devido perda de $\mathrm{CO}_{2}$ pelo orifício ruminal, assim como maiores valores eram obtidos no momento basal devido a menor formação de $\mathrm{CO}_{2}$ no interior do rúmen e menor atividade de bactérias redutoras de oxigênio (BROBERG, 1957). Além da canulação, acredita-se que os resultados mais altos encontrados no tempo basal sejam devidos ao oferecimento de dieta uma única vez ao dia surgindo assim um longo interregno entre a oferta de alimento no tempo basal. A partir daí, os valores de POR tornaram-se francamente positivos, identificando um acúmulo de oxigênio no restrito ambiente anaeróbio ruminal. Na ALR ocorre a morte de boa parte das bactérias redutoras de oxigênio, além da enfermidade provocar uma nítida anorexia (OLIVEIRA et al., 2016).

A prova de acidez titulável (Tabela 15; Gráfico 15) identificou claramente o acúmulo de ácido forte no rúmen notabilizado pela relação com os teores de lactato total (r = 0,$86 ; \mathrm{R}^{2}=0,74$; Tabela 35). Estranhamente, existiu uma correlação negativa com o total de ácidos graxos de cadeia curta $\left(r=-0,60 ; R^{2}=0,36\right.$; Tabela 34). Duas condições poderiam explicar esse fenômeno. Uma delas é que por serem ácidos fracos os AGCC necessitam de pequena quantidade de base para atingir o $\mathrm{pH}$ 7, fato inverso ao ácido láctico. O segundo ponto, talvez o mais importante, é que os ACCC no pH ruminal já inferior a 5,9 e com presença de 
ácido láctico, como identificado na $3^{\mathrm{a}}$, passam a ter um papel de tampão do ácido mais forte, não reagindo adequadamente com o $\mathrm{NaOH}$ empregado nesta prova (Brossard et al., 2003).

\section{A presente ALR gerou em parte dos bovinos $(33,3 \%)$ moderada acidose} metabólica sistêmica (Tabela 16; Gráfico 16), pois grande parte $(80 \%)$ dos acidóticos manifestaram pH sanguíneo entre 7,22 e 7,29, e só dois deles apresentaram acidose mais intensa (7,18 e 7,19). Os dados obtidos no EAB (Tabela 17; Gráfico 17) e nos teores de bicarbonato (Tabela 18; Gráfico 18) confirmam esse mesmo resultado supracitado. Existiu uma influência do acúmulo dos teores de lactato - $\mathrm{D}$ sanguíneo nessa queda de $\mathrm{pH}$ sistêmica $\left(\mathrm{r}=-0,63 ; \mathrm{R}^{2}=\right.$ 0,40; Tabela 34), com menor ação do lactato - L sanguíneo ( $r=0,315 ; R^{2}=0,09$; Tabela 34). Alguns fatores explicam esses resultados. $\mathrm{O}$ isômero $\mathrm{D}$, diferente do L, é bem menos metabolizado pelo organismo dos ruminantes, pois as atividades das enzimas que atuam nessa metabolização são diminutas para o lactato - D, fazendo com que se acumule na corrente e que interfira mais no pH sanguíneo. Por esse motivo Dunlop (1972) denominou a ALR como acidose D láctica. Contudo, esse importante autor ignorou que a acidose ruminal é mais importante que a sistêmica, esta última sendo secundária a primeira, além do fato que o autor norte-americano não trabalhou com bovinos zebuínos, em que a acidose é centrada no rúmen e não no sangue, como constatou Maruta (2000).

Atribui-se também esse pequeno grau de acidose sistêmica a formação de AGCC no rúmen $\left(\mathrm{r}=0,54 ; \mathrm{R}^{2}=0,29 ;\right.$ Tabela 34$)$. À primeira vista parece contraditório essa última relação positiva, porém nas horas mais posteriores da acidose ocorreu rápida diminuição dos AGCC no rúmen, pois estes foram absorvidos para corrente circulatória levando consigo íons $\mathrm{H}^{+}$. $\mathrm{Na}^{12}$ hora o $\mathrm{pH}$ ruminal médio girou em torno de 4,38 muito inferior ao pKa dos AGCC fazendo com que grande parte desses ácidos se tornem associados e sejam rapidamente absorvidos para a corrente sanguíneo (OWENS, 1998). 
Os teores de lactato - L sanguíneo (Tabela 19; Gráfico 19) são de difícil interpretação biológica, pois embora sejam advindos do rúmen são rapidamente oxidado consumindo íons $\mathrm{H}+$ e se transformando rapidamente em $\mathrm{CO}_{2}$ e $\mathrm{H}_{2} \mathrm{O}$ (Leal et al., 2007), explicando porque no presente trabalho tais teores têm baixa correlação com lactato $-\mathrm{L}$ do rúmen $\left(\mathrm{r}=-0,32 ; \mathrm{R}^{2}=\right.$ 0,10; Tabela 34), o $\mathrm{pH}$ do sangue $\left(r=0,315 ; \mathrm{R}^{2}=0,09\right.$; Tabela 34$)$, bicarbonato $\left(r=0,31 ; \mathrm{R}^{2}\right.$ $=0,09 ;$ Tabela 35) e EAB $\left(r=0,326 ; \mathrm{R}^{2}=0,10 ;\right.$ Tabela 35).

O presente experimento confirmou que a ALR nesse modelo provoca temporariamente hiperglicemia (Tabela 24; Gráfico 24). Como esperado, parte do aumento da glicemia foi oriunda da absorção de glicose gerada no rúmen $\left(r=0,50 ; R^{2}=0,25\right.$; Tabela 34), a qual foi provavelmente absorvida nos intestinos. Contribuiu também para a hiperglicemia o lactato - L sanguíneo $\left(r=0,54 ; R^{2}=0,29\right.$; Tabela 34$)$, pois parte desse isômero no fígado pode ser tanto oxidado como ser convertido em glicose, em rota gliconeogênica (Leal et al., 2007).

Maior porcentual de bovinos exibiram quadro de desidratação $(66,6 \%)$ que acidose metabólica sistêmica $(33,3 \%)$ (Quadro 1). A desidratação foi intensa (DVP < $-40 \%$ ) em três casos, moderada (- $30 \%$ a $-40 \%)$ em seis outros e leve $(-20 \%$ a - $30 \%)$ em onze fêmeas. A causa da desidratação deveria ser a o aumento de osmolaridade ruminal, porém a correlação entre esta variável e o DVP foi fracamente positiva $\left(r=0,23 ; R^{2}=0,05\right.$; Tabela 35), não tendo significado biológico. Porém, quando a mesma relação foi feita entre os teores totais de lactato ruminal e o DVP a mesma foi alta e negativa $\left(r=-0,63 ; R^{2}=0,40\right.$; Tabela 35$)$, explicando o papel que esse catabólito têm na passagem dos fluidos sistêmicos para o rúmen.

Os dados acima descritos confirmaram as afirmações de Ortolani et al. (2010) que esse modelo de indução de ALR, com uso de sacarose, provoca um nítido quadro de acidose sistêmica em taurinos, enquanto que nos zebuínos a manifestação clínica é preponderadamente de desidratação. 
Como esperado a maioria dos animais manifestaram diarreia na $12^{\mathrm{a}} \mathrm{h}$ e/ou $18^{\mathrm{a}} \mathrm{h}$, sinal muito comum no quadro natural ou experimental de ALR, idêntico ao descrito por Ortolani et al. (2010) numa revisão sobre manifestações clínicas causadas por esse modelo experimental. Essa diarreia era acompanhada em $\mathbf{2 6 , 7} \%$ dos casos de secreção mucosa nas fezes. Coincidentemente, a diarreia ocorria quando o pH fecal decrescia (Tabela 33; Gráfico 31). Maruta (2000) constatou que a diminuição do pH fecal era devida ao aumento de excreção fecal de lactato. No presente experimento existiu uma correlação negativa $\left(r=-0,54 ; R^{2}=0,29\right.$; Tabela 35) entre o pH fecal e os teores de lactato total do rúmen, mas desafortunadamente não foi determinado as concentrações deste catabólito nas fezes. A presença de muco nas fezes ocorreu por irritação da mucosa pelo baixo pH fecal visto que esta variável foi menor $(\mathrm{P}=$ $0,005)$ nas amostras diarreicas secretivas $(\mathrm{pH} 5,22 \pm 0,05)$ que nas não secretivas $(5,63 \pm 0,12)$ (Tabela 25). Até o momento, nenhum autor descreveu essa influência do $\mathrm{pH}$ fecal sobre a presença de muco nas fezes.

Outro fato pouco relatado na literatura foi a descrição da presença de secreção mucosa nas narinas entre 12 e $18 \mathrm{~h}$, em $\mathbf{2 6 , 6} \%$ dos animais. Ortolani et al. (2010) relataram que esse sinal geralmente está presente em todos os animais empregados no mesmo modelo experimental. Tentou-se relacionar, no presente trabalho, esse sinal com a intersecção de outras manifestações clínicas, encontrando-se coincidentemente em $63 \%(5 / 8)$ dos casos depressão nervosa e necessidade de tratamento, sendo que em quatro destes cinco bovinos coexistiu altos teores de lactato - D no sangue e desidratação. A possível explanação desse sinal continua obscuro. É digno de nota que nenhum bovino apresentou quadro de broncopneumonia, visto que a ALR pode predispor a este quadro respiratório (HERNANDÉZ et al., 2014).

A depressão nervosa ocorreu em cerca de metade das fêmeas (14/30), caracterizada por diferentes graus de apatia, falta de resposta aos estímulos externos, ataxia, decúbito esternal mais prolongado, pálpebras e pavilhões auriculares ligeiramente caídos etc. A depressão está 
intimamente ligada a presença sistêmica de altos tores de lactato - D. A análise dessas concentrações indicaram que metade dos deprimidos tinham valores de lactato - D sanguíneo considerados altos (> 2,8 mM/L), enquanto que os demais apresentavam concentrações abaixo desse valor. Contudo, Hernandéz et al. (2014) firmaram que nem sempre os teores altos sanguíneos de lactato - D levam a depressão e que esta é causada pela eficiente passagem deste isômero pela barreira hematoencefálica ao fluido cérebro-espinhal, por ação de transportadores de monocarboxilatos. Assim, é possível que tal fenômeno tenha ocorrido em bovinos deprimidos e que apresentavam teores de lactato - D não tão elevados no sangue.

A atonia ruminal foi uma constante nesse experimento, só não acometendo um animal num conjunto de 30 deles. Segundo Ortolani et al. (2010) os zebuínos com ALR geralmente têm atonia ruminal, não correndo o mesmo com os taurinos que tendem a manter alguma movimentação ruminal. Segundo Crichlow e Chaplin (1985) a parada ruminal é causada por ação direta do excesso de AGCC, e em menor grau de ácido láctico, nos receptores ruminais, em especial quando os ácidos estão associados, ou seja, próximos do seu pKa, que gira de 4,9 para o ácido acético, 4,8 para o propiônico e 4,7 para o butírico. Crichlow (1988) constatou que $95,3 \%$ dos receptores de parede respondem ao butirato, $76,7 \%$ ao acetato, $53,5 \%$ ao propionato e 30,2 \% lactato DL. O presente $\mathrm{pH}$ ruminal constatado na $6^{\mathrm{a}} \mathrm{h}$ (Tabela 1; Gráfico 1) era muito próximo do $\mathrm{pKa}$ dos $\mathrm{AGCC}$, coincidindo com a parada ruminal na maioria dos animais já nesta mesma hora (Tabela 30; Gráfico 30). É digno de nota que existiu uma alta correlação positiva entre o $\mathrm{pH}$ ruminal e os movimentos de rúmen $\left(\mathrm{r}=0,806 ; \mathrm{R}^{2}=0,65\right.$; Tabela 35). A atonia ruminal que poderia ser um sinal negativo, na verdade tem uma vantagem biológica, pois quanto menor for a movimentação do rúmen menor será a absorção de ácido láctico para a corrente sistêmica, prevenindo uma acidose metabólica de caráter intenso (MARUTA, 2000). 
O tratamento foi eficiente em todos os casos e reverteu os sintomas apresentados. Porém, há necessidade de se comentar sobre quais sintomas exigiram a necessidade de um tratamento. Percentualmente, o sinal mais determinante foi a depressão, pois de 15 fêmeas tratadas 14 apresentavam-se deprimidas ( $\mathrm{P}<0,0001)$, seguindo-se da desidratação com $75 \%$ delas requerendo o tratamento $(\mathrm{P}=0,001)$ e complementada pela acidose sistêmica, em especial naqueles com curso mais intenso $(P=0,02)$. Também é digno de nota a constatação de que os animais que exigiram tratamento apresentaram na $18^{\mathrm{a}} \mathrm{h}$ maiores teores de lactato - D sanguíneo em relação aos não medicados (Tabela 26), reforçando o papel que este isômero tem na ALR.

No conjunto do exame clínico chamava mais atenção da equipe que realizou o experimento e decidiu pelo tratamento pela presença de depressão, pois a falta de resposta aos estímulos e aparente apatia e letargia, seguida em alguns casos de desidratação mais intensa, transparecia um quadro de grande debilitação e necessidade de rápido tratamento de suporte.

O fito do experimento não era o acompanhamento clínico pós-tratamento. Mas, constatou-se que dentro de $6 \mathrm{~h}$ boa parte dos animais tratados (11/15) apresentavam-se mais alertas e permanecendo mais tempo em estação. Mesmo assim, quatro deles com quadro mais comprometido só exibiram sinais evidentes de melhora após 24h. Acredita-se que o efeito do uso de solução hipertônica, aumentado a absorção de fluido ruminal (Kitamura et al., 2010), associado aos demais tratamento tenha ajudado a excreção renal de lactato - D. De fato, Lorenz e Gentile (2014) descreveram que bezerros diarreicos e desidratados devidamente medicados para reposição da volemia apresentaram melhora significativa do quadro de depressão concomitante com grande aumento no volume urinário e no clearance renal de lactato - D dentro de seis horas.

Também foi uma constante a taquicardia a partir da $3^{\mathrm{a}} \mathrm{h}$ (Tabela 27; Gráfico 25). Esse sintoma é frequentemente citado na ALR e de certa forma tem uma relação com volume 
globular $\left(r=0,50 ; R^{2}=0,25\right.$; Tabela 35$)$ e o déficit de volume plasmático $\left(r=-0,342 ; R^{2}=\right.$ 0,12; Tabela 35) (Leal et al., 2007; Ortolani et al., 2010; Constable et al., 2017).

Boa parte $(66,7 \%)$ dos bovinos com taquicardia acima de 130 bat./min apresentaram concomitantemente altos teores de lactato - $\mathrm{D}$ no sangue $(\mathrm{P}=0,077)$. Embora não exista uma relação marcante entre taquicardia e desidratação, como descrito por Ortolani et al., (2010), supreendentemente foi encontrada certa coincidência com o lactato - D sanguíneo. Na revisão sobre o acúmulo de lactato - D em bezerros Lorenz e Gentile (2014) nem mesmo citaram entre os principais sintomas a taquicardia, embora tenham relatado a íntima condição entre o excesso deste isômero com síndrome desidratação. Maiores estudos são necessários para entender tal correspondência.

\section{Existiu, inicialmente, um aumento discreto na frequência respiratória na $6^{\mathrm{a}} \mathrm{h}$ e} posteriormente uma moderada tendência de diminuição na $18^{\mathrm{a}} \mathrm{h}$ (Tabela 28; Gráfico 26). Segundo Hernandéz e colaboradores (2014) o aumento de frequência respiratória é derivado da acidose metabólica intensa associada a possível hipercalemia. Tal afirmação é duvidosa. Segundo Ortolani et al. (2010) ocorre exatamente o oposto, pois a bradipnéia é oriunda de uma acidemia mais intensa, em especial quando o pH sanguíneo é inferior a 7,18 que pode deprimir o centro respiratório. No presente trabalho, quando se correlacionou a frequência respiratória inferior a 20/min, contadas na $18^{\mathrm{a}} \mathrm{h}$, com o pH do sangue obteve-se uma correlação positiva (r $\left.=0,765 ; \mathrm{R}^{2}=0,59 ; \mathrm{p}=0,076\right)$.

Por outro lado, credita-se o aumento pontual da frequência respiratória na $6^{\mathrm{a}} \mathrm{h}$ à dilatação de volume abdominal causado pelo hidrorúmen, plenamente observado neste experimento, mas não mensurado, por meio de perímetro abdominal. Oliveira et al. (2015) administraram melão rico em açúcares para provocar ALR em ovinos, obtendo pleno sucesso. Os autores demonstraram claramente que no início do quadro acidótico existia uma alta correlação positiva $\left(r=0,83 ; R^{2}=0,6884\right)$ entre a taquipneia e o perímetro abdominal, sem 
existir qualquer relação com o pH sanguíneo, que no momento se encontrava normal, tal qual no presente experimento.

Ocorreu hipertermia durante a plena fermentação ruminal, em especial na $6^{\mathrm{a}} \mathrm{h}$, (Tabela 29; Gráfico 27), atingindo em alguns casos valores superiores a $41^{\circ} \mathrm{C}$, declinando para valores normais no decorrer do quadro. Sem dúvida, esse resultado sistêmico espelha o calor gerado durante a intensa fermentação ruminal, principalmente na $3^{\mathrm{a}}$ e $6^{\mathrm{a}} \mathrm{h}$, quando a quantidade de glicose ruminal era maior $\left(r=0,495 ; R^{2}=0,245\right.$; Tabela 36). Reis (2011) induziu ALR com sacarose em ovinos e mensurou a temperatura ruminal, encontrando maiores valores $\left(40^{\circ} \mathrm{C} \mathrm{a}\right.$ $41,5^{\circ}$ ) na faixa do $\mathrm{pH}$ entre 5,3 a 4,7, indicando que a geração de calor oriunda da fermentação ruminal pode interferir na temperatura sistêmica. Contudo, neste mesmo ano Rose-Dye et al. registraram que existe uma alta correlação positiva $\left(r=0,89 ; R^{2}=0,792\right)$ entre as duas temperaturas e que uma hipertermia causada por um quadro de broncopneumonia também pode aumentar a temperatura ruminal.

Embora ocorresse queda de $\mathrm{pH}$ urinário no decorrer da ALR, a acidúria foi bem moderada refletindo de certa forma $\left(r=0,397 ; R^{2}=0,157\right.$; Tabela 36) a acidemia de mesmo grau. Chama atenção que na $3^{\mathrm{a}} \mathrm{h}$ (Tabela 31; Gráfico 29) ocorreu uma diminuição na acidúria, a qual acredita-se que seja por aumento de produção de tampões sistêmicos (ABE x pH urina $\mathrm{r}=0,481 ; \mathrm{R}^{2}=0,231$; Tabela 36), em especial de bicarbonato sanguíneo (- $\mathrm{HCO}_{3} \mathrm{x} \mathrm{pH}$ urina $\mathrm{r}$ = 0,498; $\mathrm{R}^{2}=0,248 ;$ Tabela 36), o qual é mais produzido no início da ALR, por motivos ainda não devidamente compreendidos.

\section{A densidade urinária incrementou-se consideravelmente no início da ALR}

(Tabela 32; Gráfico 30), em especial na $3^{\mathrm{a}}$ e $6^{\mathrm{a}} \mathrm{h}$ da indução, declinando estranhamente até a $18^{\mathrm{a}} \mathrm{h}$. Essa variável acompanhou a dinâmica da osmolaridade sanguínea $\left(\mathrm{r}=0,557 ; \mathrm{R}^{2}=0,310\right.$; Tabela 36), mas não a do DVP $\left(r=0,131 ; R^{2}=0,017\right.$; Tabela 36). É de sobejo conhecido que num quadro de desidratação existe um mecanismo compensatório de economia de fluidos pela 
diminuição da irrigação renal, aumentando automaticamente a densidade urinária. Era de se esperar que tal operação ocorresse nos momentos mais avançados da ALR, porém isso ficou restrito no ápice da fermentação, quando deve ter ocorrido enorme migração de fluidos para o rúmen, pois existiu uma correlação média dessa variável discutida e a glicose ruminal ( $\mathrm{r}=$ 0,594; $\mathrm{R}^{2}=0,352$; Tabela 36) e total de ácidos orgânicos ruminais $\left(\mathrm{r}=0,536 ; \mathrm{R}^{2}=0,287\right.$; Tabela 36). É possível que o sequestro de fluidos sanguíneos para o rúmen se de nas primeiras horas da ALR, refletindo exponencialmente no aumento da densidade urinária, fluindo aos poucos a digesta ruminal para segmentos posteriores dos intestinos, porém sem dar tempo de ocorrer grande absorção dos fluidos perdidos anteriormente, aumentando nesse interim o DVP, porém diminuindo lentamente a densidade urinária. $\mathrm{O}$ assunto é intrigante e merece estudos mais detalhados.

\subsection{EFEITOS PREVENTIVO DOS ADITIVOS NA ALR}

O presente experimento identificou claramente que alguns tratamentos interferiram de alguma forma no desenvolvimento da ALR. Deve ser enfatizado que o modelo de indução proposto provoca um quadro intenso de ALR e que por melhor que seja a ação do aditivo dificilmente este evitará por completo os aparecimentos dos sinais mais característicos da enfermidade, devendo-se focar mais nos efeitos mitigativos da geração e acúmulo de ácidos ruminais e de suas consequências ao organismo.

Analisando os dados de forma panorâmica é possível identificar que os melhores resultados surgiram quando da associação de aditivos (VM+MON), comparativamente aos tratamentos isolados.

A combinação VM + MON teve um efeito sinérgico contra a ALR já na $3^{a} \mathrm{~h}$ do processo refreando a queda brusca do $\mathrm{pH}$ ruminal, em relação ao grupo controle, e interferindo 
nitidamente pela menor produção de lactato-L ruminal, em relação a todos os grupos. Esse fenômeno também ocorreu na $6^{\mathrm{a}} \mathrm{h}$, no concernente a produção de lactato - L e D, e ao término do experimento em relação ao grupo controle. Isto pode ter ocorrido por dois fenômenos.

Para entendimento dos fenômenos acima deve-se avaliar inicialmente o que aconteceu com a geração de AGCC no início da ALR, em especial na $3^{\mathrm{a}}$ e na $6^{\mathrm{a}} \mathrm{h}$. Aparentemente, nem a virginiamicina nem a monensina interferiram no desdobramento inicial da sacarose em glicose e frutose, assim analisado pelos teores de glicose ruminal (Tabela 2) e das quantidades dos AGCC individuais e total na $3^{\mathrm{a}} \mathrm{h}$. Contudo, esses aditivos associados promoveram nessa mesma $3^{\mathrm{a}} \mathrm{h}$ uma intensa transformação do lactato $-\mathbf{L}$ em acetato $\left(\mathrm{R}^{2}=0,942\right.$; Gráfico 33$)$ num pH médio de 5,59, diminuindo essa eficiência na $6^{\mathrm{a}}\left(\mathrm{R}^{2}=0,0896\right.$; Gráfico 34$)$, quando o pH médio era mais baixo $(4,91)$. Essa transformação é feita principalmente pela bactéria Selenomas ruminantium que atua entre o $\mathrm{pH}$ 6,7 e 5,4 (NAKAMURA; TAKAHASHI, 1971; COUNETTE; PRINZ, 1981). Nos outros grupos, que não o VM + MON, tal conversão foi baixíssima ( $\mathrm{R} 2=0,021$; Gráfico 35$)$, pois na $3^{\mathrm{a}} \mathrm{h}$ o $\mathrm{pH}$ já era inferior a 5,4 , na maioria dos casos.

Mesmo com baixa produção de propionato ruminal, por motivos já explicados anteriormente, a associação VM + MON ajudou na transformação do lactato - L em propionato $\left(\mathrm{R}^{2}=0,5719\right.$; Gráfico 36$)$ no decorrer do processo, em especial na $6^{\mathrm{a}} \mathrm{h}$, enquanto que nos demais grupos essa conversão foi inferior $\left(\mathrm{R}^{2}=0,3306\right.$; Gráfico 37). Dois fatores devem ter influenciado nessa conversão de ácido láctico para propionato. O primeiro deles diz respeito a quantidade de ácido láctico presente no meio, pois quanto maior for este, até o teor de 29 mM/L, maior será a conversão (NAKAMURA; TAKAHASHI, 1971; COUNETTE et al. 1983). Outro ponto importante é o $\mathrm{pH}$ do meio, pois a conversão é feita pela bactéria Megasphaera elsdenii, a qual cresce e atua numa faixa de pH entre 6,0 e 4,8 (COUNETTE; PRINZ, 1981). No grupo VM+ MON na $6^{\mathrm{a}} \mathrm{h}$ os teores de ácido láctico L eram 22,30 mM/L e 
o pH ruminal 4,91, enquanto nos demais grupos a média das concentrações de ácido láctico L era $47 \mathrm{mM} / \mathrm{L}$ e o pH ao redor de 4,65 (tabela 3 e 1). Assim, as condições no ambiente ruminal eram mais favoráveis ao grupo de associação dos aditivos em relação aos demais tratamentos.

Essas transformações temporárias de lactato - L em acetato e em menor graus propionato contribuíram decisivamente para que nas primeiras seis horas o $\mathrm{pH}$ não diminuísse tanto postergando assim a explosiva produção de lactato em $\mathrm{pH}$ inferior a 5,4.

Os principais AGCC tiveram uma concentração ruminal maior na $3^{\mathrm{a}} \mathrm{h}$, diminuindo gradativamente a partir daí (tabela 10; gráfico 10), semelhante ao descrito por Coe et al. (1999). Constituiu-se uma exceção o grupo VM + MON que manteve na $6^{\mathrm{a}} \mathrm{h}$ maior concentração desses ácidos. Dois fenômenos podem explicar essa diminuição nos teores na $6^{\mathrm{a}} \mathrm{h}$ : menor produção de AGCC e/ou aumento de sua absorção. Provavelmente as duas situações devem ter ocorrido, mas acredita-se que a segunda possa ter interferido mais. Os ácidos graxos de cadeia curta podem ser absorvidos passiva ou ativamente, sendo o primeiro processo o mais natural e o mais rápido (CHURCH, 1988). Na absorção passiva o ácido deve estar não-ionizado, enquanto no outro ele ionizado. Quanto mais próximo ou abaixo de seu pKa correspondente maior será o percentual de ácidos não-ionizados favorecendo grandemente a sua absorção. De fato, a análise, empregando-se como exemplo o coeficiente de determinação $\left(\mathrm{R}^{2}=0,4973\right.$; Gráfico 38) entre o $\mathrm{pH}$ ruminal e os teores de ácido propiônico ruminal na $6^{\mathrm{a}} \mathrm{h}$ constatou-se um efeito do $\mathrm{pH}$ na flutuação dos teores deste ácido (Gráfico 38). Em outras palavras, quanto mais ácido for o pH ruminal maior a absorção de AGCC do rúmen.

O ponto central da ALR é a excessiva produção do fortíssimo ácido láctico, que faz reduzir drasticamente o $\mathrm{pH}$, aumentando sobremaneira a quantidade de oxigênio no rúmen e a criação de um ambiente impróprio para bactérias ruminais usuais, quer sejam Gram negativas ou positivas. A geração de ácido láctico pode ser feita na faixa de $\mathrm{pH}$ entre 5,5 e 5,1 por 
Streptococcus bovis e abaixo desse valor pelo crescimento de várias espécies de Lactobacillus (DUNLOP, 1972; OWENS, 1998; NAGARAJA; TITGEMEYER, 2007).

Assim, além do excesso de substrato três grandes fatores mediam a intensidade da ALR, ou seja, o pH do meio e o crescimento desses dois gêneros de bactérias Gram positivas. A literatura até o momento realizada traz elementos por vezes contraditórios quanto a ação da monensina e da virginiamicina no desenvolvimento dessas bactérias.

O trabalho-base do uso preventivo de monensina na ALR realizado pelo grupo de Nagaraja et al. (1981) demonstrou em bovinos que este aditivo tem uma ação muito efetiva nesse propósito, em relação ao grupo controle, não permitindo uma drástica redução no pH, diminuindo a produção de ácido láctico e aumentando a ação das bactérias lactilíticas. Os autores identificaram que o aditivo tinha ação melhor na redução de Streptococcus bovis que Lactobacillus $\mathrm{sp}$. Contudo, esse trabalho teve seu término abrupto na $12^{\mathrm{a}} \mathrm{h}$ da ALR, quando o processo mórbido ainda estava em andamento. Num modelo semelhante, porém com duração até a $24^{\mathrm{a}} \mathrm{h}$, Reis (2011) provou que a monensina tinha uma ação relativamente positiva até a $12^{\mathrm{a}} \mathrm{h}$ da ALR, porém era semelhante ao grupo controle a partir daí.

Coe at al. (1999) foi o primeiro a comparar num modelo in vivo a ação isolada dos aditivos em questão na prevenção da acidose em bovinos por ácidos graxos de cadeia curta, também conhecida como SARA, constatando que a virginiamicina teve melhor atuação que a monensina, e que a primeira controla mais adequadamente tanto o crescimento de Streptococcus como o Lactobacillus.

No presente experimento não foi possível trabalhar com bactérias ruminais em geral, mas pode-se constatar que a associação VM + MON foi muito efetiva no início do experimento (até $6^{a} h$ ), não apenas pela maior atuação de bactérias lactilíticas, mas também no controle de microrganismos que geram ácido láctico, em especial o isômero D que não é convertido em outros ácidos mais fracos, sendo um excelente indicador da geração 
global de ácido láctico. Na tabela 4 fica evidente isso, pois na $6^{\mathrm{a}} \mathrm{h}$ o teor de lactato - D é mínimo em relação aos outros grupos, provavelmente pelo maior $\mathrm{pH}$ ruminal, superior a 4,5, que não permitiu o crescimento explosivo das bactérias geradoras de lactato. Esses resultados permitem inferir que a associação dos aditivos favoreceu um maior controle do Streptococcus bovis, tanto pela ação sinérgica da virginiamicina como da monensina tendo como um bônus a ação do primeiro aditivo contra o Lactobacillus.

Como salientado anteriormente, o modelo de ALR empregado é bastante desafiador e muito mais agressivo que os realizados por Nagaraja et al. (1981), Golder et al. (2014), e semelhante ao empregado por. Coe et al. (1999). Nesses modelos estrangeiros, em especial nos dois últimos, os aditivos empregados tiveram uma eficiência muito maior em mitigar a acidose ruminal, principalmente pois eles associaram em um dos tratamentos monensina e tilosina. Porém, no presente experimento por melhor que fosse a atuação dos aditivos empregados estes não foram possíveis de deter o desenvolvimento da acidose a partir da $6^{\mathrm{a}} \mathrm{h}$. Mesmo assim, na $18^{\mathrm{a}} \mathrm{h}$, quando se encerrou o ensaio, pode-se evidenciar que o grupo VM + MON mitigou a acidose em relação ao grupo controle, proporcionando maior pH ruminal, menores produção de lactato - L ruminal, acidez titulável, grau de depressão nervosa e necessidade de tratamento, justificando o uso destes aditivos associados na prática zootécnica.

Um ponto que deve ser esclarecido é quanto ao $\mathrm{pH}$ ruminal final destes dois grupos: $(\mathrm{CON}$ e $\mathrm{VM}+\mathrm{MON})$. Embora ocorresse diferença significativa na $18^{\mathrm{a}} \mathrm{h}$, para um leitor menos atento a diferença média de pH entre estes grupos é ínfima e de apenas 0,31 graus (tabela 1). Contudo, como o pH é uma função log de base 10 quando se calcula a quantidade de moles de íons $\mathrm{H}^{+}$entre o $\mathrm{pH}$ médio desses grupos obtém-se um valor 2,04 vezes superior no controle, ou seja, neste a quantidade de íons $\mathrm{H}^{+}$é simplesmente o dobro do aditivado.

A virginiamicina per se aparentemente diminui o desdobramento da glicose ruminal em lactato no decorrer da ALR, pois os grupos que continham este aditivo tinham 
aparentemente maiores teores de glicose que o controle e a monensina, a despeito de uma diferença tendenciosa entre o grupo CON x VM + MON $(\mathrm{P}=0,09)$ e $\mathrm{C}$ x VM $25(\mathrm{P}=0,06)$, minimizada pelo pequeno número de amostras analisadas (Tabela 2; Gráfico 2).

A virginiamicina em alta concentração ou associada a monensina atua temporariamente $\left(12^{\mathrm{a}} \mathrm{h}\right)$ na não elevação do potencial de oxirredução, não favorecendo o acúmulo de oxigênio no rúmen, o que diminui a acidez titulável e a osmolaridade ruminal, inclusive em relação ao grupo monensina.

A eficiência isolada das duas diferentes concentrações de virginiamicina foi semelhante, porém inferior a VM + MON e ligeiramente superior ao MON. Infere-se isso pois ambas tiveram resultados semelhantes no final do experimento por promoverem maior $\mathrm{pH}$ ruminal que o controle, e enquanto a VM 25 gerou menor síntese de ácido láctico - L, a VM 34 interferiu negativamente na produção de lactato - D e na acidez titulável. Em relação à monensina constatou-se que as duas doses geraram temporariamente menor acidez titulável (Tabela 15) e osmolaridade (Tabela 13). Assim, o presente trabalho concorda com a afirmativa de COE et al. (1999) que as duas doses de virginiamicina têm efeitos semelhantes.

A monensina per se, embora seja empregada enormemente em nossos confinamentos (93\%), conforme identificou Oliveira e Millen (2014), não é a melhor opção para diminuir o risco de ALR intensa, pois ao término experimento apresenta semelhantes resultados com o grupo controle, com destaque para $\mathrm{pH}$ ruminal, lactato - L, total de ácidos orgânicos e acidez titulável. Mesmo assim, muitos nutricionistas continuam empregando esse aditivo, pois no início do período de adaptação no confinamento restringe o consumo de matéria seca, na ordem de $5 \%$ a $6 \%$, em dietas muito ricas em carboidratos solúveis oferecidas para bovinos (SCHELLING et al. 1984).

Finalmente, um importante ponto de comparação é a presença de complicações clínicas decorrentes da ALR. No grupo VM + MON apenas um animal (16\%) teve que ser 
tratado enquanto que no controle isso ocorreu em $83 \%$ dos casos, com igual frequência na presença de sinais de depressão (Quadro 1). Embora não fosse submetido a um teste estatístico, é digno de nota que dois bovinos do grupo controle tiveram intensa desidratação, enquanto esse fenômeno foi nulo no grupo VM + MON. Os demais tratamentos tiveram resultados intermediários quanto essas variáveis. 


\section{CONCLUSÃO}

Quanto aos efeitos gerais do modelo de indução de ALR pode-se afirmar:

- A sacarose foi fermentada à glicose nas primeiras horas da ALR, coincidindo com aumento de AGCC, com predomínio de ácido acético, os quais foram posteriormente substituídos por ácido láctico, com preponderância do isômero L em relação ao D;

- A osmolaridade ruminal foi maior no início do modelo devido ao acúmulo de ácidos orgânicos e glicose ruminal;

- O modelo gerou moderada acidose sistêmica, sendo mais evidente a desidratação nos animais;

- A depressão nervosa e desidratação foram as principais causas de tratamento;

- A hipertermia detectada foi máxima no momento de maior fermentação ruminal.

Quanto aos efeitos preventivos dos aditivos conclui-se:

- Nenhum tratamento preveniu o desdobramento da sacarose em glicose;

- Os melhores resultados foram obtidos com a associação VM + MON que postergou a produção de ácido láctico, devido ao maior desdobramento em acetato e propionato e menor síntese de ácido láctico;

- Ao termino do experimento a associação $\mathrm{VM}+\mathrm{MON}$ permitiu que o $\mathrm{pH}$ ruminal fosse maior; que a produção de lactato - L e o número de animais que exigiram um tratamento fossem inferiores ao grupo controle. 
- Os dois tratamentos com diferentes doses de virginiamicina tiveram eficiência intermediária, sendo seguidas da monensina que não é a melhor opção para prevenir a ALR. 


\section{REFERÊNCIAS}

ANNISON, E. F.; ARMSTRONG, D. G. Volatile fatty acid metabolismo and energy supply. In: PHILLPSON, A. T. (ed). Physiology of digestion and metabolismo em the ruminant, 1969. Cambridge. Proceedings of the Third International Symposium Cambringe: Oriel Press. p. 422-437, 1970.

Anuário DBO. Janeiro de 2018, n. 447. Ano 36. P. 44.

APPUHAMY, J.A.; STRATHE, A. B.; JAYASUNDARA, S.; WAGNER-RIDDLE, C.; DIJKSTRA, J.; FRANCE, J.; KEBREAB, E. Anti-methanogenic effects of monensin in dairy and beef cattle: a meta-analysis, Journal Dairy Science, doi: 10.3168/jds.2012-5923, v. 96(8), p. 5161-73, 2013.

ASCHENBACH J. R.; KRISTENSEN N. B.; DONKIN S. S.; HAMMON, H. M.; PENNER, G. B. Gluconeogenesis in dairy cows: the secret of making sweet milk from sour dough, IUBMB Life, https://doi.org/10.1002/iub.400, v. 62(12), p. 869-77, 2010.

ASCHENBACH, J. R.; G. GABEL. Effect and absorption of histamine in sheep rumen: Significance of acidotic epithelial damage, Journal Animal Science, v. 78, p. 464-470, 2000.

BADAWY, S.A.; YOUNIS, M.; SHALASH, M.R. Monensin effects on rumen metabolic profile, methane production and protozoal population in buffalo heifers, Egyptian Journal of Veterinary Science, v.30, p. 49-56, 1996.

BAGG, R. Mode of action of ionophores in lactating dairy cattle. Usefulness of ionophores in lactating dairy cattle. Guelph: Ontario Veterinary College, p.13-21, 1997.

BALDWIN, R. L.; EMERY, R. S. The oxidation-reduction potential of rumen contents. Journal Dairy Science, v. 43, p. 506, 1960.

BANNINK, A.; FRANCE, J.; LOPEZ, S.; GERRITS, W. J. J.; KEBREAB, E.; TAMMINGA, S.; DIJKSTRA. J. Modelling the implications of feeding strategy on rumen fermentation and functioning of the rumen wall. Animal Feed Science Technology, v. 143, p. 3-26, 2008.

BARAN, M.; BOĎA, K.; SIROKA, P. The effect of monensin on rumen fermentation in sheep fed on all-roughage and barley/roughage diets. Animal Feed Science and Technology, v. 15, n. 1, p. $7-12,1986$.

BENTON, L. A search for sovereingnty, Law and geography in European Empires, 1400 1900. New York, NY: Cambridge University Press, (2010).

BERCHIELLI, T. T.; PIRES, A. V.; OLIVEIRA, S. G. Nutrição de ruminantes. 2. ed. Jaboticabal, SP: FUNEP, xxii, 619 p, 2011. 
BROBERG, G. Measurements of the redox potential in rumen contents. III. Investigations into the effect of oxygen on the redox potential and quantitative in vitro determinations of the capacity of rumen contents to consume oxygen, Nord. Vet. Med, v. 9, p. 942-950, 1957.

BROSSARD, L.; MARTIN, C.; MICHALET-DOREAU, B. Ruminal fermentative parameters and blood acido-basic balance changes during the onset and recovery of induced latent acidosis in sheep, Animal Research, v. 52, p. 513-530, 2003.

CAMILO, F.R.; MOBIGLIA, A.M.; BERTI, G.F.; JERONIMO, N.M.; GRIZOTTO, R.K.; MANELLA, M.Q.; RESENDE, F.D.; SIQUEIRA, G.R.; FERNANDES, J.J.R. Ruminal parameters of conined steers fed with diets containing virginiamycin and monensin sodium. In: ADSA- Asas Joint Annual Meeting, 2014, Kansas City. ADSA- Asas Joint Annual Meeting, 2014.

CARTER, R. R.; GROVUM, W. L. Factors affecting the voluntary intake of food by sheep. 5. The inhibitory effect of hypertonicity in the rumen, British Journal of Nutrition, DOI: 10.1079/BJN19900029, v.64, p.285-299, 1990.

CHOW, J. M., RUSSELL, J. B. Effect of ionophores and pH on growth of Streptococcus bovis in bath and continuous culture, Applied and Environmental Microbiolog, v. 56, p. 1588-1593, 1990.

CHURCH, D. C.; The Ruminant Animal: Digestive Physiology and Nutrition, Prentice Hall, Englewood Cliffs, p.147, 1988.

COCITO, C. Antibiotics of the virginiamycin family, inhibitors which contain synergistic components, Microbiological Reviews, Washington, v. 43, n.2, p. 145 - 198, 1979.

COE, M. L.; NAGARAJA, T. G.; WALLACE, N.; TOWNE, E. G.; KEMP, K. E.; HUTCHENSON, J. P. Effect of virginiamycin on ruminal fermentation in cattle during adaptation to a high concentrate diet and during in induced acidosis, Journal of Animal Science, Savoy, v. 77, n.8, p. 2259-2268, 1999.

CONSTABLE, P.; HINCHCLIFF, K.W.; DONE, S.; GRUENBERG, W. Veterinary Medicine, 11th Edition, p. 2278, 2017.

CORAH, L. R.; LEMENAGER, R. P.; HOUGHTON, P. L.; BLASI. D. A. Feeding your cows by body condition, KAES Report of Progress, p. 842, 1991.

COUNOTTE, G.H., VAN'T KLOOSTER, A.T., VAN DER KUILEN, J., PRINS, R.A. An analysis of the buffer system in the rumen of dairy cattle, Journal Animal Science, v. 49, p. 1536-1544, 1979.

COUNOTTE, G. H. M.; PRINS, R. A. Regulation of lactate metabolism in the rumen. Veterinary Research Communications, Elsevier Scientific Publishing Company, Amsterdam -Printed in The Netherlands, v. 5, p. 101-115, 1981. 
COUNOTTE, G. H. M.; LANKHORST, A.; PRINS, R. A. Role of DL-Lactic acid as an intermediate in rumen metabolism of dairy cows, Journal Animal Science, v. 56, p. 1222$1235,1983$.

CRICHLOW, E. C. Ruminal lactic acidosis: Forestomach epithelial receptor activation by undissociated volatile fatty acids and rumen fluids collected during loss of reticuloruminal motility, Research Veterinary Science, v.45, p.364-368, 1988.

CRICHLOW, E. C.; CHAPLIN, R. K. Ruminal lactic acidosis: Relationship of fore stomach motility to no dissociated volatile fatty acids levels, Animal Journal Veerinary. Research, v.46, p.1908-1911, 1985.

DANSCHER, A. M.; LI, S.; ANDERSEN, P. H.; KHAFIPOUR, E.; KRISTENSEN, N. B.; PLAIZIER, J. C. Indicators of induced subacute ruminal acidosis (SARA) in Danish Holstein cows, Acta Veterinaria Scandinavica, v. 57:39, 2015.

DIJKSTRA, J.; FORBES, J. M.; FRANCE, J. Quantitative aspects of ruminant digestion and metabolism, Oxfordshire: CABI, p. 759, 2005.

DIRKSEN, G.; GRUNDER, H. D.; STOBER, M. Exame clinico dos Bovinos. $3^{\text {a }}$ ed. Editora Guanabara Koogan S.A., p. 402, 1993.

DUCKETT, S. K.; WAGNER, D. G.; YATES, L. D. DOLEZAL, H. G.; MAY, S. G. Effects of time on feed on beef nutrient composition, Journal of Animal Science, v. 71, p. 20792088, 1993.

DUFFIELD, T. F.; LEBLANC, S.; BAGG, R. Effect of monensin controlled released capsule on metabolic parameters in dairy cows. Journal of Dairy Science, v. 86, p. 1171-1176, 2003.

DUNLOP, R. H.; HAMMOND, P. G. D - lactic acidosis of ruminants, Ann. NY Acod. Science, v. 119, p. 1109, 1965.

DUNLOP, R. H. Pathogenesis of ruminant lactic acidosis. Advances in Veterinary Science and Comparative Medicine, v. 16, p. 259-302, 1972.

ELLIS, J. L.; DIJSKTRA. J.; BANNINK, A.; KEBREAB, E.; HOOK, S. E.; ARCHIBEQUE S.; FRANCE J. Quantifying the effect of monensin dose on the rumen volatile fatty acid profile in high-grain-fed beef cattle, Journal Animal Science, v. 20, p. 2717-2726, 2012.

ERWIN, E. S.; MARCO, G. J.; EMERY, E. M. Volatile fatty acid analyses of blood and rumen fluid by gas chromatography, Journal Dairy Science, v. 44, p. 1768-1771, 1961.

FLINT, H. J. The rumen microbial ecosystem--some recent developments, Trends in Microbiology, v. 5, n. 12, p. 483-488, 1997.

GÄBEL, G.; ASCHENBACH, J. R. SCFA, protons and ruminal epithelium: the good, the bad, the barrier. In: FURLL, M. Production diseases in farm animals. Leipzig, Germany: Universität Leipzig, p. 291-297, 2007. 
GÄBEL, G.; ASCHENBACH, J. R. Ruminal SCFA absorption: channelling acids without harm. In: SEJRSEN, K.; HVELPLUND, T.; NIELSEN, M. O (Ed.). Ruminant physiology: digestion, metabolism and impact of nutrition on gene expression, immunology and stress. Wageningen, The Netherlands: Wageningen Academic Publishers, p. 173-195, 2006.

GIESECKE, D.; STANGASSINGER, M. Lactic acid metabolism. In Digestive Physiology and Metabolism in Ruminants (Edited by RUCKEBUSCH Y. \& THIVEND P.) M.T.P. Press, Lancaster, 1980.

GOLDER H. M.; CELI P.; RABIEE A. R.; LEAN I. J. Effects of feed additives on rumen and blood profiles during a starch and fructose challenge, Journal of Dairy Science, v. 97, p. 985-1004, 2014.

GOLDER, H. M.; THOMSON, J. M.; DENMAN, S. E.; MCSWEENEY, C. S.; LEAN I. J. Genetic Markers Are Associated with the Ruminal Microbiome and Metabolome in Grain and Sugar Challenged Dairy Heifers, Front Genetic, 2018 Feb 27;9:62. doi: 10.3389/fgene.2018.00062. eCollection 2018.

GOTTSCHALL, D. W.; WANG, R.; KINGSTON D. G. Virginiamycin metabolism in cattle rumen fluid, Drug Metabolism \& Disposition. Nov-Dec, v. 16(6), p. 804-12, 1988.

GOZHO, G. N.; PLAIZIER, J. C.; KRAUSE, D. O.; KENNEDY, A. D.; WITTENBERG, K. M. Subacute ruminal acidosis induces ruminal lipopolysaccharide endotoxin release and triggers an inflammatory response, Journal of Dairy Science, v. 88, p. 1399-1403, 2005.

HANEY, M.; HOEHN, M. Monensin, a new biologically active compound I: Discovery and isolation, Antimicrob. Agents Chemother, p. 349:349, 1967.

HATCH, R. C. Venenos que tem efeitos singulares. In: BÖ̈TH, N. H.; McOONALD, L. E. Farmacologia e terapêutica em veterinária. Rio de Janeiro: Guanabara Koogan, p. 919-927, 1992.

HEGAZY, M.A.; ELIAS, A.N. Influence of dietary monensin and lasalocid on age and weight of Barki ram and ewe lambs at puberty. Assiut Veterinary Medical Journal, v.37, n.74, p.1-15, 1997.

HERNÁNDEZ, J.; BENEDITO, J. L.; ABUELO, A.; CASTILLO, C. Ruminal Acidosis in Feedlot: From Aetiology to Prevention. The Scientific World Journal Volume 2014, Article ID 702572, http://dx.doi.org/10.1155/2014/702572, p. 8, 2014.

HOWARD, J. L. Ruminant metabolic acidosis, Bovine Practitioner, v. 16, p. 44-53, 1981.

HUBER, T. L. Effect of acute indigestion on compartmental water volumes and osmolality in sheep, American Journal Veterinary Research, v. 32, p. 887, 1971.

HUNGATE, R. E. Symposium: selected topics in microbial ecology. I. Microbial ecology of the rumen, Bacteriol Rev, v. 24, n. 4, p. 353-64, 1960. 
HUNGATE R.E. The rumen and its microbes. Academic Press, New York P. 533, 1966.

IBEGE-Instituto Brasileiro de Geografia e Estatística. Rio de Janeiro, 2016.

KANEKO, J. J. Clinical biochemistry of domestic Animal. 5.ed. San Diego: Academic, p. 932, 1997.

KITAMURA, S.S. ; ANTONELLI, A.C. ; MARUTA, C.A. ; SUCUPIRA, M.C.A. ; MORI, C.S. ; YONEZAWA, L.A. ; MICHIMA, L.E.S. ; SOARES, P.C. ; ORTOLANI, E. L.

Avaliação laboratorial do uso de solução salina hipertônica e isotônica e de furosemida no tratamento da intoxicação por amônia em bovinos, Ciência Rural (UFSM. Impresso), v. 40, p. 1779-1785, 2010.

KRAJCARSKI-HUNT, H.; PLAIZIER, J. C.; WALTON, J. P. Short communication: effect of subacute ruminal acidosis on in situ fiber digestion in lactating dairy cows, Journal Dairy Science, v.85, p.570-573, 2002.

KRAUSE, K. M.; COMBS, D. K.; BEAUCHEMIN, K. A. Effects of forage particle size and grain fermentability in midlactationcows. ii. ruminal $\mathrm{pH}$ and chewing activity, Journal of Dairy Science, v. 85, p. 1947-1957, 2002.

KRAUSE, K. M.; OETZEL, G. R. Understanding and preventing subacute ruminal acidosis in dairy herds: A review, Animal Feed Science and Technology, v. 126, n. 3, p. 215-236, 2006.

LEAL, M. L. R.; MARUTA, C. A.; ORTOLANI, E. L. Uso de bicarbonato e lactato-L para correção da acidose metabólica sistêmica em bovinos com acidose láctica ruminal aguda, Arquivo Brasileiro de Medicina Veterinária e Zootecnia, v. 59, p. 971-976, 2007.

LEWIS, T. R.; EMERY, R. S. Intermediate products in the catabolism of amino acids by rumen organisms. Journal. Dairy Science, v. 45, p. 1363, 1962.

LITTLE, T. M.; HILLS, F. J. Agricultural experimentation, design and analysis. New York: John Wiley, p. 368, 1978.

LORENZ, I. GENTILE, A. D-lactic acidosis in neonatal ruminants, Veterinary Clinical North Am Food Animal Practice, doi: 10.1016/j.cvfa.2014.03.004. Epub 2014 May 28. Review, v. 30(2), p. 317-31, 2014.

MAAS, J. A.; WILSON, G. F.; McCUTCHEON, S. N. The effect of season and monensin sodium on the digestive characteristics of autumn and spring pasture fed to sheep. Journal of Animal Science, v.79, n.4, p.1052-1058, 2001.

MARDEN, J. P.; BAYOURTHE, C.; ENJALBERT, F.; MONCOULON, R. A New Device For Measuring Kinetics of Ruminal $\mathrm{pH}$ and Redox Potential in Dairy Catlle, Jornal of Dairy Science, v. 88, p. 277-281, 2005.

MARINI, J. C.; VAN AMBUR, G. H, M. E. Nitrogen metabolism and recycling in Holstein heifers, Journal of Animal Science, v. 81, p. 545-552, 2003. 
MARUTA, C. A. Comparação da susceptibilidade de bovinos das raças Jersey e Gir à acidose láctica ruminal, induzida experimentalmente com sacarose. 2000. 120

(Mestrado). Faculdade de Medicina Veterinária e Zootecnia, Universidade de São Paulo, São Paulo, 2000.

MARUTA, C. A.; ORTOLANI, E. L. Susceptibilidade de bovinos das raças Jersey e Gir à acidose láctica ruminal: I - variáveis ruminais e fecais, Ciência Rural, Santa Maria, v. 32, n. 1, p. 55-59, 2002a.

MARUTA, C. A.; ORTOLANI, E. L. Susceptibilidade de bovinos das raças Jersey e Gir à acidose láctica ruminal: II - acidose metabólica e metabolização do lactato - L, Ciência Rural, Santa Maria, v. 32, n. 1, p. 61-65, 2002 b.

McANALLY, R. A.; PHILLIPSON, A. T. Absorption of volatile acids from the rumen of sheep, Journal Physiology, v. 101, p. 13, 1942.

McGUFFEY, R. K.; RICHARDSON, L. F.; WILKINSON, J. I. D. Ionophores for dairy cattle: current status and future outlook, Journal of Dairy Science, v. 84, Suppl. E, p. 194203. 2001.

MENDES NETTO, D. Comparação do uso de soluções de bicarbonato e ringer com lactato no tratamento da acidose metabólica de garrotes com acidose láctica ruminal aguda. São Paulo, 1997. 81p. Dissertação (Mestrado) - Faculdade de Medicina Veterinária e Zootecnia, Universidade de São Paulo, 1997.

MENDES NETTO, D.; ORTOLANI, E. L. Evaluation of sodium bicarbonate or lactated ringer's solution for the treatment of rumen lactic acidosis in steers, Veterinária Notícias, Uberlândia, v. 6, n.2, p. 31-39, 2000.

MILLEN, D. D.; R. D. L.; PACHECO, M. D. B.; ARRIGONI, M. L.; GALYEAN, AND J. T. VASCONCELOS. A snapshot of management practices and nutritional recommendations used by feedlot nutritionists in Brazil, Journal Animal Science. n. 87, p. 3427-3439, 2009.

MOULD, F. L.; ØRSKOV, E. R.; MANNS, O. Associative effects of mixed feeds. I. Effects of type and level of supplementation and the influence of the rumen $\mathrm{pH}$ on cellulolysis in vivo and dry matter digestion of various roughages, Animal Feed Science and Technology, v. 10, p. 15-30, 1983.

MOURIÑO, F.; AKKARAWONGSA, R.; WEIMER, P. J. Initial $\mathrm{pH}$ as a determinant of cellulose digestion rate by mixed ruminal microorganisms in vitro, Journal Dairy Science, v. 84, p. 848-859, 2001.

NAGARAJA, T. G.; AVERY, T. B.; BARTLEY, E. E. Prevention of lactic acidosis in cattle by lasalocid or monensin. Journal of Animal Science, v. 53, n. 2, p. 206-215, 1981.

NAGARAJA, T. G.; CHENGAPPA, M. M. Liver abscesses in feedlot cattle: a review. Journal of Animal Science, v. 76, n. 1, p. 287-298, 1998. 
NAGARAJA, T. G.; LECHTENBERG, K. F. Acidosis in feedlot cattle. Veterinary Clinics of North America: Food Animal Practice, v. 23, p. 333-350, 2007.

NAGARAJA, T. G.; TAYLOR, M. B. Susceptibility and resistance of ruminal bacteria to antimicrobial feed additives. Applied and Environmental Microbiology, v. 53, n. 7, p. 1620-5, Jul 1987.

NAGARAJA, T. G.; TITGEMEYER, E. C. Ruminal acidosis in beef cattle: the current microbiological and nutritional outlook. In: (Ed.), Journal of Dairy Science. United States, v. 90, Suppl 1, p. 17-38. 2007.

NAGARAJA, T.G.; TAYLOR, M.B.; HARMON, D.L.; BOYER, J.E. "In vitro" lactic acid inhibition and alterations in volatile fatty acid production by antimicrobial feed aditives, Journal Animal Science, Champaign, v. 65, n. 4, p. 1064-1076, 1987.

NAKAMURA, K.; KANEGASAKI, S.; TAKAHASHI, H. Adaptation of ruminal bactéria to concentrated feed, Journal Gen. Appl. Microbiol, v. 17, p. 13-27, 1971.

OBARA, Y.; DELLOW, D. W.; NOLAN J. V. The influence of energy-rich supplements on nitrogen kinetics in ruminants. In: TSUDA, T.; SASAKI, Y.; KAWASHIMA, R.

Physiological aspects of digestion and metabolism in ruminants. New York: Academic Press, p. 515-539, 1991.

OLIVEIRA, C. A.; MILLEN, D. D. Survey of the nutritional recommendations and management practices adopted by feedlot cattle nutritionists in Brazil, Animal Feed Science and Technology, v. 197, v. 64-75, 2014.

OLIVEIRA, F. L. C. Avaliação da ingestão súbita de melão com alto teor de açúcar sobre a saúde ruminal em ovinos não adaptados. 2013. 86f. Dissertação (Mestrado em Ciências)

- Faculdade de Medicina Veterinária e Zootecnia, Universidade de São Paulo, São Paulo, 2013.

OLIVEIRA, F. L. C.; BARRÊTO JÚNIOR, R. A.; MINERVINO, A. H. H.; REIS, L. F.; TAVARES, M. D.; VALE, R. G.; GAMELEIRA, J. S.; SOUZA, F. J. A.; MORI, C. S.; ORTOLANI, E. L. Avaliação clínica de ovinos não adaptados submetidos à ingestão súbita de melão com alto teor de açúcar, Semina Ciências Agrárias (Online), v. 36, p. 37213729, 2015.

OLIVEIRA, F. L.C.; BARRÊTO JÚNIOR, R. A.; MINERVINO, A. H.H.; TAVARES, M. D.; VALE, R. G.; ARAÚJO, C. A. S. C.; SOUSA, R. S.; ORTOLANI, E. L. Effects of sudden melon intake on ruminal parameters of non-adapted sheep, Pesquisa Veterinária Brasileira (Online), v. 36, p. 378-382, 2016.

ORTOLANI, E. L.; BIRGEL, E. H.; ARAÚJO, L. M. Comportamento do pH do suco de rúmen dos bovinos in vitro, Arquivos da Escola de Veterinária da Universidade Federal de Minas Gerais, Belo Horizonte, v. 32, n.2, p. 217-223, 1980. 
ORTOLANI, E. L. Induction of lactic acidosis in catle with sucrose: Relationship between dose, rumen fluid $\mathrm{pH}$ and animal size, Veterinary and Human Toxicology, Manhattan, v.37, n. 5, p. 462-464, 1995.

ORTOLANI, E. L.; MARUTA, C. A.; MINERVINO, A. H. H. Quadro clínico de zebuínos e taurinos submetidos à acidose láctica ruminal aguda, Brazilian Journal of Veterinary Research and Animal Science, v. 47, p. 253-261, 2010.

ORTOLANI, E. L.; TAKIMOTO, C. Estudos comparativos da fauna do rúmen entre Bos taurus, Bos indicus e mestiços, Aspectos quantitativos. Arquivo Brasileiro de Medicina Veterinária e Zootecnia, Belo Horizonte, v. 39, p. 81-91, 1987.

OWENS, F. N.; SECRIST, D. S.; HILL, W. J.; GILL D. R. Acidosis in cattle: a review, Journal of Animal Science, v. 76, n. 1, p. 275-286, 1998.

PAGE, S. W. The role of enteric antibiotics in livestock production, Australia: Avcare Limited, p. 337, 2003.

PRESSMAN, B. C.; FAHIM, M. Pharmacology and toxicology of the mono-valent carboxylic ionophores, Annual Review of Pharmacology and Toxicology, v. 22, p. 465490, 1982.

RADOSTITS, O. M.; GAY, C. C.; HINCHCLIFF, K. W.; CONSTABLE, P. D. Veterinary medicine, 10th ed. London: Elsevier Saunders, p. 2156, 2007.

REIS, J. C. Estatística aplicada à pesquisa em ciência veterinária / José de Carvalho Reis Olinda: J. C. R. p. 65, 2003.

REIS, L. F. Estudo comparativo do uso de probiótico e monensina na prevenção e tratamento da acidose láctica ruminal aguda em ovinos. 2011. 115f. Dissertação (Mestrado em Ciências) - Faculdade de Medicina Veterinária e Zootecnia, Universidade de São Paulo, São Paulo, 2011.

REISET, J. Compt. Rend. V. 56, p. 740, 1863.

RODRIGUES, F. A. M. L. Tratamento adicional da acidose láctica ruminal aguda em bovinos por meio da infusão de solução salina hipertônica (7,2\%). 2009. $118 \mathrm{f}$. Dissertação (Mestrado em Ciências) - Faculdade de Medicina Veterinária e Zootecnia, Universidade de São Paulo, São Paulo, 2009.

RODRIGUES, F. A. M. L.; MINERVINO, A. H. H.; BARRÊTO JÚNIOR, R. A.; ANTONELLI, A. C.; REIS, L. F.; ARAÚJO, C. A. S. C.; FERREIRA, R. N. F.; VECHIATO, T. A. F.; MORI, C. S.; ORTOLANI, E. L. Avaliação clínica do uso de solução salina hipertônica no tratamento da acidose láctica ruminal aguda em bovinos, Brazilian Journal of Veterinary Research and Animal Science, v. 48, p. 446-453, 2011.

ROSE-DYE, T. K.; BURCIAGA-ROBLES, L. O.; KREHBIEL, C. R.; STEP, D. L.; FULTON, R. W.; CONFER, A. W.; RICHARDS, C. J. Rumen temperature changes 
monitored with remote rumen temperature boluses after challenges with bovine viral diarrhea virus and Mannheimia haemolytica, Journal of Animal Science, v. 89, p. 1193-1200, 2011.

RUSSELL, J. B.; RYCHLIK, J. L. Factors that alter rumen microbial ecology, Science, v. 292, p. 1119-1122, 2001.

RUSSELL, J. R.; HINO, T. Regulation of lactate production in Streptococcus bovis: A spiraling effect that contributes to rumen acidosis, Journal of Dairy Science, v. 68, n. 7, p. 1712-21, 1985.

RUSSELL, J. B. Bacteria. "Mechanisms of ionophore action in ruminal bacteria". In: Symposium Sponsored by: Elanco Animal Health. Scientific Update "On rumensin/Tylan/Micotil for the professional feedlot consultant". Symposium... Amarillo, p. 119, 1996.

RUSSELL, J. B.; STROBEL, H. J. Effects of additives on in vitro ruminal fermentation: a comparison of monensin and bacitracin, another Gram-positive antibiotic, Journal Animal Science, v. 66, p. 552-558, 1988.

RUSSELL, J.B.; WALLACE, R.J. Energy-yielding and energy-consuming reactions. In: HOBSON, P .N.; STEW ART, C.S. (Eds.) The rumen microbial ecosystem, 2.ed. London: Blackie Academic \& Professional, p.267-268, 1997.

SCHELLING, G. T. Monensin mode of action in the rumen, Journal Animal Science, v. 58(6), p. 1518-27, 1984.

SEGEL, I. H. Bioquímica: Teoria e Problemas. Rio de Janeiro: Livros Técnicos e Científicos, p. 525, 1979.

SIEGEL, SIDNEY. Estatística Não-paramétrica Para as Ciências do Comportamento. São Paulo: McGraw-Hill, 1975.

SILVA, S. L.; ALMEIDA, R.; SCHWAHOFER, D. Effects of salinomycin and virginiamycin on performance and carcass traits of feedlot steers, Journal of Animal Science, v. 82, suppl. 1, p. 41-42, 2004.

SITTA, C. Aditivos (ionóforos, antibióticos não ionóforos e probióticos) em dietas com alto teores de concentrado para tourinhos da raça Nelore em terminação. 2011. 87p. Escola Superior de Agricultura "Luiz Queiroz”, Universidade de São Paulo, Dissertação (Mestrado Medicina Veterinária), Piracicaba.

SLYTER, L. L. Influence of Acidosis on Rumen function. Journal of Animal Science, October 1, v. 43, n. 4, p. 910-929, 1976.

SNYDER, E.; CREDILLI, B. Diagnosis and Treatment of Clinical Rumen Acidosis, Veterinary Clinical North American Food Anim Pract, 2017. 
TEDESCHI, L. O.; FOX, D. G.; TYLUTKI, T. P. Potential environmental benefits of ionophores in ruminant diets, Journal of Environmental Quality, v. 32, n. 5, p. 1591-1602, 2003.

UNDERWOOD, W. J. Rumen lactic acidosis. Part I. Epidemiology and pathophysiology, Compendium Continuing Education for the Veterinary Practice, v. 14, n. 9, p. 11271134, 1992a.

UNDERWOOD, W. J. Rumen lactic acidosis. Part II. Clinical signs, diagnosis, treatment and prevention, Compendium Continuing Education for the Veterinary Practice, v. 14, n. 9, p. 1265-71, 1992b.

VAN SOEST, P. J. Nutritional ecology of the ruminant, 2. ed. Ithaca: Cornell University Press, p. 476, 1994.

VECHIATO, T. A. F. Estudo retrospectivo e prospectivo da presença de abscessos hepáticos em bovinos abatidos em um frigorifico paulista. 102f. Dissertação (Mestrado em Medicina Veterinária) - Universidade de São Paulo, 2009.

ZEBELI, Q.; METZLER-ZEBELI, B.U.; AMETAJ, B.N. Meta-analysis reveals threshold level of rapidly fermentable dietary concentrate that triggers systemic inflammation in cattle. Journal Dairy Science, v. 95, p. 2662-2672, 2012. 